LALP-82-36

Issued: December 1982

LLLP- $-82-36$

DE33 007096

\title{
Los Alamos National Laboratory Institutional Plan
}

\author{
FY 1983-FY 1988
}

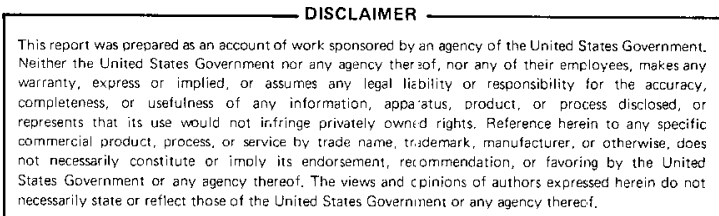

Y.... NOTICE

PORTIONS OF THIS REPORT ARE ILLEGIBLE

it has bien reproduced from the best: available copy to permit the broadest; possible avallability.

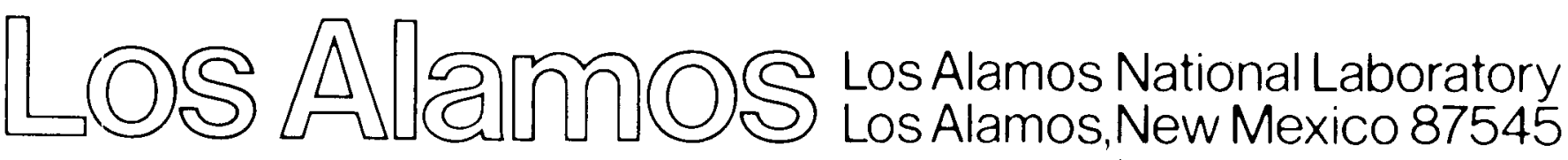




\section{DISCLAIMER}

This report was prepared as an account of work sponsored by an agency of the United States Government. Neither the United States Government nor any agency Thereof, nor any of their employees, makes any warranty, express or implied, or assumes any legal liability or responsibility for the accuracy, completeness, or usefulness of any information, apparatus, product, or process disclosed, or represents that its use would not infringe privately owned rights. Reference herein to any specific commercial product, process, or service by trade name, trademark, manufacturer, or otherwise does not necessarily constitute or imply its endorsement, recommendation, or favoring by the United States Government or any agency thereof. The views and opinions of authors expressed herein do not necessarily state or reflect those of the United States Government or any agency thereof. 


\section{DISCLAIMER}

Portions of this document may be illegible in electronic image products. Images are produced from the best available original document. 


\section{CONTENTS}

I. DIRECTOR'S OVERVIEW............................. 3

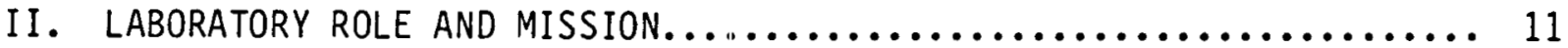

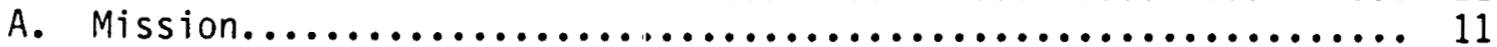

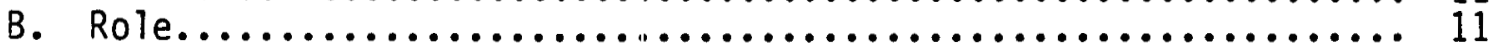

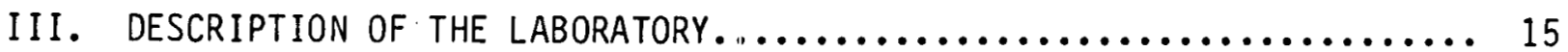

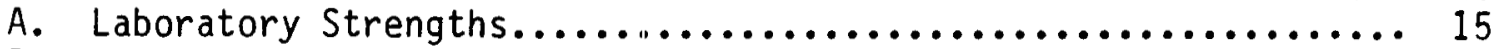

B. Long-Range Trends and Projections.................... 18

IV. SCIENTIFIC AND TECHNICAL ACTIVITIES.................... 29

DEPARTMENT OF ENERGY PROGRAMS

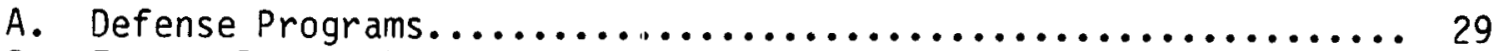

B. Energy Research................................ 43

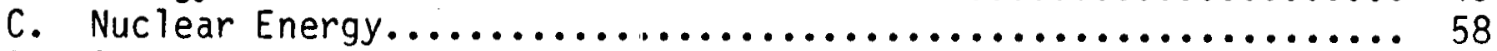

D. Conservation and Renewable Energy................... 63

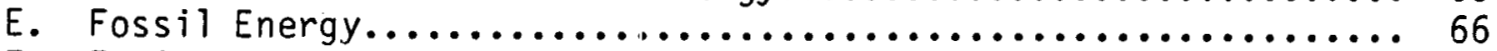

F. Environmental Protection, Safety, and Emergency Preparedness... 69

G. International and Energy Policy Programs................ 70

WORK FOR OTHER THAN DOE (WFO)

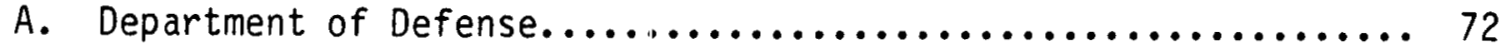

B. Nuclear Regulatory Commission (NRC)................... 76

C. Other Federal Agencies and Other Entities................ 77

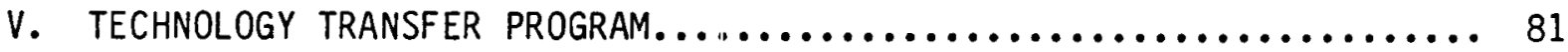

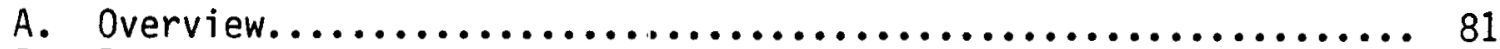

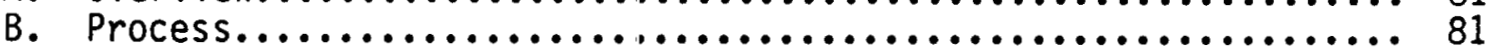

C. Estimated Resources: Persionnel and Funding.............. 82

VI. PERSONNEL RESOURCES $\ldots \ldots \ldots \ldots \ldots \ldots \ldots \ldots \ldots \ldots \ldots \ldots \ldots \ldots \ldots \ldots \ldots \ldots \ldots \ldots$

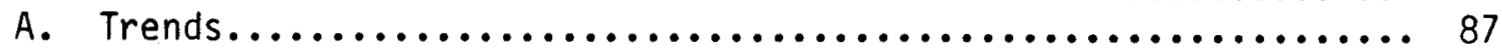

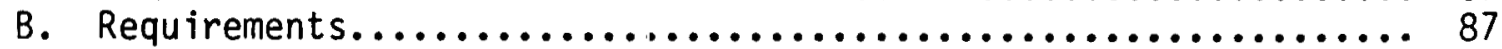


Los Alamos

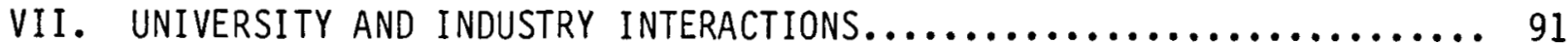

A. Subcontracting................................. 91

B. Laboratory User Facility Participation.................... 94

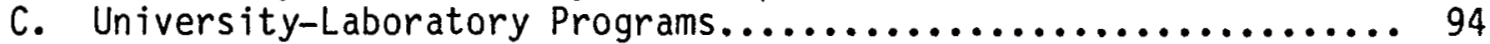

D. Minority Institution-Laboratory Programs................. 94

E. Industry-Laboratory Programs....................... 95

VIII. SITE AND FACILITIES DEVELOPMENT...................... 99

A. Laboratory Site and Facilities Development............... 99

B. Multiprogram General Purpose Facilities.................. 106

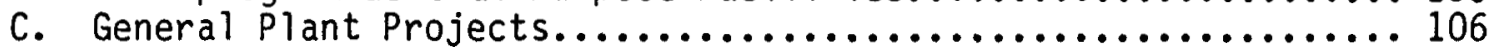

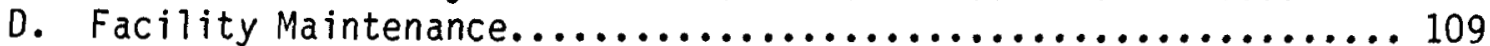

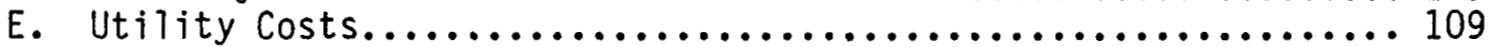

F. Automatic Data Processing Requirements.................. 112

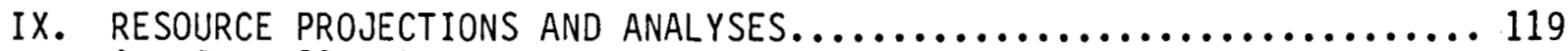

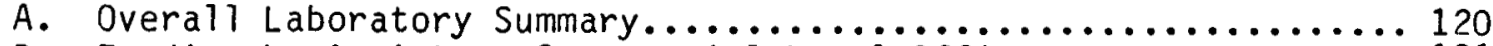

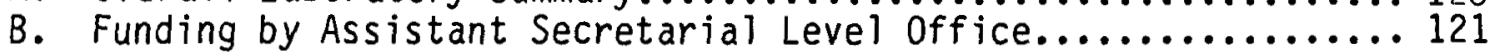

C. Personnel by Assistant Secretarial Level Office............... 124

D. Resources by Subprogram............................. 126

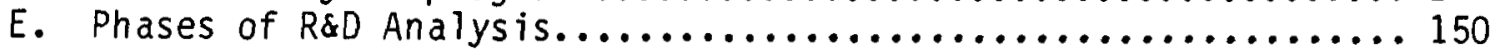

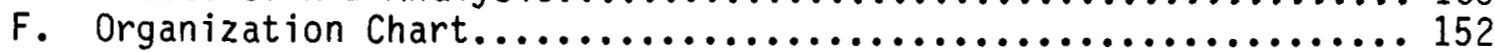




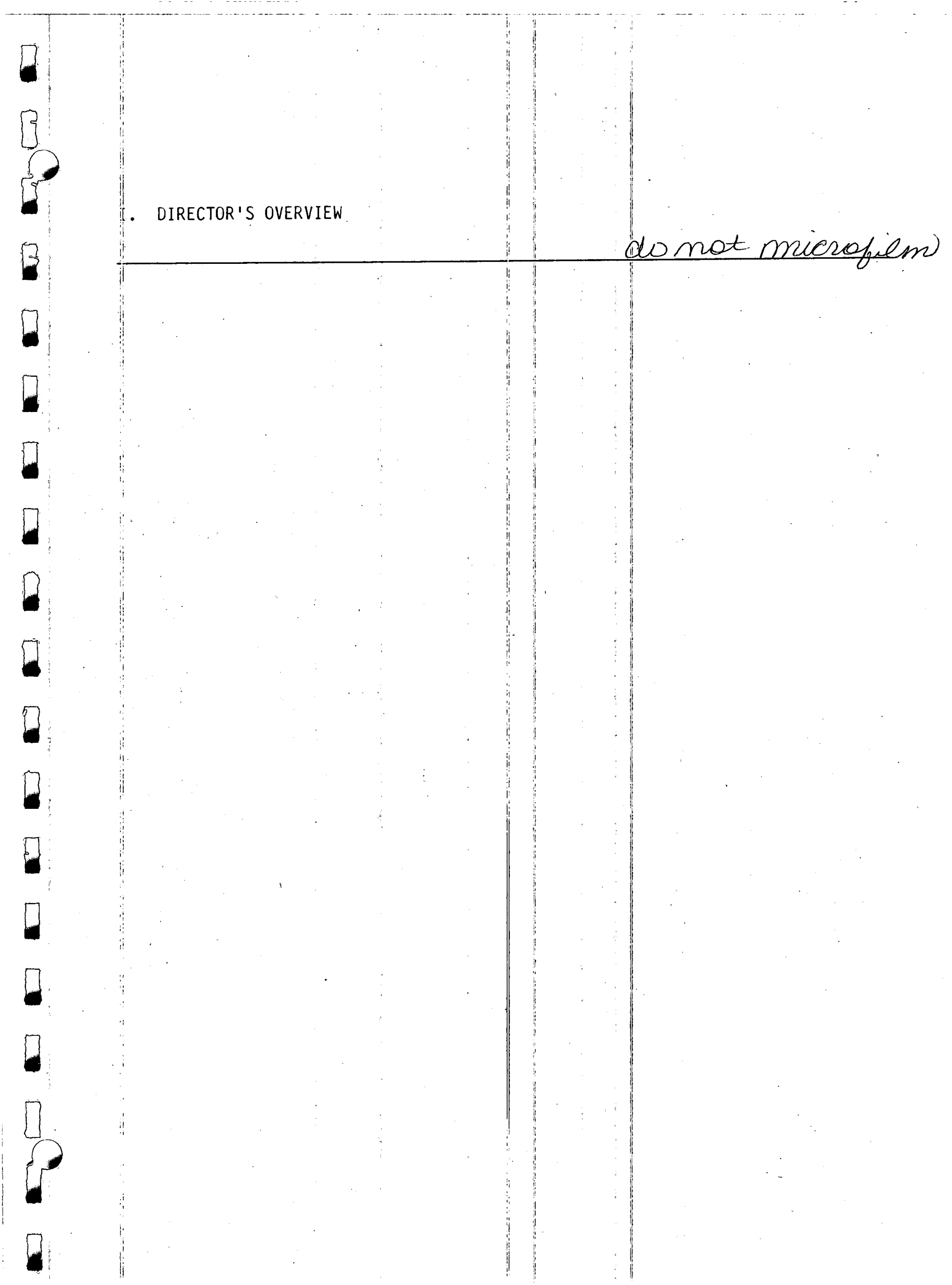




\section{DIRECTOR'S OVERVIEW}

In the past, Los Alamos National Laboratory was a multidisciplinary laboratory with one job--to design and test nuclear weapons. Since those early cays of one job and one sponsor, we have become a laboratory with multiple tasks and sponsors. Although our largest single program still is weapons research and development, we also have substantial programs in energy, health, environment, and basic scientific research. There is hardly an area in the physical and life sciences in which we cannot rapidly respond to specific national needs.

This Institutional Plan is based on our primary mission, the advancement and application of science and technology in programs that contribute to a strong national defense, but it also emphasizes fulfilling arms control commitments and guaranteeing a secure energy supply for the future. The foundation for this mission is a staunch science and technology base composed of the many talents of our scientists arid engineers and our unique facilities. We will continue developing the broad staff capabilities and the specialized facilities needed for work on important national security issues.

\section{The Past Year}

In FY 1982 we saw continued growth and strengthening of Defense Programs, increased support for Energy Research, and significant decline in national priorities for Nuclear Energy, Solar, Geothermal, and Conservation programs. Clur worst expectations were not realized, since the Laboratory was able to cobtain new programs. In spite of major changes, such as loss of the Molecular Laser Isotope Separation program, we maintained relative stability in our scientific and technical staff.

Our role, mission, and capabilities have been examined by various panels, boards, and committees such as the Energy Research Advisory Board (ERAB). These reviews are beneficial because they provide a basis for communicating cour strengths and potential contributions to national needs to a broader audience.

This past year was one of significant scientific accomplishments. During FY 1982, we at Los Alamos achieved the following:

- The number of nuclear weapons tests was increased, and successful tests were conducted at extreme temperatures.

- In life sciences, we were designated by the National Institutes of Health as a national resource for flow cytometry and a national Genetic Sequence Data Bank (GENBANK). 
Los Alamos

- The Tritium Systems Test Assembly (TSTA), for the development and demonstration of tritium technology required for fusion energy programs, was completed.

- An extremely sensitive x-ray detector for x-ray sources in space was developed, which could also lead to reductions in medical x-ray dosage.

- A cooperative agreement with Mexico for the exchange of information in nuclear energy research was signed.

- New laser techniques for applied problems such as monitoring gases in coal gasifiers were successfully applied.

- Preliminary studies of parallel processing computers, which promise greatly increased computing speeds, were completed.

- Very high speed photoconductive detectors for diagnostic measurements at the Nevada Test Site were developed.

In addition, we accomplished several institutional management tasks. These major accomplishments, which occurred during the last three years, include the following:

- Our approach to administering the nuclear weapons program was completely reformulated and restructured.

- Three research centers were established: the Institute for Geophysics and Planetary Physics, the Center for Nonlinear Studies, and the Center for Materials Science.

- Institutional Supporting Research and Development as an investment strategy for future programs was implemented.

- Fellow and Senior Fellow positions were created, with our first appointments made in 1980.

- The Distinguished Performance Awards program was initiated to recognize outstanding employee contributions.

- A long-range facility and site development plan was completed.

- The Laboratory publication process was streamlined, which included creation of the Los Alamos Science, the Annual Report, and the Public Affairs office.

- A review of management information systems needs was conducted, and preliminary steps toward implementation were initiated. 
- An employee orientation program was reinstituted.

- A coordinated review process for construction projects was established. Looking to the Future

Our commitment to maintaining the nation's nuclear deterrent continues. Frograms reflected in this Plan will allow weapons R\&D to grow slightly through 1984 and then continue at stable levels. We anticipate some growth in verification and control activities in support of arms control measures. Thus the national security programs at Los Alamos should remain the major source of overall Laboratory stability in the foreseeable future.

We are concerned about the downward trend in the office of Energy Research (OER) sponsorship for Los Alamos research. Although we project relatively level support beyond FY 1982, we are below historical levels. The historically broad base of supporting research at Los $A$ lamos has been a key factor in our ability to provide innovative technical solutions to national problems. We must not allow this capability to deteriorate.

A crucial area of uncertainty, with potential loss of Laboratory programs, continues to be in energy technology R\&D. The Administration's basic policy is that much of the energy R\&D previously conducted by the government would be better carried out by private industry, except for certain high-risk, long-term programs that are appropriate for Federal funding. We are not certain that this transition is indeed occurring. Although we stand ready to assist, we fear that many valuable resclurces paid for by public dollars will be lost. In the meantime, we feel that support for nuclear energy programs at the Laboratory is an important and appropriate Federal investment in the future of nuclear power.

The national debt and deficit continue to symbolize the pressures facing government economic policy. We expect the Administration to continue its efforts to reduce Federal spending and to interpret more clearly the Federal role in energy R\&D to assure that long-term, high-risk R\&D is supported with Federal funds. Our best strategy in this environment is to protect and maintain the quality of the Laboratory's scientific and engineering capabilities as new national priorities are established.

The overall effect of these changes is that, although we experienced a modest decline in the total number of full-time equivalents (FTEs) from our peak of approximately 7,200 in FY 1982, we expect to support approximately 6,900 FTEs in 1983. Beyond 1983 we project a total laboratory staff of 7,000 FTEs, which could vary by 100 to 200 . 
Los Alamos

New Pursuits

We anticipate that our major areas of emphasis will remain the same, but the details of our activities may change substantially. The Laboratory cannot do everything that we or our sponsors may wish us to do. We are limited by the size and capabilities of our staff and our facilities. However, we do have some choice in determining those areas of science we strengthen or maintain and the relative emphases placed on them. Our decisions concerning programs will be based on technical and scientific challenge, suitability for the Laboratory, long-term prospects, and the relative benefits to the nation. We prefer programs that will take three to ten years to complete, so we can apply our staff and facilities effectively.

We believe that our multidisciplinary capabilities, our record of successes, and our defense orientation make us well suited for certain new pursuits. We would like to accomplish several activities at Los Alamos in the next few years:

- increased Basic Energy Sciences support in chemical and materials sciences;

- increased OER support of basic research in plasma and particle physics, magnetic fusion, medium-energy physics, underground science, and neutrino research;

- substantial Department of Defense (DoD) support of accelerator technology, free-electron lasers, conventional munitions, defense energy security, and counterterrorist technology;

- continued growth in our analytical capability to assist intelligence agencies;

- a strong role in assisting the Department of Energy (DOE) with technical direction for a new production reactor; and

- nuclear reactors for space and defense applications.

To help stabilize our staff in the face of declining programs, we will pursue opportunities with other Federal and state agencies and particularly with industrial concerns that can use our science and technology base. Our goal is to make the Laboratory's science and technology base available to industry, consistent with the DOE guidelines of assuring that such efforts do not conflict with our primary mission. We do not expect that these activities wi11 exceed $15 \%$ of Laboratory effort. 


\section{Maintaining and Using Laboratory Facilities}

Many of our facilities were constructed in the early 1950s and so are expensive to maintain. Under current budgetary constraints and with very few new construction projects approved, we are unable to replace old facilities as needed. Therefore, as our facilities grow older, we must invest the resources needed to maintain them at acceptable performance levels. We are trying to acquire additional maintenance funds and to devote a larger fraction of our budget to maintaining and upgrading these facilities.

\section{Planning Ahead}

Institutional Planning continues to be a useful tool for Laboratory management. We are striving to improve our internal planning during each annual planning cycle. However, a mechanism should be found in DOE to avoid reissue of outlay associated with multiyear appropriations. More consistent adherence to the DOE's forward financing policy is needed. Effective R\&D, which occurs over a period of years, cannot be accomplished in an environment of continual budget uncertainty. Long-term $R \& D$ projects require consistent year-to-year funding, permitting project leaders to focus their attention on technical management rather than on pursuit of next year's funds.

Implementing the ERAB recommendations for two-year funding and for allowing Laboratory Directors to reprogram a small fraction of the funds in their financial plans would be major contributions to more effective use of $R \& D$ funds. We strongly support these recomnendations.

The institutional planning and budgeting process would be improved if DOE could realize its goal of a coordinated long-range planning and budgeting process that includes setting long-range goals, defining major missions for laboratories and field offices, and permitting greater discretion at the laboratories. Such long-range planning should result in mutual commitment to accomplishing the goals of multiyear programs.

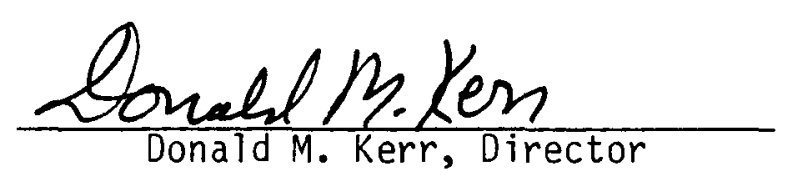




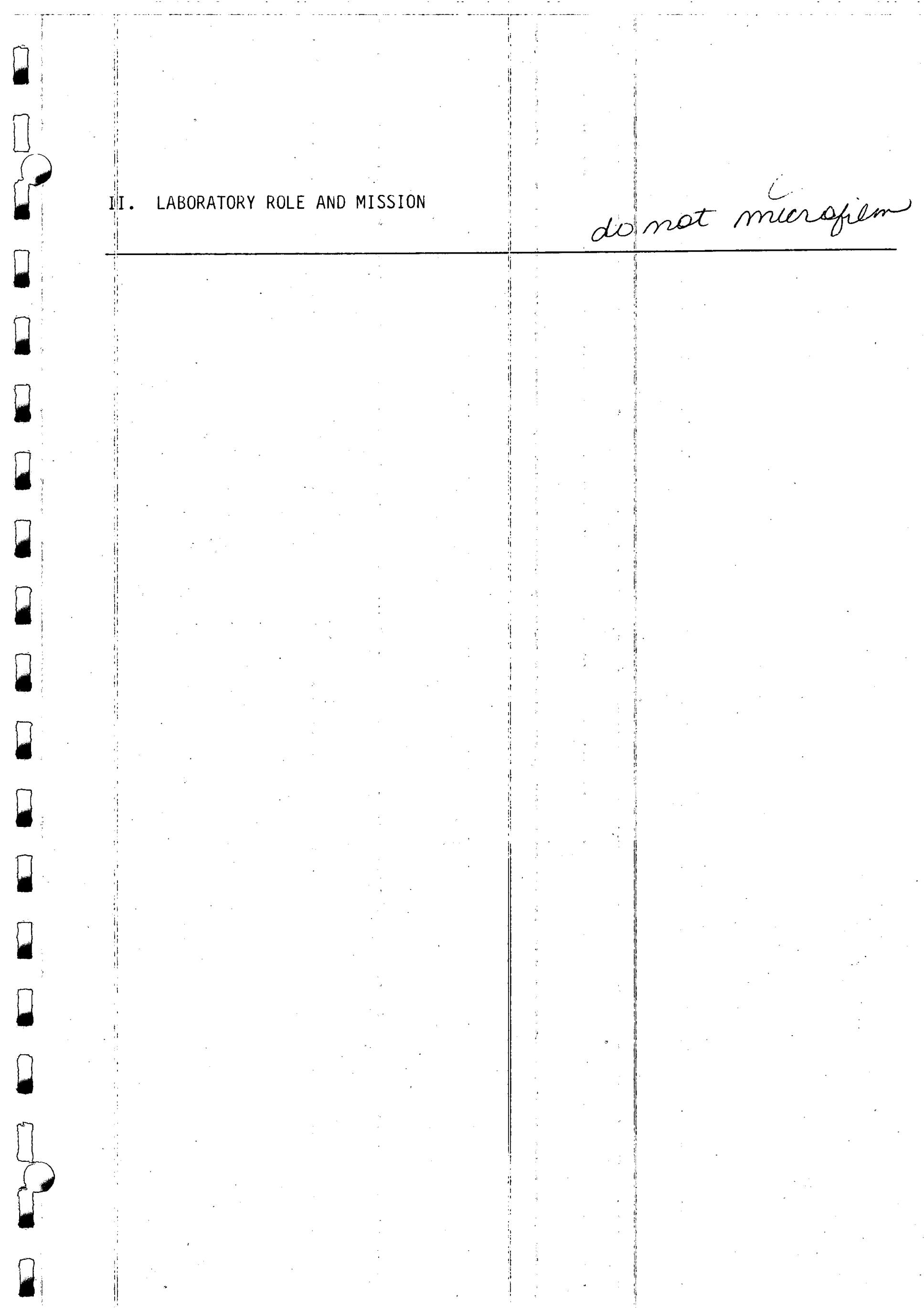


Los Alamos

\section{LABORATORY ROLE AND MISSION}

\section{A. Mission}

The primary mission of the Los Alamos National Laboratory since its founding in 1943 has been the advancement and application of science and technology in national security programs. During the Manhattan Project, the goal was to develop and build the world's first nuclear weapon. The Laboratory's mission now is much broader; namely, support for our military posture of nuclear deterrence, our arms control commitments, and our need to provide a secure energy supply for the future. Thus the first part of our mission statement is

- to advance science and technology and to apply them in programs that contribute primarily to the maintenance of a strong defense, and also to the fulfillment of arms control commitments, and the guarantee of a secure energy supply for the future.

A strong science and technology base is the foundation for our success in implementing our mission. Los Alamos researchers have designed 65 percent of the weapons in the nation's stockpile, including all new strategic-warhead designs entering the stockpile since 1979 -- the W78 for Minuteman III, the W76 for the C4 missile on Trident and Poseidon submarines, and the W80 for cruise missiles. In addition, Los Alamos is providing the baseline warhead (W78) for the proposed MX missile, the designs for the B61 strategic bombs, the Navy's ship defense Standard Missile-2 warhead (W81), and the Pershing II (airburst/surface burst W85 and earth penetrator W86 warheads). Each leg of the American triad of deterrence is supported by these new designs.

We must also continue to develop the multidisciplinary capabilities and specialized facilities necessary to solve important national security problems. The second part of our mission statement is then as follows:

- To ensure that this mission is fulfilled, the Laboratory will maintain and enhance a vital scientific research and technology base and remain alert and responsive to new demands for solutions to emerging national problems.

B. Role

The Laboratory role is best defined by our relation to others and the character of our programs and facilities. Therefore, the Los Alamos National Laboratory

- is an integral scientific and technical element of the nation's nuclear weapons program; 
- provides the nuclear design and associated research, development, and test activities for all phases of a nuclear weapon from concept development through stockpile maintenance and retirement;

- contributes multidisciplinary skills for solving national problems;

- emphasizes basic science, engineering, and technological innovation;

- conducts basic and applied research and development;

- undertakes long-term, complex programs;

- has unique facilities;

- engages in technical initiatives with universities, industry, and foreign governments; and

- supplies informed and independent scientific opinion. 


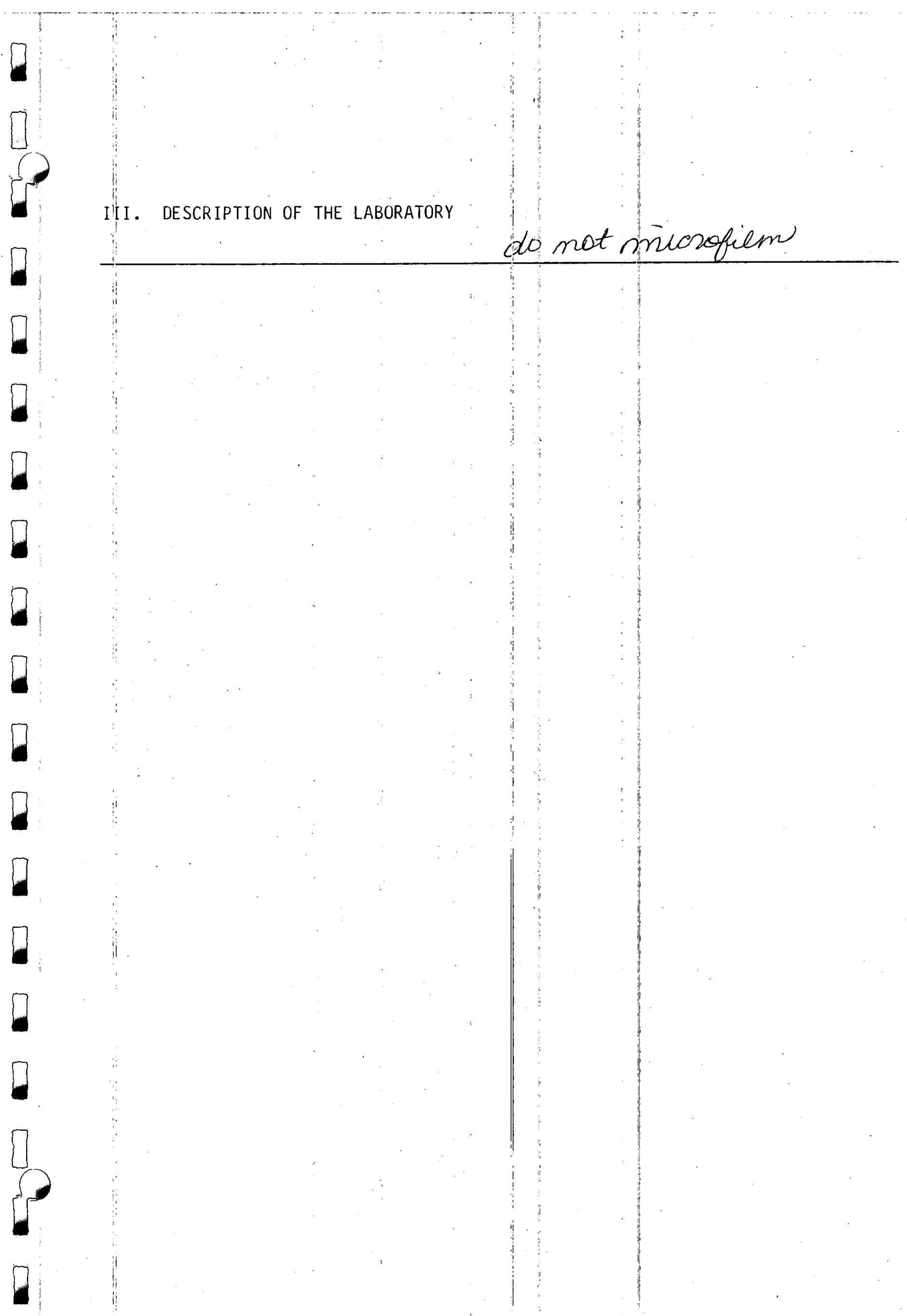




\section{DESCRIPTION OF THE LABORATORY}

Los Alamos National Laboratory is one of the nation's foremost scientific research institutions; it encompasses 125 facilities on 43 square miles of mesas and canyons in the Jemez Mountains of northern New Mexico. These facilities and their associated equipment occupy nearly 4.5 million square feet of floor space and would cost approximately three billion dollars to replace. The Laboratory was established in 1943 as part of the Manhattan Project to develop the first nuclear weapons; it diversified to include nonnuclear research in the early 1970s. Today our research includes nuclear weapons design, development, and testing; magnetic and inertial fusion; nuclear fission; nuclear safeguards and security; solar, fossil, and geothermal energy; energy conservation; environmental sciences; and basic research in physics, chemistry, mathematics, engineering, computer, and life sciences.

The Laboratory's operating budget for the fiscal year ending September 30, 1982, was $\$ 497$ million; an additional $\$ 77$ million was allocated for capital equipment and construction. Nearly 50 percent of this budget went toward salaries and benefits for the Laboratory's 6,800 full-time employees.

About 2700 of the Laboratory's FTEs hold one or more college degrees, distributed approximately as follows:

\begin{tabular}{|c|c|c|c|}
\hline \multicolumn{2}{|c|}{ By Degree } & \multicolumn{2}{|l|}{ By Degree Field } \\
\hline $\mathrm{PhD}$ & $51 \%$ & Physics & $33 \%$ \\
\hline MS & $25 \%$ & Engineering & $33 \%$ \\
\hline BS & $24 \%$ & Chemistry & $13 \%$ \\
\hline & & Math \& Computer Science & $8 \%$ \\
\hline & & Other & $13 \%$ \\
\hline
\end{tabular}

Los Alamos is managed by the University of California for the United States Department of Energy.

\section{A. Laboratory Strengths}

Among the unique strengths of the Laboratory are weapons research, the capability to fabricate complete weapons, the plutonium facility, the Los Alamos Meson Physics Facility (LAMPF), accelerator technology and particle beams, explosives science research, and the Central Computing Facility. These strengths are well matched to our mission.

\section{Weapons Research}

We examine the vulnerability of our strategic weapons deterrent as well as the effects of one nuclear blast on another from the aspect of recent scientific advancements. Such fundamental work cannot be done as effectively 
anywhere else in the western world and may well prove essential to the nation's future defense and deployment of MX missiles. The Laboratory is striving to improve its working knowledge of high-explosives (HE) assembled devices, device performance, weapon output, thermonuclear weapon behavior, and pure fusion research, which will enhance substantially our design capabilities for future weapons.

\section{Capability to Fabricate Complete Weapons}

It is a source of pride at Los Alamos that our prototype devices are so well engineered that few changes are required when they go into production. One reason for this is that we have the knowledge, skills, and facilities to completely fabricate a weapon at Los Alamos. This requires that we not only employ gifted scientists and technologists but also talented engineers who understand the production process.

\section{Plutonium Processing}

The plutonium facilities plant was designed and constructéd to meet the latest DOE criteria for plutonium operations. These facilities are the most complete and versatile research and development plutonium facilities in the country. The technical staff has a wide range of expertise in the fields of plutonium metallurgy and chemistry and has the laboratory equipment to make outstanding technical achievements. Their work has produced a number of notable "firsts," including purification, preparation, and fabrication of plutonium and its alloys; plutonium parts for the first nuclear weapons (including all associated metallurgy and chemistry); development of recycling operations for the reclamation of plutonium from the scrap; preparation of the core for the first plutonium-fueled nuclear reactor; preparation of the first "medical grade" 238Pu; preparation of the first prototypical SNAP and artificial-heart isotopic power sources; preparation and studies on the first plutonium ceramic and cermet materials; and preparation of the plutonium analytical standard for the National Bureau of Standards.

\section{Los Alamos Meson Facility (LAMPF)}

We operate an 800-MeV, 1-mA proton accelerator, LAMPF, as a unique international nuclear facility. LAMPF research includes fundamental studies of weak interactions, muonic $x$-rays, strong force (pion-nucleon) interactions, nucleon-nucleon scattering, studies of muon-induced activation, chemical structure effects on meson capture, properties of proton-rich nuclei far from stability, nuclear chemistry studies, and radiation damage studies. A design study is under way for an extension of the facility to higher energy, which will provide important new capabilities for research in LAMPF II nuclear and particle physics. We have given very high priority to the use of pi mesons for cancer radiation therapy in a program funded by the National Cancer Institute. The LAMPF accelerator is also used to inject protons for neutron 
production into a new facility, the weapons neutron research (WNR) pulsed neutron source. The Proton Storage Ring (PSR), now under construction, will make the WNR the best pulsed neutron source in the world. The application of neutron scattering techniques to a broad range of problems in condensed matter science is an important new area of our materials science programs.

\section{Accelerator Technology and Particle Beams}

Los Alamos National Laboratory is extending the science and art of subatomic particle accelerators to a wide spectrum of contemporary needs:

We are building a PSR that will be used in conjunction with LAMPF and WNR to make the world's most intense pulsed neutron source.

We are building a very high intensity deuteron accelerator for the Fusion Materials Irradiation Test program.

We are designing an efficient high-power, free-electron laser that will operate at $10.6 \mu \mathrm{m}$.

We are investigating the defense applications of particle beams.

We are building an electron microtron accelerator in collaboration with the National Bureau of Standards that will demonstrate basic technology for high-intensity electron machines for physics research.

We developed, under a National Cancer Institute program, the components of a hospital-based accelerator for cancer therapy using pions. This technology can serve a variety of needs by altering the configuration of the component parts. Pions, neutrons, or light-to-heavy ions could be provided for radiotherapy. Radioisotopes also could be produced in copious quantities.

We place heavy emphasis on the development and application of a major new type of accelerator structure, the radio-frequency quadrupole (RFQ), that has attracted attention around the world.

We are developing electron linar components and systems for a wide range of radiographic applications, for example, a machine that could obtain x-rays of turbine engines operating under simulated flight-maneuver conditions on a centrifuge.

\section{Explosives Science Research}

The explosives science research program at Los Alamos seeks to establish (1) a fundamental understanding of explosives behavior, (2) more accurate determination of explosives behavior, and (3) the discovery of new explosive materials with unique properties and capabilities. Our research includes 
Los Alamos

reactive hydrodynamics, synthetic chemistry, analytical chemistry, physical and thermal chemistry, chemical physics, and molecular physics.

\section{Central Computing Facility}

Since the development of the first atomic bomb, scientists at Los Alamos have relied heavily upon numerical calculations to design nuclear weapons. The detonation of a nuclear weapon involves complex, interacting physical processes that occur simultaneously. Exact solutions of equations that include all the interactions are beyond present capabilities. Consequently, designers must rely on numerical approximation methods to solve the problems, and there is always a demand for the next generation of computers. The first Cray Research supercomputer ever produced was installed at Los Alamos in March 1976. A second Cray-1 was installed in 1979. Los Alamos scientists have demonstrated that the Cray-1 can execute as many as 100 million floating-point operations per second on frequently occurring computational tasks (such as solving partial differential equations). By upgrading the memory of one of its Cray-1s in 1981, Los Alamos became the first installation whose users have the benefit of a multimillion-word Cray-1.

B. Long-Range Trends and Projections

During the past decade the Laboratory experienced a relatively high growth rate, approximately $7 \%$ per year. Near the end of that growth period, constraints to our physical abilities to pursue new programs became apparent. Although we pursued many exciting and challenging programs during this period, the unplanned growth led to crowding conditions and the need to use facilities under nonoptimal conditions. This lack of optimum facilities and space, compounded by transportation problems, etc., has led us to conclude that the Laboratory should maintain a relatively constant size of approximately 7,000 FTEs for the foreseeable future. Currently, however, growth is not our major problem. Indeed, maintaining a level of 7,000 FTEs has been our major focus of attention in the last 2 years. We must continually balance between closing down low-priority programs and seeking new initiatives which will maintain the desired level.

Figure III-1 depicts activity by Assistant Secretary. National Security programs comprise approximately $53 \%$ of the efforts of the Laboratory. Approximately $17 \%$ of our efforts are devoted to Energy Research, and $9 \%$ is devoted to Nuclear Energy. The remaining $21 \%$ of Laboratory efforts are spread over a number of small programs for DOE and non-DOE sponsors.

Figure III-2 depicts historical and projected personnel levels broken down by Direct and Indirect personnel. We plan to maintain a ratio of approximately 23\% Indirect to Total Laboratory personnel during the planning period.

Figures III-3 and III-4 show recent trends and future projections for program mix and for overall Laboratory growth. In order to assure continuing 
turnover of programs and thus the maintenance of vital and challenging technical and scientific programs, we pursue a portfolio of new initiatives as shown in Table III-1. These new initiatives are discussed in detail in Section IV.

Defense Programs: As sponsoring Secretarial Officer for Los Alamos, the Assistant Secretary for Defense Programs (ASDP) funds programs in nuclear weapons, inertial confinement fusion, verification and control technology, nuclear materials safeguards and security, and nuclear materials production. DOE laboratories and contractors reporting to the ASDP sponsor a small number of additional projects at LoS Alamos. In FY 1982 these programs comprised approximately $56 \%$ of the total Laboratory budget. of this, $39 \%$ was weapons research, $7 \%$ was inertial confinement fusion, $2 \%$ was weapons production and surveillance, $3 \%$ was materials production, $2 \%$ was verification and control technology, $2 \%$ was nuclear materials safeguards and security, and the remaining $1 \%$ was defense waste management.

Defense Programs have shown a modest but continuing increase in level of effort during the past eight years (Fig. III-5). We expect this trend to continue and possibly accelerate somewhat as nondefense programs activities decline.

Energy Research: Major Los Alarnos programs funded by the office of Energy Research (OER) include basic energy sciences, health and environmental research, a large component in mediunt-energy nuclear physics, and magnetic fusion. These programs comprised approximately $14 \%$ of the total Laboratory FY 1982 budget. Basic Energy Sciences is 1\%, Health and Environmental Research is 2\%, Nuclear and Medium Energy Physics is 7\%, and Magnetic Fusion is $4 \%$ of the total FY 1982 Laboratory efforts.

These programs show a slight decline in the past eight years (Fig. III-6). We would like to see this trend reversed and project an increase over the next five to eight years in Energy research.

Energy Programs: Nuclear Energy has suffered most significantly in the last two years as nuclear programs, particularly Laser Isotope Separation activities, have declined by more than $50 \%$ over previous levels (Fig. III-7). Although we do not expect to regain the peak in Nuclear Energy achieved in the late 70s, we would like to see our Nuclear programs, particularly Nuclear Safety and Advanced Concepts, increase by 400 FTEs.

Other DOE programs such as Solar, Geothermal, and Fossil energy grew significantly in the late $70 \mathrm{~s}$, peaked in the early 1980s, and are now declining to a modest level of 250 FTEs in the mid-to-late 80 s (Fig. III-8). The decline in these programs, as well as Nuclear Energy, requires an emphasis on new initiatives, which we project will increase as we pursue non-DOE Work for Other Initiatives. 
Los Alamos

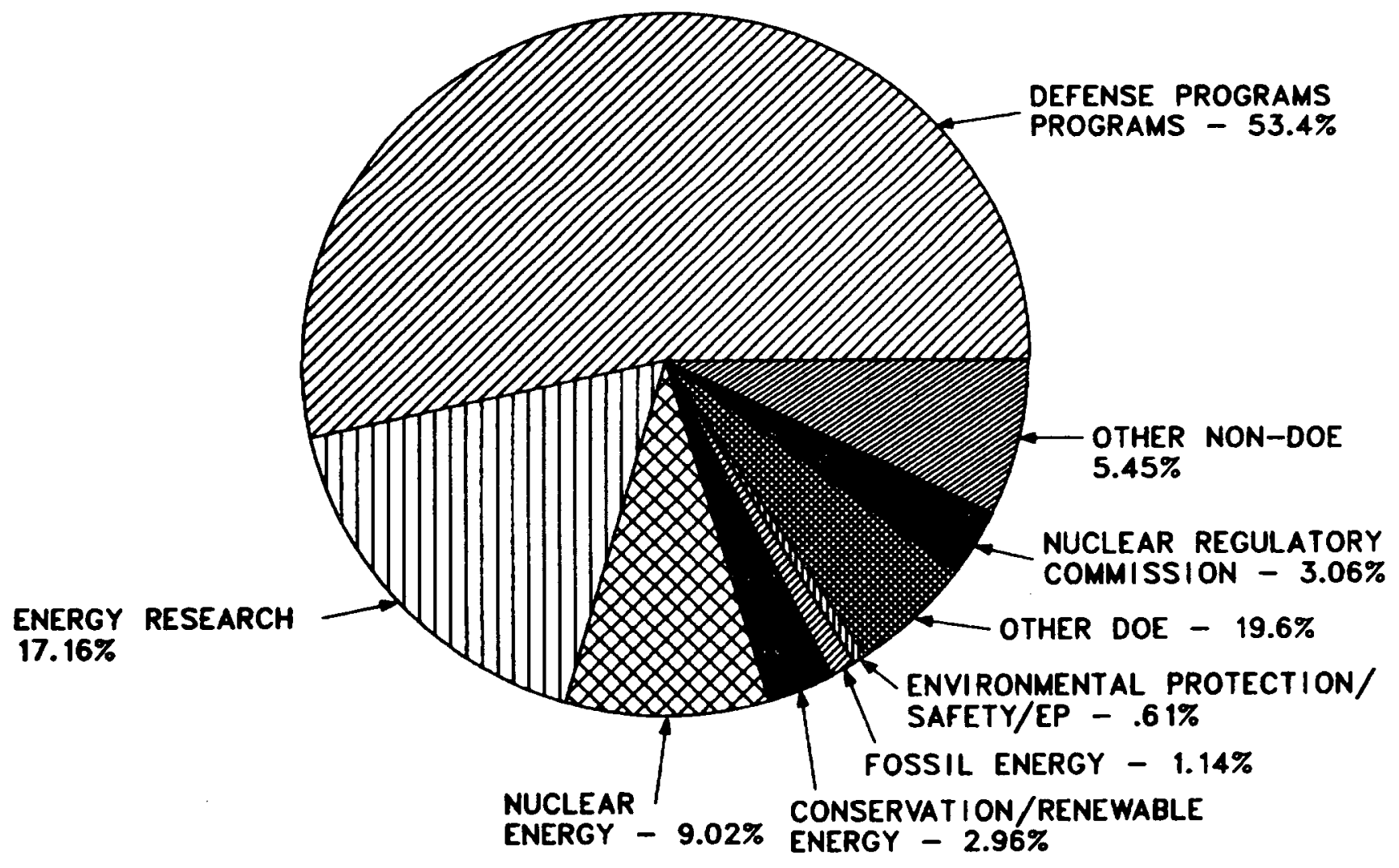

Fig. III-1. Activity by Assistant Secretary 


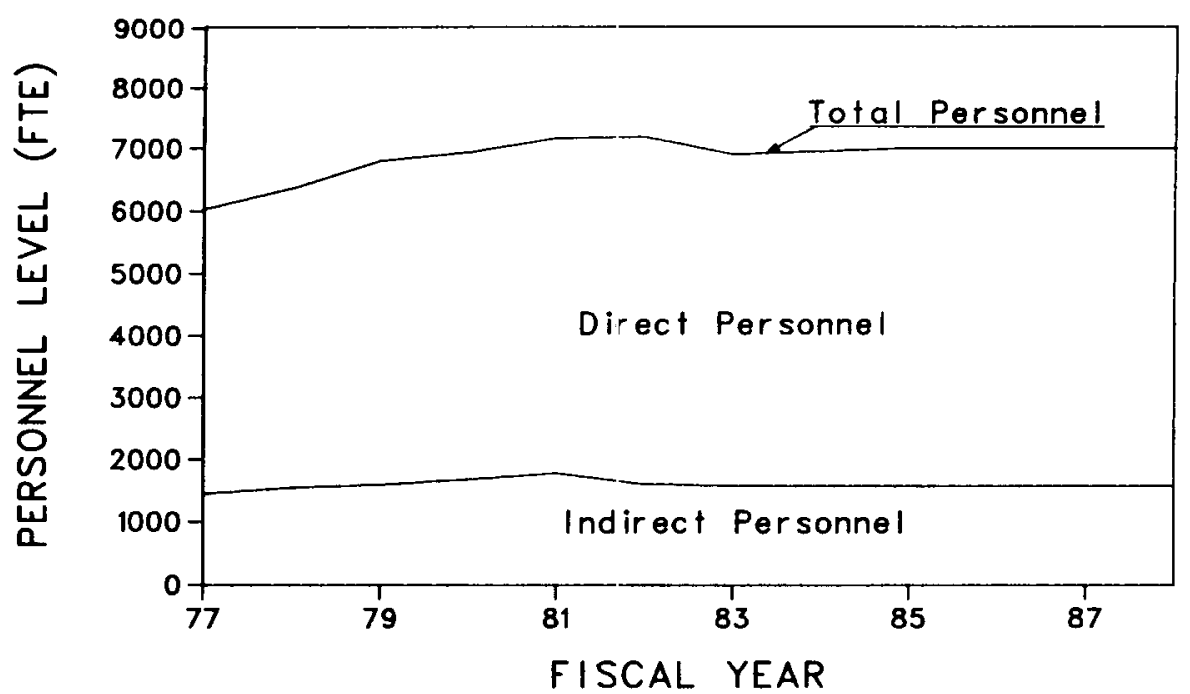

Fig. III-2. Personnel Level

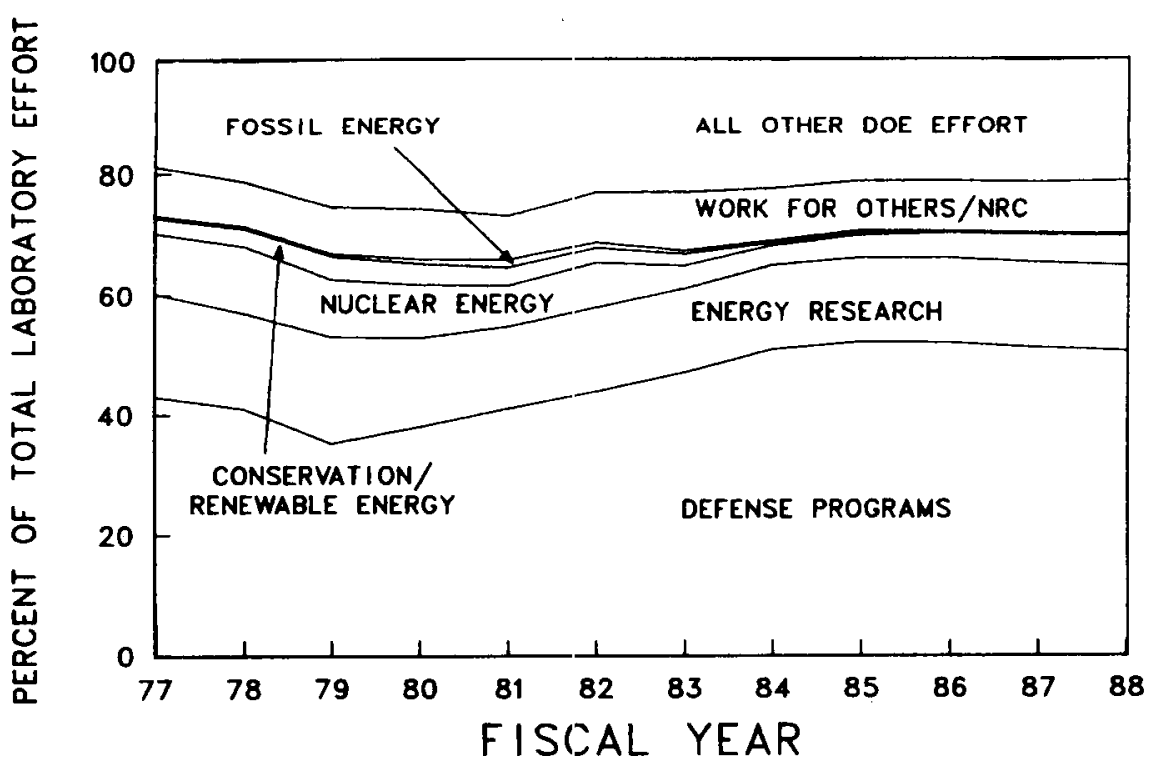

Fig. III-3. Major Technology Programs 
Los Alamos

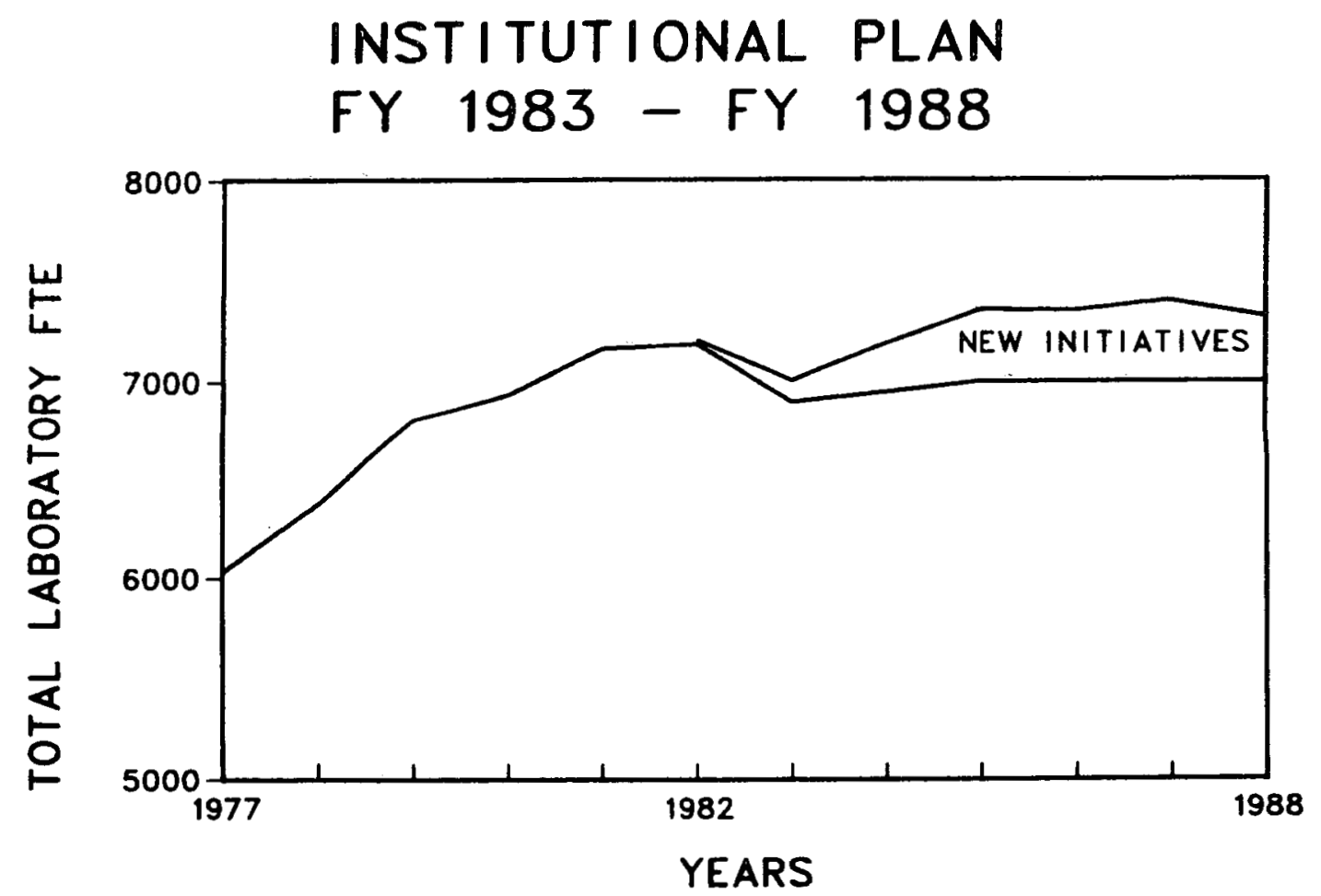

Fig. III-4 
TABLE \|\|$-1$

\section{INSTITUTIONAL PLAN FY 1983 - FY 1988 \\ PROPOSED INITIATIVES (FTE)}

\section{DEFENSE PROCRAMS \\ INTERNATIONAL TECHNOLOGY \\ NEW PRODUCTION REACTOR \\ MILITARY ENERGY SECURITY
ENERGY RESEARCH
REVERSED FIELD PINCH (RFP)
IGNITION TEST REACTOR/
ENGINEERING TEST REACTOR
LAMPF "
MATIONAL UNDERGROUND
SCIENCE FACILITY
MEUTRINO FACILITY

MUCLEAR ENERGY

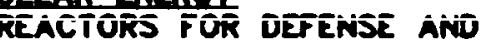

SPACE APPLICATIONS

COMSERYAUON AND RENEWAELE ENERGY

FUEI CELLS

EOSSIL ENERTY

UNCONVENTIONAL GAS

OIL SHALES AND TAR SANDS

COAL/WATER MIXTURES

INTERMATIONAL AKD ENERGY POLICY PROCRAMS

CARIESEAN BASIN INITIATIVE

U.S. - MEXICO COOPERATION

\section{WFO - D.0D}

DIRECTED ENERGY

TECHNOLOCY DEMONSTRATION

ACCEIERATOR

FREE ELECTRON LASER

COUNTERTERRORISM

CONVENTIONAL MNITIONS

\begin{tabular}{|c|c|c|c|c|c|c|}
\hline EY82 & EY83 & EY84 & EY85 & EY86 & EYBZ & EY8B \\
\hline \multirow[t]{3}{*}{5} & $\begin{array}{l}13 \\
15\end{array}$ & $\begin{array}{l}30 \\
32\end{array}$ & $\begin{array}{l}50 \\
50\end{array}$ & $\begin{array}{l}50 \\
64\end{array}$ & $\begin{array}{l}50 \\
80\end{array}$ & 50 \\
\hline & 8 & $\begin{array}{r}16 \\
5\end{array}$ & $\begin{array}{l}32 \\
10\end{array}$ & $\begin{array}{l}48 \\
13\end{array}$ & $\begin{array}{l}60 \\
13\end{array}$ & $\begin{array}{l}70 \\
13\end{array}$ \\
\hline & 1 & 3 & 3 & 5 & 5 & \\
\hline \multirow[t]{3}{*}{3} & 7 & sô & 50 & कิ & 100 & i00 \\
\hline & 13 & 20 & 20 & 20 & 20 & 20 \\
\hline & & $\begin{array}{r}10 \\
7 \\
4\end{array}$ & $\begin{array}{r}15 \\
9 \\
8\end{array}$ & $\begin{array}{r}15 \\
10 \\
8\end{array}$ & $\begin{array}{r}15 \\
10 \\
8\end{array}$ & $\begin{array}{r}15 \\
10 \\
8\end{array}$ \\
\hline
\end{tabular}

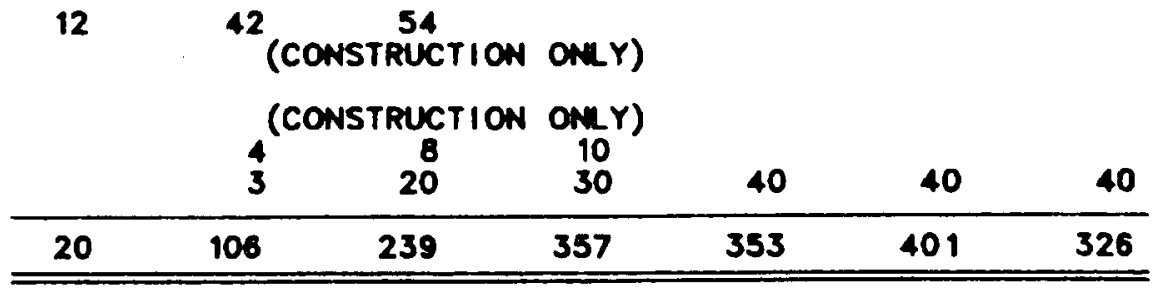


Los Alamos

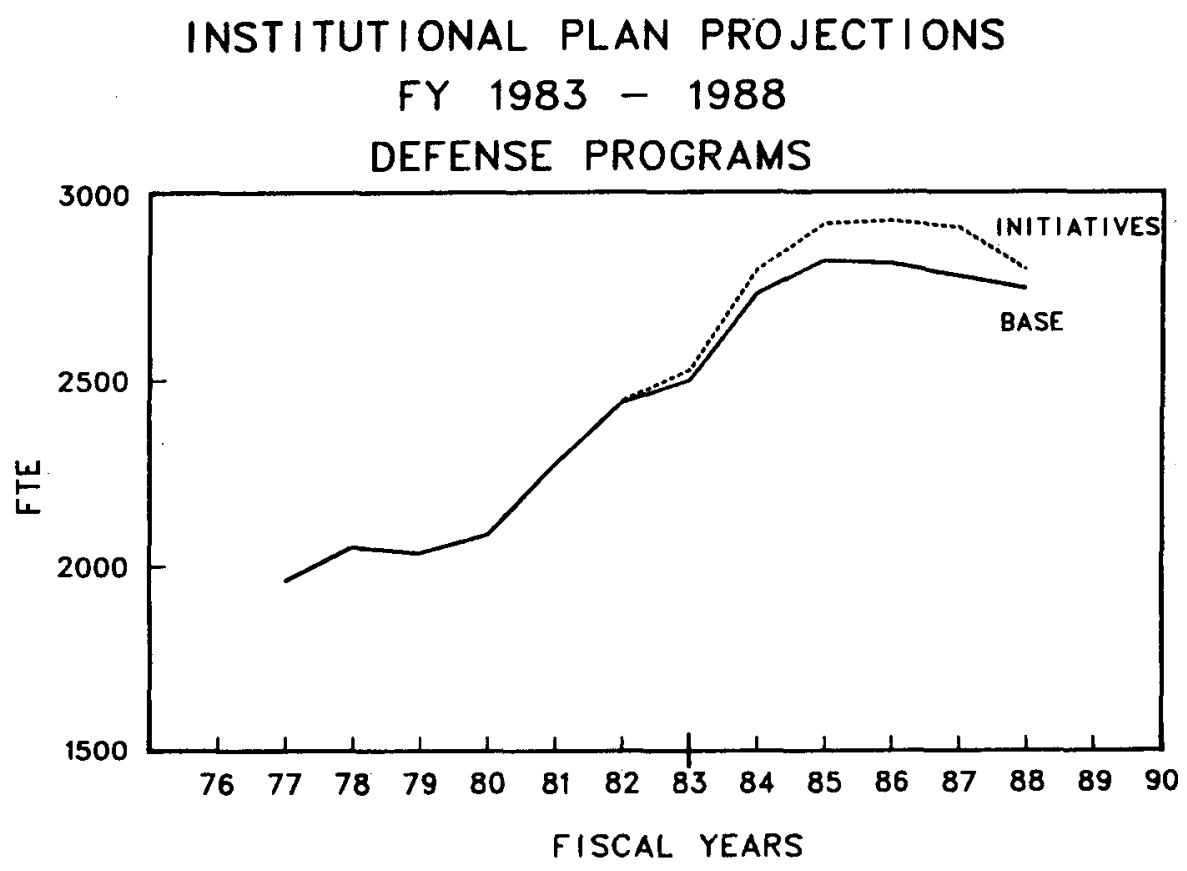

Fig. ||$l-5$

INSTITUTIONAL PLAN PROJECTIONS

FY 1983 - 1988

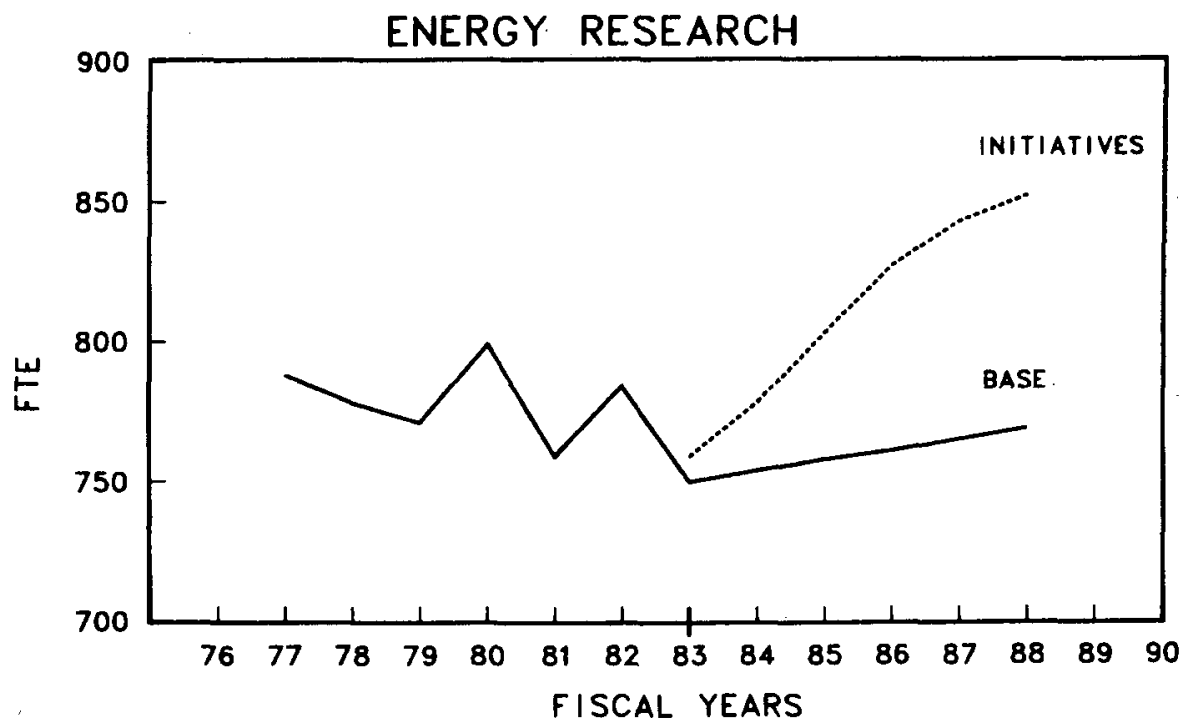

Fig. $|I|-6$ 
INSTITUTIONAL PLAN PROJECTIONS

FY 1983 - 1988

$\square$

NUCLEAR ENERGY

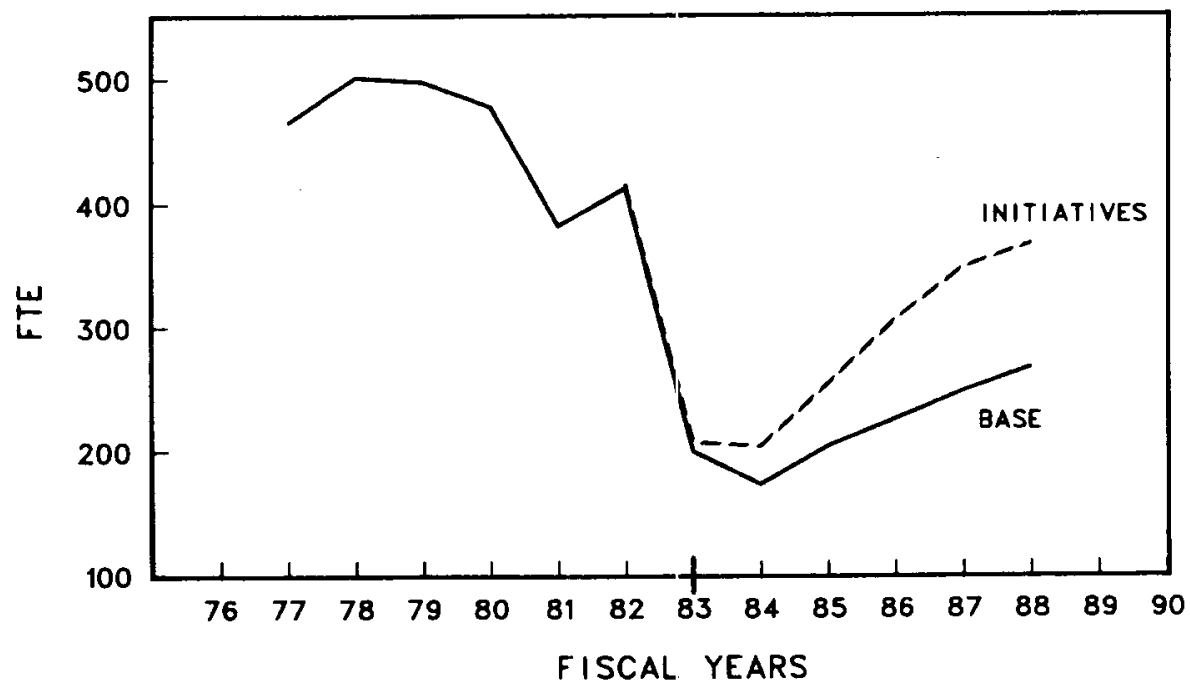

Fig. III-7

INSTITUTIONAL PLAN PROJECTIONS

FY 1983 - 1988

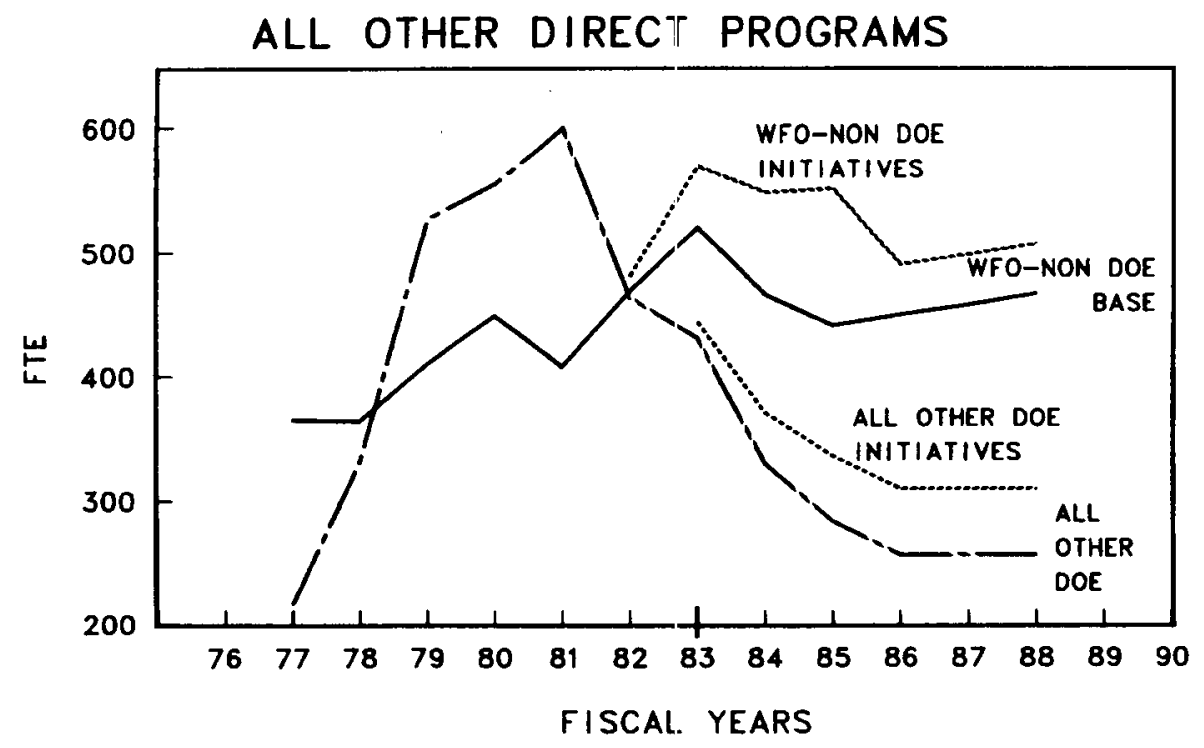

Fig. $|l|-8$ 

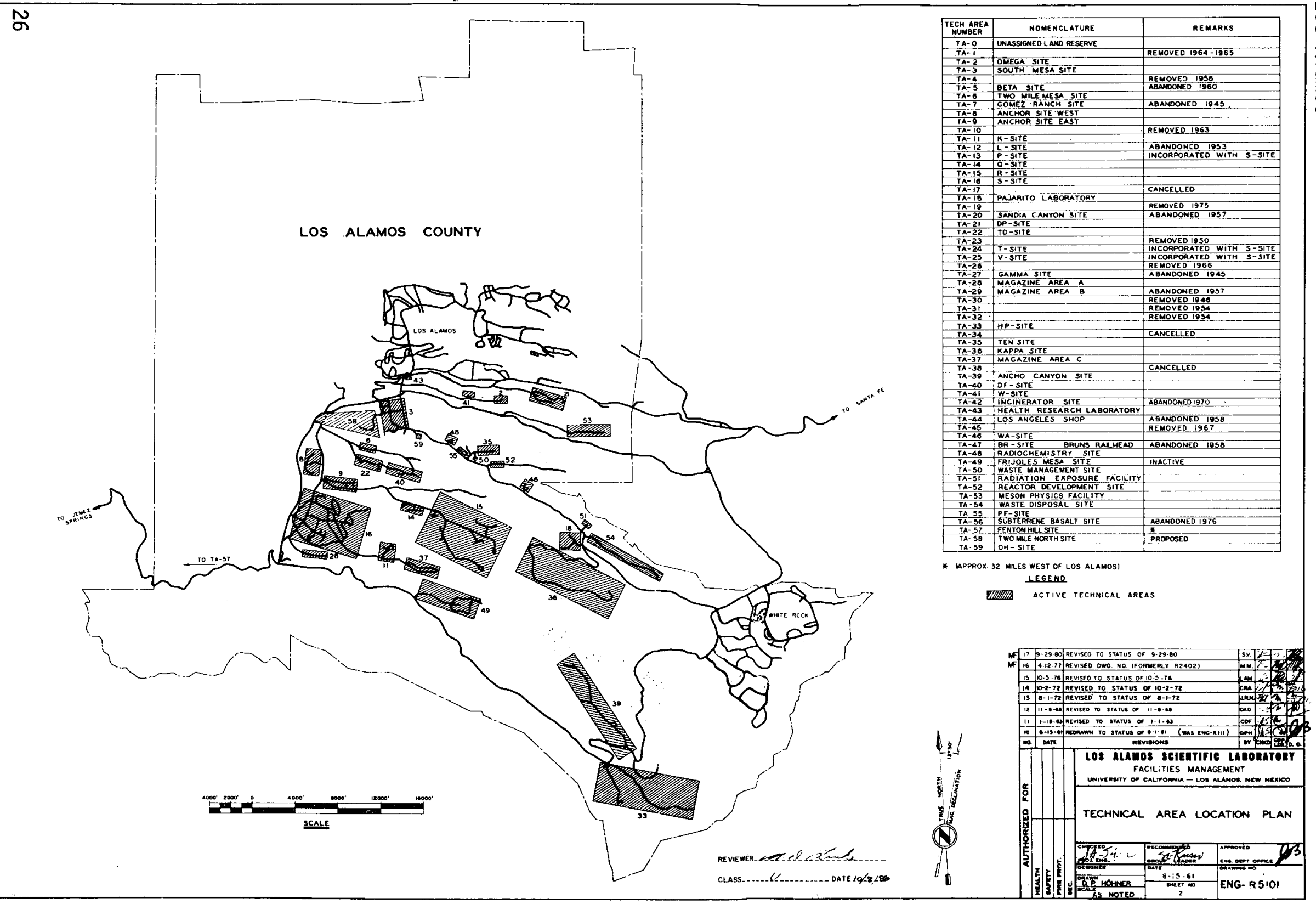


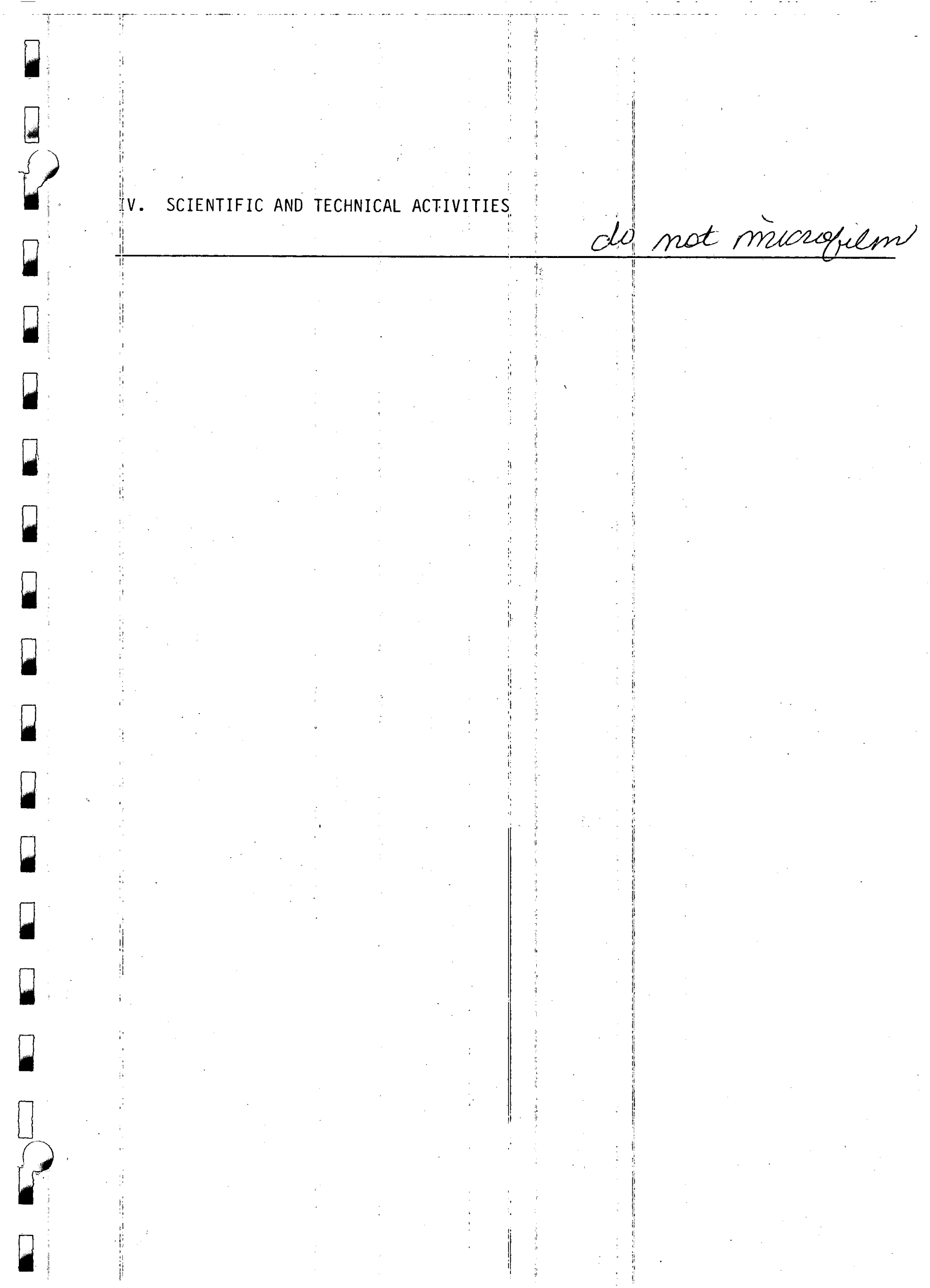




\section{SCIENTIFIC AND TECHNICAL ACTIVITIES}

\section{DEPARTMENT OF ENERGY PROGRAMS}

A. Defense Programs

\begin{tabular}{|c|c|c|c|c|}
\hline$B \& R$ Code & Major Program (Title) & FY 1982 & FY 1983 & FY' 1984 \\
\hline $\begin{array}{l}\text { AR } \\
\text { GB-01 } \\
\text { GB-02 } \\
\text { GB-03 } \\
\text { GC } \\
\text { GD } \\
\text { GE }\end{array}$ & $\begin{array}{l}\text { Defense Waste Management } \\
\text { Weapons Research } \\
\text { Inertial Conf inement Fusion } \\
\text { Weapons Prod/Surveillance } \\
\text { Verification \& Contr Tech. } \\
\text { Nuc Mtls Safeguards \& Sec } \\
\text { Materials Production }\end{array}$ & $\begin{array}{r}4.0 \\
193.1 \\
35.7 \\
10.0 \\
12.6 \\
8.8 \\
13.1 \\
\end{array}$ & $\begin{array}{r}4.5 \\
214.4 \\
39.4 \\
8.7 \\
13.6 \\
8.8 \\
13.8 \\
\end{array}$ & $\begin{array}{r}2.0 \\
256.3 \\
41.6 \\
8.5 \\
18.1 \\
12.5 \\
30.6 \\
\end{array}$ \\
\hline \multicolumn{2}{|l|}{ Total } & 277.3 & 303.2 & 369.6 \\
\hline \multicolumn{2}{|c|}{$\begin{array}{l}\text { Percent of Total } \\
\text { Laboratory Funding }\end{array}$} & 56 & 61 & 63 \\
\hline 1. Current & Defense Programs & & & \\
\hline a. Weapons & tivities & & & \\
\hline
\end{tabular}

(1) Nuclear Weapons. The primary goal of the Los Alamos nuclear weapons program is the development of state-of--the-art nuclear weapons that will continue to ensure our national security commitments. Weapon requirements are determined through close interactions between the DoD, military services, their contractors, and the DOE Office of Military Application. Through the years, to meet these requirements we have developed warheads that are safer, smaller, more efficient, more reliable, and more survivable. Since 1979, all new strategic warheads that have entered the stockpile have been Los Alamos designs. These include the W76, W78, and the W80. We continue to provide designs for the B61 bomb, the warhead for the Navy's Standard Missile II (W81), and the airburst/surface burst warhead (W85) for the Pershing II. We are currently working on conceptual and feasibility studies for several future nuclear weapons systems, most notably the Trident II.

We have just completed the FY 1983 budget allocation process at Los Alamos for the nuclear weapons RD\&T program. This process, initiated about a year ago, was designed to produce a weapons program aimed at responsiveness to programmatic needs, rather than what could be done for a fixed budget. It involved a complete restructuring of the program to try to enhance the balance in research, development, and weaponization activities so necessary in meeting 
our goals. Management of the program was also restructured to unite technical leadership and program management responsibilities.

The first of the three major categories, Research Activities, constitutes about $22 \%$ of the overall effort and is typically high-risk/high-payoff studies. The second category, Development Activities, is the technology base directed to improving state-of-the-art technologies available for applying to Weaponization activities, including our nuclear test execution activities. These constitute $51 \%$ of the total. The Weaponization category consists of $27 \%$ of the total and involves theoretical and engineering design, of current and future weapons, and management of the LoS Alamos-developed portion of the stockpile.

The research category consists of three elements: institutional supporting research, new concepts, and weapons physics. This category is designed to be the generator of new ideas directed to high-risk research which, if successful, could lead to major improvements in our defense posture. Among our new research facility plans are the Proton Storage Ring to increase the capabilities of the Weapons Neutron Research facility for national defense studies using pulsed neutrons and a synchrontron beam line for improved $x$-ray physics measurements of importance to weapons work.

The development category is subdivided into six program elements: advanced design technology, computation, advanced weapons engineering, materials and fabrication, high-explosives technology, and test operations. The advanced technology element consists of theoretical and experimental studies to improve nuclear weapons technology directed toward reduced size and weight and increasing yield. The computation element strives to improve our modeling capabilities through advances in computer codes and the maintenance of existing codes. The advanced weapons engineering and materials and fabrication elements investigate problems, with the former specializing in the engineering and design areas and the latter concentrating on the materials aspects. All aspects of high explosives are studied in the high-explosives technology element. Studies on detonators, new classes of HE, safety, dynamic experiments, and chemical behavior of high explosives lead to safer and more efficient weapons systems. The last major program element in this series is test operations, which is the responsibility for the execution of our nuclear test effort.

The weaponization and applications category involves weapons studies, current weapons development, new production, and evaluation and maintenance of the stockpile. Weapons studies include our efforts in the areas of concept and feasibility studies of future weapons. In the current weapons program element, we include the development of specific weapon systems, such as the development of the warhead for the new Trident II missile.

With this new structure, during the past year we developed in-depth plans for the weapons program that specified directions, objectives and goals, 
anticipated time scales, and resource requirements. This planning activity was performed from the bottom up and iterated back down through the performing organizations in reaching the final plan. This new planning process clearly revealed the condition that has been created in recent years by operating in a mode where the budget constrains the program. In the planning process, we identified activities by priority levels 1, 2, and 3. The complete plan totaled $\$ 298 \mathrm{M}, 40 \%$ greater than the FY 1983 Presidential budget mark. Detailed screening of the activities reduced the budget figure to $\$ 240 \mathrm{M}$, which was still $>\$ 30 \mathrm{M}$ over the Presidential budget mark.

The \$242-M program was a lean, Priority 1 program. The trimming of this programmatic, Priority 1 program in the resource plan to fit within the \$211.9 M Presidential budget mark required difficult decisions, which again force us to live within a crisis environment. Because of this, our outyear projections for FY 1984 through FY 1988 are based upon our just-completed Priority 1 programmatic plan, assuming that in FY 1984 we are at that activity level which would be consistent with a \$240-M FY 1983 level. More detailed information regarding program content and plans for the nuclear weapons activities is available only in classified documents.

(2) Inertial Confinement Fusion. Los Alamos is actively engaged in the pursuit of inertial confinement fusion with the primary emphas is on evaluating $\mathrm{CO}_{2}$ lasers as the driving energy source. The primary goals of the present program are (1) to examine and understand the ICF physics at a level needed to determine the scientific feasibility of $\mathrm{CO}_{2}$ lasers as drivers for practical ICF targets, (2) to investigate weapons physics issues, and (3) to develop and implement plans to determine the feasibility of affordable future ICF drivers.

We are also involved as the lead laboratory in the investigation of heavy ion accelerators as a driver. This program is viewed as having primarily commercial applications, and funding under the Office of Energy Research is being sought for FY 1984 and beyond.

At the present time the central issue of the nation's ICF program is the demonstration of scientific feasibility through efficient thermonuclear burn of small fuel masses. This near-term objective must be accomplished before proceeding with any of the various long-range applications.

By the end of FY 1982, candidate target configurations were determined with Helios experiments. During FY 1983, a selection of the most promising target concepts will be made for the initial Antares tests. Experiments will begin with Antares in FY 1984. If target performance at the Antares energy level demonstrates the viability of 10-micron light to scale to ignition, Los Alamos. will recommend implementing a development program to provide prototype modules for a $\mathrm{CO}_{2}$ laser capable of driving fusion targets to energy breakeven. A conceptual design of the next generation $\mathrm{CO}_{2}$ system has been completed by a team from Los Alamos and industry and indicates no major 
technical obstacles to further energy scaling. This possibility emphasizes that it is of crucial importance to maintain a key technology base in laser engineering intact until the decision is made concerning the feasibility of a $\mathrm{CO}_{2}$ laser driver.

If the target physics reveals major, fundamental problems with compression and preheat that are uniquely traceable to irradiation by $\mathrm{CO}_{2}$ laser light, then LoS Alamos will recommend no further development of large $\mathrm{CO}_{2}$ lasers for fusion and effort will be directed to development of an affordable short wavelength gas laser. Even if no new $\mathrm{CO}_{2}$ laser facilities are developed, the commonality of inertial confinement fusion and weapon physics may permit Antares to provide a great deal of data useful to the weapons design effort. This facility should receive operational support for this purpose as long as it is able to provide critical data in a cost effective fashion.

The ultimate weapon goal for the ICF program is the attainment of a laboratory facility in which fusion burn can be studied from pellet performance. From present estimates this is believed to require several megajoules of driver energy. At the present time no laser system can be projected to this size with costs that are under roughly $\$ 500 \mathrm{M}$. Hence, cost reductions in driver technology are critical to future program objectives. We have therefore initiated a low-level technology demonstration to investigate the feasibility of low-cost gas excimer lasers.

The current program includes research and development in both classified and unclassified areas of the following: laser-target interaction physics; target implosion studies; theory and code development, including both nuclear design codes and plasma physics codes; target interaction experiments with $\mathrm{CO}_{2}$ lasers; target fabrication for such experiments; the Centurion program; diagnostics development; advanced laser R\&D; ICF systems studies; and weapons applications experiments.

The major facility now in operation is the Helios 8-beam, 8-kJ lasertarget system. Supporting physics experiments have been conducted with the Gemini, 2-beam, 1-kJ facility which was shut down early in FY 1982. Helios is used to explore laser-target interaction physics and to provide the experimental basis for target design for the Antares, 24-beam, 40-kJ facility now under construction on which definitive ignition scaling experiments are to be performed.

\section{b. Verification and Control Technology}

The goals of the verification and arms control technology program are to provide technical, analytical, and other support to the DOE arms control measures. These include foreign technology assessments, technology transfer issues, and detection of nuclear explosions underground, in the atmosphere, and in space. 
(1) Nonseismic Nuclear Explosion Detection. The ionospheric monitoring and infrasonic programs are directed to verification of nuclear test ban treaties. The programs seek to detect and measure atmospheric and underground nuclear explosions by observing ionospheric and atmospheric signatures which result. As a longer range goal, we hope to develop the capability to estimate yields from these data. With this effort, Los Alamos will provide technical guidance to $D O E$ and other agencies to ensure that adequate verification provisions are included in negotiated treaties.

(2) Satellite-Based Nuclear Explosion Detection. Satellite-based test detection is a continuing Los Alamos program that began about 1960 with design and preparation of the first pair of Vela satellites, launched in 1963. Of all of the Vela satellites that were launched, none are totally operational and only a few are partially functiorlal. Satellite-based test detection is continuing in multimission Air Force satellite programs for which Los Alamos and Sandia National Laboratories (SNLA) jointly provide instrumentation for verification of its Limited Test Ban Treaty. In general, Los Alamos is responsible for instrumentation to detect the direct $x$-ray, gamma-ray, neutron, and charged-particle radiations from nuclear detonations in space; SNLA provides optical instrumentation for sensing atmospheric detonations and provides electronic logic for data handling.

In addition to providing surveillance of foreign nuclear explosions in space and in the atmosphere, this joint project supports DoD requirements for wartime information on tactical nuclear bursts. It also supplies data on natural and artificial space radiation. Finally, the project conducts R\&D in related technologies, including those for potential detection of directedenergy weapon testing.

There is a recognized need to augment the deep-space and Southern Hemisphere detection capability. In the past, satellite deployment has emphasized and has been designed for detection of explosions relatively near the earth and in the Northern Hemisphere. Deep space may offer an attractive region for clandestine tests with yields larger than allowed by the Threshold Test Ban Treaty; the September 22, 1979, event pointed out the need for improved surveillance of the Southern Hemisphere for verification of the Limited Test Ban and Nonproliferation Treaties. Achieving an effective deep-space detection capability will require both instrumentation development and deployment on either dedicated or multimission satellite systems in low-radiation background orbits. Southern Hemisphere coverage will be enhanced when new satellite systems become operational in the next few years, but new diagnostic techniques and deplayment scenarios are needed to provide independent corroborative evidence that otherwise ambiguious signals are of nuclear origin.

(3) Other Verification Research. We are implementing research programs in innovative nuclear explosion detection techniques and yield verification 
Los Alamos

analysis, and we plan to consider policy implications of detecting nuclear tests by states previously not known to possess nuclear weapon capabilities.

\section{c. Nuclear Material Safeguards and Security}

The Safeguards and Security R\&D Program at LoS Alamos is designed to address current, evolving, and future needs, primarily in the area of materials control and accounting ( $M C$ and $A$ ). Strong interfaces with physical protection, containment/surveillance, and nuclear facility operations are necessarily included, as well as substantial activities in computer and operations security. The program activities range from development of individual measurement devices to complete systems integrated with physical protection and process operations elements, from fundamental measurement physics through engineering of the hardware and software to implement those measurements. The applications of the program cover the DOE complex, the commercial nuclear industry, and the international community. Consequently, the program includes not only $R \& D$ efforts but applications in operating facilities. The program structure comprises four tasks:

- Task I: Directed Facility Support

- Task II: Security Development and Support

- Computer Security

- Operations Security

- Task III: Safeguards Technology

- Equipment Development

- Methods Development

- Task IV: International Support

The program is carried out in close cooperation with nuclear facility designers and operators and operational safeguards and security personnel. The intent is twofold: (1) to ensure effective application of the best available technology and (2) to direct the technology development at identified and emerging needs.

\section{d. Special Isotope Separation}

This program has the goal of producing weapons-grade material from existing DOE-owned N-Reactor fuel-grade material. The production plant will be constructed utilizing existing facilities at either the Savannah River Plant or at the Rockwell-Hanford site. An integrated Molecular Laser Isotope Separation (MLIS) prototype system will be constructed at Los Alamos using existing plutonium facilities at TA-55 by the end of FY 1984 . 


\section{e. Defense Waste Management}

Complementary emphasis in the defense waste effort is on nondestructive waste assay instrumentation development, volume reduction through incineration, and the development of safe means for disposing of low-level waste in shallow land burial sites. Advances in assay instrumentation have greatly enhanced our ability to distinguish accurately between low-level wastes and TRU wastes, and the improved segregation is permitting us to reduce the volume of TRU waste that must be stored for long periods of time.

2. Defense Initiatives

a. New Production Reactor Project

To assure an adequate supply of reactor products for weapons needs, the Assistant Secretary for Defense Programs (ASDP) has formed a New Production Reactor (NPR) Program office at DOE headquarters. An NPR Program Requirements Office has been formed at Los Alanos to provide technical support to the Program office.

In FY 1982 the Program Requirements Office is providing technical support in the following three areas:

(1) A Concept and Site Selection Federal Advisory Panel is being commissioned by ASDP to rank the candidate NPR concepts and sites. The Laboratory is providing direct technical support to this Panel, including publishing the Panel's final recommendation report.

(2) Los Alamos will be responsible for the safety review of the NPR. During FY 1982, the Laboratory is developing general design criteria for the safety review.

(3) Los Alamos is providing, on a continuing basis, up-to-date projections of U.S. weapons program nuclear material requirements and production rates.

In future years, the activities of the Program Requirements office will shift to independent technical evaluation and review activities, with the safety review constituting a major share of the effort. follows:

Projected staffing (FTES) for the Program Requirements Office is as NEW PRODUCTION REACTOR PROJECT

$\begin{array}{lllllllll}\text { ( } 8 \text { in millions) } & \text { FY82 } & \text { FY83 } & \text { FY84 } & \text { FY85 } & \text { FY86 } & \text { FY87 } & \frac{\text { FY88 }}{5} \\ \text { Personnel } & 5 & 13 & 30 & 50 & 50 & 50 & 50\end{array}$




\section{b. Military Energy Security}

The Laboratory is vigorously pursuing the establishment of a Military Energy R\&D Center at Los Alamos and Albuquerque Operations Office. This will provide DoD with a single point of contact for energy R\&D, similar to that which we provide for nuclear weapons. The major differences are that Los Alamos would serve as a lead center including a technical management role, and Albuquerque would have oversight responsibility.

MILITARY ENERGY SECURITY

\begin{tabular}{|c|c|c|c|c|c|c|c|c|c|c|}
\hline \multirow[b]{2}{*}{ ( 8 in millions) } & \multicolumn{2}{|c|}{ FY83 } & \multicolumn{2}{|c|}{ FY84 } & \multicolumn{2}{|c|}{ FY85 } & \multicolumn{2}{|c|}{ FY86 } & \multicolumn{2}{|c|}{ FY87 } \\
\hline & $\mathrm{BA}$ & $\mathrm{BO}$ & $\mathrm{BA}^{-}$ & $\mathrm{BO}$ & $\mathrm{BA}$ & 80 & $B A-$ & $\mathrm{BO}$ & $\mathrm{BA}^{-}$ & $\mathrm{BO}$ \\
\hline $\begin{array}{l}\text { Operating } \\
\text { Capital Equipment } \\
\text { Total } \\
\text { Direct Personnel }\end{array}$ & $\begin{array}{c}2.0 \\
\frac{-}{2.0} \\
1\end{array}$ & $\begin{array}{l}2.0 \\
\frac{-}{2.0}\end{array}$ & $\begin{array}{l}7.0 \\
0.2 \\
7.2\end{array}$ & $\begin{array}{l}7.0 \\
0.2 \\
7.2\end{array}$ & $\begin{array}{l}6.25 \\
0.3 \\
6.55\end{array}$ & $\begin{array}{l}6.25 \\
0.3 \\
6.55\end{array}$ & $\begin{array}{l}8.0 \\
0.4 \\
8.4\end{array}$ & $\begin{array}{l}8.0 \\
0.4 \\
8.4\end{array}$ & $\begin{array}{r}10.0 \\
0.5 \\
10.5\end{array}$ & $\begin{array}{r}10.0 \\
0.5 \\
10.5\end{array}$ \\
\hline
\end{tabular}

\section{c. International Technology}

Although this existing program is a small part of the Laboratory (approximately 75 FTEs), it represents a rapidly expanding area of activity. Growth in this area in the last 3 years has been approximately $20 \%$ per year; we expect it to continue. It is included in the "New Initiatives" section because of projected rapid growth and to state our intentions to pursue aggressively special analyses for Federal agencies including DOE where they match our unique and expanding capabilities.

\section{Proposed Defense Program Construction}

During the last year LoS Alamos performed an extensive evaluation of its facility requirements, tying it directly to its developed weapons program plan. This effort was initiated in support of the weapons complex test revitalization study, expanded because of a request to evaluate our R\&D facility needs to support our weapons program, resulting in establishment of priorities for the consolidated weapons program facilities. The last effort resulted from the realization that test facilities, in many cases, cannot be completely or cleanly separated from R\&D facilities.

The list of project candidates that surfaced during these studies was much more extensive than had been anticipated, as this was the first time we had worked a total weapons program resource plan, as opposed to a separate operating plan and a separate facilities plan. We have reviewed the list and divided it into those projects for which we would maintain up-to-date engineering studies and those for which such studies must be postponed. This final step of consolidating our lists was a difficult one in which we took a 
hard look at priorities from an overall view of the weapons program, prioritizing the FY 1984 and FY 1985 lists and deleting from formal submission all projects of lower priority.

GB-01-Weapons Activities

Advanced Radiochemical Weapons Diagnostics Facilities (TEC \$8.1 M, FY84): This project will provide necessary laboratory, laboratory support space, and equipment to support advanced radiochemical diagnostics of weapons tests. The proposed facilities include two new buildings to be constructed adjacent to the existing Radiochemistry Laboratory Building.

Test Fabrication Facility, Phase I (TEC 88.1 M, FY84): This project will consolidate, upgrade, and expand critical test facilities to meet current and projected Nevada Test Site test schedules.

It will provide for the procurement and installation of special equipment at the TA-3-38 Zia Fabrication Shop, construction of a Dry Run and Alignment Facility, construction of a wire rope Harness Fabrication and Tensile Testing Facility with provisions for storage of both raw materials and completed assemblies, construction of a Painting Facility, and relocation of the tensile test equipment.

Dual-Axis Radiographic Hydrotesting Facility (TEC \$24.9 M, FY84): The project provides for a weatherproof facility to maintain the radiographic system and for the modification and upgrade of explosives firing site R-280, the principal feature being the procurement and installation of a second, high-intensity, flash $x$-ray machine for dual-axis radiography.

Nuclear Materials Storage Facility (TEC \$20.0 M, FY84): Construction of a hardened repository for the storage of nuclear materials (long-term and intermediate shelf storage of nuclear materials) designed to meet the appropriate criteria for the storage and protection of nuclear materials and as a Safe and Secure Transport (SST) shipping/receiving port.

X-Ray Calibration Capability Upgrade (TEC \$4.6 M, FY84): This project consists of two parts: (1) the design, procurement, and installation of beam line components at a major synchrotron radiation facility and (2) the expansion and upgrade of $x$-ray characterization equipment and facilities at Los Alamos. This project will provide important new R\&D capabilities for the weapons program, particularly the development of new test diagnostics.

Improved Central Guard Facility (TEC \$6.0 M, FY84): This is a strengthened subterranean building with a capability to withstand a light weapons fire attack while maintaining the communications, armory, and vault support functions necessary to coordinate security resources as required. 
Salt Facility Upgrade (TEC \$2.8 M, FY84): This project will modify seven existing rooms located adjacent to the present Salt Fabrication Facility in Building 209 at Technical Area 21. The conversion of this space (2300 sq. ft.) to laboratory and support space use will permit the installation of new equipment, support equipment, and staff.

TA-55 Control Room Upgrade (TEC \$3.0 M, FY85): This project will provide for upgrading of the existing computer controls and instrumentation in our Plutonium Handling Facility. The controls and instrumentation are rapidly becoming obsolete and should be upgraded to assure proper operation of the facility.

Compressed Gas Facility. (TEC \$2.5 M, FY85): It is Laboratory management's desire to relocate the Compressed Gas Facility (CGF) to a less populated area. The CGF was formerly isolated from most of the Laboratory, which has since grown up around the present location at SM-170.

The new facility will permit the CGF to have modern equipment with better and shorter flow patterns for the movement of heavy gas cylinders and dewars. More space will permit installation of argon and air compressors for the safe and economic filling of high-pressure trailers and cylinders.

Device Fabrication R\&D Facilities (TEC \$44.0 M, FY85): This project will provide additions to some facilities, upgrade other facilities, and provide new state-of-the-art equipment at numerous facilities throughout the Los Alamos National Laboratory. It will provide metal fabricating equipment, composite material equipment, facilities for electroplating and electroforming, new plastics forming equipment, and facilities for nondestructive testing and assembly of weapons subcomponents. These facilities are badly in need of updating.

Laboratory Communications Center (TEC $\$ 25.0 \mathrm{M}, \mathrm{FY} 85$ ): This building is necessary to house a government-owned telecommunications facility, expand the network equipment for the Integrated Computer Network (ICN), and expand the data communications needed for the ICN.

Materials Science Laboratory (TEC \$29.0 M, FY85): Needed laboratory space and facilities for the materials work important in national security programs [a two-story building of approximately $43,000 \mathrm{sq}$. ft. combining laboratory space $(27,000 \mathrm{sq} . \mathrm{ft}$.$) and office space (16,000 \mathrm{sq}$. ft.)].

The materials requirements in modern sophisticated weapons systems are very stringent and often unique. Nonradioactive materials with special nuclear properties are usually of little academic or commercial interest but can be crucial components of weapons systems. These and other more common materials are often subjected to conditions and loadings not encountered elsewhere. As a result, much of the materials science research on processing, 
structure, and properties important in weapons design, production, and stockjile must be conducted by the weapons complex. A recent report by the Materials Science Working Group at Los Alamos pointed out the need for renewed emphasis within the weapons community on some general areas of materials science including physical metallurgy, fracture mechanics, environmental fracture, constitutive relations, polymers, composites ceramics, powder metallurgy, and behavior of materials under high pressure/temperature/strain. Los Alamos facilities and capabilities to deal with such topics have not kept pace with developments in modern materials science and technology. The condition will continue until project funding occurs. It is envisioned that the Laboratory's Center for Materials Science would eventually be housed in this facility.

Weapons Design Engineering Complex (TEC \$21.0 M, FY85): A multistory office and laboratory facility of approximately $110,000 \mathrm{sq}$. $\mathrm{ft}$. is to be constructed at Tech Area 16. Office and work space for about 320 Design Engineering Division employees along with laboratory facilities for physical testing, electronics and diagnostics development, and specialized plastic material research and development will be provided.

High-Energy Radiographic Facility (TEC \$8.8 M, FY86): This project consists of replacing an existing betatron with a higher energy electron accelerator. Building modifications will be necessary to permit vertical radiography of Nevada Test Site (NTS) devices and for installation of the machine. Additional shielding will be required to operate the machine at full capacity for photon activation analysis.

Explosives Physics Experimental Facility (TEC \$25.8 M, FY86): The Explosives Physics Experimental Facility will provide Los Alamos with the capacity for high-resolution, state-of-the-art plysics experimentation on detonation of high explosives.

New capabilities resulting from this project will be the ability to study detonation in large and small charges with the new physics techniques of laser interferometry and spectroscopy, laser-doppler measurements, multiple flash $x-r a y$ illumination that could permit tomographically assembled 2-D views of interior phenomena, and multiple corroboration by conventional and developmental diagnostics by streak cameras, image intensifier cameras, and pin diagnostics.

WNR Office/Laboratory Building (TEC \$7.1 M, FY86): An office-laboratory building is proposed to provide facilities for the research programs and for the operations at the Weapons Neutron Research/Proton Storage Ring (WNR/PSR) neutron source. These efforts are now being performed using temporary facilities (transportable buildings). When construction of the proton storage ring is completed and the research program at the WNR is fully developed, there will be a need for approximately 30 additional offices as well as additional laboratory spaces. 
Test Fabrication Facility, Phase II (TEC \$21.0 M, FY86): The purpose of this project is to provide a new administration and craft operations complex for the Support and Fabrication Contractor, adjacent to the existing Supply and Transportation Facility at TA-3, Sigma Mesa. The new facility would centralize and consolidate the Contractor's operations and would be occupied by all of the personnel and functions presently located in the TA-3, SM-37 and SM-38 area. This would make available, in the core area of TA-3, highly desirable facilities and land for Laboratory use with moderate modifications and routine refurbishing.

Safeguards and Security Upgrade I (TEC \$14.5 M, FY86): Increased security of classified/nuclear material and physical plant security (new construction and upgrading of existing Laboratory facilities, i.e., additional perimeter fencing, enhanced and additional alarm and lighting systems complete with back-up power, back-up to the central alarm system computer, and special communications installations).

Health Instrumentation and Measurement Facility (TEC \$4.3 M, FY86): This facility would consolidate related programs in radiation health instrumentation and measurements presently being conducted at three widely separated facilities and would provide improved health and safety support to weapons programs in areas such as dosimetry, maintenance, calibration, supply of instruments, and analytical data from sampling programs. This facility would provide for a state-of-the-art calibration capability to replace the existing 25-year-old radiation instrument calibration range.

Utility Operations Center (TEC \$1.3 M, FY86): The purpose of this project is to provide a building for consolidating personnel and upgrading the functions of the Support and Fabrication Contractor's Utilities Department. The new facility will be adjacent to the west side of the existing TA-3-2? Power Plant.

Hypervelocity Impact Facility (TEC \$15.6 M, FY87): This project is composed of an electromagnetic projectile accelerator, an experimental area, and a facility to house both. The accelerator consists of 25-35 modular sections. Each section contains a capacitor bank, a rail section, and the required controls and diagnostics. The experimental area will require EMI shielding, a projectile stop, and provisions for protecting apparatus from high-velocity fragments. This project would provide projectile velocities in the $25-50$ $\mathrm{km} / \mathrm{sec}$ range, which is of direct interest in the solution of many weapons problems.

Antares Upgrade Project (TEC \$20.0 M, FY87): An Antares upgrade is proposed to ensure that LoS Alamos has a useful facjlity for conducting weapons physics, directed-energy, and inertial fusion experiments in the late 1980s. The decision to upgrade the Antares facility now nearing completion is to be based on a critical assessment of current laser-target physics experiments. 
The proposed modifications would not interfere with the timely execution of the $\mathrm{CO}_{2}$ experimental program currently planned for Antares.

Weapons Subsystem Laboratory (TEC, \$16.2 M, FY87): This project will provide upgrading and modernization of our weapons laboratories, including new remote-control, high-pressure gas test cells and hydraulic test cells, with contaminants control for toxic materials. It will be constructed at TA-16 near other weapons laboratories for imoroved effectiveness in weapons component development.

Weapons Chemistry and Radiochemistry R\&D Laboratory (TEC $\$ 34.6$ M, FY87): The weapons-related effort in the Isotope and Nuclear Chemistry Division is located in widely separated facilities built shortly after or during World War II. Replacement and consolidation of these activities at a single site would enhance the experimental effort in the detailed understanding of thermonuclear burn, the verification of predictive weapons explosion code calculations, the understanding of the structural basis for sensitivity and energy propagation of explosives, and the development of ultrasensitive analytical techniques for weapons diagnostics. Failure to provicle funding for such a centralized facility will result in continued loss of productivity due to substandard physical plant and geographic separation of related programs.

Relocation of Salvage and Surplus Operations and Roads and Grounds Operations (TEC \$1.6 M, FY88): This project consists of relocating the SaTvage and Surplus Operations and the Roads and Ground Operations of the Support and Fabrication Contractor to a location or Sigma Mesa in proximity to other contractor operations. The project will provide for the consolidation and centralization of facilities to an area designated for industrial land use in accordance with the Los Alamos National Laboratory Master Plan. Major benefits include the vacating of high-value and prominent real estate near the entrance to Tech Area 3, relocation of existing facilities and operations to a more desirable area defined for industrial 1 and use, and improved services for the Laboratory.

Sanitary Landfill (TEC \$1.7 M, FY88): A sanitary landfill dedicated to Laboratory use will permit us to dispose of low-hazard waste without involvement with the public and also will reduce the volume of waste stored more expensively at TA-54.

Safeguards and Security Upgrade, Fhase II (TEC \$14.2 M, FY88): Continuation of work to be initiated in Phase I.

Equipment and Service Facility (7EC \$3.6 M, FY88): This building will house instrumentation and machine maintenance units for the weapons test diagnostic program. It will allow economies in stocking, travel of personnel, and number of machines needed. 
Supply and Distribution Warehouse Relocation (TEC \$25.0 M, FY88): It is Laboratory management's desire to remove the Supply and Distribution Warehousing functions from TA-3. The buildings SM-30, 31, and 142 will be reoccupied by Laboratory technical and scientific groups, which will improve the functional interaction and effectiveness of scientific efforts.

It will also allow the Materials Management Division (MAT) to apply new and modern techniques to acquisition, receipts, storage, inventory management, and distribution.

GE--Materials Production

Site Preparation SNM Complex (TEC $\$ 10.0 \mathrm{M}$, FY86): Future planning indicates a need to make preparation for a SNM Complex at TA-55.

This project will provide design and site preparation for such a complex, including earthwork and a separate utility building to provide all required utilities for future construction, including HVAC, electrical, water, etc.

GD--Nuclear Materials Safeguards and Security

Nuclear Safeguards Technology Laboratory (TEC \$12.2 M, FY85): Construction of a laboratory office facility to consolidate elements of the nuclear safeguards research and development program (facilities and equipment necessary to develop systems to safeguard against terrorist nuclear threat, to provide nuclear material accountability, and to enhance the nuclear community's ability to control and respond to nuclear problems worldwide). Funding is required during the planning period in order to consolidate critical safeguards R\&D activities. 


\section{B. Energy Research}

1. Current Energy Research Programs

Our long-range objective for the fundamental sciences at Los Alamos is to maintain our existing commitment to excellence while increasing our awareness of and contribution to solving specific national problems.

Major Los Alamos programs funded by the Office of Energy Research (OER) include basic energy sciences, health and environmental research, a large component in medium-energy nuclear physics, high-energy physics, and magnetic fusion.

$B \& R$

$A$
$H A$
$H B$
$K A$
$K B$
$K C$
$K D$

Total

Percent of Total Laboratory Funding
Major Program (Title)

Magnetic Fusion

Biomed \& Environ Research

Life Sci Res \& Nuc Med App

High-Energy Physics

Nuclear Physics

Basic Energy Sciences

Technical Assessment Projects

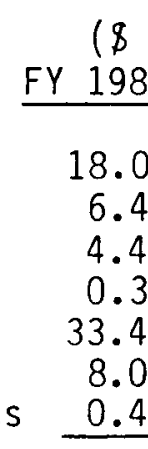

70.9

18.0

6.4

4.4

0.3

8.0

0.4
( 8 in Millions - BA)

14
FY 1983

18.1

5.8

3.9

0.3

36.3

8.0

0.0

72.4

15
FY 1984

24.4

7.4

4.5

1.1

41.9

9.3

0.0

88.6

\section{a. Basic Energy Sciences}

Los Alamos conducts a comprehensive program of basic research to support applied work in national security and energy technology programs, to strengthen its multidisciplinary scientific base, and to expand possibilities and future options for the nation. Basic research is fundamental to the health of the Laboratory and crucial to our overall success. We view a lack of broadbased support from DOE as a serious deficiency and are striving to correct it by making all funding elements aware of the need.

(1) Materials Sciences. Materials sciences activities at Los Alamos provide knowledge essential to national defense technologies and to development of materials required in advanced energy technologies and in strategic materials substitution. Relatively fundamental and long-term research efforts are categorized into three major areas: metallurgy and ceramics, materials chemistry, and solid state physics. Ongoing projects in metallurgy and ceramics include structural ceramics, study of materials under multiaxial deformation, self-irradiation damage of ceramic nuclear waste, and ultrasonic 
Los Alamos

wave scattering as a technique for determining the structural properties of materials. Materials chemistry constitutes studies of mechanisms of compound formation on surfaces and of selective modification of chemisorption properties. Solid state physics work includes compilation of an equation-of-state library, properties of hydrogen under ultrahigh pressure, and heat engines.

In the materials science program, several significant new research areas will receive emphasis in future years. Los Alamos has a small but highquality program, unique in the United States, of muon spin rotation studies at the LAMPF muon channel. This program was developed under nuclear physics funding; it is now appropriate to move it to basic energy sciences. In another area, we propose to study the fundamental mechanisms in high-rate deformation that control plastic flow over a large range of strain rates. An understanding of microscopic deformation mechanisms will permit us to develop realistic constitutive relations for high-rate deformation associated with many transient and impact problems associated with numerous energy technologies.

A major thrust in Los Alamos' materials science research programs is the application of neutron-scattering techniques using the Weapons Neutron Research (WNR) Facility for a broad range of problems in condensed matter science. When the Proton Storage Ring (PSR) is brought on line in 1985, this facility will be the most intense pulsed source in the world for this field of materials science studies. The experimental program with the more modest intensity presently available with the WNR alone is aimed at developing the full capability for the PSR era.

To further the study of materials science and technology, the Laboratory has created a Center for Materials Science (CMS). The objectives of the CMS are to enhance the contributions of materials science and technology to the Laboratory's defense, energy, and scientific missions. The long-range plan is to locate the CMS in the new Materials Science Laboratory that is part of the Laboratory's FY 1985 construction request.

(2) Chemical Sciences. Chemical sciences projects provide fundamental understanding in a broad range of topics. These include the formation and properties of complexes of helium and hydrogen isotopes; the chemistry of $\mathrm{SO}_{2}$ bonding to catalytic substrates; actinide chemistry in near-neutral solutions; the effects of ion size and radiation on actinide valence stabilities in selected oxide matrices; the measurement of the heat and entropy of vaporization of actinide elements and their compounds; computation of thermophysical properties of mixtures; production of exotic nuclei at LAMPF; and the synthesis of thermochemical cycles, potentially capable of "splitting" water to produce hydrogen and oxygen.

(3) Engineering, Mathematics, and Geosciences. Geosciences research focuses on basic questions relevant to radioactive waste disposal and to 
geothermal, fossil fuel, and fusion energy. Geophysics comprises studies in rock mechanics and fracture, geodynamics, petrology, and seismology. Geochemistry work includes coal and peat maturation studies, aqueous geochemistry, mineralogy, and geothermometry. Thermal regimes constitute several site investigations (in the Jemez Mountains and Rio Grande Rift region of northcentral New Mexico) that yield geophysical and structural information pertinent to continental scientific drilling investigations of magma-hydrothermal systems. Space plasma physics deals with the structure and flow of plasma energy in the solar wind, magnetosphere, and ionosphere and with the electrodynamical aspects of the solar wind-magnetosphere interaction.

An engineering research project is intended to develop the concept of thermionic integrated circuits for instrumenting and providing electronic control systems in high-temperature and high-radiation environments. The program has emphasized developing fundamental device understanding, manufacturing techniques, and finally prototype circuitry.

Nuclear data continue to play a major role in improvements of nuclear fission energy technology and will play a major role in the engineering of practical nuclear fusion reactors of the future. This Laboratory has unique capabilities in the WNR/PSR and in its versatile van de Graaff laboratory for satisfying these data needs. A program is presently under way concentrated in studies of charged-particle cross sections required by the fusion program and of gamma-ray production in neutron-nuclear processes.

Numerical mathematical models at the heart of current energy research problems involve, in an essential way, the numerical solution of complicated systems of nonlinear partial differential equations. Another project in mathematics is to unify and simplify new solution algorithms for such systems. Recent developments emphasize adaptive mesh methods such as adaptive multigrid and front tracking to resolve subgrid scale structures of discontinuous solutions. We also are creating software to resolve large nonsymmetric, nonlinear algebraic systems arising on irregular meshes. In multidimensional computational fluid dynamics, this program has partially supported numerical methods development in a particle-fluid model for spray dynamics, a new free-Lagrangian computing technique, and documenting a general code for calculating transient aerodynamics flow's.

Recent fundamental discoveries at Los Alamos in the mathematical properties of nonlinear transformations promise to improve understanding of the onset and development of turbulence. To emphasize studies of nonlinear systems and to develop closer connections with other workers in this important field, a Center for Nonlinear Studies (CNLS) has been established at the Laboratory. The CNLS uses its extensive external visitor program, coupled with internal collaboration from personnel within existing technical divisions at Los Alamos, as the basis for its research efforts. Much of the external 
visitor program and the internal collaboration is coordinated with general research themes.

(4) Advanced Energy Projects. The basic unit of electric charge is onethird that of the electron. Negative fractionally charged particles are interesting because they could replace electrons in atoms, molecules, and solids, leading to superdense states of matter. A combined theoretical and experimental effort is under way to search for fractionally charged particles in a wide variety of materials, to determine which materials are most abundant in fractionally charged particles, and to enrich the fractional charge content of sample materials.

Another Advanced Energy Project, in the science of magnetic refrigeration, promises significantly greater efficiency for cooling in the temperature range from 4-300 K. The program involves the testing and selection of materials, the evaluation of innovative mechanical designs, and the construction of refrigerators of pilot model size to demonstrate practical applications. Applications are in cryogenic methods for gas production, liquid $\mathrm{H}_{2}$ fuel for space launch vehicles, heat control in satellite systems, and eventually air conditioning for large structures such as apartment complexes and industrial buildings.

(5) Fusion Materials Irradiation Project. This project is in collaboration with the Hanford Engineering Development Laboratory. Los Alamos is designing and developing the 35-MeV, 100-mA CW deuteron linear accelerator for materials irradiation studies.

(6) Racetrack Microtron. This project is in collaboration with the National Bureau of Standards. Los Alamos will demonstrate electron microtron technology for proposed high-intensity electron physics facilities.

\section{b. Nuclear and High-Energy Physics}

(1) High-Energy Physics. To broaden the scientific base of our theoretical nuclear physics research and to develop new mathematical techniques to study nonlinear phenomena that have applications in materials sciences, fluid dynamics, and laser physics, we maintain a high-quality research program in the frontier area of theoretical high-energy nuclear physics. The research emphasizes understanding models that unify strong, electromagnetic, weak, and gravitational forces; understanding the confinement of quarks; and understanding the dynamics and symmetries of various field theories.

We also have an excellent program in astrophysics, including the new areas of particle physics and cosmology. The theoretical astrophysics program presents a great opportunity for symbiosis of physics at the forefront of basic science and physics in the weapons program. Many of the phenomena studied in astrophysics have direct applications in weapons physics, and many of the numerical techniques used are the same. 
Los Alamos

(2) Medium-Energy Physics. The Los Alamos role as the lead laboratory in medium-energy physics is fulfilled by the operation and development of LAMPF and LoS Alamos participation in the research programs using LAMPF. This, the world's largest and most sophisticated nuclear science facility, provides unique accelerator-generated beams of protons, pions, muons, neutrons, and neutrinos to carry out a research program that includes fundamental studies of weak interactions and conservation laws, nuclear structure studies, nucleon-nucleon and pion-nucleon interactions, mesonic x-rays, condensed matter physics, atomic physics, and nuclear chemistry. Practical application usage of the facility includes isotope production, biomedical studies, investigations of radiation effects in materials, and national-defense-related studies.

Nuclear chemistry research at LAMPF is dominated by two major areas: pion-nucleus studies and thin target area studies. The first area involves utilization of activation and on-line counter techniques to study the interactions of pions with complex nuclei resulting in single- and multiple-nucleon removal, single charge exchange, and pion production by pions. The second area of study involves the systematic investigation of the very neutron rich and neutron deficient nuclei produced in high yields by the intense $800-\mathrm{MeV}$ proton beam on medium and heavy mass targets. The main objective of the program is the direct measurement of the masses of an entire region of light nuclei that lie far from beta stability. These mass measurements are of fundamental importance, not only as a test of current atomic mass models, but as a means of exploring important nuclear structure effects. These studies will be greatly facilitated by means of a unique, time-of-flight magnetic spectrometer that is currently under development.

These research programs are conducted by a combination of Los Alamos scientists and visitors, primarily uriversity-based; experiments, especially the most difficult ones, are often conducted by collaborations of local and visiting scientists.

We maintain a very active theoretical group and also involve eminent theoreticians from the academic community. This program provides support and guidance for the LAMPF experimental program and seeks to interpret the experimental results from research here and from other laboratories. This research is directed toward elucidating those aspects of nuclear structure, and other nuclear properties, determined by medium-energy probes of the nucleus, as well as understanding the characteristics of the fundamental meson-nucleon interaction inside the nuclear medium. This program includes research into strong interaction amplitudes, reaction theory, nuclear structure, electromagnetic interactions with nuclei, weak interactions, hadron structure and decay, and manifestations of unified theories at low and medium energies. Theoretical investigations are conducted within the group in close collaboration with participants in the extensive visitor program. Effort is divided between fundamental theoretical developments and phenomenological 
Los Alamos

analyses. The latter requires close ties between the theorists and the experimentalists working in Medium Energy Physics Division, in Physics Division, and at experimental facilities in this country and abroad; special emphasis is directed at understanding those experiments performed at LAMPF.

Several programs not employing LAMPF will also make major contributions in nuclear and particle physics. Among these are a search for exotic states of nuclear matter using antiprotons and studies of the fission process using heavy-ion reactions.

\section{c. Magnetic Fusion}

The current need to control government spending will delay the expansion of the Magnetic Fusion Energy (MFE) program called for in the MFE Engineering Act of 1980. The start on a fusion engineering device (FED) or engineering test reactor (ETR) authorized in the act will now be postponed to the late 1980s, and program emphasis will shift to improving the scientific and technical basis on which the ETR decision will ultimately be made. The Los Alamos MFE program will make important contributions during this phase.

A substantial part of the Los Alamos program is devoted to the development of two advanced fusion concepts, the reversed field pinch and the compact toroid, that could lead to a more economic fusion reactor than presently envisioned for the mainline confinement concept. These systems derive their qualitative superiority from potential compactness and utilization of higher power densities that approach those of fission reactors.

Complementing the experimental work, the theoretical and computational group provides analytical and numerical support for the MFE program. Plasma equilibrium and stability are studied in straight and toroidal geometries, using MHD, VIasov, and hybrid particle simulation codes as required by the physical conditions of a particular experiment.

Los Alamos also makes a significant contribution to the national effort in magnetic fusion technology with its work in the areas of tritium handling, neutronics, insulators and ceramics, reactor system studies, and engineering support for the Fusion Engineering Design Center (FEDC) at ORNL. The Laboratory expects to fulfill an increasingly important role in developing the needed technologies for compact high-power-density systems.

Los Alamos is also developing a capability in the Stellarator magnetic confinement area, with view to providing the national program with crucially needed equilibrium and stability information by utilizing a relatively lowcost experimental approach.

(1) Reversed Field Pinch Program. The RFP is a toroidal, magnetically confined plasma system that has the potential of being ohmically heated to 
ignition, of achieving stable plasma behavior at the high ratios of plasma pressure to magnetic pressure $(B)$ required for economic reactor operation, and of reducing reactor complexity. The ZT-40M experiment has significantly extended RFP performance by achieving plasma temperatures of $350 \mathrm{eV}$ for a toroidal current of $200 \mathrm{kA}$ and sustaining RFP configurations for 20 to $25 \mathrm{~ms}$. These favorable results have considerably exceeded the milestone objectives originally set down for $Z T-40$. We plan to design a follow-on experiment, the ZT-40 Upgrade. This will result in a proposal by the end of CY 1982.

(2) Compact Toroid Program. A CT is a toroidal plasma configuration in which the major confining fields are created by internal currents in the plasma, rather than by currents in external conductors. Experiments began in FY 1980 on the newly completed CTX facility studying spheromak-type compact toroids.

In addition to work on advanced fusion concepts, Los Alamos is pursuing projects that will make major contributions to the technology required by the ETR and other fusion reactor systems.

(3) Magnetic Field Systems Design and Development. This program develops superconducting magnets and associated energy storage and transfer systems to supply programmable poloidal and equilibrium magnetic fields needed for future tokamaks and other toroidal systems. The program includes design and assessment of poloidal-field coil systems and low-aspect-ratio, equilibriumfield coil systems; this work is in support of and coordinated with the Fusion Engineering Design Center at Oak Ridge. The program also designs, develops, and tests high-current interrupters as switching systems for poloidal and toroidal field coil systems.

(4) Tritium Systems Test Assembly Program. The Tritium Systems Test Assembly (TSTA) will integrate and demonstrate aTl technologies related to the deuterium-tritium fuel cycle for fusion reactor systems and for the ETR. The construction of TSTA was completed on schedule and within budget in FY 1982; preliminary operation with tritium will begin in January 1983, followed by full operation in June 1983.

(5) Fusion Reactor Insulators and Ceramics Program. This program assesses and develops electrical insulators and ceramics for fusion reactor applications and provides design information for the ETR. The effects of neutron irradiation on the electrical and mechanical properties of various first-wall and insulator materials are also studied.

(6) Reactor Systems Studies Program. This effort evaluates the reactor potential of various alternative fusion confinement concepts. The broad nature of this task requires extensive, multidisciplinary interaction with groups inside and outside the Laboratory. These reactor studies are extremely useful in guiding research in alternative approaches to fusion. 
d. Health and Environmental Research

(1) Biological and Environmental Research. Human health studies consist of a series of studies of cancer incidence and causes of mortality in workers at six major DOE plants, where exposures to plutonium occur, and the determination of the distribution of plutonium in tissues obtained at post-mortem examinations. The data provide needed knowledge about the dose distribution to various tissues and allow comparison with occupational exposure records, plutonium deposition estimates, and plutonium fallout exposure estimates.

Studies of oil shale toxicology constitute a major program at Los Alamos and include health studies of oil shale workers; pulmonary and epidermal studies of animals exposed to oils and by-products produced in the mining, retorting, and upgrading of oil shale; and cellular studies of the cytotoxic, mutagenic, and clastogenic potentials existing in various oil shale related materials.

The environmental studies integrate modeling, chemistry, and field ecology experiments to the problems of the transport and the ultimate fate of pollutants in the environment. Two unique resources, the National Environmental Research Park (NERP) and the low-level waste simulation site, provide the opportunity to study pollutant transport and behavior in both undisturbed ecosystems and controlled simulations. Of particular interest are the migration of radioactive elements in a spectrum of ecosystems and the use of data thus gained in controlling contaminant mobility in the environment and understanding the various transport pathways leading to man.

The atmospheric sciences program consists of studies of terrain-influenced meteorological transport and diffusion in the boundary-layer, studies of the constituents of the upper troposphere and lower stratosphere, and the development of specialized tracers and detection systems for studies of atmospheric dispersion.

(2) Life Sciences Research and Nuclear Medicine Applications. The Life Sciences Research program at Los Alamos studies the basic mechanisms of carcinogenesis, develops and validates systems for determining carcinogenic activity, and applies these systems in the context of integrated programs designed to define the hazards posed by nuclear and oil shale technologies. Our basic and applied studies in regulation of gene expression and structure, genetic protective mechanisms, chromosome structure and function, chromosome damage assessment, heterogeneity of tumor cells, and the molecular basis of cell growth provide a unique combination of capabilities for exploring basic questions in carcinogenesis. They enable us to determine the roles of mobile genetic elements, chromosome alterations, mutations, gene amplification, and DNA methylation in the transformation of normal cells to malignancy. The combination of flow cytometry, molecular genetics and somatic cell genetics is especially useful in exploring the relationship of aneuploidy to cancer. At 
present, the sorting of chromosomes with specific cancer-associated aberrations is being followed by cloning and isolation of the affected genes.

Our long-standing expertise in flow cytometry led to the establishment of the National Flow Cytometry Resource on July 1, 1982, through joint sponsorship of NIH and DOE. The major goals of this resource are to make advanced instrumentation available to the biomedical community, to perform research and development on flow instrumentation and relevant methodology, and to identify new investigative and clinical applications.

The medical radioisotopes prograri utilizes the unique Los Alamos Meson Physics Facility to prepare a wide range of medically useful radionuclides. Expertise in target encapsulations, irradiations, radiochemical separations, remote chemical processing, and supporting analytical capabilities has been developed over the years. In addition, a major programmatic effort is directed toward radiopharmaceutical labeling research, and we are developing a strong effort in organic synthesis. We have also developed the capability to perform in vivo studies of the biodistribution and metabolism of labeled biochemicals in animals. Our high-resolution gamma camera permits sequential imaging of labeled compounds in vivo.

The program to investigate the use of negative pions for cancer therapy, funded by the National Cancer Institute, provided treatment at LAMPF for about 250 patients in the period 1976-1981 with encouraging results. Although the program is presently in abeyance, important work in three-dimensional treatment planning code development is continuing and the biomedical channel is being maintained in operational status with the expectation that patient treatments will be resumed.

LAMPF accelerator-related technology is being applied to the development of biomedical instrumentation for electrosurgery, radio-frequency hypertherma for cancer therapy, and electrothermal techniques for corneal shape modification. An extensive network of collaboration has evolved permitting the transfer of instrumentation and design to medical schools, hospitals, and the private sector.

\section{Energy Research Initiatives \\ a. National Underground Science Facility}

There are a number of extremely important scientific experiments that should be performed but which require enormous amounts of shielding greatly exceeding what can be supplied in a normal laboratory environment on the earth's surface. These experiments include searches for spontaneous nucleon decay and for magnetic monopole catalyzed nucleon decay, solar neutrino, cosmic ray muon, and cosmic-ray neutrino experiments, neutrino oscillation 
experiments, and double beta decay experiments. In addition, the "quiet" environment offered at great depth will make possible new gravity wave experiments.

To provide a location in which such experiments can be conducted, the Los Alamos National Laboratory proposes to establish and operate a National Underground Science Facility dedicated to basic research. The Facility will be located in an open area of the Nevada Test Site and will be available to any scientist with an appropriate experiment to pursue, subject only to peer review and availability of space.

The Facility will consist of a twelve-foot-diameter vertical shaft that will ultimately extend to a depth of 4,500', with laterally excavated chambers to accommodate experiments. In addition to hoist and elevator, power, and other utilities, the Facility will provide surface technical support in the form of a modest machine shop, an electronics shop, computer capacity, and dormitory space for scientists. Those working at the facility will therefore have technical support approximating that in their home laboratories and making possible experiments utilizing the most advanced technology of modern science. Operating and support staff will be required, but no increase in scientific FTEs from Los Alamos is anticipated.

In the initial phase of the facility the shaft will extend to $3600^{\prime}$ and two chambers $\left(40^{\prime} \times 200^{\prime} \times 46^{\prime}\right.$ and $\left.30^{\prime} \times 50^{\prime} \times 25^{\prime}\right)$ will be excavated at a total estimated cost of $\$ 42 \mathrm{M}$. The design will allow for an extension to a depth of $4500^{\prime}$ or more and for the addition of other chambers as needed.

NATIONAL UNDERGROUND SCIENCE FACILITY

$\begin{array}{lrrrrrr}\text { ( } 8 \text { in millions) } & \text { FY83 } & \text { FY84 } & \text { FY85 } & \text { FY86 } & \text { FY87 } & \text { FY88 } \\ \text { Operating } & 0.2 & 0.2 & 0.2 & 2.0 & 2.0 & 2.0 \\ \text { Capital Equipment } & & 5.2 & 0 & 0.3 & 0.3 & 0.3 \\ \text { Construction } & & 11.5 & 18.9 & \frac{6.7}{9.0} & \frac{0.0}{2.3} & \frac{0.0}{2.3} \\ \quad \text { Total } & 0.2 & \frac{16.9}{19.1} & 13.0 & 13.0 & 13.0\end{array}$

The operating amount for $F Y 1983$ is for geological exploration, evaluation, and test-drilling to prepare for actual Phase I construction in FY 1984 and FY 1985. Phase II is planned for FY 1987 and FY 1988.

b. Neutrino Facility

The Laboratory is proposing the construction of a national facility for neutrino physics in conjunction with the Proton Storage Ring at LAMPF. This facility will provide a unique capability unmatched anywhere in the world for experiments with low-energy neutrinos. The project calls for the construction 
of a 19- x 3- x 3-m beam tunnel, a 30- $\times 4-\times 4-m$ decay volume with railroad tracks to vary the production target position, four detector buildings (two adjacent to the decay volume, one at a distance of $20 \mathrm{~m}$ and one at a distance of $3,800 \mathrm{~m}$ from the decay volume), shielding for the near buildings, and additional shielding on an existing beam line. It also calls for an upgrade of the Proton Storage Ring to $24-\mathrm{Hz}$ operation, so that there will be no interference with previous commitments to BES and OMA.

The project is required to obtain the best measurements of possible oscillation modes of muon neutrinos, to make precision measurements of neutrino-electron scattering, and to conduct experiments on electron and muon neutrino interactions in nuclei. Construction during the planning period is required to permit the conduct of early experiments.

This facility, coupled with the LAMPF II initiative, results in the further development of the accelerator facilities at Los Alamos for nuclear and high-energy physics.

\section{NEUTRINO FACILITY}

\begin{tabular}{|c|c|c|c|c|c|c|}
\hline ( 8 in millions) & FY82 & FY\&3 & FY84 & FY85 & FY86 & FY87 \\
\hline Operating & 0 & 0.15 & 0.5 & 0.5 & 1.5 & 1.5 \\
\hline Construction & 0 & & 2.1 & 10.84 & 14.4 & 10.66 \\
\hline $\begin{array}{l}\text { Total } \\
\text { Personnel (FTE) }\end{array}$ & 0 & $\begin{array}{l}0.15 \\
1.0\end{array}$ & $\begin{array}{l}2.6 \\
3.0\end{array}$ & $\begin{array}{c}11.34 \\
3.0\end{array}$ & $\begin{array}{r}15.9 \\
5.0\end{array}$ & $\begin{array}{c}12.16 \\
5.0\end{array}$ \\
\hline
\end{tabular}

c. LAMPF II Facility

We are developing a proposal for a major upgrade of LAMPF, which will extend U.S. leadership in medium-energy physics into the decade of the 1990s. Under consideration is a high-intensity, rapid-cycling synchrotron that will increase the maximum energy to $16 \mathrm{GeV}$ and the beam power by a factor of 3 to 6. Such a machine would increase the scope of the nuclear-physics programs to include kaons, hyperons, and antinucleons. Existing beams of pions and muons would be increased in intensity by a factor of 10 (100 for negative muons), and duty factors would be improved either by increases from the present $6 \%$ to $90 \%$ or, in some instances, by reduction to as little as $10^{-5}$. The program of decay experiments will be expanded to include the exciting fields of kaon decays and CP violation. The increased intensity will allow rare decay experiments of a sensitivity greater than possible anywhere else in the world. The upgrade would also provide the world's best facility for low-energy neutrino physics. For example, the counting rate in neutrino-electronscattering experiments will be 1000 times higher than the counting rates available at existing facilities, allowing precision narrow-band measurements where only crude total cross sections exist today. The basic machine will be versatile and conservative and, even though its initial goals include beam 
Los Alamos

intensity 100 times higher than existing machines in this energy region, options for future improvements will be open.

The initial cost estimate for such a facility is $\$ 150$ million (in 1982 dollars), equally divided between the new accelerator and new experimental areas. An increase in the present LAMPF operating budget by $\$ 15$ million will be required to operate the new facility and to carry out the experimental program.

The Los Alamos National Laboratory is presently evaluating the physics justification for the proposed facility and is carrying out a feasibility study for the accelerator and experimental areas. During the next two years, we will hold additional physics workshops and prepare a facility proposal. The proposal will be ready by the end of CY 1984. Given timely funding, a construction start in FY 1987 will be possible. Completion of the construction will be in CY 1991, with commissioning for research in 1992.

\section{LAMPF II FACILITY}

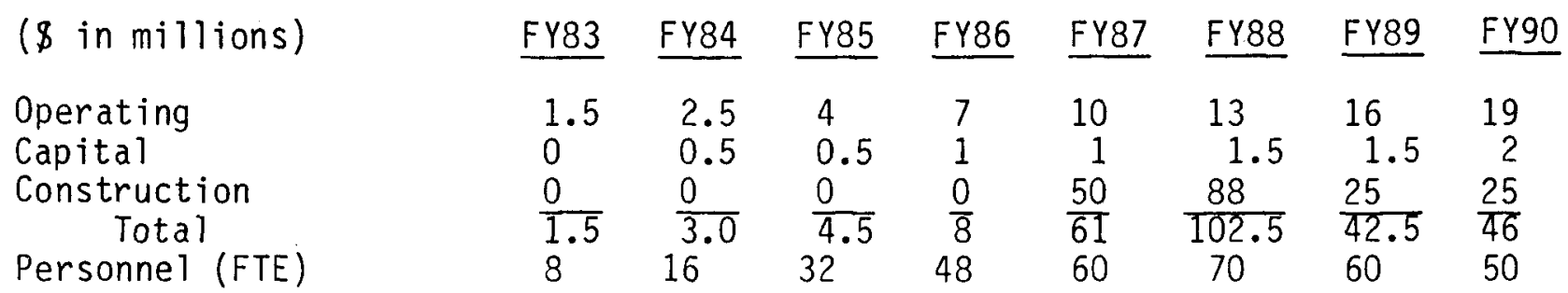

\section{d. Reversed Field Pinch (RFP) Ignition Test Reactor (ITR)/Engineering Test Reactor (ETR)}

Successful achievement of the ZT-40 Upgrade experimental goals will contribute significantly to demonstrating that the Reversed Field Pinch (RFP) will lead to a uniquely viable, highly competitive magnetic fusion energy (MFE) reactor concept and that it can be extended to a practical, high-powerdensity, compact reactor, using largely state-of-the-art technology. This achievement can also be accomplished faster than with any other concept. The timely implementation of the $2 T-40$ Upgrade experiment and subsequent successful results will allow the proposal of a staged ITR/ETR device based on the RFP principle in the 1987-1988 time frame. The goal of the RFP program is a compact, steady-state, D-T reactor with a direct and credible extension to a D-D reactor system.

The ITR/ETR device will address the following reactor issues: (1) reactor current densities for D-T and D-D fuels; (2) ohmic heating to ignition; (3) fusion burn physics, including both D-T and D-D ignition and burn, and refueling/exhaust systems; (4) efficient long-pulsed or ideally steadystate operation using either low-frequency current drive ( $F-\Theta$ pumping, which 
is unique to the RFP) or an RF drive being considered for tokamaks; (5) impurity control using divertors and a neutral gas blanket; (6) successful design and operation of a high-heat-flux first-wall; (7) high-power-density breeding blanket design; (8) radiation damage and component lifetimes; (9) remote maintenance; and (10) net power production.

The ITR/ETR device will require an initial design period of two years followed by a five-year construction period. Approval for design in 1987-1988 would allow construction completion and initial operation in 1995-1996. Preliminary costing has not been carried out.

\section{Proposed Energy Research Construction}

AT--Magnetic Fusion

Motor Generator Set Facility (TEC \$6.1 M, FY84): Procurement and installation of a 100-MVA motor generator set to be used in support of the magnetic fusion energy (MFE) research program.

The Laboratory experimental program in advanced fusion concepts and in fusion engineering programs requires a high-power (100-MVA), high-energy (250-MJ) storage system. These requirements will be cost effectively satisfied by a 100-MVA motor generator set (MGS). The MGS will store and provide energy to large dc power supplies used in existing and in future Los Alamos magnetic fusion energy (MFE) experiments: the proposed ZT-40 Upgrade experiment as well as extended-performance operation of the current ZT-40M device will require the MGS power facility. Immediate procurement and installation of the 100-MVA MGS are required to capitalize on recent achievements in the RFP program and to extend present program capabilities.

$\begin{array}{lcccccc}(\$ \text { in millions }) & \text { FY83 } & \text { FY84 } & \text { FY85 } & \text { FY86 } & \text { FY87 } & \text { FY88 } \\ \text { Construction } & 0 & 0.8 & 2.3 & 3.0 & \end{array}$

ZT-40 Upgrade Experiment (TEC $860.0 \mathrm{M}, \mathrm{FY} 85$ ): The ZT-40 Upgrade experiment is proposed to extend the performance of the reversed field pinch (RFP) toward the conditions required for compact high-power-density reactor systems. The ZT-40 Upgrade will exceed the operational limits of the present ZT-40M experimental facility principally in terms of higher current, high plasma temperatures, longer confinement times, and longer pulse duration. It will also have the potential of achieving larger current densities. These extended capabilities are required to develop accurate scaling laws for evaluation of the compact reverse field pinch reactor (CRFPR) concept. The ZT-40 Upgrade will be an axisymmetric toroidal device with a 40-cm minor radius and a $2-\mathrm{m}$ major radius. The device will develop toroidal plasma currents of 2 MA and demonstrate energy confinement times of more than $20 \mathrm{~ms}$. A 100-MVA MGS will be used to power an inductive energy storage system. The MGS will store and transfer $250 \mathrm{MJ}$ of energy to the system. 
Los Alamos

(\$ in millions)

Construction

\section{FY83 FY84 FY85 $\underline{\text { FY86 }} \quad \underline{\text { FY87 }} \quad \underline{\text { FY88 }}$

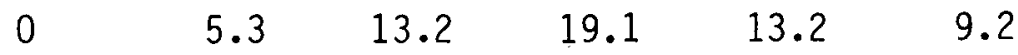

Engineering Building (TEC \$8.0 M, FY86): A new facility to support the engineering feasibility activity in the national Magnetic Fusion Energy (MFE) program (to develop and test various technologies in sizes that culminate with the prototypical units required by the Fusion Engineering Test Facility and to make Los Alamos engineering experience fully available to the national MFE program).

The present physics-oriented MFE program will shift to a more engineering-oriented program to prove engineering feasibility of magnetic fusion. In particular, the building is needed to develop technology for the proposed large Fusion Engineering Device. Failure to fund the project will result in a less than optimum effort.

Laboratory/0ffice Building (TEC \$1.5 M, FY87): A new facility to provide laboratory space and to replace office space presently confined to crowded temporary buildings.

The new facility is needed to provide a conference room, a report library, and laboratory space and to replace present office space in crowded temporary buildings, thereby significantly enhancing the Laboratory's capability for carrying out its Magnetic Fusion Energy (MFE) program, including confinement experiments, development and technology activities, and associated research programs. Funding is required during the planning period in order to provide adequate space and facilities.

KB--Nuclear Physics

Accelerator Improvements (TEC \$3.5 M, FY84): Continuing program to provide upgraded equipment at the Clinton P. Anderson Meson Physics Facility.

Construction during the planning period is required to permit orderly improvements to the facility.

Engineering Support Building (TEC \$3.1 M, FY86): A new building of approximately 24,000 square feet proposed as a two-leve 1, 14,000-square-foot office structure and an attached 10,000-square-foot shop and laboratory structure.

This building is needed to provide space for research and development work related to new facilities and experimental programs at the Clinton $P$. Anderson Meson Physics Facility. Funding during the planning period will permit the orderly support required. 
HA 02--Health and Environmental Research - Biological and Environmental Research

Toxic Chemical Containment Facility (TEC \$1.4 M, FY84): Expansion of specialized facilities for handling toxic chemicals and for housing and exposing small animals to potential toxins.

As the environment, health, and safety program at the Laboratory has changed over the past five years from a predominantly nuclear research effort to major emphasis on the health effects of nonnuclear energy sources, it has become increasingly apparent that the current physical plant cannot remain in compliance with Federal regulations controlling the use of toxic chemicals. Moreover, Federal regulations are changing in the direction of stringency in a manner that leads to uncertainties in the Laboratory's capability to continue these studies. The project will upgrade an existing facility to meet the new requirements. Construction during the planning period will permit compliance with Federal regulations.

Biomedical Research Facility (TEC 819.0 M, FY87): Expansion of the Health Research Laboratory (HRL) to reestablish adequate working facilities and to satisfy new facility needs for conducting current and future biomedical and environmental research. Built 30 years ago for 60 occupants engaged in radiobiology studies, HRL now houses more than double that number of scientists who are pursuing a far wider range of research. Expansion is needed for work in inhalation and genetic toxicology, immunology, flow cytometry, and recombinant DNA technology.

The proposed 29,700-sq.-ft. structure provides specialized laboratories and improved additional animal quarters as well as office and core space critically needed to relieve crowded quarters. This building would complement the \$1.9-million toxic containment facility by providing long-term specialized animal quarters and hazardous material laboratories. 
Los Al amos

C. Nuclear Energy

\begin{tabular}{|c|c|c|c|c|}
\hline$B \& R$ Code & Major Program (Titie) & FY 1982 & FY 1983 & FY 1984 \\
\hline $\begin{array}{l}A E \\
A F \\
A G \\
A H \\
A P \\
A W \\
C D\end{array}$ & $\begin{array}{l}\text { Space Nuclear Systems } \\
\text { Breeder Reactors } \\
\text { Converter Reactors } \\
\text { Remedial Action Programs } \\
\text { Comm Nuclear Waste Mgt } \\
\text { Adv Isotope Separ Techn } \\
\text { Uran Supply and Enrichmnt }\end{array}$ & $\begin{array}{r}3.6 \\
11.2 \\
0.7 \\
0.7 \\
0.5 \\
18.4 \\
0.3\end{array}$ & $\begin{array}{l}4.4 \\
9.4 \\
0.9 \\
0.2 \\
0.3 \\
0.0 \\
0.0\end{array}$ & $\begin{array}{r}10.0 \\
11.3 \\
1.2 \\
0.3 \\
0.0 \\
0.0 \\
0.0\end{array}$ \\
\hline \multicolumn{2}{|l|}{ Total } & 35.4 & 15.2 & 22.8 \\
\hline $\begin{array}{l}\text { Percent of } \\
\text { Laboratory }\end{array}$ & al & 7 & 3 & 4 \\
\hline
\end{tabular}

\section{Current Nuclear Energy Programs}

Los Alamos conducts major programs in space reactor design, breeder reactor fuel development, and waste management sponsored by the Assistant Secretary for Nuclear Energy (ASNE).

\section{a. Space and Terrestrial Applications}

(1) Space Technology Advanced Reactor. Los Alamos is currently conducting a technical research program to estabTish the technology base for a hightemperature, compact nuclear reactor $(10-100 \mathrm{kWe})$ for use in space. Los Alamos provides the mainline technology in a broader based space power effort referred to as the SP-100 program. This program became a joint DOE and NASA activity in FY 1982 with DOE providing LOS Alamos $\$ 1 \mathrm{M}$ and NASA $\$ 700 \mathrm{~K}$. In addition, NASA will spend $\$ 1.4 \mathrm{M}$ on the electric conversion system at the Jet Propulsion Laboratory (JPL). It is expected that the funds for this program will be augmented by funds from the Defense Advanced Research Projects Agency (DARPA) starting in FY 1983.

The overall objective is to develop a compact, lightweight nuclear subassembly that, when combined with direct energy conversion technology being developed by the JPL, will provide spacecraft power for exploration of the solar system and cislunar satellites and, potentially, support of DoD's surveillance and communications programs. The characteristics of such a power system are low weight, low volume, long life, high reliability, flexibility, minimum integration complexity, and low costs compared to other alternatives. The current Los Alamos power system is the combination of a fast fission heat pipe reactor with an advanced modular thermoelectric conversion subsystem for multimission applications. 
The nuclear subassembly objectives are to

- establish the technology base for the heat pipe reactor by designing, fabricating, and testing the key components that comprise the nuclear subassembly;

- ground demonstrate a prototype power plant; and

- establish a design that meets safety requirements.

To support the component technology base, analytical design activities and safety studies will define the form and functions for the principal components to be demonstrated. Experimental work will demonstrate the technology readiness of the core heat pipe transfer system, material characterization and compatibility, irradiation component testing, and reactor control actuators. In the ground demonstration phase, a nuclear subassembly will be run as a complete unit and be supported by vibrational assemblies, critical assemblies, assembly models, and long-term component and module testing.

(2) Radioisotope Heat Source. The radioisotope heat source program provides support to DOE in the areas of safety assessment, safety testing, safety technology, environmental testing and evaluation, heat source design, and heat source production. As part of this program, fuel-form fabrication procedures were developed for SNAP-19 (cermet), multihundred watt, and general purpose heat source. Safety analyses and tests were carried out for Pioneer, Transit, LES 8/9, and Voyager. The design of the Lightweight Radioisotope Heater Unit was completed and put into production, and the design of the General Purpose Heat Source was completed. Testing of derivative General Purpose Heat Source designs was carried out, and the environmental exposures of various fueled units to simulated terrestrial and aquatic environments were accomplished.

\section{b. LMFBR Base Program}

A major thrust of our reactor fuel development effort has been the development of an advanced fuel for the liquid metal fast breeder reactor (LMFBR). This work capitalizes on intrinsic properties of the mixed uranium-plutonium carbide that promises improved breeding capability and reduced fuel cycle costs. Our advanced LMFBR fuel development project includes development of processes for the production of the carbide material, design of fuel pins, irradiation testing of candidate materials and designs, and maintenance of a strong quality-assurance activity providing standards and reference material to others. Its overall mission is to build the technology base that will permit commercial manufacture and licensing of LMFBR cores fueled with uranium-plutonium carbide instead of the uranium-plutonium oxide of conventional design. The project is concluding a highly successful phase of test irradiations in the Experimental Breeder Reactor II. Highly reliable 
performance has been demonstrated at power and temperature conditions typical of those expected to be experienced in large, commercial LMFBRs. Process development and irradiation tests in the new Fast Test Reactor at the Fast Flux Test Facility are continuing activities.

Other projects in reactor fuel development exploit unique facilities at Los Alamos, such as our new Plutonium Facility, or special technologies, such as graphite-composite fabrication, in the supply of various services and products to the nation's reactor development programs.

A new emphasis in 1983 will integrate our historically disparate efforts in fuels and materials development, reactor physics and safety analysis, and core component design. These efforts will be combined to address the analysis of LMFBR advanced cores optimized for performance, safety, and economy of construction and operation through materials developments and innovative design features.

In addition to the reactor fuel development effort, DOE supports work bearing on the safety of the LMFBR. This work emphasizes the analysis of the response of the plant to anticipated transients, emergency events, and hypothetical accidents leading to core disruption. Such accidents played a large role in licensing CRBR and are expected to be equally important in licensing larger plants. We are investigating advanced safety licensing strategies for large (1000-MWe) plants.

\section{c. Commercial Waste Management}

The Los Alamos waste management program is an integrated activity embracing commercial and defense radioactive wastes and nonradioactive hazardous wastes. Highlights of all these activities are discussed together here, but only the commercial radioactive waste efforts funded by ASNE are emphasized in this section. These efforts will lead to improved methods for managing, treating, and disposing of radioactive contaminated wastes generated by industry. They also include evaluation of tuff at the Nevada Test Site (NTS) to determine its seismic, geologic, and radionuclide sorptive properties. The latter studies (funded by ASNE through the Nevada Operations Office) are designed to assess NTS tuff as a medium for a high-level waste depository.

Controlled air incineration as a means of reducing the volume of transuranic (TRU) combustible waste has been proven; transfer of this technology to other DOE contractors and to the nuclear power industry is an objective of the ongoing commercial program. Included in the process are equipment for waste packaging, receiving, assay, incineration, and handling of aerosol and ash. Emphas is in the low-level waste research program is on finding means to dispose of low-level wastes in shallow land burial sites, the development of techniques to prevent infiltration by plants and animals, and the demonstration of remedial action programs. 


\section{d. TMI Support}

A modest program supporting TMI diagnostics was initiated in FY 1982 and will carry over through FY 1984. The work primarily involves use of the Los Al amos MIMAS code to produce a quasi two-dimensional TMI-2 core damage assessment. Follow-on efforts will integrate the MIMAS code into the Los Alamos TRAC code to predict fission product transport and hydrogen concentrations in the primary system. This computational effort will introduce the specific thermal, hydraulic, and structural models needed to achieve the necessary results.

\section{e. Remedial Action}

These efforts are phasing down in FY 1983. An elaborate and comprehensive array of actual samples representative of all principal mill tailings in CONUS are stored at LoS Alamos. However, primary responsibility for storage and further analytical work have been transferred to another contractor. Close-out efforts during FY 1983 will involve Health Effects Guides of Formerly Utilized Sites and certain engineering aspects of Trinity Ground Zero.

\section{Nuclear Energy Initiatives Reactors for Defense and Space Applications}

Currently, we are funded to carry out technology development on a 10- to 100-kwe space power plant (SP-100). Anticipated time for a flight qualified demonstration of this system will be in the latter years of this decade. Military uses for SP-100 include (1) space-based radar, (2) hardened $C^{3}$, (3) blue-green laser subcommunicator, (4) high-altitude large optics, (5) electronic jammers, (6) chemical lasers, and (7) electric propulsion systems.

The military has a number of requirements for power to fulfill future operational demands of their assigned missions. A logical expansion of the ongoing SP-100 work is to develop the vastly increased power levels dictated by particle beam weapons systems. The Laboratory's background in nuclear rocket technology (Rover Program) has left a strong cadre of skilled personnel with appropriate technical backgrounds and experience in precisely these areas.

Other future military reactor needs include a power source for the underground $M X$ concept, remote site power, and secure base power. Current dependence on fossil fuels for these requirements introduces vulnerabilities to disruption of energy supplies for the worldwide deployment of U.S. forces. Modification of the SP-100 or modern high-efficiency reactor technology to meet any of these needs is clearly within the existing capability at Los Alamos.

The basic resources to initiate any single one of these programs are: 
Los Alamos

REACTORS FOR DEFENSE AND SPACE APPLICATIONS

( 8 in millions)

FY82 FY83 FY84 FY85 FY86 FY87 FY88

Operating

$\begin{array}{lllllll}0.3 & 0.7 & 3.0 & 5.0 & 8.0 & 10.0 & 10.0\end{array}$

Capital Equipment Total

Personnel

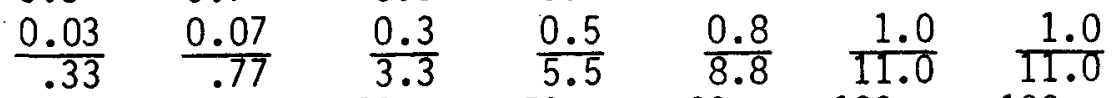
3 30 50 80 100 100

Note: The ongoing SP-100 studies are already included in our resource tables (Section IX). 
D. Conservation and Renewable Energy

\begin{tabular}{|c|c|c|c|c|}
\hline$B \& R$ Code & Major Program (Title). & FY 1982 & FY 1983 & FY 1984 \\
\hline $\begin{array}{l}A K \\
A L \\
A M \\
E B \\
E C \\
E E \\
E G\end{array}$ & $\begin{array}{l}\text { Electric Energy Systems } \\
\text { Energy Storage Systems } \\
\text { Geothermal } \\
\text { Solar Energy } \\
\text { Bldg \& Community Systems } \\
\text { Transportation Energy Con } \\
\text { Multi Sector }\end{array}$ & $\begin{array}{r}0.0 \\
3.2 \\
10.4 \\
2.8 \\
0.1 \\
0.7 \\
0.5 \\
\end{array}$ & $\begin{array}{l}0.0 \\
1.5 \\
7.5 \\
0.0 \\
0.0 \\
0.0 \\
0.6\end{array}$ & $\begin{array}{l}0.0 \\
0.0 \\
5.3 \\
0.0 \\
0.0 \\
0.0 \\
0.0\end{array}$ \\
\hline Total & & 17.7 & 9.6 & 5.3 \\
\hline $\begin{array}{l}\text { Percent of } \\
\text { Laboratory }\end{array}$ & $\begin{array}{l}\text { tal } \\
\text { nding }\end{array}$ & 4 & 2 & 1 \\
\hline
\end{tabular}

1. Current Conservation and Renewable Energy Programs

Programs sponsored by the Assistant Secretary for Conservation and Renewable Energy (ASCE) include solar applications, solar technology, energy storage and conservation, and geothermal energy. Current budget guidance indicates that these programs will be severely curtailed or terminated in FY 1983.

\section{a. Solar Applications}

Passive solar systems for heating and cooling buildings can be used for both near-term and long-term reduction of oil use. Los Alamos is recognized as the national leader in this field. This is budgeted for termination in FY 1983.

\section{b. Solar Technology}

The study of the hydrodynamic stability of salt-gradient stratified solar ponds is a program that utilizes the hydrodynamic modeling capability unique to Los Alamos. A small research pond has been constructed to provide data with which to verify the computer models. This is budgeted for termination in FY 1983.

\section{c. Conservation}

The superconducting magnetic energy storage (SMES) program is investigating the use of large, superconducting magnets for diurnal energy storage and other load management problems. A 30-MJ coil system, operating at $0.3 \mathrm{~Hz}$, has been assembled to provide stabilization for the Bonneville Power 
Los Alamos

Administration's transmission lines from Washington state to Los Angeles. This program is scheduled for close-out in FY 1983.

The fuel cell program, budgeted for termination in FY 1983, is described in the section on Initiatives.

\section{d. Geothermal Energy}

Virtually all geothermal energy produced today involves extraction of naturally occurring subsurface hot water or steam, removal of the thermal energy, and reinjection of the spent fluid. The Los Alamos Hot Dry Rock (HDR) concept is unique in that it requires only high subsurface temperatures and relatively impermeable rock. Naturally occurring hot rock is far more abundant than the combination of hot rock, adequate permeability, and water or steam. Extraction of thermal energy from hot dry rocks requires creation of a subsurface fracture system (heat exchanger) connected to the surface by wel1bores capable of injecting cold fluid, providing pathways through the fracture system for fluid heating, and returning the hot fluid to the surface. At the surface, the thermal energy is extracted and the fluid is then reinjected in a continuous closed-10op operation.

A small (about 5-MW) HDR research reservoir has been constructed at Fenton $\mathrm{Hill}$ west of LoS Alamos. The fracture system was created hydraulically in low-permeability rock almost two miles deep and at a temperature of about 200 degrees $C$. Tests over a period of about three years, and with one single extraction test covering nine months, have proven the concept. Electricity was generated by a specially designed 60-KVA binary turbo-alternator. Two deeper, hotter wells have been completed to a depth of nearly three miles and with rock temperatures of about 320 degrees C. During FY 1983 plans are to complete the engineering reservoir by creating connecting fractures between the inclined wellbores. This may lead to a 3- to 10-Mwe pilot electrical demonstration plant constructed and operated by a local utility.

Through an International Energy Agency Implementing Agreement, the Federal Republic of Germany and the government of Japan participate both financially and with resident staff in the planning and conduct of the Fenton Hill effort. The Agreement spans four years and concludes (if not extended) at the end of FY 1983. Reductions in the DOE geothermal budget have resulted in $\$ 7.5 \mathrm{M}$ for this program for $F Y$ 1983. This, coupled with the $\$ 2.5 \mathrm{M}$ from FRG and $\$ 2.5 \mathrm{M}$ from Japan, permits us to continue on a somewhat reduced level toward the program goals.

\section{Conservation and Renewable Energy Initiatives}

Fuel Cel1s

The fuel cell program, budgeted for termination in FY 1983, is presented as an initiative. 
Fuel cells for transportation applications, funded by the office of Energy Systems Research (OESR), is a two-part program to determine the feasibility of fuel cells as power supplies for consumer vehicles, buses, locomotives, and ships. The basic research part of the program takes advantage of the Laboratory's capability in electrochemistry and catalysis, focusing on alternate catalysts, size reduction, performance increases, and cost reduction. The applied research portion utilizes the systems integration, modeling, technology assessment, and economics capabilities of the Laboratory.

\section{FUEL CELLS}

( 8 in millions)

$\underline{F Y 83} \quad \underline{F Y 84} \quad \underline{F Y 85} \quad \underline{F Y 86} \quad \underline{F Y 87} \quad \underline{F Y 88}$

Dperating

Personnel (FTE)

2.0

13
4.0

20
4.5

20

\section{5}

20
5

20
5

20 
Los Alamos

E. Fossil Energy

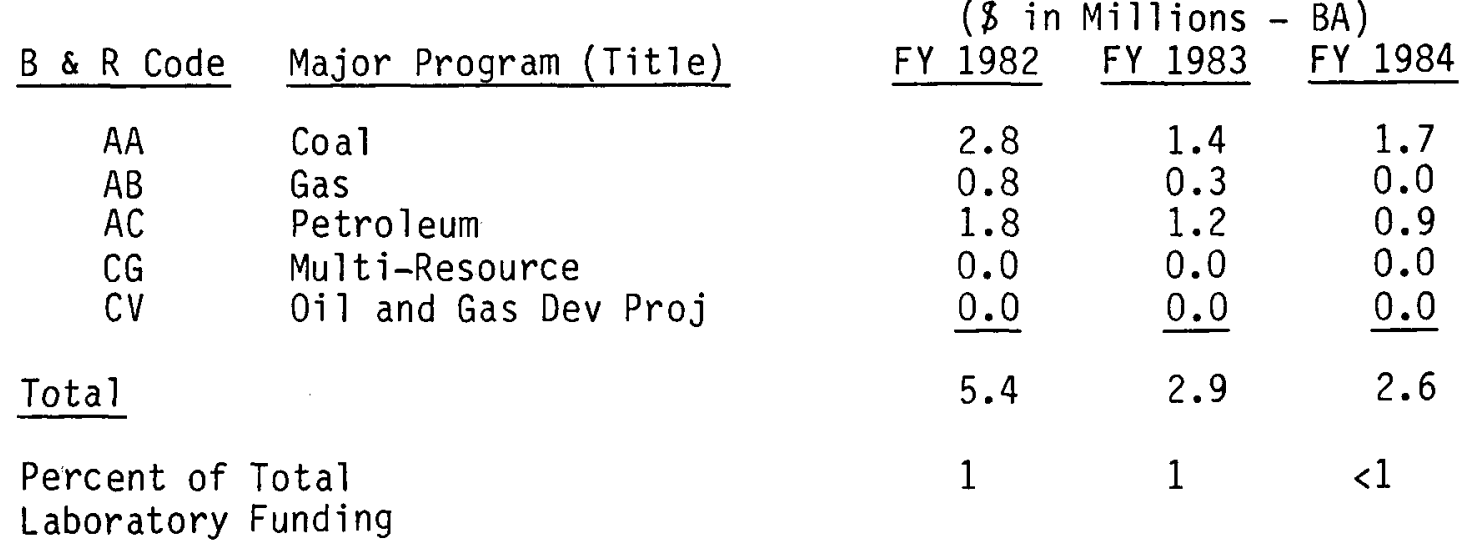

\section{Current Fossil Energy Programs}

The Fossil Energy program at Los Alamos is based upon our unique capability in four areas: Computer Modeling, Basic and Process Chemistry and Engineering, Instrumentation and Control, and Advanced Materials Development.

The largest fossil program deals with the explosive fracture of oil shale. Los Alamos researchers are developing a technology for rubblizing and evaluating in situ oil shale retorts by performing field tests and evaluating the resulting fragmentation using finite difference multicomponent fluid flow hydrocodes. Stress wave propagation and material failure analysis are being used to predict and interpret explosive fragmentation events. The field component of this work is taking place at the Anvil Points 0il Shale Mine in Colorado.

For several years now, Los Alamos researchers have been developing laserbased diagnostic techniques for in situ measurements of the composition of coal gasification process streams. Laser-induced breakdown studies (LIBS), infrared absorption, laser-induced fluorescence (LIF), and coherent antistokes raman spectroscopy (CARS) are among those techniques which have been developed and tested to date. Field tests of LIBS and CARS were conducted at METC in FY 1982. In addition to composition of majority, minority, and trace molecular species, total elemental assays and other process variables such as temperature, pressure, and velocity can be measured by the laser-based techniques. Also in the area of instrumentation development, an innovative in situ nuclear magnetic resonance (NMR) measurement tool has been developed. This tool has the ability to characterize the fluid saturations in gas stands. Porosity, permeability, and other pertinent reservoir properties can also be determined by NMR. 
The Los Alamos expertise in structural ceramics is being applied to solving fossil-related materials problems. One program investigates utility of whisker reinforcement technology for producing structural ceramic composites of improved strength and fracture toughness. A second program is designed to develop specific brittle-materials design methodology and accompanying fabrication methods for the development of a ceramic type III Lock hopper valve.

\section{Fossil Energy Initiatives}

a. Unconventional Gas

We are proposing a comprehensive study designed to detect possible sources of natural gas originating primarily in the mantle. Identification of deep gas sources could lead to identifying new reservoirs in unconventional locations and to new prospecting techniques.

UNCONVENTIONAL GAS

$\begin{array}{lccccc}\text { ( } \$ \text { in millions) } & \text { FY84 } & \text { FY85 } & \text { FY86 } & \text { FY87 } & \frac{\text { FY88 }}{\text { Operating }} \\ \text { Personnel (FTE) } & 1.0 & 1.5 & 1.5 & 1.5 & 1.5 \\ & 10 & 15 & 15 & 15 & 15\end{array}$

b. 0 il Shales and Tar Sands

The objective of this program would be to develop and analyze innovative oil extraction techniques from oil bearing shales. Internal funds have been provided in order to build a small high-temperature, high-pressure retorting facility. This facility will be used to test and evaluate innovative oil extraction processes. The ASPEN process simulation code will be used in order to determine the cost effectiveness of various research efforts under consideration.

OIL SHALES AND TAR SANDS

( 8 in millions)

Operating

Personnel (FTE)

$\begin{array}{ccccc}\frac{\text { FY84 }}{3} & \text { FY85 } & \text { FY86 } & \text { FY87 } & \text { FY88 } \\ 0.7 & 0.9 & 1 & 1 & 1 \\ 7 & 9 & 10 & 10 & 10\end{array}$

c. Coal/Water Mixtures

The objective of this program would be the combination of Los Alamos capabilities to study the entire technology involved in the use of coal/water mixtures as a fuel for IC engines, turbines, and direct combustors. Los Alamos has relevant expertise in the areas of comminution, beneficiation, nozzle design, combustion modeling, and instrumentation. 
Los Alamos

COAL/WATER MIXTURES

$\begin{array}{llllll}\text { (8 in millions) } & \text { FY84 } & \text { FY85 } & \text { FY86 } & \text { FY87 } & \text { FY88 } \\ \text { Operating } & 0.5 & 1.0 & 1.0 & 1.0 & 1.0 \\ \text { Personnel (FTE) } & 4 & 8 & 8 & 8 & 8\end{array}$


F. Environmental Protection, Safety, and Emergency Preparedness (ASEPSEP)

\begin{tabular}{|c|c|c|c|c|}
\hline$B \& R$ Code & Major Program (Title) & FY 1982 & FY 1983 & FY 1984 \\
\hline$H A$ & Biomed \& Environ Research & 2.9 & 1.6 & 2.1 \\
\hline $\begin{array}{l}\text { Percent of } \\
\text { Laboratory }\end{array}$ & $\begin{array}{l}\text { otal } \\
\text { unding }\end{array}$ & 1 & $<1$ & $<1$ \\
\hline
\end{tabular}

Current Environmental Protection, Safety, and Emergency Preparedness Programs

Ongoing programs provide technical support and management of projects designed to identify health and environmental hazards relating to energy resource development and hazardous waste management. Technical support and guidance are also provided to DOE to ensure that DOE and DOE contractor personnel are equipped with adequate protective equipment and safety training. Proposed regulations and standards are reviewed and guidance is provided to DOE in the preparation of regulations, reports, and technical documentation relating to radiation protection.

Hazardous Waste Management. Los $A_{i} l$ amos has been designated the principal DOE Laboratory for nonradioactive hazardous waste R\&D activities. Current activity is concentrated on the design of a management system to assure DOE compliance with provisions of the Resource Conservation and Recovery Act. Rapidly changing direction and staff in Washington have caused some management lags in this program. However, recent realignments have stabilized program direction and scope, and some modest growth for outyears is cautiously anticipated. 
Los Alamos

G. International and Energy Policy Programs

1. Current International and Energy Policy Programs

Current international energy programs aim at creating a Los Alamos program of international technology cooperation in support of foreign policy initiatives by the Department of State (DOS), Agency for International Development (AID), and Department of Energy (DOE).

There are several current activities in support of the above objective, including development of cooperative laboratory agreements with the Mexican Nuclear Research Institute (ININ) and the Mexican Petroleum Institute (IMP) for the purpose of conducting joint research.

Los Alamos is also conducting research for DOE on the application of sensitivity techniques to the National Energy Policy Plan model and determination of the impact of different deregulation schemes on electric utilities. Analytical support is being provided on other electric utility policy issues in areas such as financing of capacity expansion, electricity conservation efforts, power wheeling for $0 i 1$ and gas use reduction, acid rain, and severance tax issues.

An energy and minerals component of the Caribbean Basin Initiative has been developed to assist countries in that region to develop indigenous energy and mineral resources essential to economic development and reduction of their dependence on high-cost imported oil. Preliminary discussions have been initiated with government officials in Barbados, St. Vincent, St. Lucia, and Dominica, which were favorably received. Follow-up proposals requested by these governments are being developed in areas such as geothermal, mineral reconnaissance, and volcanic hazard prediction.

2. International and Energy Policy Initiatives

a. Caribbean Basin Initiative

The Caribbean countries which were recently visited have expressed considerable interest in various aspects of the energy and minerals component as an essential vehicle for developing secure energy sources which will assist their economic development. The Dominican Republic and Jamaica have also expressed interest in the component, and visits to those countries are planned for early 1983.

The primary difficulty in implementing a substantial program in the region is funding. AID and the Caribbean Development Bank appear to be the most likely sources for funds. If the program can be reasonably funded initially, there appears to be a likelihood that other countries in Latin America will be interested in participating and sharing the cost of work done within the ir countries. 


\section{b. U.S.-Mexico Cooperation}

Los Alamos-ININ nuclear cooperation has a good beginning despite Mexico's current economic problems and the budget constraints of the U.S. Government. In FY 1982 LoS Alamos and ININ scientists conducted joint research in economies of scale by reactor size, expansion of the Mexican nuclear electrical system, and design and construction of a research reactor. Plans for joint sensitivity testing in economies of scale and additional reactor experiments are being developed for FY 1983. In addition, implementation of exchanges of scientific personnel between Los Alamos and the Center for Nuclear Studies at the National Autonomous University of Mexico (UNAM), in such areas as neutron activation analysis and radioisotopes and nuclear medicine, would greatly enhance the scope of cooperation if DOE support can be obtained. It is also hoped that the Los Alamos-Mexican Petroleum Institute (IMP) agreement, which was negotiated in FY 1982, will receive the approval of the new Mexican Government and that implementation of joint research activities will begin in FY 1983. 
Los Alamos

WORK FOR OTHER THAN DOE (WFO)

Los Alamos capabilities are also applied to the solution of national problems that either lie outside the DOE charter or that derive portions of their support outside DOE. Such projects generally are accepted only if they complement and benefit Los Alamos activities, use available staff and facilities, and can be conducted without interference to our major commitments to DOE. In FY 1983, reimbursable projects of this nature supported by non-DOE sponsors total about $11 \%$ of the Laboratory work load. Three-fourths of this is work performed for the major non-DOE sponsors, DOD and NRC, and is described more fully in this section. The bulk of the remainder is work performed for other Federal agencies, but support is also given to the needs of other governmental units, universities, and industry. Highlights of these activities are described below.

\section{A. Department of Defense}

Los Alamos has a sizable effort on programs carried out under DoD funding. While some of this work supports the DoD role in nuclear defense, the Laboratory's main effort is in programs such as directed energy weapons, laser photochemistry applications, and nonnuclear ordnance that exploit unique Los Alamos capabilities for developing nonnuclear weaponry and countermeasures.

1. Current WFO Programs

a. Laser Photochemical Applications

As a result of Los Alamos' research on laser isotope separation, we have established a unique capability in precision photochemistry. Techniques of laser photochemistry show high promise for application to battlefield detection and detoxification of chemical and/or biological agents. Other areas under assessment for military application are laser diagnostics of transient phenomena (including opacity), explosive products, and diagnostics of trace materials associated with the weapons program.

\section{b. Conventional Ordnance and Materials Technology}

Expert knowledge about materials, high explosives, and the interactions so essential for nuclear weapons development is being applied to DoD materials and conventional ordnance problems. Examples are nonnuclear warheads to attack ballistic missiles and cruise missiles, antiarmor and antisubmarine warheads, advanced armors, and improved high-speed cutting tools. Work is also being done to develop inexpensive AN-based bomb fills and ceramic armors and to understand deflagration-to-detonation transition in high-energy propellants. We are currently developing a 3-D calculation technique including the coupling of a hydrodynamic code to a finite element code so that we can calculate the complete nonnuclear ABM process from fragments striking the reentry vehicle through the warhead structural response. 


\section{c. Chemical and Biological Warfare (CBW) Countermeasures}

The CBW countermeasures program exploits R\&D capabilities to develop antidotes to chemical agents and toxins, evaluate protective systems, provide adequately sensitive detection and warning systems, devise strategies for avoiding contamination, and devise effective and economical methods for demilitarizing the current chemical weapon stockpile. The program includes the aggregate of human effects-oriented projects supported by the DoD. Individual projects utilize special Laboratory facilities required by the DoD, but inordinately expensive to duplicate in the services laboratories. By comparison, modest improvements in existing Laboratory facilities allow pursuit of integrated effects studies with combinations of conventional, nuclear, chemical, biological, and directed-energy weapons. Results are crucial for planning defenses and countermeasures on the integrated battlefield.

\section{d. 0 ther}

This group of activities includes improved methods for weapons test detection; ongoing nuclear weapons effects evaluation and support of Defense Nuclear Agency effects tests; and space-radiation evaluation wherein Los Alamos assists military agencies to iriterpret data from space and to select instrumentation for space.

\section{WFO Initiatives \\ a. Directed Energy}

We are focusing a number of our new concept activities toward directedenergy applications. The Los Alamos effort includes an effort in scientific investigations of lasing media, with most of our emphasis being placed on a variety of concepts involving electromagnetic effects and directed particles and fragments. Work which we had been carrying out over the last five years in the areas of plasma production and nagnetohydrodynamics with explosives has also shown the dominance of plasma effects and uncovered the opportunities to apply them to a variety of directed-energy missions. We have discovered within the Inertial Fusion program major effects due to plasma production throughout irradiated pellets. We kelieve it is appropriate that these efforts be increased in size and scope in order to take advantage of the exciting possibilities.

These efforts will require enhanced budgetary support if we are to augment the efforts without wholesale reductions in other parts of the weapons program. While we intend to initiate such efforts within our presentiy projected budgets, we solicit additional DOE support for future years. This type of frontier R\&D activity had been given far too little emphasis in the past decade and must be revived if the Laboratory is to carry out its advanced technology mission. 
Los Alamos

DIRECTED ENERGY

( 8 in millions)

Operating

Capital

Total

Personnel
FY82

1.7

0.2

1.9

12

\section{FY83}

3.8

0.4

4.2

42
FY84

FY85

9.6

12.5

0.7

0.7

10.3

13.2

54

70

\section{b. Free-Electron Laser - Defense Advanced Research Projects Agency (DARPA)}

Recent results obtained at LoS Alamos National Laboratory have demonstrated an order of magnitude increase in the efficiency of free-electron lasers and confirmed theoretical predictions. These results, which represent the best efficiency achieved to date, have generated considerable interest in free-electron lasers for high-power strategic applications. Los Alamos is uniquely capable of developing such lasers owing to its broad expertise in lasers and electron accelerators. At the present time, the Laboratory has an important DARPA-sponsored program whose objective is to demonstrate, on a small scale, a complete high-efficiency free-electron laser system embodying the technology required for a high-power device. This program will be completed in FY 1985 and would logically be followed by the construction of a high-power device over the period FY 1984 to FY 1988. This will require that some preparation be carried out in parallel with the small-scale study to examine subsystems, preliminary design, and site planning. The estimated large unit construction costs are summarized below (FY 1982 dollars).

\section{FREE-ELECTRON LASER}

( $\$$ in millions)

Construction
FY84 FY85

$3.0 \quad 18.0 .60 .0$
FY87

FY88

83.0

25.0

\section{c. Technology Demonstration Accelerator - (DARPA)}

This facility should serve as an invaluable tool in the program for assessing the feasibility of using neutral particle beams weapons. Although not intended to serve as a prototype, this accelerator facility should be most useful in verifying chosen designs and in identifying problem areas. This facility will contain all the major components to allow testing of the negative ion accelerator, output optics, and neutralizer cell. 


\section{TECHNOLOGY DEMONSTRATION ACCELERATOR}

\begin{tabular}{|c|c|c|c|c|c|c|c|c|}
\hline \multirow{2}{*}{ ( 8 in millions) } & \multicolumn{2}{|c|}{ FY85 } & \multicolumn{2}{|c|}{ FY86 } & \multicolumn{2}{|c|}{ FY87 } & \multicolumn{2}{|c|}{ FY88 } \\
\hline & $\mathrm{BA}$ & $\mathrm{BO}$ & $\mathrm{BA}$ & BO & $\mathrm{BA}$ & BO & $B A$ & BO \\
\hline Construction & 10.0 & 7.0 & 10.0 & 7.0 & 30.0 & 23.0 & 0 & 13.0 \\
\hline
\end{tabular}

\section{d. Counterterrorism}

We are in the early developmental stages of a Laboratory Counterterrorism Program and are presently brainstorming project ideas that can be submitted for outside sponsorship. The successful development of this program depends largely on the quality of these project proposals; moreover, some will undoubtedly need small amounts of seed money for proof of principle or other demonstration. There will be small, quick turnaround experiments best funded out of a modest, undivided category of money.

\section{COUNTERTERRORISM}

( $\$$ in millions)

Operating

Capital Total

Personne 1

\begin{tabular}{|c|c|c|c|}
\hline FY82 & FY83 & FY84 & FY85 \\
\hline 0 & 0.4 & 0.8 & 1.1 \\
\hline 0 & 0 & 0.1 & 0.2 \\
\hline 0 & $\overline{0.4}$ & $\overline{0.9}$ & $\overline{1.3}$ \\
\hline 0 & 4 & 8 & 10 \\
\hline
\end{tabular}

\section{e. Conventional Munitions}

The Laboratory, along with LLNL and SNLA, is evaluating the possibility of an expanded role in conventional munitions development. This joint Los Alamos, LLNL, SNLA initiative would be block funded by the DoD and would be under Laboratory technical management. Los Alamos would apply its unique capabilities in the areas of explosives technology, computer simulation, and engineering development to the research and development of improved conventional munitions.

\section{CONVENTIONAL. MUNITIONS}

$\begin{array}{llccccc}\text { (\$ in millions) } & \text { FY83 } & \text { FY84 } & \text { FY85 } & \text { FY86 } & \text { FY87 } & \text { FY88 } \\ \text { Operating } & 0.5 & 5.0 & 7.5 & 10.0 & 10.0 & 10.0 \\ \text { Capital Equipment } & \frac{0}{0.5} & \overline{5.0} & \overline{7.5} & \overline{10.0} & \overline{10.0} & \overline{10.0} \\ \quad \text { Total } & 3 & 20 & 30 & 40 & 40 & 40\end{array}$


Los Alamos

B. Nuclear Regulatory Commission (NRC)

The NRC work at LoS Alamos focuses on providing an understanding of the behavior of nuclear reactors under postulated accident conditions and on providing assistance in reactor licensing. This is done mainly through development, testing against experimental data, and applications of advanced computer codes that model accident behavior. All major reactor types are considered, with the emphasis adjusted as NRC needs and priorities evolve. The focus of the safety effort has been light water reactors.

The cornerstone of the Los Alamos effort is the well-developed TRAC computer code, which has been tested satisfactorily against data from pertinent experiments throughout the world and has comprehensively analyzed the events of the Three-Mile-Island (TMI) accident. This code has evolved from development to application almost in coincidence with the shift in NRC priorities from less interest in development of large computer codes to greater emphasis on providing direct applications help to the regulatory side of NRC for LWR licensing, and the code is now being used for the latter purpose. An international program with Germany and Japan in LWR safety - involving computer codes, analysis, experimentation, and instrumentation - is continuing. The need to look at potentially severe LWR accident sequences - using sophisticated codes like TRAC - is apparent, and we are participating in a multilaboratory effort to help NRC better understand these conceptual accident sequences and to identify how they can be prevented or mitigated. We are also performing computer analyses of many other less severe accident sequences, modeling experiments, and assessing structural problems in reactor systems and containments.

A wide variety of technical assistance projects are also undertaken for the NRC using the strong base of experienced engineering talent available at the Laboratory ranging from safeguards and security expertise to respirator research. These assistance projects pertain to many of the nuclear facilities under NRC jurisdiction, including power reactors, nonpower reactors, and fuel cycle facilities.

A strong effort in the advanced reactor field is continuing with emphasis on the LMFBR. The Laboratory has been able to maintain a strong and unique LMFBR capability with the expectations of continued effort in the future. Continued development and experimental assessment of the fast reactor SIMMER code to better understand LMFBR fuel melting is being supported by the NRC, and the capability to model entire LMFBR accident sequences using a combination of codes, including SIMMER, is the goal. Such studies have already shown that previously used techniques tend to substantially overestimate system damage that could result from a core meltdown accident. The expertise developed and maintained in the LMFBR area is being directed toward the Clinch River Breeder Reactor licensing review where the Laboratory is the principal technical assistance contractor. 


\section{Other Federal Agencies and Other Entities}

Research and Development presently totalling around $\$ 10 \mathrm{M}$ annually is done for the National Aeronautics and Space Administration, Environmental Protection Agency, Department of Interior (primarily U.S. Geological Survey), Department of Health and Human Services (primarily National Institutes of Health and National Cancer Institute), Department of Agriculture, the Department of State, and other Federal departments and agencies. For them we study such things as solar terrestrial phenomena, reduced gravity fluid dynamics, space power systems, oil shale operations, waste incineration, hydrocarbon production analysis, seismic evaluation of coal, flow cytometry, therapeutic particles, serological tests, cell analysis, industrial hygiene sampling, trace contaminants, and nuclear material safeguards.

We also fabricate lightweight radioisotope heater units (LWRHUs) for the Galileo space mission; investigate and maintain a national stable isotopes resource; and collect and maintain (with some DOE support as well) a computerbased national data bank of DNA sequerces (GenBank) that supports basic and applied research in biology, medicine, and agriculture. We have established a hearing laboratory to study speaker-independent machine recognition of natural speech in the presence of noise, with the aim of finding general algorithms for solving problems in speech recognition; and, for the Department of State, we provide safeguards training for IAEA inspectors.

We also do work supporting non-Federal public and private sponsors, ranging from aiding the many universities conducting research at LAMPF to doing pipe break analysis and developing nuclear data for reactor analysis for the Electric Power Research Institute. We receive about $\$ 3.1 \mathrm{M}$ combined support and participation in the Fenton $\mathrm{Hill}$ geothermal energy project from Japan and the Federal Republic of Germany. We study klystrons for the Stanford Linear Accelerator Center and assist the Saclay accelerator in France. And we study fluid migration, examine fiber aerosol inhalation toxicity, and conduct analogous projects for other sponsors, all subject to the ground rules initially mentioned. 
Los Alamos

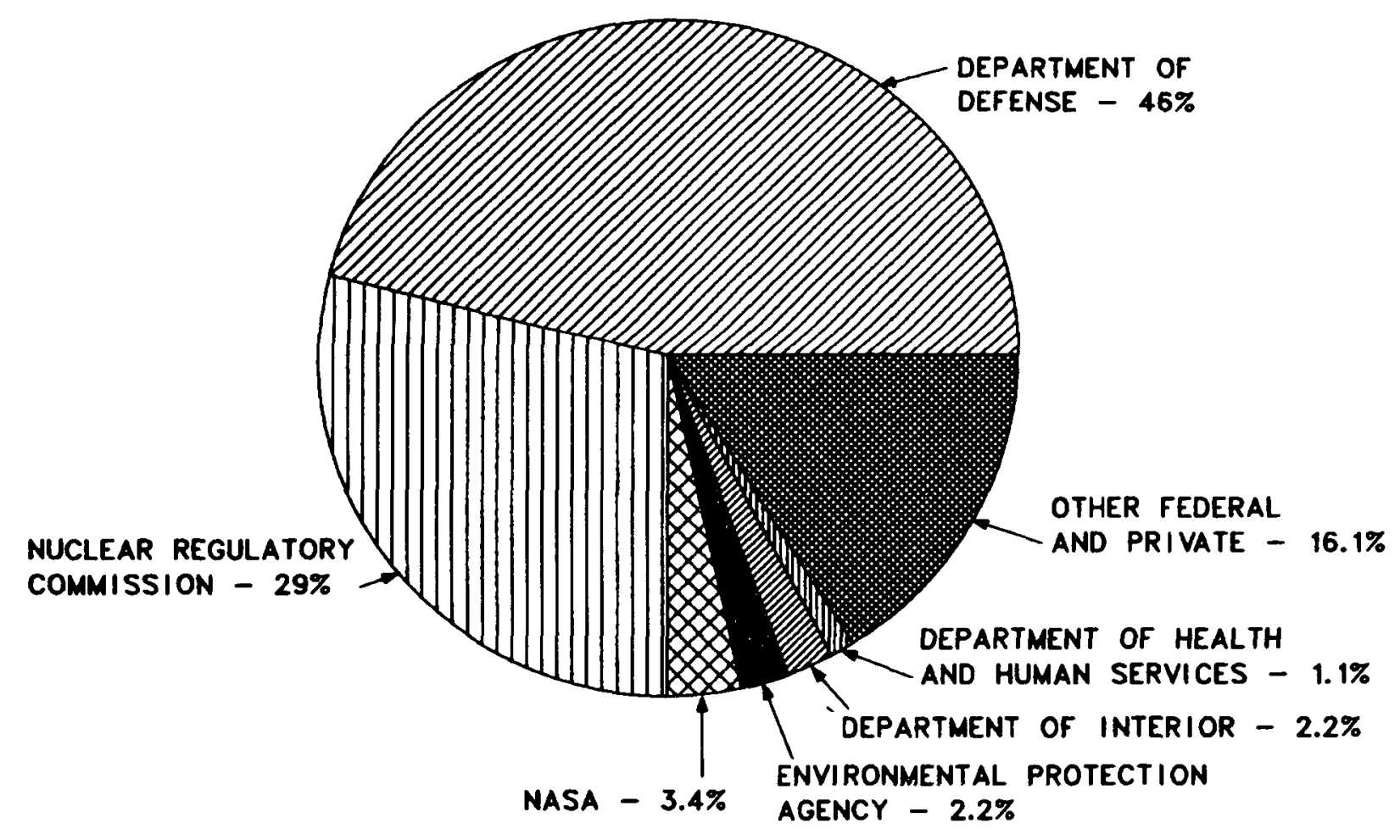

Fig. IV-1. Distribution of Work for Other than DOE. 


\section{TECHNOLOGY TRANSFER PROGRAM}

\section{A. Overview}

The Laboratory's program has two sets of goals: external and internal. On a national scale, the goals are to help affect the optimum use of Laboratory technology by industry to contribute to the nation's industrial strength and to strengthen the Laboratory's science and technology base. The regional goal is to provide appropriate technicall assistance to state and local governments, private industry, Indian tribes, educational institutions, and other regional entities.

The internal goals are to strengthen the value of the Laboratory's applied programs through early and sustained liaison with the ultimate developers and suppliers of the resulting technology and to enhance the scientific, technical, and managerial vitality of the staff through collaboration with industry and others.

In context, this program is part of a larger effort to develop a full range of liaison in both applied (typically energy-related) programs and in the basic sciences and underlying technology areas.

The Laboratory is located in al sparsely populated region, and its expertise and technology are typically at the frontiers of the physical and mathematical sciences. Because of this smaller concentration of state/local governments and level of technology, the Laboratory's technology transfer efforts relatively emphasize the private sector over the public sector more than other national laboratories might.

The full-time professional responsible for the Office of Research \& Technology Applications (ORTA) functions reports to the Assistant Director for Institutional Relations. The individuals responsible for outreach and technical assistance to neighboring local and state governments and regional entities also report to this Assistant Director. Because the technical resources for these functions are spread throughout the Laboratory, there are formal or informal lines of communication with virtually every level of management in both discipline and program, weapons and nonweapons areas. There is specifically assigned legal support for this function in the Patent Law Division. The Laboratory's institutional planning organization relies upon the ORTA-equivalent to develop and describe the technology-transfer plans.

\section{B. Process}

The Technology Transfer Program uses a five-part process to develop the supply, demand, and execution of appropriate transfers:

Industry: To establish beneficial liaison with industry, the strategy is to work simultaneously on development of Laboratory interest, 
industry contacts, and methods for cooperation and on identification and reduction of barriers. Large companies are targeted nationwide to develop liaison in both technology and programmatic areas, typically through invited visits with planned personal follow-up in specific technical areas. Work with small business is focussed regionally, with particular attention to liaison with the University of New Mexico's Technical Innovation Center, existing small businesses, and interest in the spinoff of companies locally to exploit Laboratory technology.

Outreach: Personal contacts are made with local and state government officials, chambers of commerce and tribal officials. Discussions and projects in both technical and nontechnical areas are intended to develop an environment of mutual trust that will increase the opportunities for technology transfer.

Federal Laboratory Consortium: Through active participation in the FLC network, the Laboratory is able to draw upon the unique expertise of other Federal Laboratories in addressing requests for assistance and is conversely a resource to entities outside its geographical region.

Information Development: Although most "information dissemination" is passive and yields little direct technology transfer, it can have an important role in establishing personal contacts, from which productive transfer can result. Information targeted directly to potential users, e.g., trade journal articles, and distribution of applications assessments have particular emphasis; and professional publications, press releases, and the magazine Los Alamos Science also have an important role.

Internal Laboratory: Develop motivation and interest within the Laboratory's staff and management in technology-transfer-related activities; institute an ongoing inventory of new ideas, technologies, and research results for review and transfer; provide an environment which encourages working-level staff to propose and pursue technical initiatives with industry.

C. Estimated Resources: Personnel and Funding

Funding

( 8 in thousands)

ORTA

Other (estimate)

Total
FY 1982

200

4100

4300
FY 1983

230

4650

4880

\begin{tabular}{|c|c|}
\hline FY 1984 & FY 1985 \\
\hline $\begin{array}{r}260 \\
5200 \\
5460\end{array}$ & $\begin{array}{r}260 \\
5200 \\
5460\end{array}$ \\
\hline
\end{tabular}

FY 1986

260

5200

5460
FY 1987

260

5200

5460
FY 1988

260

5200

5460 
Staffing (in FTEs)

Professional Staff

ORTA

Other

$\begin{array}{llll}1.5 & 1.5 & 1.5 & 1.5\end{array}$

Total

$\begin{array}{llll}20 & 20 & 20 & 20\end{array}$

21.5

21.5

21.5

21.5

20

1.5

20

21.5

21.5

1.5

Support Staff

ORTA

Other

Total

$\begin{array}{ccc}0.5 & 0.5 & 0.5 \\ 10 & 10 & 10\end{array}$

0.5

0.5

0.5

10

10.5

$10.5 \quad 10.5$

10

10.5

10

10.5

20

21.5

10.5

0.5

10

10.5

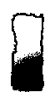

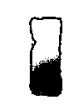

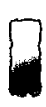

Q

5

$\square$

$\square$

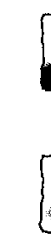

5 


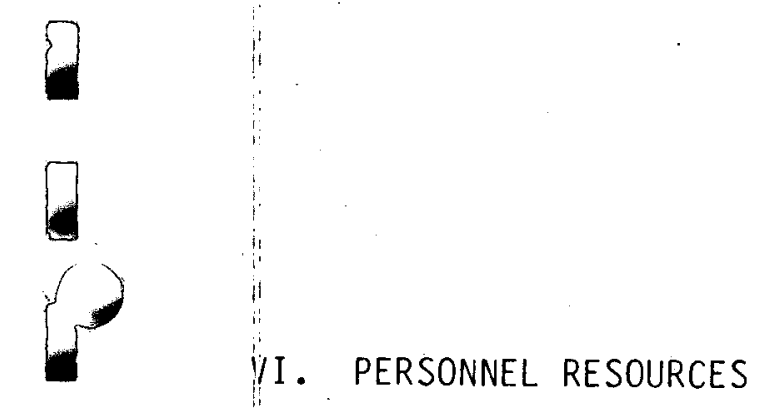

a

do nat mucrofiem

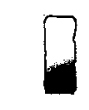

D

G

d
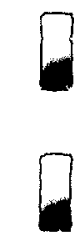

$\square$
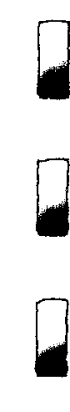
5

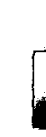




\section{PERSONNEL RESOURCES}

\section{A. Trends}

Major factors influencing planned personnel trends at Los Alamos continue to be the Administration policy of strengthening the national defense posture and the Department of Energy guidance which shifts emphasis to long-term, high-risk, high potential payoff energy R\&D programs. The Plan projects growth in Defense Programs while Energy Programs are expected to experience limited growth in some programs and deciline in others.

We expect to maintain a total Laboratory strength of approximately 7,000 FTEs for the foreseeable future. The ratio of indirect- to direct-funded FTES, currently about 1 to 3 , will be maintained through reorganization of support functions to achieve increased efficiency.

\section{B. Requirements}

Projected increases in Defense Programs and decreases in Energy Programs will necessitate some realignment of skills to effectively execute Laboratory programs. The Laboratory will pursue realignment of skills and any necessary reductions in operating strength in a manner that retains the qualified personnel best able to efficiently execute programs that are to continue.

Plans for realignment emphasize internal reassignment of personnel where feasible. Control of Laboratory strength to minimize involuntary reductionsin-force features management of backfill for normal attrition by controlled external hiring, which allows external hire to fill only the most critical needs that cannot be satisfied internally.

Planned recruiting will be primarily targeted toward professional and technical staff with weapons, diagnostics, and engineering expertise. Additionally, to support both defense and energy R\&D, there is a continuing need to maintain high-quality technical support personnel in the computer sciences, mechanical design and assembly, electronics design and assembly, and chemical processing, which are key recruiting areas.

The current distribution of professional staff experience is presented in Fig. VI-1: 


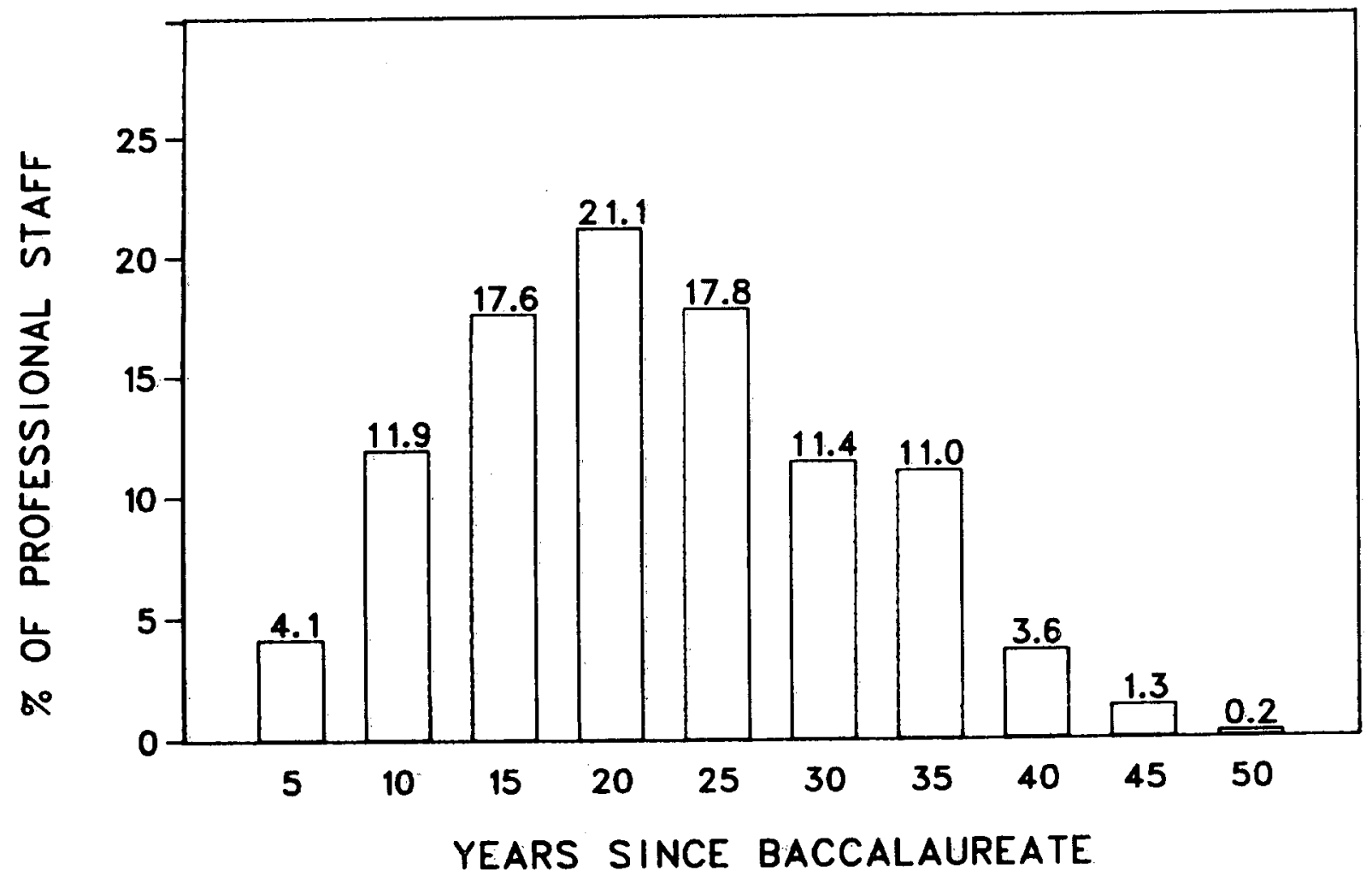

Fig. VI-1. Professional Staff Experience ${ }^{1}$ IINCLUDES FULL-TIME REGULAR EMPLOYEES ONLY. 


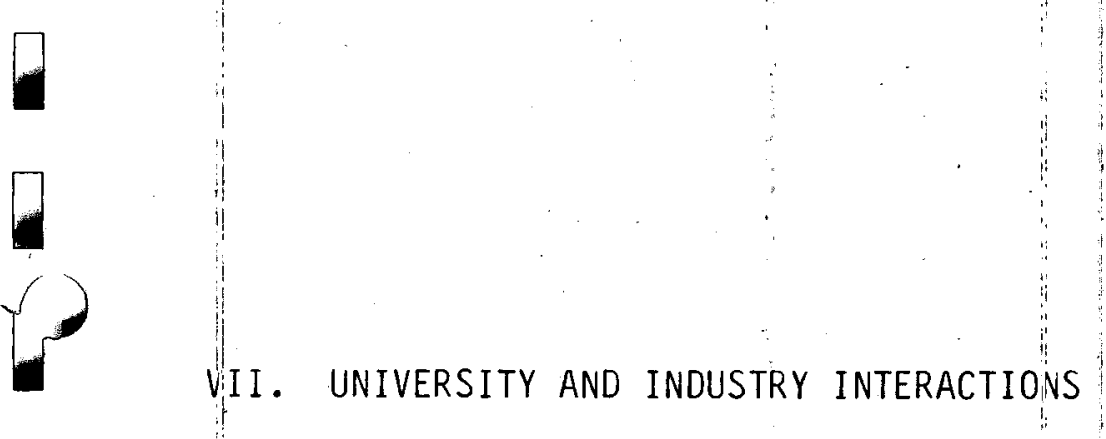

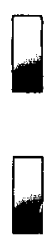

.

.

.

.

.

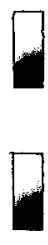

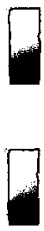

.

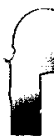

Q 


\section{UNIVERSITY AND INDUSTRY INTERACTIONS}

A. Subcontracting

Subcontracting to industry and universities is an integral part of Laboratory programs, permitting the support of specialized expertise not available within the Laboratory. In some cases, subcontracting of either R\&D or hardware fabrication is undertaken in a deliberate effort to develop commercial sources of Laboratory technology or to help develop areas of excellence within universities. In this context, some of our strongest interactions with industry and universities occur in the process of technical contract monitoring.

The Laboratory has an active Socio-Economic Program which is administered by a full-time Liaison officer. The programs include diligent and affirmative action placement of subcontracts and purchase orders with small businesses, small disadvantaged businesses, women-owned businesses, and businesses located in labor-surplus areas.

In furtherance of goals established for each of these program areas, the Laboratory attends numerous trade fairs across the country, is an active member of the New Mexico Minority Supplier Development Council, and has sponsored in-house socioeconomic trade shows. The Laboratory has developed an automated socioeconomic vendor listing which enables buyers and requesters quick access in matching procurement needs with qualified socioeconomic vendors. The Laboratory is also a subscriber and user of the Procurement Automated Source System (PASS), which was developed jointly by the Small Business Administration (SBA) and the DOE. It presently has eight computer terminals which the Laboratory purchased and tied into the system.

The Laboratory has participated in numerous conferences and provided speakers to discuss its programs in this area and throughout the country, i.e., the National Association of Purchasing Management, the New Mexico Minority Supplier Development Council, and the DOE Procurement Managers Conference.

During the previous four years, the Laboratory has received the rating of "excellent" on its joint review by the SBA and the DOE for program compliance. In 1981, the Laboratory received recognition for outstanding accomplishments in the Small Business Program by DOE Secretary Edwards.

The following are dollar statistics for the Small Business and Small Disadvantaged Business Programs, commencing with Fiscal Year 1979. Dollars are being shown, rather than percentages, because in FY 1980 the bases for computing percentage was changed from "Total Available Commercial Procurement Dollars" to "Total Procurement Dollars. "The figures below are a more realistic trend of the Laboratory's commitment to these programs: 
Los Alamos

SMALL BUSINESS

SMALL DISADVANTAGED BUSINESS
$\frac{F Y 1979}{\$ 51.671 M} \frac{F Y 1980}{\$ 63.648 M} \frac{F Y 1981}{\$ 70.248 M} \frac{F Y 1982}{\$ 73.200 M}$

$\$ 2.025$ M $\$ 2.577$ M $\$ 3.484$ M $\$ 3.500 M$ 
Transter to Other DOE Laboratories I

Z

University Subcontracts and Purchases 2

m

All other subcontracts \& Purchases 3

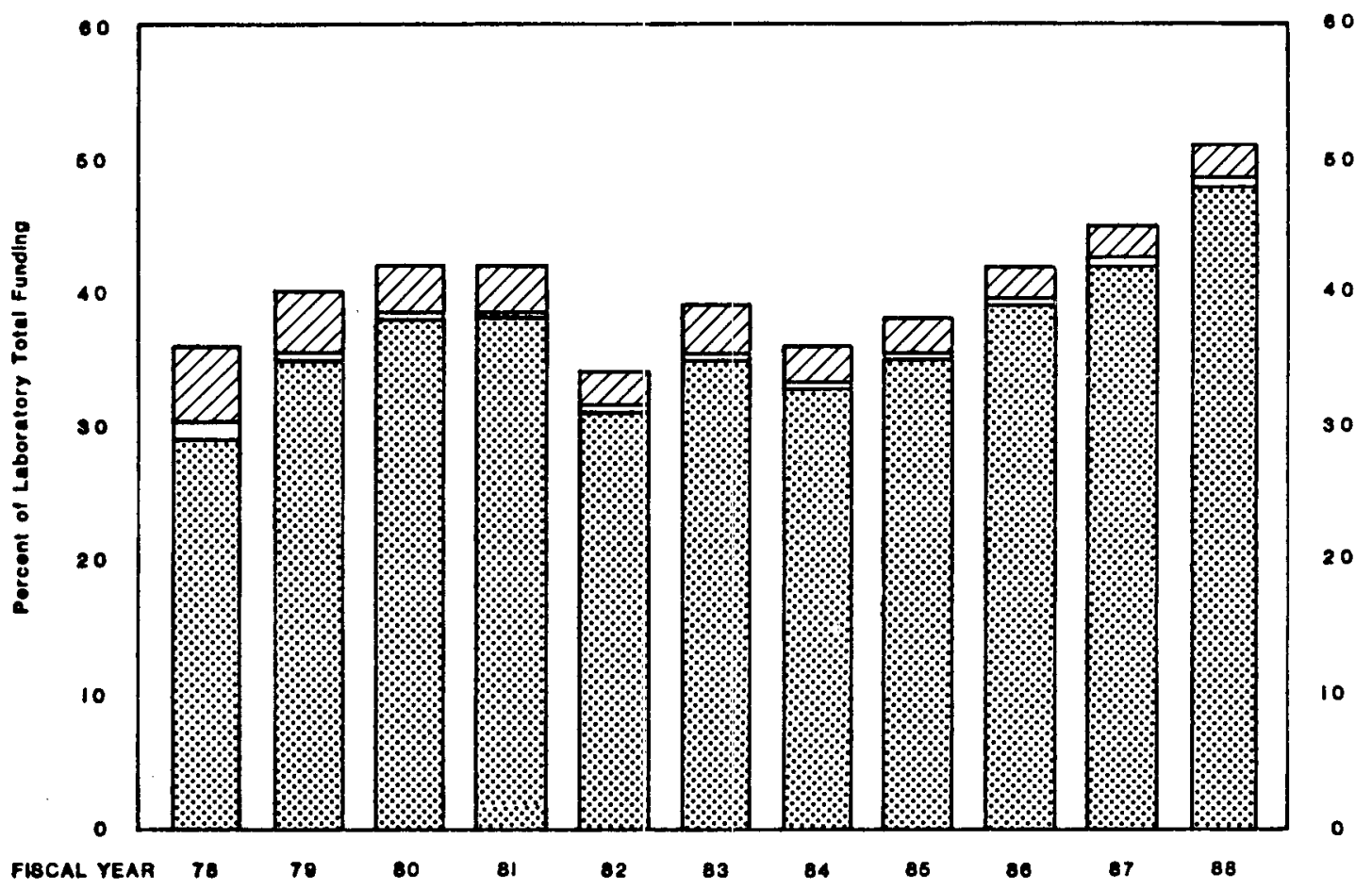

0

\begin{tabular}{|c|c|c|c|c|c|c|c|c|c|c|c|}
\hline $\begin{array}{l}\text { TRANSFER TO OTHER DOE } \\
\text { LABORATORIES } 1\end{array}$ & 6.7 & 42 & 3.8 & 4.0 & 2.6 & 3.0 & 2.6 & 2.6 & 2.7 & 2.7 & 2.7 \\
\hline $\begin{array}{l}\text { UNIVERSTYY SUACONTRACTS } \\
\text { \& PURCHASES 2 }\end{array}$ & 1.2 & .4 & .4 & 3 & .4 & .4 & .4 & .4 & $A$ & .5 & .6 \\
\hline $\begin{array}{c}\text { AL OTHER SUBCONTRACTS } \\
\text { \& PURCHASES } 3\end{array}$ & 28.3 & 34.8 & 37.8 & 37.6 & 31.2 & 35.4 & 32.5 & 35.4 & 38.5 & 41.8 & 47.7 \\
\hline
\end{tabular}

\begin{tabular}{|c|c|c|c|c|c|c|c|c|c|c|c|}
\hline $\begin{array}{l}\text { TOTAL LAB. FUNUING BA } \\
\text { (MILLIONS) }\end{array}$ & 368.5 & 367.6 & 378.0 & 428.8 & 878.7 & 562.4 & 871.2 & 660.3 & 680.3 & 658.8 & 648.0 \\
\hline
\end{tabular}

1) TRANSFERS THAT REPRESENT DOE FUNDING TO THE LABORATORY THAT WILL BE USED TO REIMBURSE ANOTHER DOE CONTRACTOR FOR WORI: DONE

2' TOTAL FUNDING FOR PROCUREMENTS AND SUBCONTRACTS TO UNIVERSITIES

3/ ALl OUTSIDE TRANSFERS, SUBCONTRACTS, AND PURCHASES, INCLUDING CONSTRUCTION (WITHDRAWALS FROM STOCK INCLUDED IN OVERHEAD OR INDIRECTLY CHARGED SHOULD NOT BE INCLUDED.)

Fig. VII-1. Procurements, subcontracts, and Transfers 
Los Al amos

B. Laboratory User Facility Participation

Los Alamos has made a major commitment to a broad range of scientific collaboration with universities and industry and backs that commitment by providing access to many of its facilities, both designated users' facilities and others available on a noninterference basis. Descriptions of 30 such facilities, with arrangements and contacts, are available to potential users.

The major dedicated users' facility in FY 1982 was the Los Alamos Meson Physics Facility (LAMPF). Most all experiments are collaborative efforts between Laboratory staff and experimentalists from other institutions, primarily universities. For this reason, we cannot accurately apportion the relative use by outside participants, although the numbers of experimental personnel given below provide a crude measure.

Experimenter Personne1

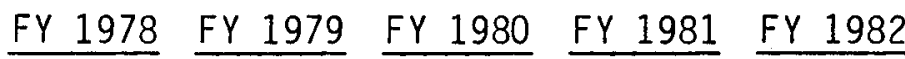

Los Al amos

Other (mostly university)
100

289

18.8
131

242
123

319
128

314

23.2
102

346

26.3

Operating Budget ( $\$$ M)

21.0

22.8

23.2

C. University-Laboratory Programs

The Laboratory develops and maintains relationships with approximately 335 universities and colleges and encourages research of mutual benefit to the Laboratory, the universities and colleges, and the individuals involved. Approximately 140 guest scientists, 40 alien guest scientists, 530 visiting scientists, 370 short-term visiting staff members, 15 panel members, and a variable number of consultants participate in a variety of programs annually. Additionally, the Laboratory sponsors approximately 80 postdoctoral appointees annually.

D. Minority Institution-Laboratory Programs

The Laboratory actively supports the Graduate Minorities in Engineering (GEM) Program and sponsors a variety of special outreach programs principally oriented toward training and development. The special programs foster an acquaintance with the Laboratory as it relates to the local geographic area and local universities. Various programs also support other broad social purposes, such as opportunities for disadvantaged persons.

Special employee programs include the Machinist Apprenticeship Program, Skills Training Employment Program, Undergraduate Co-op Program, Summer Undergraduate Student and Graduate Research Assistant Programs, the Associated Western Universities Program, and Long-Term Visiting Staff Members. 
Los Alamos

Typical of the approximately 10 universities and other organizations that participate with the Laboratory in these programs are the National Consortium for Graduate Degrees for Minorities in Engineering, the University of New Mexico, New Mexico State University, the New Mexico Institute of Mining \& Technology, and Eastern New Mexico University. The Laboratory High School Student Honors Program, Undergraduate Student program, and others also feature interaction with local high schools and vocational schools.

\section{E. Industry-Laboratory Programs}

Los Alamos seeks to interact with industry both to help ensure that the U.S. economy can take full advantage of Laboratory technology and to strengthen its internal scientific and technical expertise and its applied programs. These interactions can take many forms ranging from strictly informal to contractual relationships.

In recognition of the potential importance of Laboratory-industry interactions, a Director-appointed committee operated during FY 1982 to recommend policy and initiatives.

We are happy to arrange visits for company representatives for either general or focused exposure to Laboratory technology and programs. When industry identifies specific technologies or expertise of interest, the transfer process can include written communications, meetings, workshops, or extended visits to Los Alamos.

Staff assignments or exchanges are of particular interest to Los Alamos. Under the Industrial Staff Member Program, industry staff can work at the Laboratory for typically one to two years to gain hands-on knowledge in specific technical areas. The DOE has recently approved a Laboratory-industry staff exchange program for Los Alamos. Under this program, staff can be exchanged on a general quid pro quo basis, not necessarily in the same technical area. Each organization bears the full cost of its employee's salary, etc; intellectual property developed on an exchange assignment belongs to the organization where the work is done.

Technical collaborations have been undertaken with and without financial support flowing in either direction. These can include government-sponsored or industry-sponsored programs. We have worked with privately held firms, publicly traded companies, industry consortia, and industry trade associations.

Los Alamos cosponsored with Sandia National Laboratories and the Federal Laboratory Consortium a major technical meeting, the Showcase for Technology, in 0ctober 1981. This was a major introduction of industry to the technology and programs of several Federāl laboratories and universities, attended by 250 industry representatives. Introductory visits to the Laboratory were conducted during FY 1982 for companies such as 3M, Combustion Engineering, Rohm 
and Haas, Gould, Gearhart Industries, and Hughes Aircraft. The Commercial Development Association sponsored a visit of representatives from 15 companies for two days of in-depth presentations and discussions.

Technical collaborations with industry are under way in areas such as multiphase fluid-flow system modeling; combustion modeling; hot rock geothermal energy; a nucleic acid sequence (DNA) data bank; radiation-detection instrumentation. In addition to these outstanding programs, there are countless informal interactions between Laboratory staff and industry.

Special technology-transfer workshops are held occasionally in areas such as accelerator technology, personnel radiation dosimetry, solar energy, geothermal energy, and optics technology.

Future Plans: In recognition of the Laboratory's commitment to appropriate interactions with industry, several new or strengthened initiatives are under consideration. These include the newly approved Staff Exchange Programs, strengthened efforts to obtain partial or full industry support for new reimbursable programs, conduct of an inventory of Laboratory technology as a basis for broader interactions, work with trade associations and industry research consortia to develop interaction opportunities, and consideration of a program to encourage some Laboratory staff to move into industry as a means of direct technology transfer. 


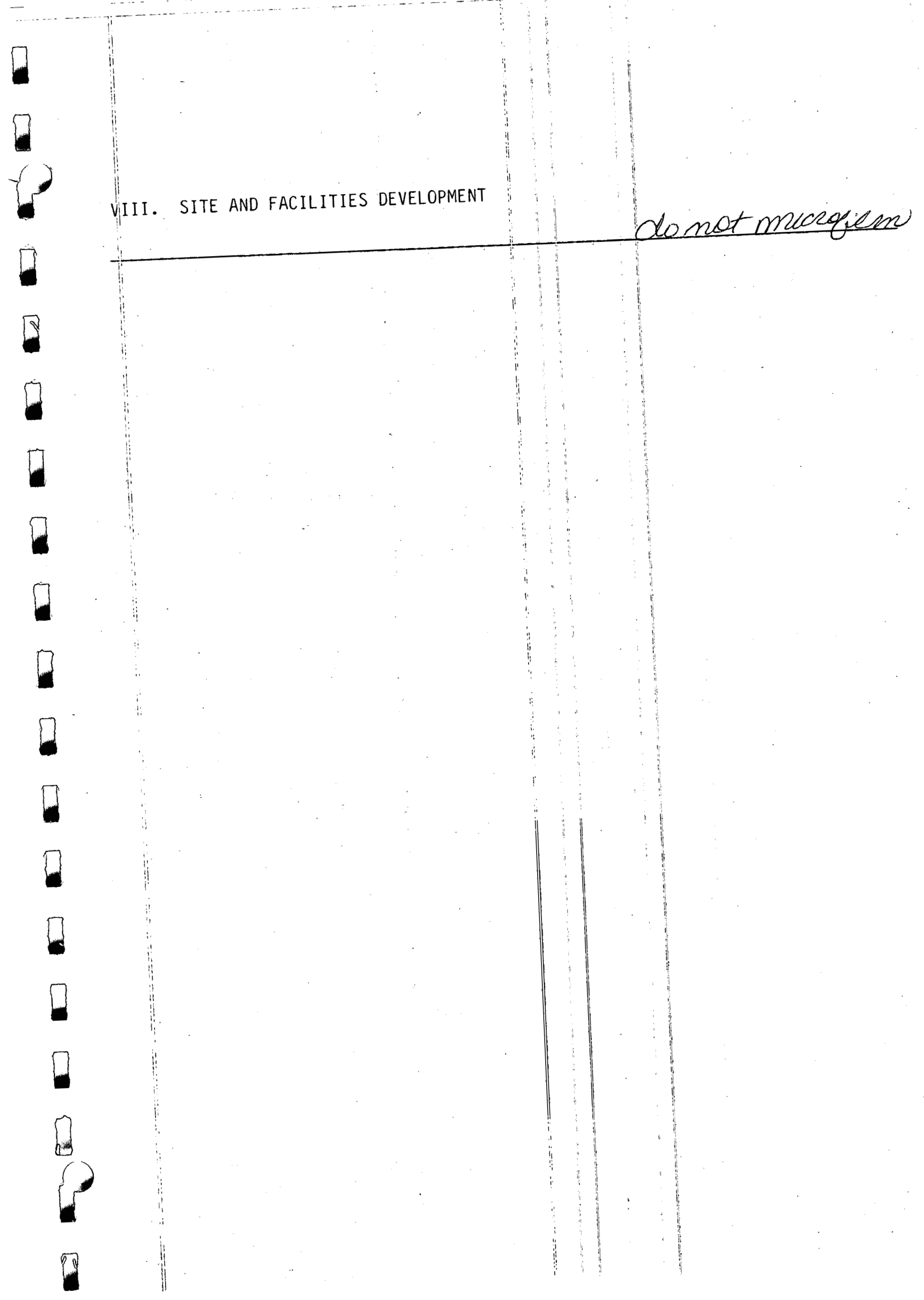




\section{SITE AND FACILITIES DEVELOPMENT}

\section{A. Laboratory Site and Facilities Devellopment}

Los Alamos National Laboratory was founded in 1943 and still has many facilities that were constructed in the early 1950s. Consequently, we need to replace and upgrade buildings and certain research tools and mechanical facilities. In many instances, the present arrangements limit the efficiency of the staff, inadequately satisfy or even impede experimental needs, and generate heavy costs for maintenance and utilities because of their obsolescence and their energy inefficiency. The modernization program begun in the FY 1979 budget continues in FY 1982, and we strongly support further efforts to strengthen it.

The Test Complex Revitalization and R\&D Revitalization programs are vitally needed by the Laboratory. In FY 1983 the space shortfall will exceed 300,000 square feet. This will require the Laboratory to continue to utilize temporary and leased space.

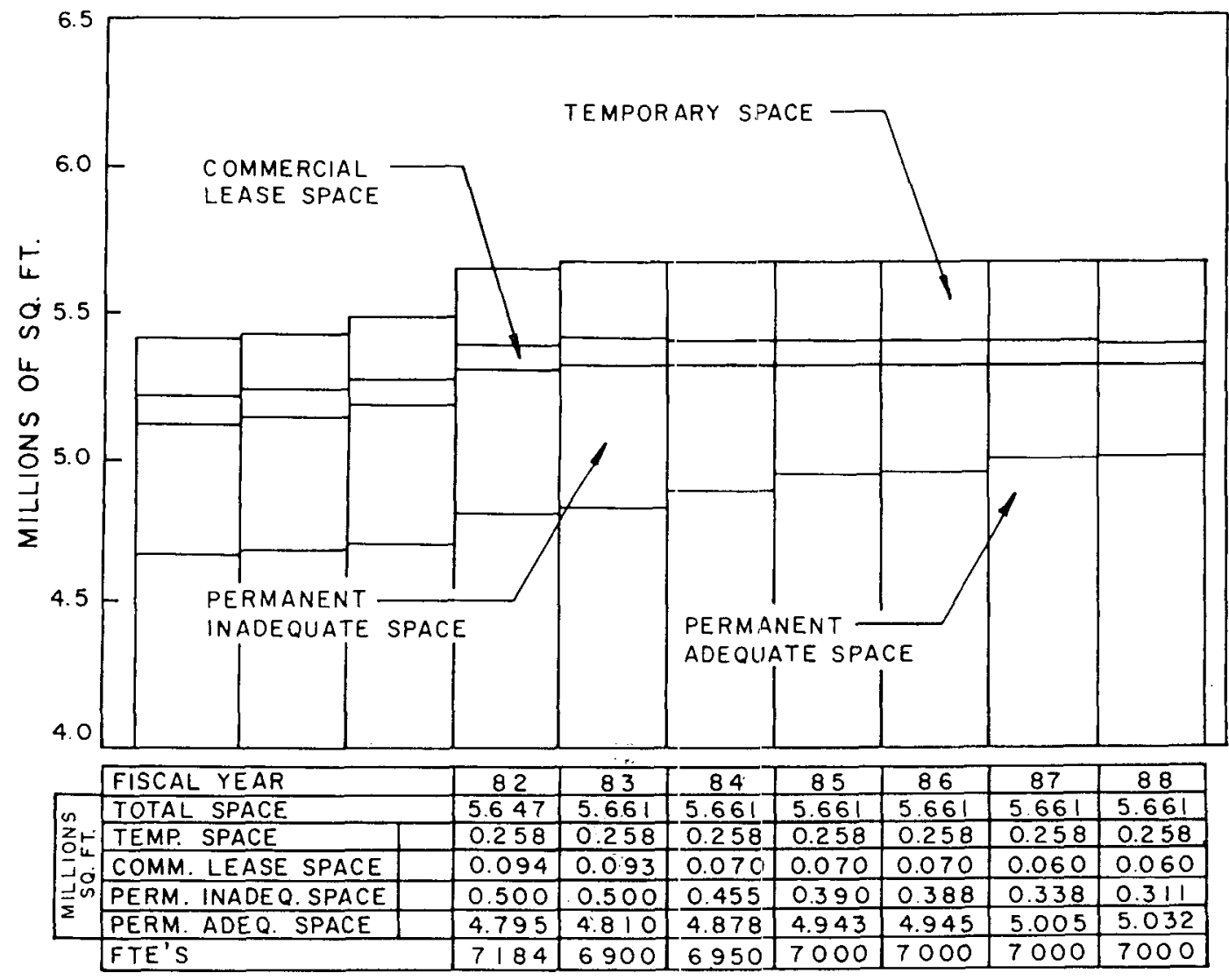

Fig. VIII-1. Laboratory and Office Space. 
The Long-Range Site Development Plan will be used as a guide by the Laboratory in its future development.

Requested construction projects are summarized in Fig. VIII-2 and Table VIII-1. In view of the limited number of construction projects approved by DOE in recent years, our most urgent facilities needs have moved forward into FY 1985 and beyond. To meet these needs, the level of approximately 50 to 100 million dollars per year should be maintained.

\section{LINE ITEM CONSTRUCTION PROJECTS}

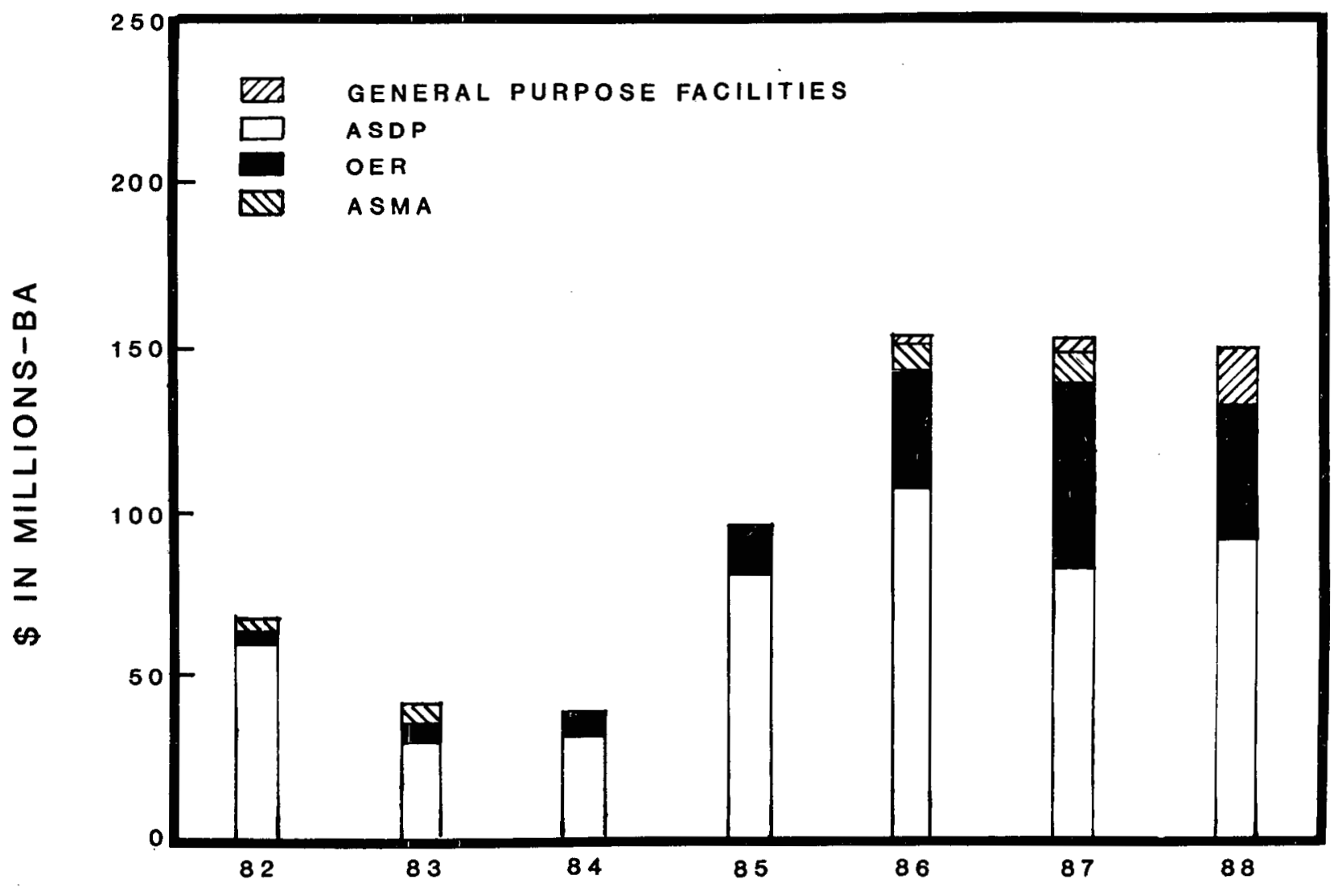

FISCAL YEAR

Fig. VIII-2. Construction Projects 
TABLE VIII - I

MAJOR CONSTRUCTION PROJECTS

Funded Construction ( $\$$ in millions)

$\frac{F Y 1982}{B A} \quad \frac{F Y 1983}{B A} \quad \frac{F Y 1984}{B A} \quad \frac{F Y 1985}{B A} \quad \frac{F Y 1986}{B A} \quad \frac{F Y 1987}{B A} \quad \frac{F Y 1988}{B A} \quad \frac{T E C}{B A}$

ASDP

\begin{tabular}{l} 
GB-01 - Weapons R\&D Activities \\
\hline Proton Storage Ring \\
Upgrading Indus Waste Treat Plants \\
Water Systems Upgräde \\
New Tritium Facility \\
New Detonator Facility \\
Collection System Improvements
\end{tabular}

$$
\text { Subtotal GB-01 }
$$

GB-02 - Inertial Conf inement Fusion High-Energy Gas Laser Fac (Antares) Target Fabrication Facility

$$
\text { Subtotal GB-02 }
$$

$$
\text { TOTAL ASDP }
$$

$\frac{\text { GR-03 - Production and Surveillance }}{\text { Equip/Utility Restoration FY81 }}$ Equip/Utility Restoration FY81
Equip/Utility Restoration FY82

$\underline{O E R}$

$$
\text { Subtotal GB-03 }
$$

$\underline{K B-01 \text { - Nuclear Physics }}$

Accelerator Improvements

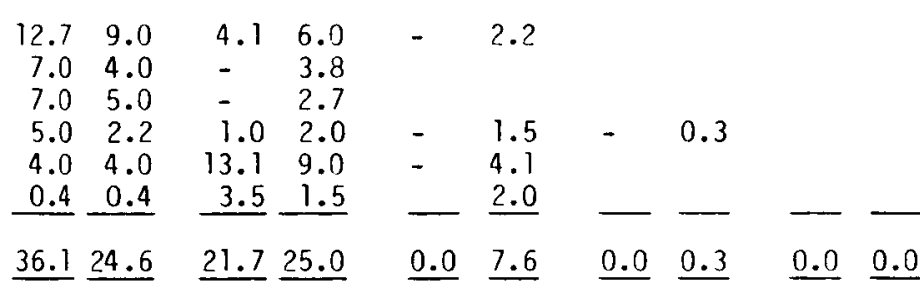

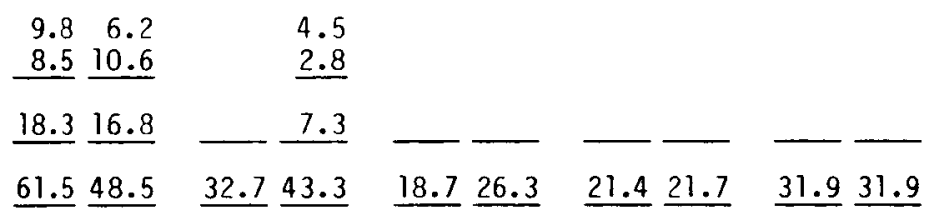

62.5

$\underline{15.3}$

77.8

$\underline{252.1}$

$\begin{array}{ll}1.4 & 1.4 \\ 5.7 & 5.7\end{array}$

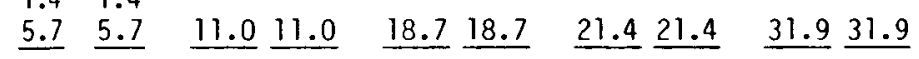

7.9

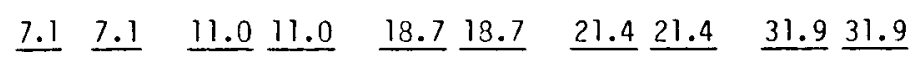

$\underline{88.7}$

$\underline{96.6}$

$\begin{array}{ll}0.7 & 0.7\end{array}$

ASNE

$$
\text { AW-AIST }
$$

AW-00 Isotopes R\&D Lab

\section{ADMINISTRATION}

WB-00 - In-House Energy Management High-Temperature Water Distribution System Energy Conservation Retrofit 
TABLE VIII-1 (continued)

Budgeted Construction ( $\$$ in millions)

$\underline{\text { OER }}$

KB-01 - Nuclear Physics Accelerator Improvements

KC-00 - Basic Energy Sciences

Improvements to Weapons Neutron Res. Facility

TOTAL BUDGETED
$\begin{array}{llll}0.2 & 0.1 \quad-\quad 0.1\end{array}$

0.2

$\underline{2.7} \quad \underline{2.7}$

2.7

$2.9 \quad 2.8$

0.1 \begin{tabular}{lrlll}
$F Y$ & 1987 & $F Y$ & 1988 \\
\hline$B A$ & $B O$ & BA & $B O$
\end{tabular}

$\frac{F Y 1986}{B A}$ 
TADLE VIII-i (́CONLINUEd)

Proposed Construction ( $\$$ in millions)

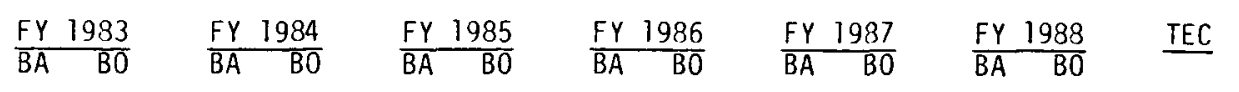

$\underline{A S D P}$

GB-01 - Weapons Activities

Adv. Radio. Chem. Wpns. Diag. Fac

TEST Fabrication Fac. (Phase 1)

Dual Axis Radio. Hydro Fac.

Nuclear Mat. Storage Facility

$X$-Ray Calibration Cap. Upgr.

Central Guard Fac.

Salt Facility Upgrade

TA-55 Control Room Upgrade

Compressed Gas Fac. Reloc.

Device Fabrication Facility

Laboratory Communications Center

Materials Science Laboratory

Weapons Design Engng. Complex

High-Energy Radiographic Fac.

Explosives Physics Exp. Fac.

WNR Office/Laboratory BIdg.

Test Fabrication Fac. (Phase 2)

Safeguards \& Security Upgrade

Health Inst. \& Meas. Fac.

Utility Operations Center

Hyper-Vel Impact Fac.

Antares Upgrade Project

Weapons Subsystem Laboratory

Weapons Chem \& Rad Chem R\&D Lab

Relocate Salvage \& Road Operations

Sanitary Landfill

Safeguards \& Security Upgrade II

Equipment Service Facility

Supply \& Dist. Warehouse Reloc.

Subtotal GB-01

GE-02 - Materials Production

Site Preparation SNM Complex

GD-00 - Nuclear Mat'ls S\&S

Nuclear Safeguards Technology Lab

TOTAL ASDP

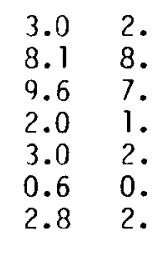

$\begin{array}{lll}2.0 & 5.1 & 6.1 \\ 8.1 & & \\ 7.2 & 15.3 & 17.7 \\ 1.6 & 18.0 & 16.5\end{array}$

$3.0 \quad 3.0$

$\begin{array}{lll}2.5 & 2.0-0.5\end{array}$

$\begin{array}{llll}9.0 & 8.0 & 35.0 & 22.0\end{array}$

$\begin{array}{lll}8.0 & 4.5 & 25.0 \\ 14.5 & 3.0 & 29.0\end{array}$

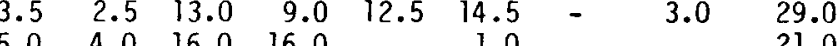

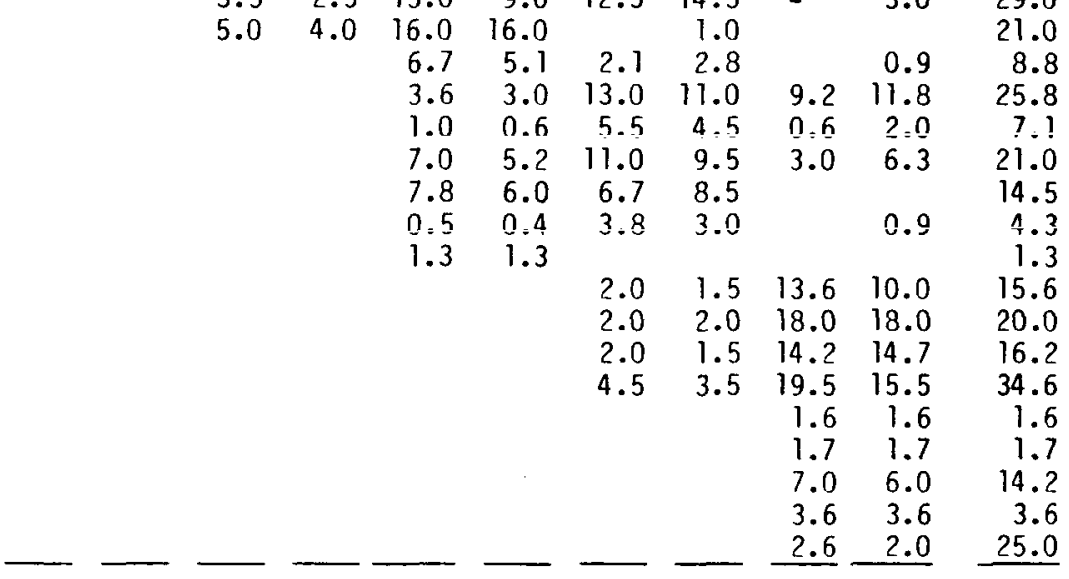

$\begin{array}{lllllllllll}29.1 & 24.9 & 71.0 & 67.6 & 107.3 & 82.4 & 72.1 & 86.0 & 94.6 & 102.5 & 414.3\end{array}$

$\begin{array}{lllllll} & & 1.0 & 1.0 & 9.0 & 9.0 & 10.0 \\ 5.6 & 1.0 & 6.6 & 5.3 & & 5.9 & 12.2\end{array}$


$\underline{\text { OER }}$

\section{AT-00 - Magnetic Fusion}

Motor Generator Set Facility

ZT-40 Upgrade Experiment

Engineering Building

Lab/Office Building

Reversed Field Pinch (RFP)

\section{Subtotal AT}

\section{KB-01 - Nuclear Physics}

Accelerator Improvements

Engineering Support Building

Subtotal KB

HA-02 - Health and Environmental Research -

\section{Biological and Environmental Research}

Toxic Chemical Containment Facility

Biomedical Research Facility

$$
\text { Subtotal HA }
$$

\section{General Purpose Facilities \\ CMR Building Upgrade \\ Road Improvements}

Electronics Lab/office

Subtotal GPF

TOTAL OER

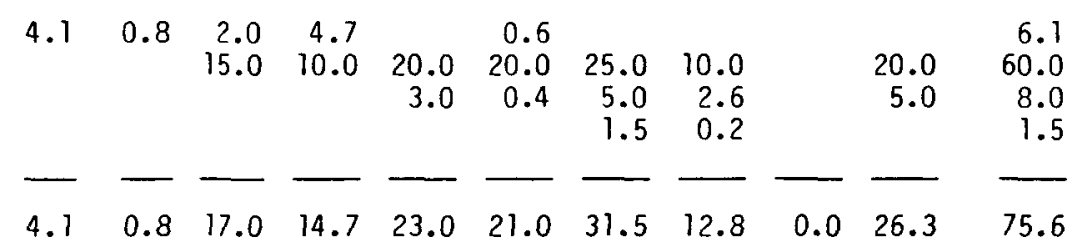

$\begin{array}{llllllllllll}0.7 & 1.0 & 0.7 & 0.7 & 0.7 & 0.7 & 0.7 & 0.7 & 0.7 & 0.7 & 3.5 \\ - & - & - & - & 3.1 & \underline{0.5} & - & \underline{2.6} & - & - & - & \end{array}$

$\begin{array}{lllllllllll}0.7 & 1.0 & 0.7 & 0.7 & 3.8 & 1.2 & 0.7 & 3.3 & 0.7 & 0.7 & 6.6\end{array}$

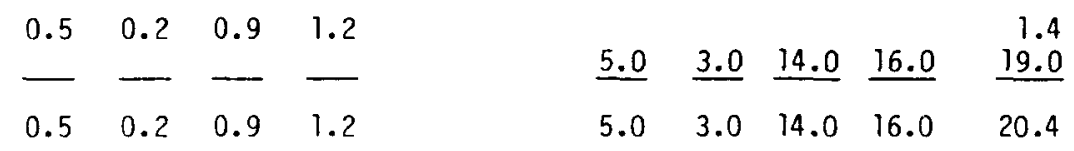

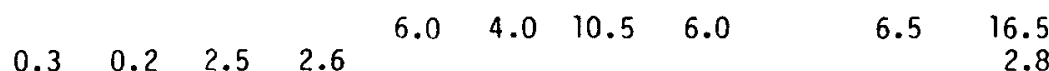

\begin{tabular}{llllllllll}
$0.3 \quad 0.2$ & 2.5 & 2.6 & - & - & -7.5 & 0.8 & 6.7 & 7.5 \\
\hline & - & - & - & - &
\end{tabular}

$\begin{array}{llllllllllll}0.3 & \underline{0.2} & 2.5 & \underline{2.6} & 6.0 & 4.0 & 18.0 & 6.8 & - & 13.2 & 26.8\end{array}$

$\begin{array}{lllllllllll}5.6 & 2.2 & 21.1 & 19.2 & 52.8 & 26.2 & 55.2 & 25.9 & 14.7 & 56.2 & 129.4\end{array}$ 
TABLE VIII-1 (cont inued)

Proposed Construction (\$ in millions)

ASMA

WB-00 - In-House Energy Management

Energy Monitoring and Control Sys.

Sigma Building Heat Recovery

Energy Management

TOTAL ASMA

TOTAL PROPOSED

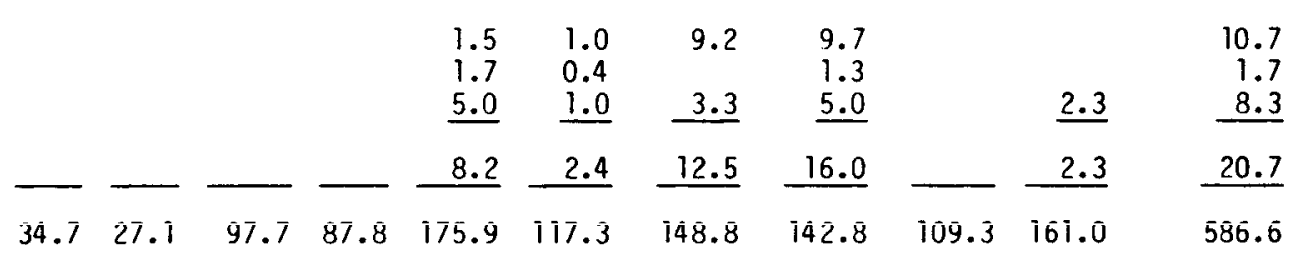


Los Alamos

B. Multiprogram General Purpose Facilities

The Laboratory has a need for facilities in this funding category. The identified needs have been selected as those considered to be the most urgent of the general purpose projects.

\section{Proposed Construction}

CMR Building Upgrade (TEC \$16.5 M, FY86): Enhanced air filtration and replacement of vital existing building services (such as chilled water) that are no longer adequate. Other approaches are also being considered.

The CMR Building (largest single laboratory facility at Los Alamos) is nearly 30 years old. Many services are no longer adequate to meet the demands of changing program needs and to meet current codes and standards. Failure to fund this project during the planning period will result in continued operations in a substandard facility.

Road Improvements (TEC \$2.8 M, FY84): Reconstruction, widening, and upgrading of arterial roads and intersections along the spine of the Laboratory where $75 \%$ of its working population is located.

The rugged topography of alternating mesas and canyons limits traffic circulation to a few major arterial roads, the majority of which were constructed 30 to 35 years ago. Although the roads have been maintained, there are major design deficiencies which no maintenance program is capable of correcting. This project will correct current congestion and safety problems by constructing additional turning lanes, by selective road widening, by adding more lanes, by providing pedestrian/bicycle sidewalks and paths to reduce conflicts with motor vehicles, and by improving intersection capacities in accordance with the long-range plan. Funding during the planning period will permit orderly upgrading of the road system.

Electronics Laboratory/0ffice (TEC \$7.5 M, FY87): 30,000 square feet of offices and electronics laboratories for approximately 150 engineers and support personnel (centralization of electronic engineering support and R\&D functions -- enhancement of the total effort by providing efficiencies that cannot be realized with scattered activities).

Until funded, operations must continue to be carried out under less than satisfactory conditions.

C. General Plant Projects

The issue of General Purpose Plant (GPP) funding is an important aspect of facilities management because it is used for both major repairs as well as minor improvements. The demand for the latter is higher at sites engaged in 
research because of the need for frequent space reconfigurations and utility changes to accommodate changing program needs. Underfunding in this area results in the consumption of the capital plant through the uneconomical deferral of repairs, which ultimately results in the requirement for major replacements later. At the same time a lack of GPP funding can prevent space and utilities from being improved in a timely manner to keep pace with program requirements, thus reducing the capabilities and efficiency of operations. We have a need for increased funding support in this area. Our requests for projects in this funding category for F' 1983 were over $\$ 20 \mathrm{M}$.

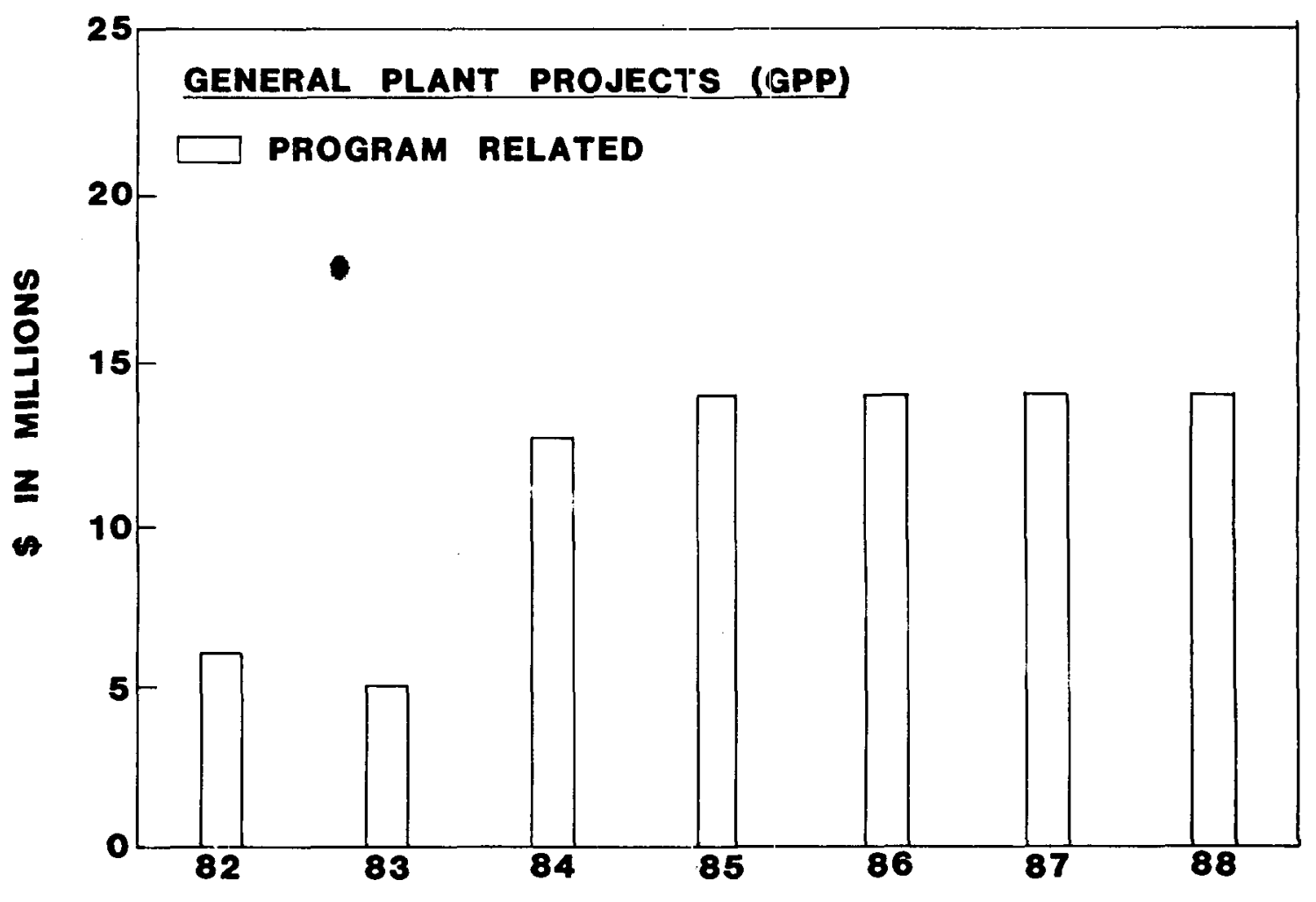

FISCAL YEAR

Fig. VIII-3. General Plant Projects (GPP) 
( $\$$ in millions)

$\underline{A S D P}$

$A R-O A$ - Defense Waste Management

$G B-01$ - Weapons Activities

GD-00 - Nuclear Materials S\&S

GE-03 - Materials Production

Subtotal ASOP

$\begin{array}{ll}0.5 & 0.3 \\ 6.2 & 4.0 \\ \underline{0.6} & - \\ \underline{7.3} & \underline{4.3}\end{array}$

1.0
6.9
1.1
0.5

1.0

9.0
1.1

1.1
0.2

$\underline{9.5}$

11.3

9.0
1.1

\begin{tabular}{l}
1.1 \\
0.2 \\
\hline
\end{tabular}

9.0
1.1
0.2

1.0

1.1

\begin{tabular}{l}
1.1 \\
0.2 \\
\hline
\end{tabular}

$\underline{7.3}$

0.2
0.5
0.7
-
1.4

\begin{tabular}{ll}
0.5 & 1.1 \\
0.2 & 0.8 \\
- & 0.6 \\
$\underline{0.7}$ & $\underline{0.3}$ \\
\hline
\end{tabular}

\begin{tabular}{l}
1.1 \\
0.8 \\
0.6 \\
0.3 \\
\hline 2.8 \\
\hline
\end{tabular}

17.3

11.3

11.3

OER

AT-20 - Magnetic Fusion

HA-02 - Environ. R\&D/LSR

KB-01 - Nuclear Physics

other ER

Subtotal OER

NE

$A W-00$ - Is otopes R\&D

0.2

TOTAL GPP REQUIREMENTS

\begin{tabular}{|c|c|c|c|c|c|c|}
\hline 8.9 & 5.0 & 12.6 & 14.1 & 14.1 & $14.1^{\prime}$ & 14.1 \\
\hline
\end{tabular}

aGPP requirements are based on estimated funding support through FY 1983 and comparable requirements thereafter, with all figures expressed in constant dollars without adjustment for escalation. FY 1982 figures include BA reallocated from the prior year. 


\section{Facility Maintenance}

The facility maintenance activity in FY 1982 has decreased slightly since FY 1979. Custodial support for FY 1982 has decreased $6 \%$ from FY 1979. While the reduced maintenance funds have little, if any, adverse effect on the overall operation of the Laboratory, this situation has caused the backlog of "must do" maintenance to grow substantially. Some Buildings, Roads and Grounds Maintenance funds have been diverted into the electrical and mechanical maintenance programs to keep critical systems operational. Appearance items such as painting, floor, and grounds have received little attention.

The planned restoration of maintenance funds in FY 1984 will bring the Laboratory maintenance effort to an acceptable level.

\section{E. Utility Costs}

Costs are escalated annually to FY 1984 and are constant FY 1984 dollars through FY 1988 with one exception. Natural gas costs have been escalated through FY 1985 to reflect the abnormality of deregulation of natural gas, which will occur January 1, 1985. In order to minimize the cost increase to the consumer in 1985, the Federal Energy Riegulatory Commission is planning to administratively allow increases in the selling price of natural gas prior to the legislative deregulation occurring in 1985 and this is also reflected in this estimate. Energy conservation measures will contribute to holding the rate of increase in electricity use to approximately two percent per year. Natural gas consumption for power generation was drastically reduced from $F Y$ 1978 through FY 1981 time frame by refinement of procedures as a result of the Time of Day Study in FY 1977. Although there was an increase in FY 1982, continued benefits from this study and energy conservation efforts are projected to hold level the consumption of natural gas through FY 1988 . Los Alamos will continue to purchase low-cost hydroelectric power from the Colorado River Storage Project to the maximum extent possible. Purchase of surplus power at favorable rates frorn Public Service Company of New Mexico will also be made when it is econonically feasible. Despite cost saving measures, the cost of both electricity and natural gas will continue to increase significantly through FY 1988. As a percent of the total Laboratory operating funds, electricity costs will rise from 3.0 percent in FY 1982 to 4.5 percent in FY 1988. Fuel (natural gas) costs will rise from 1.7 percent in FY 1982 to 2.5 percent in FY 1985 where they will stabilize in constant dollars through FY 1988. Essentially all operating programs will be impacted by these utility cost increases. 


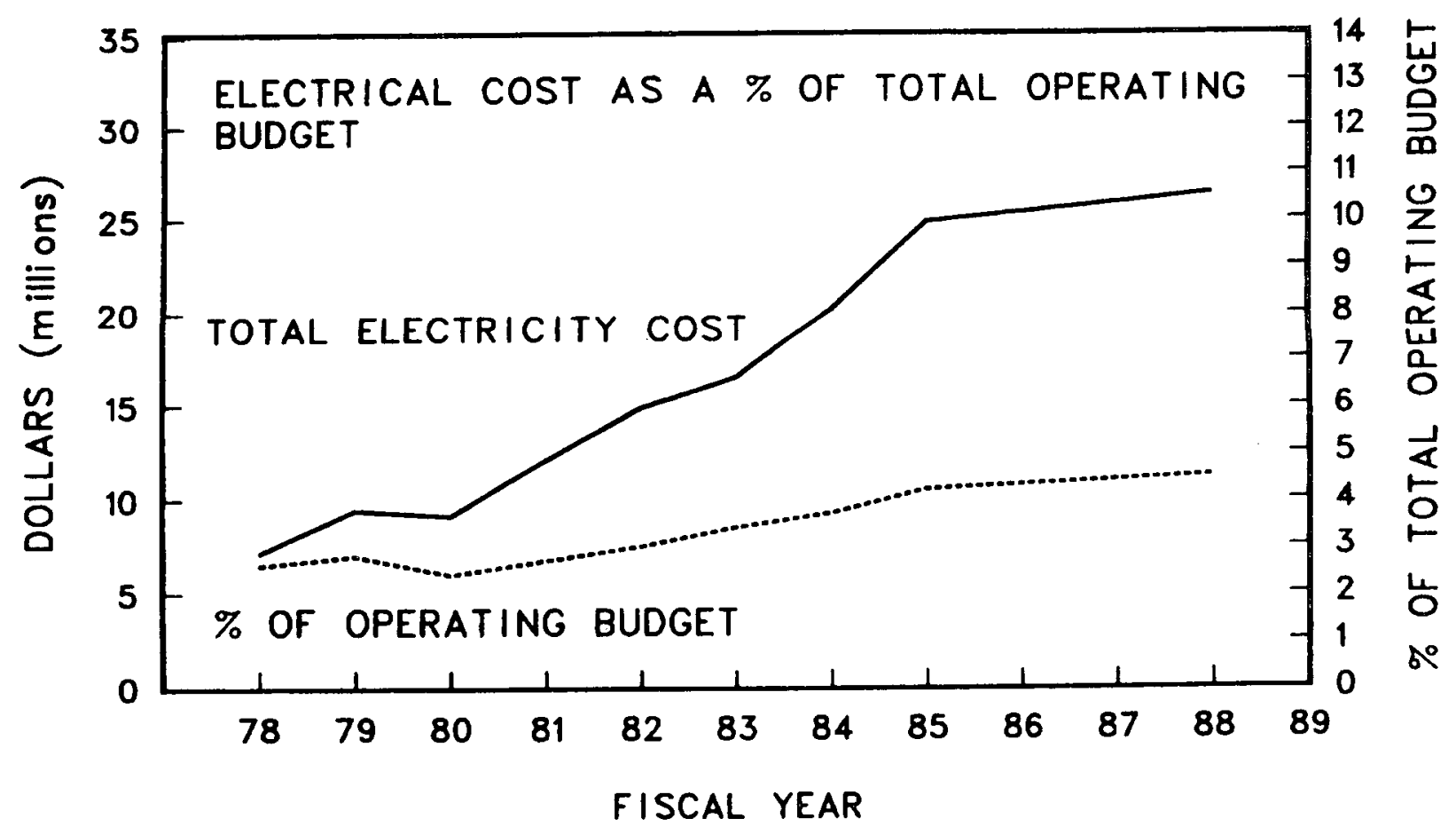

NOTE: Includes natural gas used in generating electricity

Fig. VIII-4. Utilities Cost-Electrical 
TÁBLLE VIIII-3

UTILITY AND FUEL COST AND CONSUMPTION DATA

$$
(\$ 000)^{(1)}
$$

Electricity Costs

\begin{tabular}{|c|c|c|c|c|c|c|c|c|}
\hline \multirow[b]{2}{*}{ Year } & \multicolumn{3}{|c|}{ Lrechilliby coses } & \multirow[b]{2}{*}{$\begin{array}{c}\% \text { of } \\
\text { Oper } \\
\text { Budget }\end{array}$} & \multirow[b]{2}{*}{$\begin{array}{l}\text { Usage (2) } \\
\text { GWH } \\
\end{array}$} & \multicolumn{3}{|c|}{ ruet cosls } \\
\hline & $\mathrm{KW}$ & $\mathrm{KWH}$ & TOTAL & & & Natural Gas & $\begin{array}{r}\% \text { of } \\
\text { Oper } \\
\text { Budget }\end{array}$ & $\begin{array}{c}\text { Usage } \\
\text { Billions } \\
\text { Cubic Feet } \\
\end{array}$ \\
\hline 1978 & 3,147 & 4,009 & 7,156 & 2.6 & 290.6 & 5,059 & 1.8 & 3.00 \\
\hline 1979 & 4,150 & 5,284 & 9,434 & 2.8 & 315.4 & $5,77 y$ & 1.8 & 2.82 \\
\hline 1980 & 4,018 & 5,117 & 9,135 & 2.4 & 305.4 & 6,205 & 1.7 & 2.62 \\
\hline 1981 & 5,752 & 6,349 & 12,101 & 2.7 & 308.6 & 7,042 & 1.6 & 2.33 \\
\hline 1982 & 6,894 & 7,352 & 14,851 & 3.0 & 317.8 & 8,562 & 1.7 & 2.48 \\
\hline 1983 & 7,352 & 9,131 & 16,483 & 3.3 & 331.4 & 10,275 & 2.1 & $2.45^{(5)}$ \\
\hline 1984 & 9,047 & 11,112 & 20,159 & 3.6 & 334.5 & 12,330 & 2.2 & 2.45 \\
\hline 1985 & 11,254 & 13,533 & $24,797^{(4)}$ & 4.2 & 337.6 & $14,796^{(4)}$ & 2.5 & 2.45 \\
\hline 1986 & 11,489 & 13,804 & 25,293 & 4.3 & 344.4 & 14,796 & 2.5 & 2.45 \\
\hline 1987 & 11,719 & 14,080 & 25,799 & 4.4 & 351.3 & 14,796 & 2.5 & 2.45 \\
\hline 1988 & 11,953 & 14,362 & 26,315 & 4.5 & 358.3 & 14,796 & 2.5 & 2.45 \\
\hline
\end{tabular}

(1) Constant FY $1984 \$$ used for FY 1985 through FY 1988. [See (4) for exception.]

(2) Energy/usage is not linear in relationship to either demand cost or total electricity costs. Therefore, total energy consumption is provided.

(3) Total cost of natural gas includes cost and quantity of natural gas used in generation of electricity. [NOTE: Fuel costs and electricity costs are not additive due to partial duplication of costs.]

Е (4) Natural Gas cost escalated through FY 1985 to reflect impact of deregulation occurring January 1 , 1985. 券

(5) Natural Gas consumption for power generation was drastically reduced in the FY 1978 through FY 1981 time frame by refinement of procedures as a result of the Time of Day Study. 
Los Alamos

F. Automatic Data Processing Requirements

The Laboratory's historic emphasis on computing is motivated primarily by the needs of national defense, energy, and basic research programs. Starting at the birth of electronic computation shortly after World War II, Los Alamos has operated one of the world's largest computing facilities and continues to be at the forefront of scientific computing. Defense programs are the heaviest users of the total computing resources (see Fig. VIII-5). DOE and DoD programs gain important military, technical, and economic advantages by providing supercomputers to the Los Alamos scientists and engineers. These advantages include

- the development of superior quality products for the DOE and DOD,

- the ability to perform advanced development and research projects that could not otherwise be attempted,

- significant reductions in the development costs of these products, and

- significant reductions in the time needed to develop these products.

If the nuclear weapons currently under development are compared with those of 10 years ago, it is clear that modern weapons technology is far superior in terms of meeting today's national defense needs. A large share of this advance is due to the steady improvement in the capabilities of the computing resources available to weapons designers. Ultimately, it is the ability to model theoretically and to calculate accurately that determines the quality of our nuclear weapons stockpile. This, in turn, is governed by the quality and quantity of computing resources available. In a similar manner, computing is crucial not only to the Laboratory's defense programs but to virtually all of the Laboratory's R\&D programs.

The most powerful of the Laboratory's computers are four Cray Research, Inc., Cray-1 systems and four Control Data Corporation 7600 systems. These are located in the Central Computing Facility, which also houses a number of smaller computers and two supporting subsystems: the Common File System and the Print and Graphics Express Station.

Major weapons codes have been "vectorized" to adapt them to the specialpurpose architecture of the Cray-1s, and significant gains have been made in their performance, so that each $\mathrm{Cray}-1$ has an overali effectiveness of about four times that of a CDC 7600 .

All of the large Los Alamos computers are connected to an Integrated Computing Network that provides complete interactive and batch services to the 3,500 Laboratory computer users and allows rapid access to the computers while minimizing duplication of resources. The network is divided into three partitions: Secure, for classified computing; Administrative, for processing of sensitive data; and Open, for unclassified scientific and nonsensitive administrative activities. 
The power of the centralized major computers is supplemented by that of Digital Equipment Corporation VAX minicomputers that are installed at various Laboratory sites. These Distributed Processors are connected to the network and communicate with the central systems, data bases, and output equipment, as well as with other computers and people or the network.

Plans for the acquisition of computers and their necessary support and peripheral equipment are detailed in the Los Alamos input to the DOE ADP Long-Range Plan. Significant items in that plan are summarized in Table VIII-4, "Los Alamos National Laboratory Maijor ADP Leases and Purchases."

The table indicates that additional major scientific computers will be acquired in FY 1984 and FY 1986. The earlier one is identified as a Class VI/VII Computer, i.e., either another of the Cray-1 series or else a Class VII system. The latter term is used to describe a system that is, at the very least, four times as powerful as what we now have. The Laboratory's need for computing power is such that we could effectively apply a Class VII machine if one were available in the marketplace by FY 1984; however, if such is not the case, another Class VI system will be installed. The FY 1986 acquisition is identified as a Class VII Computer because it is generally assumed that such a system will have been introduced by that time.

Three of our four Cray-1s are litsted in Table VIII-4 because of expenditures, for lease or purchase, during the period covered by the table. The line item labelled Administrative Computers addresses the upgrade of obsolescent processors in the Administrative partition of the network.

Four items labelled Mass Storage Upgrade identify enhancements of the Laboratory's Common File System. This data storage facility serves the entire network; its capacity must grow as additional machines are installed, and its bandwidth must be increased to avoid degradation in the speed with which data can be accessed.

Another network resource that must keep pace with the growth in the number of machines is the Print and Graphics Express Station, which processes the printed and graphical output generated by the computers. Plans for its enhancement appear in the table as Output Station Upgrades.

The FY 1984 line item, Input/Output Station, describes a centralized data media-handling station to support the network in functions that involve magnetic tape, small disks, punch cards, and miscellaneous other storage media.

Interactive Graphics for Computer-Aided Design and Computer-Aided Manufacturing (CAD/CAM), a line item that appears in the FY 1984 through FY 1986 columns of the table, deals with equipment that will support conceptual and engineering design and manufacture of more complicated weapon components. 
Los Alamos

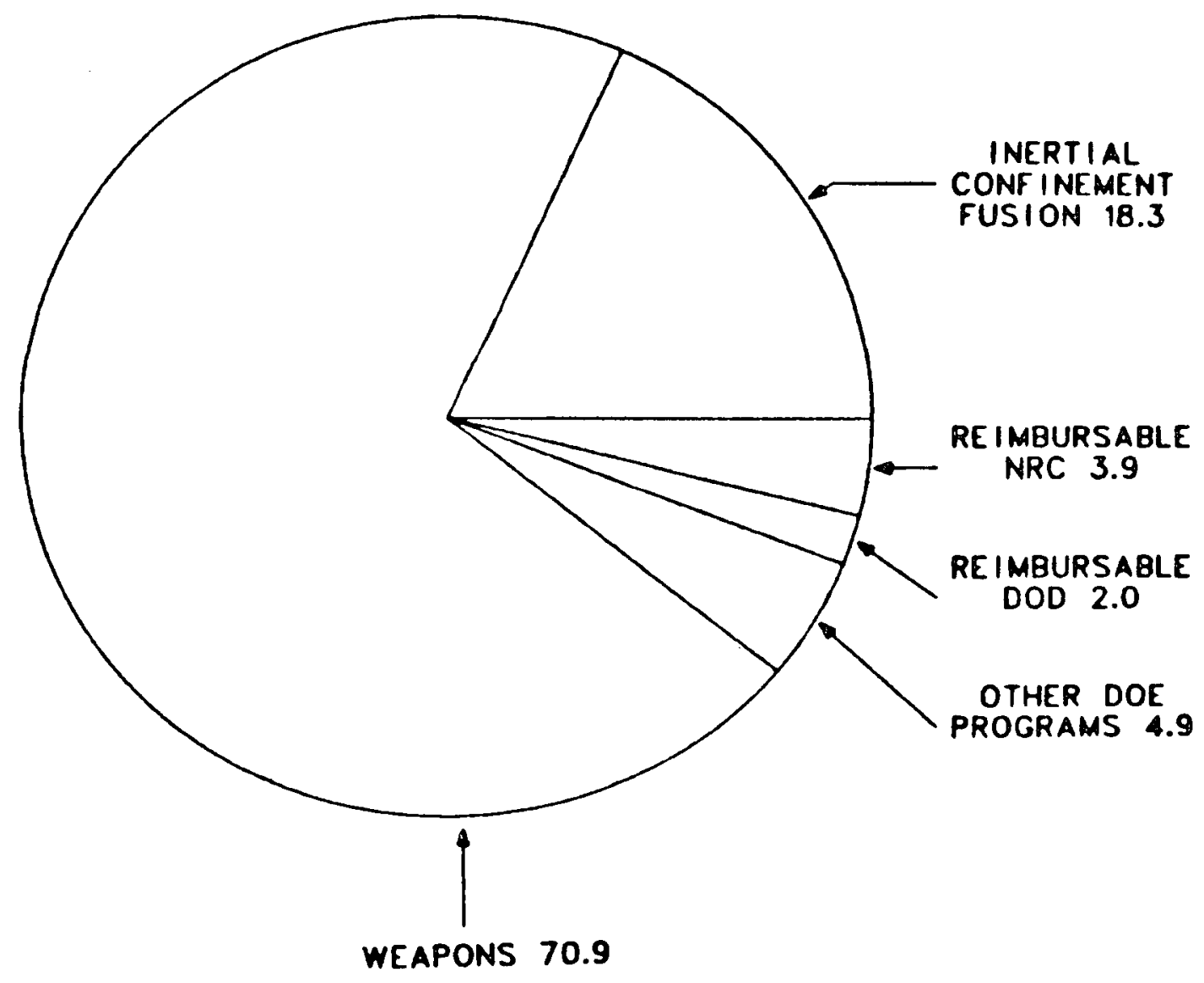

Fig. VIII-5. Percent of CCF computing by program FY 1982 
TABLE VIII -4

LOS ALAMOS NATIONAL LABORATORY MAJOR ADP LEASES AND PURCHASES

\begin{tabular}{|c|c|c|c|c|c|c|c|}
\hline & & FY 83 & FY 84 & FY 85 & FY 86 & FY 87 & FY 88 \\
\hline CRAY-1 (2nd) & $\begin{array}{l}\text { PURCHASE } \\
\text { (LEASE) }\end{array}$ & $\begin{array}{l}7500 \\
(500) \\
\end{array}$ & & & & & \\
\hline CRAY -1 (3rd) & (LEASE) & $(3400)$ & $(3400)$ & $(3400)$ & $(3400)$ & $(600)$ & \\
\hline CRAY -1 (4th) & (LEASE) & (2650) & $(3200)$ & $(3200)$ & (3200) & $(3200)$ & (550) \\
\hline $\begin{array}{l}\text { CLASS VI/VII } \\
\text { COMPUTER }\end{array}$ & $\begin{array}{l}\text { PURCHASE } \\
\text { (LEASE) }\end{array}$ & & $(2175)$ & $\begin{array}{l}13100 \\
(1090)\end{array}$ & & & \\
\hline $\begin{array}{l}\text { CLASS VII } \\
\text { COMPUTER (1st) }\end{array}$ & $\begin{array}{l}\text { PURCHASE } \\
\text { (LEASE) }\end{array}$ & & & & $(2300)$ & $(4500)$ & $\begin{array}{l}13500 \\
(1700) \\
\end{array}$ \\
\hline $\begin{array}{l}\text { CLASS VI I } \\
\text { COMPUTER (2nd) }\end{array}$ & (LEASE) & & & & & & $(2300)$ \\
\hline $\begin{array}{l}\text { ADMINISTRATIVE } \\
\text { COMPUTERS }\end{array}$ & $\begin{array}{l}\bar{P} \text { PUKCTHÁSE } \\
\text { (LEASE) }\end{array}$ & (185) & $(370)$ & $\begin{array}{l}710 \\
(95)\end{array}$ & & & \\
\hline $\begin{array}{l}\text { MASS STORAGE } \\
\text { UPGRADE (1st) }\end{array}$ & $\begin{array}{l}\text { PURCHASE } \\
\text { (LEASE) }\end{array}$ & $\begin{array}{l}290 \\
(40) \\
\end{array}$ & & & & & \\
\hline $\begin{array}{l}\text { MASS STORAGE } \\
\text { UPGRADE (2nd) }\end{array}$ & PURCHASE & & 1600 & & & & \\
\hline $\begin{array}{l}\text { MASS STORAGE } \\
\text { UPGRADE }(3 r d)\end{array}$ & PURCHASE & & & & & 3000 & \\
\hline $\begin{array}{l}\text { MASS STORAGE } \\
\text { UPGRADE (4th) }\end{array}$ & PURCHASE & & & & & & 1300 \\
\hline $\begin{array}{l}\text { ELECTRONIC SWAPPING } \\
\text { SYSTEM }\end{array}$ & PURCHASE & 1200 & & & & & \\
\hline $\begin{array}{l}\text { OUTPUT STATION } \\
\text { UPGRADE (1st) }\end{array}$ & PURCHASE & & & 1500 & & & \\
\hline $\begin{array}{l}\text { OUTPUT STAT ION } \\
\text { UPGRADE (2nd) }\end{array}$ & PURCHASE & & & & & & 1500 \\
\hline $\begin{array}{l}\text { INPUT/OUTPUT } \\
\text { STATION }\end{array}$ & PURCHASE & & 1000 & & & & \\
\hline $\begin{array}{l}\text { INTERACTAVE GRAPHICS } \\
\text { FOR CAD/CAM }\end{array}$ & PURCHASE & & 2500 & 5400 & 2900 & & \\
\hline
\end{tabular}




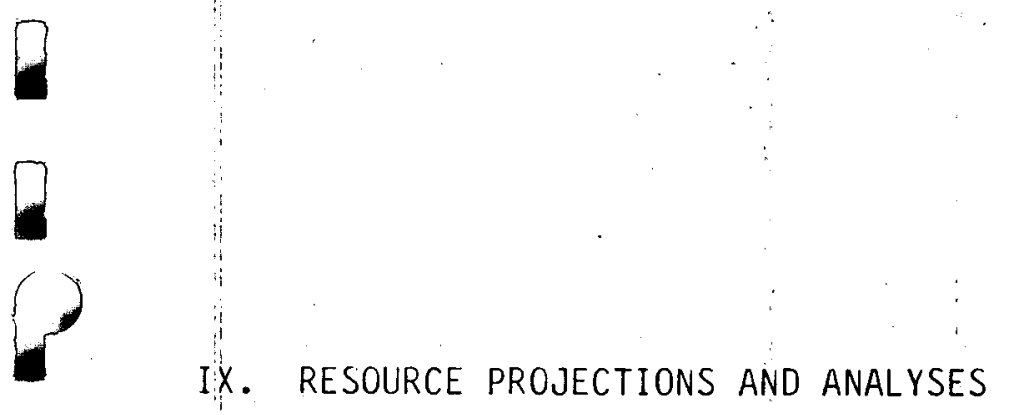

.

.

.

.

.

.

.

.

.

.

.

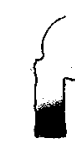

. 
IX. RESOURCE PROJECTIONS AND ANALYSES

A. Overall Laboratory Summary

B. Funding by Assistant Secretarial Level Office

C. Personnel by Assistant Secretarial Level Office

D. Resources by Subprogram

E. Phases of R\&D Analysis

F. Organization Chart 
A. OVERALL LABORATORY SUMMARY

( $\$$ IN MILLIONS)

DOE Effort

Work for Others

Total Operating

Capital Equipment

Program Construction

Gen. Purpose Fac. (GPF)

Gen. Plant Proj. (GPP)

Gen. Purpose Eq. (GPE)

Total Lab Funding

Proposed Const.

Total

(IN FTE)
Direct
DOE Effort
Work for Others
Total Operating
Construction
Total Direct Charge

Direct Recharge(Support)

Total Direct

Indirect

Total Lab Personnel

$$
\text { FUNDING SUMMARY }
$$

\begin{tabular}{|c|c|c|c|c|c|c|c|c|c|c|c|c|c|}
\hline \multirow{2}{*}{\multicolumn{2}{|c|}{$\frac{F Y \quad 1982}{B A}$}} & \multicolumn{2}{|c|}{ FY 1983} & \multicolumn{2}{|c|}{ FY 1984} & \multicolumn{2}{|c|}{ FY 1985} & \multicolumn{2}{|c|}{ FY 1986} & \multicolumn{2}{|c|}{ FY 1987} & \multicolumn{2}{|c|}{ FY 1988} \\
\hline & & $B \bar{A}$ & & $\underline{B \bar{A}}$ & $\underline{B} 0$ & $B \bar{A}$ & $\underline{B} 0$ & $B \bar{A}$ & $\bar{B} 0$ & $B \bar{A}$ & $\bar{B} 0$ & $B \bar{A}$ & $\underline{B} 0$ \\
\hline 437.7 & 443.2 & 436.9 & 437.5 & 522.0 & 494.8 & 527.7 & 522.2 & 520.6 & 520.0 & 517.8 & 518.3 & 516.9 & 517.2 \\
\hline 54.1 & 54.1 & 62.2 & 62.2 & 65.4 & 65.4 & 61.5 & 61.5 & 62.5 & 62.5 & 63.8 & 63.8 & 64.9 & 64.9 \\
\hline 497.8 & 497.3 & 499.1 & 499.7 & 587.4 & 560.2 & 589.2 & 583.7 & 583.1 & 582.5 & 581.6 & 582.1 & 581.8 & 582.1 \\
\hline 27.9 & 26.8 & 33.8 & 30.8 & 50.9 & 50.9 & 49.4 & 49.4 & 46.0 & 46.0 & 45.9 & 45.9 & 45.4 & 45.4 \\
\hline 69.9 & 43.8 & 37.6 & 49.5 & 25.1 & 31.3 & 21.4 & 23.7 & 31.9 & 31.9 & 0.0 & 0.0 & 0.0 & 0.0 \\
\hline $\begin{array}{r}8.9 \\
(\mathrm{~N}\end{array}$ & ne as & $\begin{array}{r}5.0 \\
h \text { at } L\end{array}$ & $\begin{array}{r}5.0 \\
\text { s Alam }\end{array}$ & 12.6 & 12.6 & 14.1 & 14.1 & 14.1 & 14.1 & 14.7 & 14.1 & 14.1 & 14.1 \\
\hline 598.5 & 573.0 & 575.5 & 585.0 & 676.0 & 655.0 & 674.1 & 670.9 & 675.1 & 674.5 & 641.6 & 642.1 & 641.3 & 641.6 \\
\hline 0.0 & 0.0 & 0.0 & 0.0 & 34.7 & 27.1 & 97.7 & 87.8 & 175.9 & 117.3 & 148.8 & 142.8 & 109.3 & 161.0 \\
\hline 598.5 & 573.0 & 575.5 & 585.0 & 710.7 & 682.1 & 771.8 & 758.7 & 857.0 & 791.8 & 790.4 & 784.9 & 750.6 & 802.6 \\
\hline
\end{tabular}

PERSONNEL SUMMARY

FY $1982 \quad \underline{\text { FY } 1983} \quad \underline{\text { FY } 1984}$

\begin{tabular}{llll} 
FY 1985 & FY 1986 & FY 1987 & FY 1988 \\
\hline
\end{tabular}

$\begin{array}{rrrrrrr}4,099 & 3,880 & 3,989 & 4,064 & 4,055 & 4,047 & 4,038 \\ 469 & 520 & 466 & 441 & 450 & 458 & 467 \\ 4,568 & 4,400 & 4,455 & 4,505 & 4,505 & 4,505 & 4,505 \\ 163 & 120 & 120 & 120 & 120 & 120 & 120 \\ 4,731 & 4,520 & 4,575 & 4,625 & 4,625 & 4,625 & 4,625 \\ 850 & 800 & 800 & 800 & 800 & 800 & 800 \\ 5,581 & 5,320 & 5,375 & 5,425 & 5,425 & 5,425 & 5,425 \\ 1,603 & 1,580 & 1,575 & 1,575 & 1,575 & 1,575 & 1,575 \\ 7,184 & 6,900 & 6,950 & 7,000 & 7,000 & 7,000 & 7,000\end{array}$


B. FUnding BY ASSISTANT SECRETARIAL LEVEL OFFICE

(\$ in Millions)

AS-Defense Programs

Defense Programs Total Total Operating Capital Equipment

Total DP

Construction

AS-Energy Research

Energy Research Total

Total Operating

Capital Equipment

Total ER

AS-Nuclear Energy

Nuclear Energy Total

$$
\begin{aligned}
& \text { Total Operating } \\
& \text { Capital Equipment } \\
& \text { Construction }
\end{aligned}
$$

Total NE

AS-Conservation/Renew Total

Conservation/Renew Total

$$
\begin{aligned}
& \text { Total Operating } \\
& \text { Capital Equipment } \\
& \text { Construction }
\end{aligned}
$$

AS-Fossil Energy

Fossil Energy Total

$$
\begin{aligned}
& \text { Total Operating } \\
& \text { Capital Equipment } \\
& \text { Construction } \\
& \text { Total FE }
\end{aligned}
$$

AS-Env. Pro./Safety/EP

Env Pro/Safety/EP Total

$$
\sim \quad \text { Total Operating }
$$$$
\text { Total EP }
$$

Construction

Total CE $\begin{array}{rr}32.3 & 32.3\end{array}$

$374.3 \quad 375.4$

$5.2 \quad 6.6$

$$
\begin{array}{llll}
\mathrm{FY} & 1982 \\
B \overline{\mathrm{A}} & \underline{\mathrm{COST}} & \underline{\mathrm{FY}} 1983 \\
\hline \bar{A} & \underline{B} 0
\end{array}
$$

$277.3 \quad 277.4$

$20.5 \quad 15.9$

$63.4 \quad 40.1$

$361.2 \quad 333.4$

\section{3.}

$28.4 \quad 25.5$

$32.7 \quad 43.3$

$364.3 \quad 368.9$

$\begin{array}{rr}369.6 & 354.3 \\ 40.4 & 40.4 \\ 18.7 & 26.3 \\ 428.7 & 421.0\end{array}$

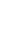

(4)

$\begin{array}{rr}35.9 & 35.9\end{array}$

383

$21.4 \quad 21.7$

$\begin{array}{rr}31.9 & 31.9\end{array}$

$377.6 \quad 379.0$ $\begin{array}{ll}0.0 & 0.0\end{array}$ $409.9 \quad 411.3$ $31.7 \quad 31.7$ $\begin{array}{rr}0.0 & 0.0 \\ 406.0 & 407.1\end{array}$

\section{$70.9 \quad 72.6$}

$\begin{array}{rr}1.4 & 2.6 \\ 77.5 & 81.8\end{array}$

$\begin{array}{rr}72.4 & 72.6 \\ 5.1 & 5.0 \\ 2.9 & 2.8 \\ 80.4 & 80.4\end{array}$

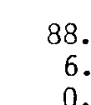

$88.6 \quad 83.7$

$6.7 \quad 6.7$

$\begin{array}{rr}0.0 & 0.1 \\ 95.3 & 90.5\end{array}$

84.5
6.7
0.5

$0.0 \quad 0.0$

$91.2 \quad 91.0$
$6.7 \quad 6.7$ $\begin{array}{rrrr}35.4 & 39.9 & 15.2 & 15.6 \\ 1.0 & 2.5 & 0.2 & 0.2\end{array}$

$\begin{array}{llll}1.0 & 2.5 & 0.2 & 0.2 \\ 0.9 & 0.8 & 0.0 & 0.0\end{array}$

$\begin{array}{llll}37.3 & 43.2 & 15.4 & 15.8\end{array}$
$22.8 \quad 17.6$

$0.4 \quad 0.4$

$0.0 \quad 0.0$

$23.2 \quad 18.0$
$22.1 \quad 20.5$

$0.4 \quad 0.4$

$0.0 \quad 0.0$

$22.5 \quad 20.9$

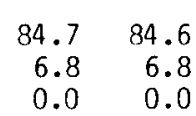

$\begin{array}{rr}0.0 & 0.0\end{array}$

$91.5 \quad 91.4$

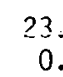

$\begin{array}{rr}3.6 & 22.8 \\ 0.4 & 0.4\end{array}$

$0.0 \quad 0.0$

$24.0 \quad 23.2$
85.185 .0

$6.8 \quad 6.8$

$0.0 \quad 0.0$

$91.9 \quad 91.8$
$\frac{F Y \quad 1988}{B A \quad B 0}$$$
406.0907 .1
$$

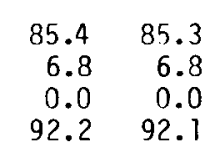

92.292 .1

$\begin{array}{rrrr}26.0 & 25.2 & 28.7 & 27.4 \\ 0.4 & 0.4 & 0.4 & 0.4 \\ 0.0 & 0.0 & 0.0 & 0.0 \\ 26.4 & 25.6 & 28.5 & 27.8\end{array}$

$\begin{array}{rrrr}17.7 & 16.6 & 9.6 & 12.4 \\ 0.7 & 1.3 & 0.0 & 0.0 \\ 0.0 & 0.0 & 0.0 & 0.0 \\ 18.4 & 17.9 & 9.6 & 12.4\end{array}$

$\begin{array}{ll}5.3 & 4.0 \\ 0.5 & 0.5 \\ 0.0 & 0.0 \\ 5.8 & 4.5\end{array}$

$\begin{array}{ll}4.0 & 4.0 \\ 0.5 & 0.5 \\ 0.0 & 0.0 \\ 4.5 & 4.5\end{array}$

$\begin{array}{ll}0.0 & 0.0 \\ 0.0 & 0.0 \\ 0.0 & 0.0 \\ 0.0 & 0.0\end{array}$

$\begin{array}{ll}0.0 & 0.0 \\ 0.0 & 0.0 \\ 0.0 & 0.0\end{array}$

$0.0 \quad 0.0$
$0.0 \quad 0.0$

$0.0 \quad 0.0$

Total EP

$\begin{array}{ll}2.6 & 2.2 \\ 0.2 & 0.2 \\ 0.0 & 0.0 \\ 2.8 & 2.4\end{array}$

$\begin{array}{ll}2.4 & 2.2 \\ 0.2 & 0.2 \\ 0.0 & 0.0 \\ 2.6 & 2.4\end{array}$

$\begin{array}{ll}2.2 & 2.2 \\ 0.2 & 0.2 \\ 0.0 & 0.0 \\ 2.4 & 2.4\end{array}$

$\begin{array}{ll}2.2 & 2.2 \\ 0.2 & 0.2 \\ 0.0 & 0.0 \\ 2.4 & 2.4\end{array}$

$\begin{array}{ll}2.2 & 2.2 \\ 0.2 & 0.2 \\ 0.0 & 0.0 \\ 2.4 & 2.4\end{array}$

$\begin{array}{llll}2.9 & 3.1 & 1.6 & 1.6 \\ 0.1 & 0.1 & 0.1 & 0.1 \\ 0.0 & 0.0 & 0.0 & 0.0 \\ 3.0 & 3.2 & 1.7 & 1.7\end{array}$

$\begin{array}{ll}2.1 & 2.0 \\ 0.6 & 0.6 \\ 0.0 & 0.0 \\ 2.7 & 2.6\end{array}$

$\begin{array}{ll}2.0 & 2.0 \\ 0.6 & 0.6 \\ 0.0 & 0.0 \\ 2.6 & 2.6\end{array}$

$\begin{array}{ll}2.0 & 2.0 \\ 0.6 & 0.6 \\ 0.0 & 0.0 \\ 2.6 & 2.6\end{array}$

$\begin{array}{ll}2.0 & 2.0 \\ 0.6 & 0.6 \\ 0.0 & 0.0 \\ 2.6 & 2.6\end{array}$


( $\$$ in Millions)

AS-EI and PE Combined

$E I$ and PE Combined Total

Total Operating

Capital Equipment

Total RB

AS-Management \& Administration

Management \& Admin Total

Total Operating

Capital Equipment

Total MA Construction

AS-Work for Other DOE Contr

Work for Other DOE Total

Total Operating

Capital Equipment

Total XA Construction

$$
\begin{array}{rr}
27.1 & 27.1 \\
0.0 & 0.0 \\
0.0 & 0.0 \\
27.1 & 27.1
\end{array}
$$

Total DOE Programs

Total Operating Capital Equipment

Total DOE

$437.7 \quad 443.2$ $27.9 \quad 26.8$ $\begin{array}{rr}69.9 & 43.8\end{array}$ $535.5 \quad 513.8$

\section{$436.9 \quad 437.5$}

$33.8 \quad 30.8$

$37.6 \quad 49.5$

$508.3 \quad 517.8$

WFO-Non DOE DOD Programs Total Operating

Subtotal Capital Equipment Construction

$\begin{array}{rr}23.5 & 23.5 \\ 0.0 & 0.0 \\ 0.0 & 0.0 \\ 23.5 & 23.5\end{array}$

$$
\begin{array}{rr}
28.7 & 28.7
\end{array}
$$

$0.0 \quad 0.0$

$0.0 \quad 0.0$

$28.7 \quad 28.7$

WF0-Non DOE NRC Programs Total Operating Capital Equipment Subtotal Construction

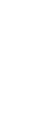

$$
\begin{array}{r}
15 \\
0 \\
0 \\
15
\end{array}
$$

$14.5 \quad 14.5$

$0.0 \quad 0.0$

$\begin{array}{rr}0.0 & 0.0 \\ 5.7 & 15.1\end{array}$

$\begin{array}{rr}0.0 & 0.0\end{array}$

$0.0 \quad 0.0$

$14.5 \quad 14.5$

$15.5 \quad 15.5$

Total Operating

Capital Equipment Subtota?
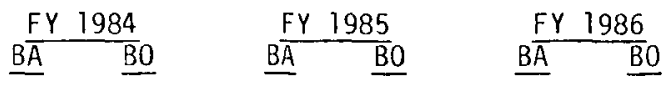

\begin{tabular}{ll}
$F Y \quad 1987$ \\
\hline$B \quad$
\end{tabular}

FY 1988

$\underline{B A} \quad \underline{B}$ 
B. FUNOING bY ASSISTANT SECRETARIAL LEVEL OFFICE (COnt.)

( $\$$ in Millions)

Total WFO - NON DOE

Total Operating Capital Equipment

Total Lab NOn DOE

General Plant Projects

Total Laboratory Funding

Total Operating Capital Equipinent Construction

Total Laboratory

Proposed Construction

Total-Including Proposed Const Total Operating Capital Equipment Total

$$
\frac{F Y \quad 1982}{B A \quad \text { COST }}
$$

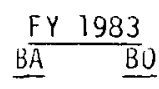

$$
\begin{array}{r}
54.1 \\
0.0 \\
04 \\
54
\end{array}
$$$$
54
$$$$
0.0 \quad 0.0
$$$$
0.0 \quad 0.0
$$

$$
8.9 \quad 5.1
$$

$\begin{array}{rr}500.7 & 502.4 \\ 27.9 & 26.8 \\ 69.9 & 43.8 \\ 598.5 & 573.0\end{array}$

$\begin{array}{rr}598.5 & 573.0 \\ 0.0 & 0.0\end{array}$

0.0

0.0

$500.7 \quad 502.4$

$27.9 \quad 26.8$

$\begin{array}{rr}5 \hat{y} .9 & 43.8 \\ 598.5 & 573.0\end{array}$

\section{$62.2 \quad 62.2$ \\ $0.0 \quad 0.0$}

$\begin{array}{rr}0.0 & 0.0 \\ 62.2 & 62.2\end{array}$

$5.0 \quad 5.0$

504.1504 .7

$\begin{array}{ll}33.8 & 30.8\end{array}$

$\begin{array}{ll}37.6 & 49.5\end{array}$

$575.5 \quad 585.0$

$0.0 \quad 0.0$

$504.1 \quad 504.7$

$33.8 \quad 30.8$

$3 \overline{3} .6 \quad 49.5$

$575.5 \quad 585.0$

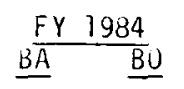

$65.4 \quad 65.4$

$\begin{array}{ll}0.5 & 0.5 \\ 0.0 & 0.0\end{array}$

$65.9 \quad 65.9$

$12.6 \quad 12.6$

$600.0 \quad 572.8$

$\begin{array}{ll}50.9 & 50.9\end{array}$

$25.1 \quad 31.3$

$676.0 \quad 655.0$

$\begin{array}{ll}34.7 & 27.1\end{array}$

$634.7 \quad 599.9$

$50.9 \quad 50.9$

$25.1 \quad 31.3$

$710.7 \quad 682.7$

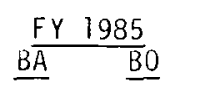

$F Y \quad 1986$
$B A \quad B O$

$\begin{array}{rr}61.5 & 61.5 \\ 3.5 & 3.5 \\ 0.0 & 0.0\end{array}$

$0.0 \quad 0.0$

$65.0 \quad 65.0$

$14.1 \quad 14.1$

$603.3 \quad 597.8$

$\begin{array}{lll}49.4 & 49.4\end{array}$

$21.4 \quad 23.7$

$674.1 \quad 670.9$

$97.7 \quad 87.8$

$701.0 \quad 685.6$

$\begin{array}{lll}49.4 & 49.4\end{array}$

$\begin{array}{rr}21.4 & 23.7\end{array}$

$771.8 \quad 758.7$

$\begin{array}{rr}62.5 & 62.5 \\ 3.6 & 3.6 \\ 0.0 & 0.0 \\ 66.1 & 66.1 \\ 14.1 & 14.1\end{array}$

597.

$597.2 \quad 596.6$

$31.9 \quad 31.9$

$675.1 \quad 674.5$

$175.9 \quad 117.3$

$773.1 \quad 713.9$

$46.0 \quad 46.0$

$\begin{array}{ll}31.9 & 31.9\end{array}$

$851.0 \quad 791.8$

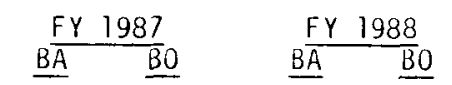

$\begin{array}{llll}63.8 & 63.8 & 64.9 & 64.9\end{array}$

$\begin{array}{llll}4.0 & 4.0 & 4.1 & 4.1\end{array}$

$\begin{array}{rrrr}0.0 & 0.0 & 0.0 & 0.0\end{array}$

$\begin{array}{llll}67.8 & 67.8 & 69.0 & 69.0\end{array}$

$\begin{array}{llll}14.1 & 14.1 & 14.1 & 14.1\end{array}$

$\begin{array}{llll}595.7 & 596.2 & 595.9 & 596.2\end{array}$ $\begin{array}{llll}45.9 & 45.9 & 45.4 & 45.4\end{array}$ $\begin{array}{rrrr}0.0 & 0.0 & 0.0 & 0.0\end{array}$ $\begin{array}{llll}641.6 & 642.1 & 641.3 & 641.6\end{array}$

$\begin{array}{llll}148.8 & 142.8 & 109.3 & 167.0\end{array}$

$\begin{array}{llll}744.5 & 739.0 & 705.2 & 757.2\end{array}$

$\begin{array}{llll}45.9 & 45.9 & 45.4 & 45.4\end{array}$

$\begin{array}{llll}0.0 & 0.0 & 0.0 & 0.0\end{array}$

$\begin{array}{rrrr}790.4 & 784.9 & 750.6 & 802.6\end{array}$ 
$\stackrel{\sim}{\sim}$

c. PERSONNEL BY ASSISTANT SECRETARIAL LEVEL OFFICE

(Personnel in FTE)

FY 1982

FY 1983

FY 1984

FY 1985

FY 1986

FY 1987

$\underline{\text { FY } 1988}$

AS-Defense Programs

Direct Personnel

2439

2499

2731

2818

2811

2777

2745

ergy Research
Direct Personnel

784

750

754

758

761

765

769

412

200

204

226

248

267

AS-Conservation/Renew Energy Direct Personnel

135

100

27

27

0

0

AS-Fossil Energy

Direct Personnel

52

30

18

18

18

AS-Env. Pro./Safety/EP Direct Personnel

AS-EI and PE Combined

Direct Personnel

0

0

0

0

AS-Management \& Administration Direct Personnel

0

0

0

0

0

AS-Work for Other DOE Contr Direct Personnel

Total DOE Programs

$$
\text { Direct Personnel }
$$

4099

3880

3989

4064

4055

4047

4038

WFO-Non DOE DOD Programs Direct Personnel

on DOE NRC Programs

WF0-Non DOE Other

Direct Personnel 


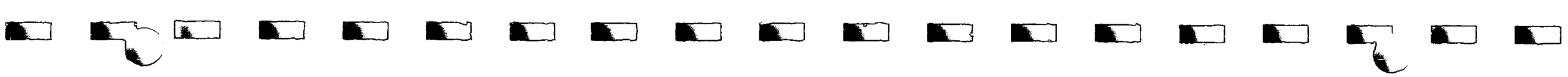

C. PERSONNEL by assistant Secretarial LeVel OFfice (cont.)

\author{
(Personnel in FTE) \\ Total Laboratory - Direct \\ Total Laboratory - Indirect \\ Total Laboratory Programs \\ Direct Personnel
}

$\frac{F Y 1982}{5581}$
1603
7184

$\frac{F Y 1983}{5320}$
1580
6900

$\frac{\text { FY } 1984}{5375}$
1575
6950

$\frac{\text { FY } 1985}{5425}$
1575
7000

$\frac{F Y \quad 1986}{5425}$
1575
7000

$\begin{array}{lll}\frac{\text { FY } 1987}{5425} & & \text { FY } 1988 \\ 1575 & 5425 \\ 7000 & 1575 \\ & 7000\end{array}$


AR05 Defense Waste

\section{Total Operating \\ Capital Equipment \\ Subtotal \\ Direct Personnel}

AR-Defense Waste Management Total Operating Capital Equipment Construction

Subtotal AR

Direct Personnel

GB01 Weapons Research

Total Operating

Capital Equipment Construction

Subtotal

Direct Personnel

GB02 Inert Conf Fus

Total Operating Capital Equipment Subtotal Construction

Direct Personnel

GB03 Weap Prod/Surv

Total Operating Capital Equipment Subtotal Construction

Direct Personnel

GB-Weapons Activities

Total Operating

Capital Equipment

Construction

Subtotal GB

Direct Personnel
D. RESOURCES BY SUB PROGRAM

ASSISTANT SECRETARY FOR DEFENSE PROGRAMS

(\$ IN MILLIONS - PERSONNEL IN FTE)
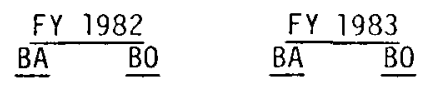

$$
\begin{array}{ll}
F Y & 1984 \\
\hline B A & B O
\end{array}
$$

$$
\begin{array}{ll}
F Y & 1985 \\
\hline B A & B 0
\end{array}
$$

\begin{tabular}{lr}
$\mathrm{FY}$ & 1986 \\
\hline $\mathrm{B}$ & $\underline{B} 0$ \\
\hline
\end{tabular}

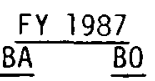

$\frac{F Y \quad 1988}{B A}$
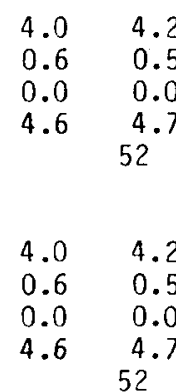

$\begin{array}{rr}193.1 & 191.8 \\ 12.7 & 9.9 \\ 39.1 & 22.1 \\ 244.9 & 223.8\end{array}$

$244.9 \quad 223.8$
1,601
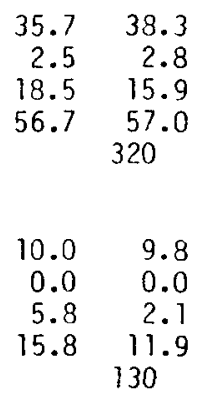

$238.8 \quad 239.9$

$\begin{array}{ll}15.2 & 12.7 \\ 63.4 & 40.1\end{array}$

$\begin{array}{rr}63.4 & 40.7 \\ 317.4 & 292.7\end{array}$ 2,051 $\begin{array}{rr}39.4 & 39.4 \\ 5.8 & 5.8 \\ 0.0 & 7.3\end{array}$

$\begin{array}{rr}0.0 & 7.3 \\ 45.2 & 52.5\end{array}$

324
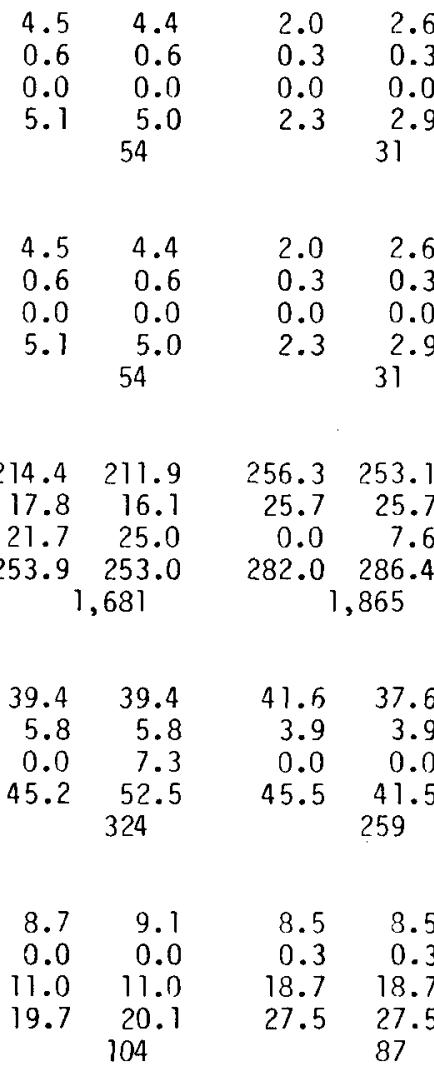

3.13 .0

0.30 .3

$0.0 \quad 0.0$

$\begin{array}{ll}3.4 & 3.3\end{array}$

3.13 .0

$\begin{array}{ll}2.0 & 2.6\end{array}$

$\begin{array}{ll}0.3 & 0.3 \\ 0.0 & 0.0\end{array}$

$\begin{array}{ll}2.3 & 2.9 \\ & 31\end{array}$

$0.0 \quad 0.0$

$\begin{array}{ll}3.4 & 3.3\end{array}$

36

$\begin{array}{ll}256.3 & 253.1\end{array}$

$\begin{array}{rr}25.7 & 25.7 \\ 0.0 & 7.6\end{array}$

$\begin{array}{rr}0.0 & 7.6 \\ 282.0 & 286.4\end{array}$

1,865

$265.7 \quad 261.4$

$\begin{array}{rr}0.0 & 0.3 \\ 284.5 & 280.5\end{array}$

1,832

$\begin{array}{rr}41.5 & 37.6 \\ 3.9 & 3.9 \\ 0.0 & 0.0 \\ 45.5 & 41.5 \\ & 259\end{array}$

$\begin{array}{rr}52.5 & 52.5 \\ 9.5 & 9.5\end{array}$

$\begin{array}{ll}9.5 & 9.5 \\ 0.0 & 0.0\end{array}$

$62.0 \quad 62.0$

368

$\begin{array}{ll}8.5 & 8.5 \\ 0.3 & 0.3\end{array}$

$\begin{array}{rr}0.3 & 0.3 \\ 18.7 & 18.7\end{array}$

$17.0 \quad 17.0$

$\begin{array}{rr}0.0 & 0.0 \\ 21.4 & 21.4\end{array}$

$\begin{array}{ll}21.4 & 21.4 \\ 38.4 & 38.4\end{array}$

119

$262.5 \quad 260.4$

$23.6 \quad 21.9$

$318.8 \quad 325.6$

2,109
$335.2 \quad 330.9$

$28.3 \quad 28.3$

$\begin{array}{rr}21.4 & 21.7\end{array}$

$384.9 \quad 380.9$
2,319 $\begin{array}{rr}18.8 & 18.8 \\ 0.0 & 0.3\end{array}$

$\begin{array}{ll}18.7 & 18.7 \\ 27.5 & 27.5\end{array}$
$306.4 \quad 299.2$

29.929 .9

$355.0 \quad 355.4$ 2,211
$3.0 \quad 3.0$

$0.3 \quad 0.3$

$\begin{array}{ll}3.3 & 3.3\end{array}$

36

$3.0 \quad 3.0$

$\begin{array}{ll}3.3 & 3.3\end{array}$

36

$259.1 \quad 259.7$

$18.7 \quad 18.7$

$\begin{array}{rr}0.0 & 0.0 \\ 277.8 & 278.4\end{array}$

1,819

$\begin{array}{rr}52.5 & 52.5 \\ 9.5 & 9.5 \\ 0.0 & 0.0 \\ 62.0 & 62.0 \\ & 368\end{array}$

$\begin{array}{rr}17.0 & 17.0 \\ 0.0 & 0.0\end{array}$

$\begin{array}{rr}0.0 & 0.0 \\ 31.9 & 31.9\end{array}$

119

$328.6 \quad 329.2$
28.2

$28.2 \quad 28.2$

$\begin{array}{rr}388.7 & 389.3\end{array}$

2,306 $\begin{array}{ll}0.3 & 0.3 \\ 0.0 & 0.0\end{array}$

$48.9 \quad 48.9$ $\begin{array}{rrrr}3.0 & 3.0 & 3.0 & 3.0 \\ 0.3 & 0.3 & 0.7 & 0.7 \\ 0.0 & 0.0 & 0.0 & 0.0 \\ 3.3 & 3.3 & 3.7 & 3.7 \\ & 36 & & 36\end{array}$

$\begin{array}{llll}3.0 & 3.0 & 3.0 & 3.0 \\ 0.3 & 0.3 & 0.7 & 0.7\end{array}$

$\begin{array}{llll}0.3 & 0.3 & 0.7 & 0.7 \\ 0.0 & 0.0 & 0.0 & 0.0\end{array}$

$\begin{array}{llll}3.3 & 3.3 & 3.7 & 3.7\end{array}$

36

$\begin{array}{llll}254.0 & 255.4 & 254.1 & 254.4\end{array}$ $\begin{array}{llll}18.4 & 18.4 & 18.4 & 18.4\end{array}$ $\begin{array}{llll}0.0 & 0.0 & 0.0 & 0.0\end{array}$

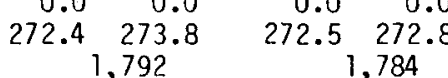
1,784

$\begin{array}{rrrr}52.5 & 52.5 & 52.5 & 52.5 \\ 9.3 & 9.3 & 9.3 & 9.3 \\ 0.0 & 0.0 & 0.0 & 0.0 \\ 61.8 & 61.8 & 61.8 & 61.8 \\ & 368 & & 368\end{array}$

$17.0 \quad 17.0$

$17.0 \quad 17.0$

$0.0 \quad 0.0$

$\begin{array}{ll}0.0 & 0.0\end{array}$

$17.0 \quad 17.0$
119

$0.0 \quad 0.0$

$\begin{array}{rr}0.0 & 0.0\end{array}$

$17.0 \quad 17.0$
119

$\begin{array}{llll}323.5 & 324.9 & 323.6 & 323.9\end{array}$

$\begin{array}{llll}27.7 & 27.7 & 27.7 & 27.7\end{array}$

$\begin{array}{rrrr}0.0 & 0.0 & 0.0 & 0.0\end{array}$

$\begin{array}{cc}351.2,352.6 & 351.3,351.6 \\ 2,279 & 2,271\end{array}$ 

GCOI Ver \& Cntr Tech
Total Operating Capital Equipment Construction
Subtota?
Direct Personnel

GC-Verification \& Contr Tech Total Operating Capital Equipment Subtotal GC

Direct Personnel

GDOI Nuclear Mat Saf

Total Operating Capita! Equipment

Subtotal Construction

Direct Personnel

GD-NuC Mt ls Safeguards \& SeC Total operating Capital Equipment Construction

Subtotal GD

Direct Personne?

GE02 Nuclear Matls

Total Operating Capital Equipment

Subtotal Construction

Direct Personnel

GE03 Support Serv

Total Operating Capital Equipment

Subtotal Construction

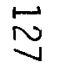

D. RESOURCES BY SUB PROGRAM (cont.) ASSISTANT SECRETARY FOR DEFENSE PROGRAMS

(\$ IN MILLIONS - PERSONNEL IN FTE)

\begin{tabular}{|c|c|}
\hline$F Y$ & 1982 \\
\hline$\overline{B A}$ & $\mathrm{~B} 0$ \\
\hline 12.6 & 12.3 \\
\hline 0.3 & 0.2 \\
\hline 0.0 & 0.0 \\
\hline 12.9 & 12.5 \\
\hline & \\
\hline
\end{tabular}
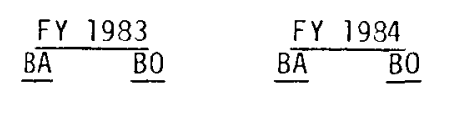

$\begin{array}{ll}F Y & 1985 \\ \underline{B A} \quad \underline{B O}\end{array}$

$\begin{array}{rr}13.6 & 13.1 \\ 0.5 & 0.5 \\ 0.0 & 0.0 \\ 14.1 & 13.6 \\ & 128\end{array}$

$\begin{array}{rr}18.7 & 16.3 \\ 1.6 & 1.6 \\ 0.0 & 0.0 \\ 19.7 & 17.9 \\ & 149\end{array}$

$\begin{array}{rr}17.2 & 17.0 \\ 0.6 & 0.6 \\ 0.0 & 0.0 \\ 17.8 & 17.6 \\ & 155\end{array}$

\section{$\begin{array}{rr}12.6 & 12.3 \\ 0.3 & 0.2\end{array}$ \\ $\begin{array}{ll}0.3 & 0.2 \\ 0.0 & 0.0\end{array}$}

$12.9 \quad 12.5$
110

$\begin{array}{rr}13.6 & 13.1 \\ 0.5 & 0.5 \\ 0.0 & 0.0 \\ 14.1 & 13.6 \\ & 128\end{array}$

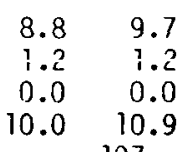

$10.0 \quad 10.9$
107

$\begin{array}{rc}8.8 & 8.8 \\ 1.2 & 0.9 \\ 0.0 & 0.0 \\ 10.0 & 9.7 \\ & 86\end{array}$

$\begin{array}{rr}18.1 & 16.3 \\ 1.6 & 1.6 \\ 0.0 & 0.0 \\ 19.7 & 17.9 \\ & 149\end{array}$

$\begin{array}{rr}17.2 & 17.0 \\ 0.6 & 0.6 \\ 0.0 & 0.0 \\ 17.8 & 17.6 \\ & 155\end{array}$

$\begin{array}{rr}12.5 & 12.0 \\ 2.4 & 2.4 \\ 0.0 & 0.0 \\ 14.9 & 14.4\end{array}$

$14.9 \quad 14.4$
108

$\begin{array}{rr}12.6 & 12.6 \\ 1.7 & 1.7 \\ 0.0 & 0.0 \\ 14.3 & 14.3 \\ & 108\end{array}$

$\begin{array}{rr}8.8 & 9.7 \\ 1.2 & 1.2 \\ 0.0 & 0.0 \\ 10.0 & 10.9\end{array}$

$\begin{array}{rr}8.8 & 8.8 \\ 1.2 & 0.9 \\ 0.0 & 0.0 \\ 10.0 & 9.7 \\ & 86\end{array}$

$\begin{array}{rr}12.5 & 12.0 \\ 2.4 & 2.4 \\ 0.0 & 0.0 \\ 14.9 & 14.4 \\ & 108\end{array}$

$\begin{array}{rr}12.6 & 12.6 \\ 1.7 & 1.7 \\ 0.0 & 0.0\end{array}$

$0.0 \quad 0.0$

$14.3 \quad 14.3$

108
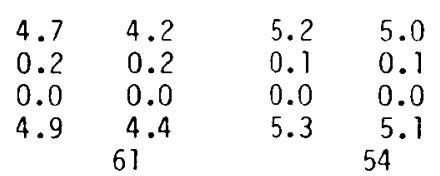

$\begin{array}{ll}6.6 & 6.2 \\ 0.2 & 0.2 \\ 0.0 & 0.0 \\ 6.8 & 6.4 \\ & 60\end{array}$

$\begin{array}{cc}6.2 & 6.2 \\ 0.0 & 0.0 \\ 0.0 & 0.0 \\ 6.2 & 6.2 \\ & 59\end{array}$

$\begin{array}{ll}0.4 & 0.5 \\ 0.0 & 0.0 \\ 0.0 & 0.0 \\ 0.4 & 0.5 \\ & 4\end{array}$

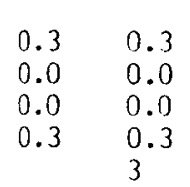

$\begin{array}{ll}0.0 & 0.0 \\ 0.0 & 0.0 \\ 0.0 & 0.0 \\ 0.0 & 0.0\end{array}$

$\begin{array}{ll}0.0 & 0.0 \\ 0.0 & 0.0 \\ 0.0 & 0.0 \\ 0.0 & 0.0 \\ & 0\end{array}$
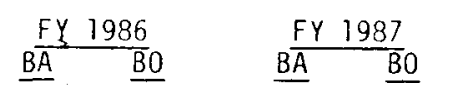

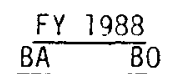

$\begin{array}{rr}19.7 & 19.0 \\ 0.6 & 0.6 \\ 0.0 & 0.0 \\ 20.3 & 19.6 \\ & 172\end{array}$

$21.7 \quad 21.0$

$0.6 \quad 0.6$

$0.0 \quad 0.0$

$22.3 \quad 21.6$

23.723 .0

$0.6 \quad 0.6$

$\begin{array}{rr}0.3 & 0.0\end{array}$

\section{$19.7 \quad 19.0$}

$0.6 \quad 0.6$

$0.0 \quad 0.0$

$20.3 \quad 19.6$
172

$21.7 \quad 21.0$

$\begin{array}{ll}0.6 & 0.6 \\ 0.0 & 0.0\end{array}$

$\begin{array}{cc}22.3 \quad 21.6 \\ & 187\end{array}$

$23.7 \quad 23.0$

0.60 .6

$\begin{array}{rr}0.0 & 0.0 \\ 24.3 & 23.6\end{array}$

$12.6 \quad 12.6$

$\begin{array}{ll}\mathbf{i} .7 & \mathrm{i} . \mathrm{i} \\ 0.0 & 0.0\end{array}$

$14.3 \quad 14.3$

108

$12.6 \quad 12.6$

$\begin{array}{ll}\mathrm{i} . \mathrm{i} & \mathrm{i} . \mathrm{j} \\ 0.0 & 0.0\end{array}$

$14.3 \quad 14.3$

108

$12.6 \quad 12.6$

i. $\overline{1} \quad \overline{1 .} \overline{1}$

$0.0 \quad 0.0$

$\begin{array}{cc}14.3 \quad 14.3 \\ & 108\end{array}$

$12.6 \quad 12.6$
1.7

$12.6 \quad 12.6$

$12.6 \quad 12.6$

$\begin{array}{ll}1.7 & 1.7 \\ 0.0 & 0.0\end{array}$

$14.3 \quad 14.3$

108

$\begin{array}{rr}1.7 & 1.7 \\ 0.0 & 0.0 \\ 14.3 & 14.3 \\ & 108\end{array}$

$1.7 \quad 1.7$

$0.0 \quad 0.0$

$14.3 \quad 14.3$
108

$\begin{array}{cc}6.2 & 6.2 \\ 0.0 & 0.0 \\ 0.0 & 0.0 \\ 6.2 & 6.2 \\ & 59\end{array}$

$\begin{array}{ll}6.2 & 6.2 \\ 0.0 & 0.0 \\ 0.0 & 0.0\end{array}$

$\begin{array}{ll}0.0 & 0.0 \\ 6.2 & 6.2\end{array}$

6.26 .2

$0.0 \quad 0.0$

$\begin{array}{ll}0.0 & 0.0 \\ 6.2 & 6.2\end{array}$

59

$\begin{array}{ll}0.0 & 0.0 \\ 0.0 & 0.0 \\ 0.0 & 0.0 \\ 0.0 & 0.0\end{array}$

$\begin{array}{ll}0.0 & 0.0 \\ 0.0 & 0.0 \\ 0.0 & 0.0 \\ 0.0 & 0.0\end{array}$

$\begin{array}{ll}0.0 & 0.0 \\ 0.0 & 0.0 \\ 0.0 & 0.0 \\ 0.0 & 0.0 \\ & 0\end{array}$

5
i
D
옹 

ASSISTANT SECRETARY FOR DEFENSE PROGRAMS ( $\$$ IN MILLIONS - PERSONNEL IN FTE)

\begin{tabular}{|c|c|c|c|c|c|c|}
\hline FY 1982 & FY 1983 & FY 1984 & FY 1985 & FY 1986 & FY 1987 & FY 1988 \\
\hline & $\underline{B A}$ & & & $B \bar{A} \quad \bar{B} 0$ & $B \overline{\mathrm{A}} \quad \overline{\mathrm{B}} 0$ & $B \bar{A} \quad \underline{B} 0$ \\
\hline
\end{tabular}

GE06 Spec Isotope Total Operating Capital Equipment

Subtotal

$$
\text { Construction }
$$

Direct Personnel

$\begin{array}{rr}8.0 & 6.6 \\ 3.0 & 1.1 \\ 0.0 & 0.0 \\ 11.0 & 7.7\end{array}$

$\begin{array}{cc}8.3 & 8.1 \\ 2.4 & 1.5 \\ 0.0 & 0.0 \\ 10.7 & 9.6 \\ & 65\end{array}$

$\begin{array}{rr}24.0 & 18.0 \\ 6.0 & 6.0 \\ 0.0 & 0.0 \\ 30.0 & 24.0 \\ & 172\end{array}$

$\begin{array}{rr}13.5 & 14.6 \\ 5.0 & 5.0\end{array}$

$13.1 \quad 13.5$

$10.6 \quad 11.3$

$\begin{array}{ll}5.0 & 5.0 \\ 0.0 & 0.0 \\ 18.5 & 19.6\end{array}$

$18.5 \quad 19.6$

$0.0 \quad 0.0$

$15.1 \quad 15.5$

130

$\begin{array}{ll}2.0 & 2.0 \\ 0.0 & 0.0\end{array}$

$\begin{array}{lll}0.0 & 0.0 \\ 12.6 & 13.3\end{array}$

108

$\begin{array}{ll}5.2 & 6.7 \\ 1.0 & 1.0\end{array}$

$0.0 \quad 0.0$

GE-Materials Production Total Operating

Construction

Subtotal GE

Direct Personnel

$\begin{array}{rr}13.1 & 11.3 \\ 3.2 & 1.3 \\ 0.0 & 0.0 \\ 16.3 & 12.6 \\ & 119\end{array}$

$\begin{array}{rr}13.8 & 13.4 \\ 2.5 & 1.6 \\ 0.0 & 0.0 \\ 16.3 & 15.0 \\ & 122\end{array}$

$\begin{array}{rr}30.6 & 24.2 \\ 6.2 & 6.2 \\ 0.0 & 0.0 \\ 36.8 & 30.4 \\ & 232\end{array}$

$\begin{array}{rr}19.7 & 20.8 \\ 5.0 & 5.0 \\ 0.0 & 0.0 \\ 24.7 & 25.8 \\ & 200\end{array}$

$\begin{array}{rr}19.3 & 19.7 \\ 2.0 & 2.0 \\ 0.0 & 0.0 \\ 21.3 & 21.7 \\ & 189\end{array}$

$\begin{array}{rr}16.8 & 17.5 \\ 2.0 & 2.0 \\ 0.0 & 0.0 \\ 18.8 & 19.5\end{array}$

Defense Programs Total Total Operating Capital Equipment Construction

Total DP

$277.3 \quad 277.4$

\section{$303.2 \quad 300.1$}

$369.6 \quad 354.3$

$387.8 \quad 384.3$

$383.2 \quad 383.5$

167

$11.4 \quad 12.9$

$63.4 \quad 40.9$

$\begin{array}{ll}28.4 & 25.5 \\ 32.7 & 43.3\end{array}$

$\begin{array}{ll}40.4 & 40.4 \\ 18.7 & 26.3\end{array}$

$35.9 \quad 35.9$

$32.8 \quad 32.8$

$361.2 \quad 333.4$

$364.3 \quad 368.9$

$428.7 \quad 421.0$

$21.4 \quad 21.7$

$\begin{array}{rr}31.9 & 31.9\end{array}$

2,439

2,499

2,818

\begin{tabular}{|c|c|c|c|}
\hline 171.6 & 379.0 & 374.3 & 375. \\
\hline 32. & 32.3 & 31.7 & 31. \\
\hline 0. & 0.0 & 0.0 & 0. \\
\hline & $\begin{array}{l}411.3 \\
2.777\end{array}$ & 406. & $\begin{array}{l}407 \\
745\end{array}$ \\
\hline
\end{tabular}

$$
2,731
$$$$
2,811
$$

2,777

$\begin{array}{rr}1.0 & 1.0 \\ 0.0 & 0.0 \\ 12.4 & 13.9 \\ & 124 \\ & \\ & \\ 374.3 & 375.4 \\ 31.7 & 31.7 \\ 0.0 & 0.0 \\ 406.0 & 407.1 \\ 2,745\end{array}$



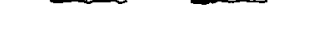

D. RESOURCES BY SUB PROGRAM (cont.)

ASSISTANT SECRETARY FOR ENERGY RESEARCH
(\$ IN MILLIONS - PERSONNEL IN FTE)

AT05 Appl Plasma Phy

Total Operating

Capital Equipment

Subtotal

Direct Personnel

\section{$\begin{array}{ll}F Y & 1982 \\ B A & B\end{array}$}

$\begin{array}{rr}13.2 & 13.1 \\ 0.8 & 1.0 \\ 0.0 & 0.0 \\ 14.0 & 14.1\end{array}$

146

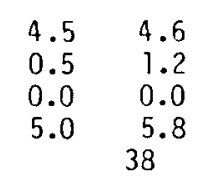

Subtotal

AT15 Develop \& Tech

Total Operating

Capital Equipment

AT25 Mag Fusion Eng

Total Operating

Capital Equipment

Subtotal

Direct Personne 1

AT-Magnetic Fusion

Total Operating

Capital Equipment

Subtotal AT

Direct Personnel

HAO2 Bio \& Envn Res

Total Operating

Capital Equipment

Subtotal

Direct Personnel

HA-Biomed \& Environ Research

Total Operating

Capital Equipment

Subtotal HA

๗ָ

$\begin{array}{ll}0.3 & 0.3 \\ 0.0 & 0.0 \\ 0.0 & 0.0 \\ 0.3 & 0.3\end{array}$

$18.0 \quad 18.0$

$1.3 \quad 2.2$

$\begin{array}{rr}0.0 & 0.0 \\ 19.3 & 20.2\end{array}$

187

$\begin{array}{ll}6.4 & 6.4 \\ 0.7 & 0.8 \\ 0.0 & 0.0 \\ 7.1 & 7.2\end{array}$

88

$\begin{array}{ll}6.4 & 6.4 \\ 0.7 & 0.8 \\ 0.0 & 0.0 \\ 7.1 & 7.2\end{array}$

88
$\frac{F Y \quad 1983}{B A \quad B O}$

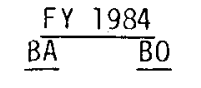

$14.0 \quad 13.7$

$0.7 \quad 0.6$

$\begin{array}{rr}0.0 & 0.0 \\ 14.7 & 14.3\end{array}$

145

$$
\begin{array}{ll}
4.1 & 4.1 \\
0.3 & 0.3 \\
0.0 & 0.0 \\
4.4 & 4.4 \\
& 38
\end{array}
$$

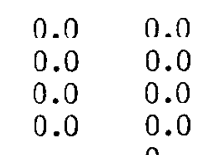

$18.1 \quad 17.8$

$1.0 \quad 0.9$

$\begin{array}{rr}19.1 & 18.7\end{array}$

183

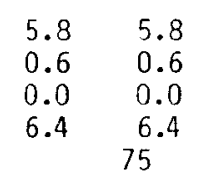

$\begin{array}{ll}5.8 & 5.8 \\ 0.6 & 0.6 \\ 0.0 & 0.0 \\ 6.4 & 6.4\end{array}$

75

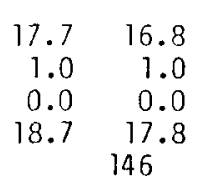

$5.9 \quad 4.4$

$0.6 \quad 0.6$

$\begin{array}{ll}0.0 & 0.0 \\ 6.5 & 5.0\end{array}$

38

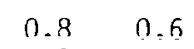

$\begin{array}{ll}0.1 & 0.1 \\ 0.0 & 0.0\end{array}$

$0.0 \quad 0.0$

$\begin{array}{ll}0.9 & 0.7 \\ & 5\end{array}$

$24.4 \quad 21.8$

$1.7 \quad 1.7$

$\begin{array}{rr}0.0 & 0.0 \\ 26.1 & 23.5\end{array}$

23.5
189

$\begin{array}{ll}7.4 & 7.0 \\ 0.7 & 0.7 \\ 0.0 & 0.0 \\ 8.1 & 7.7\end{array}$

$\begin{array}{ll}7.4 & 7.0 \\ 0.7 & 0.7 \\ 0.0 & 0.0 \\ 8.1 & 7.7\end{array}$

74
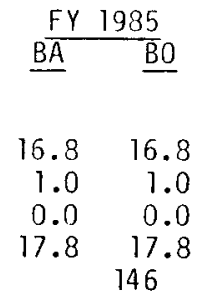

$\begin{array}{ll}4.4 & 4.4\end{array}$

$0.6 \quad 0.6$

$\begin{array}{ll}0.0 & 0.0 \\ 5.0 & 5.0\end{array}$

38

$\begin{array}{ll}0.6 & 0.6 \\ 0.1 & 0.1 \\ 0.0 & 0.0 \\ 0.7 & 0.7 \\ & 5\end{array}$

$21.8 \quad 21.8$

$1.7 \quad 1.7$

$\begin{array}{rr}23.5 & 23.5\end{array}$

189

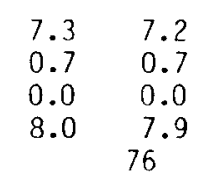

7.37 .2

$\begin{array}{ll}0.7 & 0.7\end{array}$

$\begin{array}{ll}0.0 & 0.0 \\ 8.0 & 7.9\end{array}$

76

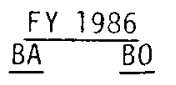

$\begin{array}{rr}16.8 & 16.8 \\ 1.0 & 1.0 \\ 0.0 & 0.0 \\ 17.8 & 17.8 \\ & 146\end{array}$

$4.4 \quad 4.4$

$0.6 \quad 0.6$

$\begin{array}{ll}5.0 & 5.0\end{array}$

38

$\begin{array}{ll}0.6 & 0.6 \\ 0.1 & 0.1 \\ 0.0 & 0.0 \\ 0.7 & 0.7 \\ & 5\end{array}$

$21.8 \quad 21.8$

$\begin{array}{ll}1.7 & 1.7\end{array}$

$\begin{array}{rr}0.0 & 0.0 \\ 23.5 & 23.5\end{array}$

189

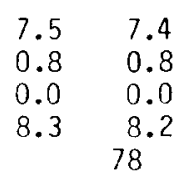

$\begin{array}{lr}7.5 & 7.4 \\ 0.8 & 0.8 \\ 0.0 & 0.0 \\ 8.3 & 8.2\end{array}$

78

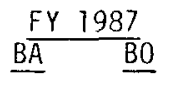

$\mathrm{BY} \quad \frac{\mathrm{FY}}{\mathrm{B}} \quad \underline{\mathrm{B} 0}$

$16.8 \quad 16.8$

$1.0 \quad 1.0$

$\begin{array}{rr}0.0 & 0.0 \\ 17.8 & 17.8\end{array}$

146

$16.8 \quad 16.8$

$1.0 \quad 1.0$

$\begin{array}{rr}17.0 & 0.0 \\ 17.8 & 17.8\end{array}$

$4.4 \quad 4.4$

$\begin{array}{ll}0.6 & 0.6 \\ 0.0 & 0.0\end{array}$

$\begin{array}{ll}0.0 & 0.0 \\ 5.0 & 5.0\end{array}$

38

$4.4 \quad 4.4$

$0.6 \quad 0.6$

$\begin{array}{ll}0.0 & 0.0 \\ 5.0 & 5.0\end{array}$

38

$\begin{array}{ll}0.6 & 0.6 \\ 0.1 & 0.1 \\ 0.0 & 0.0 \\ 0.7 & 0.7\end{array}$

$0.5 \quad 0.5$

$0.1 \quad 0.1$

$\begin{array}{ll}0.0 & 0.0 \\ 0.7 & 0.7\end{array}$

5

$21.8 \quad 21.8$

$21.8 \quad 21.8$

$\begin{array}{ll}1.7 & 1.7\end{array}$

$0.0 \quad 0.0$

$\begin{array}{rr}0.0 & 0.0 \\ 23.5 & 23.5\end{array}$

$\begin{array}{ll}23.5 & 23.5 \\ & 189\end{array}$

189

$\begin{array}{lllr}7.7 & 7.6 & 7.9 & 7.8 \\ 0.8 & 0.8 & 0.8 & 0.8 \\ 0.0 & 0.0 & 0.0 & 0.0 \\ 8.5 & 8.4 & 8.7 & 8.6 \\ & 80 & & 82\end{array}$

$\begin{array}{ll}7.7 & 7.6 \\ 0.8 & 0.8 \\ 0.0 & 0.0 \\ 8.5 & 8.4\end{array}$

80 $\begin{array}{ll}7.9 & 7.8 \\ 0.8 & 0.8 \\ 0.0 & 0.0 \\ 8.7 & 8.6\end{array}$

82 
D. RESOURCES BY SUB PROGRAM (cont.) ASSISTANT SECRETARY FOR ENERGY RESEARCH

(\$ IN MILLIONS - PERSONNEL IN FTE)

HBO 1 Gen] Life Sci

Total Operating Capital Equipment Subtotal Construction

Direct Personnel

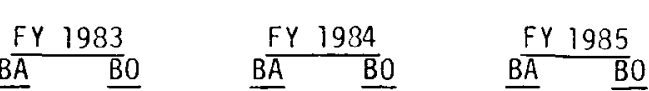

$\frac{F Y \quad 1986}{B A} \quad \underline{B} 0$

$\frac{F Y}{B \bar{A} \quad 1987}$

$\frac{F Y \quad 1988}{B A \quad B O}$

\begin{tabular}{ll}
$F Y$ & 1982 \\
$B A$ & $\underline{B} 0$ \\
\hline
\end{tabular}

$\begin{array}{ll}1.7 & 1.7 \\ 0.1 & 0.2 \\ 0.0 & 0.0 \\ 1.8 & 1.9 \\ & 21\end{array}$

$\begin{array}{ll}1.2 & 1.2 \\ 0.1 & 0.1 \\ 0.0 & 0.0 \\ 1.3 & 1.3 \\ & 11\end{array}$

$\begin{array}{ll}2.1 & 1.9 \\ 0.5 & 0.5 \\ 0.0 & 0.0 \\ 2.6 & 2.4 \\ & 16\end{array}$

$\begin{array}{ll}2.0 & 2.0 \\ 0.6 & 0.6 \\ 0.0 & 0.0 \\ 2.6 & 2.6 \\ & 17\end{array}$

$\begin{array}{ll}2.1 & 2.1 \\ 0.6 & 0.6 \\ 0.0 & 0.0 \\ 2.7 & 2.7 \\ & 18\end{array}$

$2.2 \quad 2.2$

$0.6 \quad 0.6$

$\begin{array}{ll}0.0 & 0.0 \\ 2.8 & 2.8\end{array}$

HBO2 Nuclear Medicine

Total 0perating Capital Equipment Subtota] Construction

Direct Personne 1

$\begin{array}{ll}2.7 & 2.7 \\ 0.0 & 0.0 \\ 0.0 & 0.0 \\ 2.7 & 2.7 \\ & 33\end{array}$

$\begin{array}{rr}2.7 & 2.7 \\ 0.0 & 0.0 \\ 0.0 & 0.0 \\ 2.7 & 2.7 \\ & 31\end{array}$

$\begin{array}{lr}2.4 & 2.5 \\ 0.0 & 0.0 \\ 0.0 & 0.0 \\ 2.4 & 2.5 \\ & 36\end{array}$

$\begin{array}{ll}2.5 & 2.5 \\ 0.0 & 0.0 \\ 0.0 & 0.0 \\ 2.5 & 2.5\end{array}$

HB-Lfe Sci Res \& Nuc Med App

Total Operating Capital Equipment Subtotal HB

Direct Personnel

$\begin{array}{ll}4.4 & 4.4 \\ 0.1 & 0.2 \\ 0.0 & 0.0 \\ 4.5 & 4.6 \\ & 54\end{array}$

$\begin{array}{lr}3.9 & 3.9 \\ 0.1 & 0.1 \\ 0.0 & 0.0 \\ 4.0 & 4.0 \\ & 42\end{array}$

$\begin{array}{cc}4.5 & 4.4 \\ 0.5 & 0.5 \\ 0.0 & 0.0 \\ 5.0 & 4.9 \\ & 52\end{array}$

$\begin{array}{lr}4.5 & 4.5 \\ 0.6 & 0.6 \\ 0.0 & 0.0 \\ 5.1 & 5.1 \\ & 53\end{array}$

$\begin{array}{ll}2.5 & 2.5 \\ 0.0 & 0.0 \\ 0.0 & 0.0 \\ 2.5 & 2.5 \\ & 36\end{array}$

$2.6 \quad 2.6$

$\begin{array}{ll}2.6 & 2.6 \\ 0.0 & 0.0\end{array}$

$\begin{array}{ll}0.0 & 0.0 \\ 0.0 & 0.0\end{array}$

$\begin{array}{ll}2.6 & 2.6 \\ & 37\end{array}$

2.32 .3

$0.6 \quad 0.6$ $0.0 \quad 0.0$ $\begin{array}{ll}2.9 & 2.9 \\ & 21\end{array}$

$2.6 \quad 2.6$

$0.0 \quad 0.0$

0.00 .0

$\begin{array}{ll}2.6 & 2.6 \\ & 37\end{array}$

$\begin{array}{lr}4.6 & 4.6 \\ 0.6 & 0.6 \\ 0.0 & 0.0 \\ 5.2 & 5.2 \\ & 54\end{array}$

$\begin{array}{ll}4.8 & 4.8 \\ 0.6 & 0.6\end{array}$

$0.6 \quad 0.6$

$0.0 \quad 0.0$

$4.9 \quad 4.9$

$0.6 \quad 0.6$

$\begin{array}{ll}0.0 & 0.6 \\ 0.0 & 0.0\end{array}$

KAOI Physics Research

Total Operating Capital Equipment
Construction Subtotal

Direct Personne 1

$\begin{array}{ll}0.3 & 0.3 \\ 0.0 & 0.0 \\ 0.0 & 0.0 \\ 0.3 & 0.3 \\ & 3\end{array}$

$\begin{array}{ll}0.3 & 0.3 \\ 0.0 & 0 . \\ 0.0 & 0 . \\ 0.3 & 0.3 \\ & 3\end{array}$

$\begin{array}{ll}1.1 & 0.9 \\ 0.0 & 0.0 \\ 0.0 & 0.0 \\ 1.1 & 0.9 \\ & 8\end{array}$

$\begin{array}{ll}1.3 & 1.2 \\ 0.0 & 0.0 \\ 0.0 & 0.0 \\ 1.3 & 1.2\end{array}$

$\begin{array}{rr}1.2 & 1.2 \\ 0.0 & 0.0 \\ 0.0 & 0.0 \\ 1.2 & 1.2 \\ & 10\end{array}$

KA-High Energy Physics

Total Operating Capital Equipment Subtotal KA

Direct Personnel

$\begin{array}{ll}0.3 & 0.3 \\ 0.0 & 0.0 \\ 0.0 & 0.0 \\ 0.3 & 0.3 \\ & 3\end{array}$

$\begin{array}{ll}0.3 & 0.3 \\ 0.0 & 0.0 \\ 0.0 & 0.0 \\ 0.3 & 0.3 \\ & 3\end{array}$

$\begin{array}{ll}1.1 & 0.9 \\ 0.0 & 0.0 \\ 0.0 & 0.0 \\ 1.1 & 0.9\end{array}$
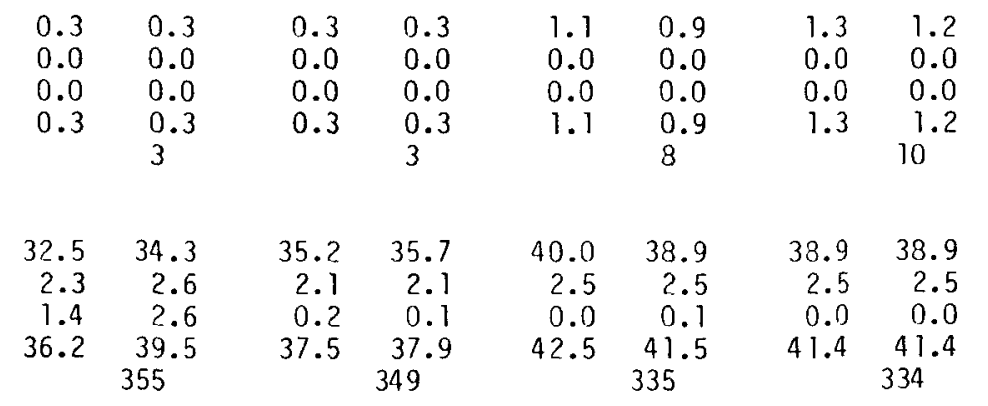

$\begin{array}{rc}1.2 & 1.2 \\ 0.0 & 0.0 \\ 0.0 & 0.0 \\ 1.2 & 1.2 \\ & 10 \\ & \\ & \\ 38.6 & 38.7 \\ 2.5 & 2.5 \\ 0.0 & 0.0 \\ 41.1 & 41.2 \\ & 333\end{array}$

$\begin{array}{rc}1.2 & 1.2 \\ 0.0 & 0.0 \\ 0.0 & 0.0 \\ 1.2 & 1.2 \\ & 10 \\ & \\ & \\ 38.7 & 38.7 \\ 2.5 & 2.5 \\ 0.0 & 0.0 \\ 41.2 & 41.2 \\ & 333\end{array}$

$$
\text { Cotal Operating }
$$

Direct Personnel

\begin{abstract}
335
\end{abstract}

\begin{abstract}
334
\end{abstract}

\begin{abstract}
333
\end{abstract}
$\begin{array}{ll}1.2 & 1.2\end{array}$
$0.0 \quad 0.0$
$0.0 \quad 0.0$ $10^{1.2}$
$\begin{array}{llll}1.2 & 1.2 & 1.2 & 1.2 \\ 0.0 & 0.0 & 0.0 & 0.0\end{array}$

$\begin{array}{llll}1.0 & 0.0 & 0.0 & 0.0 \\ 0.0 & 0.0 & 0.0 & 0.0\end{array}$$$
\begin{array}{llll}
0.0 & 0.0 & 0.0 & 0.0 \\
1.2 & 1.2 & 1.2 & 1.2
\end{array}
$$$$
10
$$

$38.6 \quad 38.6$

$2.5 \quad 2.5$

$0.0 \quad 0.0$

$\begin{array}{cc}41.1 \quad 41.1 \\ & 332\end{array}$

8




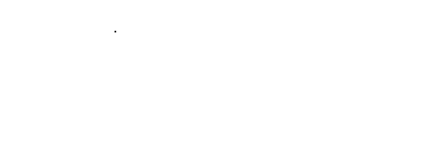

KB02 Heavy Ion Phys

otal 0perating

Capital Equipment

Subtotal

Direct Personnel

KB03 Nuclear Theory

Total Operating

Capital Equipment

Subtotal

Direct Personnel

KB-Nuclear Physics

Total Operating

Capital Equipment

Construction

Direct Personnel

KCOO

\section{Total Operating Capital Equipment \\ Subtotal}

Direct Personne]

KCOl Nuclear Sci

Capital Equipment
Construction

btotal

Direct Personnel

KCO2 Material Sci

Total Operating

Subtotal

Capital Equipment

Construction

$\stackrel{\omega}{\omega}$
D. RESOURCES BY SUB PROGRAM (cont.) ASSISTANT SECRETARY FOR ENERGY RESEARCH

( $\$$ IN MILLIONS - PERSONNEL IN FTE)

$\underline{B Y} \quad \underline{B A 82} \quad \underline{B} 0$

$$
\begin{array}{ll}
F Y & 1983 \\
\hline B \quad & B O \\
\hline
\end{array}
$$

$$
\begin{array}{ll}
F Y & 1984 \\
B A & B \\
\hline
\end{array}
$$$$
\begin{array}{ll}
F Y \quad 1985 \\
\underline{B A} \quad \underline{B O}
\end{array}
$$

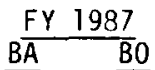

FY 1988

0.10 .1

0.10 .1

$0.0 \quad 0.0$

$0.0 \quad 0.0$

$0.1 \quad 0.1$

0.1

$\begin{array}{ll}0.0 & 0.0 \\ 0.2 & 0.2\end{array}$

$0.4 \quad 0.3$

$0.3 \quad 0.3$

$0.3 \quad 0.3$

$0.1 \quad 0.1$

$0.0 \quad 0.0$

$0.0 \quad 0.0$

$\begin{array}{ll}0.5 & 0.4\end{array}$

0.10 .1

$\begin{array}{ll}0.4 & 0.4\end{array}$

$\begin{array}{ll}0.4 & 0.4 \\ & 2\end{array}$

$0.3 \quad 0.3$

$0.1 \quad 0.1$

$0.0 \quad 0.0$

$\begin{array}{ll}0.4 & 0.4\end{array}$

0.4

$0.4 \quad 0.4$

$\begin{array}{ll}0.1 & 0.1 \\ 0.0 & 0.0\end{array}$

$\begin{array}{ll}0.5 & 0.0 \\ 0.5\end{array}$

$\begin{array}{ll}0.8 & 0.8 \\ 0.0 & 0.0 \\ 0.0 & 0.0 \\ 0.8 & 0.8\end{array}$

$\begin{array}{cc}1.0 & 1.0 \\ 0.4 & 0.4 \\ 0.0 & 0.0 \\ 1.4 & 1.4 \\ & 10\end{array}$

$1.5 \quad 1.1$

$1.1 \quad 1.1$

$1.4 \quad 1.3$

$0.1 \quad 0.1$

$0.0 \quad 0.0$

$\begin{array}{ll}0.0 & 0.0 \\ 1.6 & 1.2\end{array}$

$0.0 \quad 0.0$

10

10

$\begin{array}{rr}33.4 & 35.2 \\ 2.3 & 2.6\end{array}$

$36.3 \quad 36.8$

$41.9 \quad 40.3$

$1.4 \quad 2.6$

$2.6 \quad 2.6$

$0.2 \quad 0.1$

$2.7 \quad 2.7$

$0.0 \quad 0.1$

360

$44.6 \quad 43.1$
347

$\begin{array}{rr}40.3 & 40.3 \\ 2.7 & 2.7 \\ 0.0 & 0.0 \\ 43.0 & 43.0 \\ & 346\end{array}$

$40.3 \quad 40.3$

$\begin{array}{ll}2.7 & 2.7\end{array}$

$0.0 \quad 0.0$

$\begin{array}{cc}43.0 & 43.0 \\ & 346\end{array}$

1.31 .3

$0.1 \quad 0.1$

0.00 .0

11.4

$1.3 \quad 1.3$

$0.1 \quad 0.1$

$\begin{array}{ll}0.0 & 0.0 \\ 1.4 & 1.4\end{array}$

$$
365
$$

$\begin{array}{ll}0.0 & 0.0 \\ 0.0 & 0.0 \\ 0.0 & 0.0 \\ 0.0 & 0.0\end{array}$

$\begin{array}{ll}0.0 & 0.0 \\ 0.0 & 0.0 \\ 2.7 & 2.7 \\ 2.7 & 2.7\end{array}$

$0.0 \quad 0.0$

$0.0 \quad 0.0$

$\begin{array}{ll}0.0 & 0.0\end{array}$

$\begin{array}{ll}0.0 & 0.0\end{array}$

$0.0 \quad 0.0$

$\begin{array}{ll}0.0 & 0.0\end{array}$

$0.0 \quad 0.0$

$0.0 \quad 0.0$$$
\text { 0 }
$$$$
\begin{array}{ll}
1.4 & 1.5 \\
0.1 & 0.1 \\
0.0 & 0.0 \\
1.5 & 1.6
\end{array}
$$$$
\begin{aligned}
& 1.4 \\
& 0.0 \\
& 0.0 \\
& 1.4
\end{aligned}
$$$$
\begin{aligned}
& 1.4 \\
& 0.0 \\
& 0.0 \\
& 1.4
\end{aligned}
$$

1.4

0.0
0.0

0.0
1.4

$0.0 \quad 0.0$

$0.0 \quad 0.0$

$0.0 \quad 0.0$

0.0

$0.0 \quad 0.0$

$\begin{array}{ll}0.0 & 0.0\end{array}$

$0.0 \quad 0.0$

3.4

$\begin{array}{ll}3.1 & 3.1 \\ 0.4 & 0.4 \\ 0.0 & 0.0 \\ 3.5 & 3.5 \\ & 35\end{array}$ $\begin{array}{ll}5.0 & 5.0 \\ 0.7 & 0.7\end{array}$

$\begin{array}{ll}0.7 & 0.7 \\ 0.0 & 0.0\end{array}$

$\begin{array}{ll}0.7 & 0.0 \\ 5.7 & 5.7\end{array}$

5.7
45
40.340 .3

$2.7 \quad 2.7$

$0.0 \quad 0.0$

$\begin{array}{cc}43.0 & 43.0 \\ & 346\end{array}$

$0.0 \quad 0.0$

$\begin{array}{ll}0.0 & 0.0\end{array}$

$0.0 \quad 0.0$

$0.0 \quad 0.0$

0.0

40.340 .3

2.. 2.7

$0.0 \quad 0.0$

$\begin{array}{cc}43.0 & 43.0 \\ 346\end{array}$

$0.0 \quad 0.0$

$0.0 \quad 0.0$

$0.0 \quad 0.0$

$\begin{array}{ll}0.0 & 0.0 \\ & 0\end{array}$
37

$\begin{array}{lr}5.0 & 5.0 \\ 0.6 & 0.6 \\ 0.0 & 0.0 \\ 5.6 & 5.6 \\ & 45\end{array}$

$0.0 \quad 0.0$

$0.0 \quad 0.0$

$0.0 \quad 0.0$

$\begin{array}{ll}0.0 & 0.0 \\ 0.0 & 0.0\end{array}$

$0.0 \quad 0.0$

$\begin{array}{ll}0.0 & 0.0\end{array}$

$\begin{array}{ll}0.0 & 0.0 \\ 0.0 & 0.0\end{array}$

$0.0 \quad 0.0$

$\begin{array}{ll}0.0 & 0.0 \\ 0.0 & 0.0\end{array}$

0

$5.0 \quad 5.0$

$5.0 \quad 5.0$

$\begin{array}{ll}5.0 & 5.0 \\ 0.6 & 0.6\end{array}$

$0.6 \quad 0.6$

$\begin{array}{ll}0.0 & 0.0 \\ 5.6 & 5.6\end{array}$

$0.6 \quad 0.6$

$0.0 \quad 0.0$

45

$\begin{array}{ll}0.6 & 0.6 \\ 0.0 & 0.0\end{array}$

$\begin{array}{ll}0.0 & 0.0 \\ 5.6 & 5.6\end{array}$

45 
D. RESOURCES BY SUB PROGRAM (cont.) ASSISTANT SECRETARY FOR ENERGY RESEARCH

( $\$$ IN MILLIONS - PERSONNEL IN FTE)

KCO3 Chemical Sci

Total Operating

Capital Equipment

Subtotal

Direct Personnel

\section{$\frac{F Y}{B \quad 1982}$}

KCO4 Eng Math \& Geo
Total Operating

Capital Equipment

Subtotal

Direct Personnel

\section{KC05 Adv Energy Proj \\ Total Operating \\ Capital Equipment \\ Subtota?}

Direct Personnel

KC-Basic Energy Sciences

Total Operating

Capital Equipment

Subtotal $\mathrm{KC}$

Direct Personnel

KDOI Assessment Proj

Total Operating

Capital Equipment

Subtotal

Direct Personnel

KD-Techn Assessment Projects Total Operating Capital Equipment

Construction

Subtotal KD

Direct Personnel
$0.9 \quad 0.9$

$0.1 \quad 0.1$

$\begin{array}{ll}0.0 & 0.0 \\ 1.0 & 1.0\end{array}$

$\begin{array}{ll}1.0 & 1.0 \\ 0.0 & 0.0 \\ 0.0 & 0.0 \\ 1.0 & 1.0 \\ & 12\end{array}$

$\begin{array}{ll}2.3 & 2.3 \\ 0.2 & 0.2 \\ 0.0 & 0.0 \\ 2.5 & 2.5 \\ & 24\end{array}$

$2.0 \quad 2.0$

$0.2 \quad 0.2$

$\begin{array}{ll}0.0 & 0.0 \\ 2.2 & 2.2\end{array}$

22

$\begin{array}{ll}0.3 & 0.2 \\ 0.0 & 0.0 \\ 0.0 & 0.0 \\ 0.3 & 0.2 \\ & 2\end{array}$

$\begin{array}{ll}0.2 & 0.2 \\ 0.0 & 0.0\end{array}$

$0.0 \quad 0.0$

$\begin{array}{ll}0.0 & 0.0 \\ 0.2 & 0.2\end{array}$

$8.0 \quad 8.0$

$0.8 \quad 0.8$

$0.0 \quad 0.0$

$\begin{array}{ll}8.8 & 8.8 \\ & 84\end{array}$

$\begin{array}{ll}0.4 & 0.3 \\ 0.0 & 0.0 \\ 0.0 & 0.0 \\ 0.4 & 0.3\end{array}$

$\begin{array}{ll}8.0 & 8.0 \\ 0.8 & 0.8\end{array}$

$\begin{array}{ll}8.0 & 0.8 \\ 2.7 & 2.7\end{array}$

$\begin{array}{rr}2.7 & 2.7 \\ 11.5 & 11.5\end{array}$

87

$$
\begin{array}{ll}
0.0 & 0.0 \\
0.0 & 0.0 \\
0.0 & 0.0 \\
0.0 & 0.0
\end{array}
$$

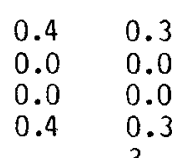

$\begin{array}{ll}0.0 & 0.0\end{array}$

$\begin{array}{ll}0.0 & 0.0 \\ 0.0 & 0.0\end{array}$

$0.0 \quad 0.0$
$F Y \quad 1983$
$B A \quad B O$

\begin{tabular}{cc} 
FY & 1984 \\
$B A$ & $B 0$ \\
\hline
\end{tabular}

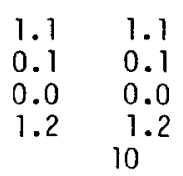

$3.2 \quad 3.2$

$0.3 \quad 0.3$

$\begin{array}{ll}0.0 & 0.0 \\ 3.5 & 3.5\end{array}$

29

$\begin{array}{ll}0.0 & 0.0 \\ 0.0 & 0.0 \\ 0.0 & 0.0 \\ 0.0 & 0.0\end{array}$

0

9.39 .3

$1.1 \quad 1.1$

$\begin{array}{rr}0.0 & 0.0 \\ 10.4 & 10.4\end{array}$

84

$\begin{array}{ll}0.0 & 0.0 \\ 0.0 & 0.0 \\ 0.0 & 0.0 \\ 0.0 & 0.0 \\ & 0\end{array}$

$0.0 \quad 0.0$

$0.0 \quad 0.0$

$0.0 \quad 0.0$ \begin{tabular}{ll} 
FY & 1985 \\
\hline $\mathrm{B} \quad \mathrm{BO}$
\end{tabular}

\begin{tabular}{ll}
$F Y$ & 1986 \\
\hline$B A$ & $\quad B 0$
\end{tabular}

$\mathrm{FY} \quad 1987$
$\mathrm{~B} \overline{\mathrm{A}} \quad \mathrm{B} 0$

$F Y \quad 1988$
$B A \quad B 0$

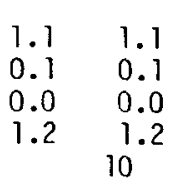

$\begin{array}{ll}1.1 & 1.1 \\ 0.1 & 0.1 \\ 0.0 & 0.0 \\ 1.2 & 1.2 \\ & 10\end{array}$

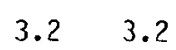

$0.3 \quad 0.3$

$0.0 \quad 0.0$

$\begin{array}{ll}3.5 & 3.5 \\ & 29\end{array}$

$0.0 \quad 0.0$

$0.0 \quad 0.0$

$0.0 \quad 0.0$

$\begin{array}{ll}0.0 & 0.0 \\ & 0\end{array}$

$9.3 \quad 9.3$

$\begin{array}{ll}1.0 & 1.0 \\ 0.0 & 0.0\end{array}$

$\begin{array}{rr}0.0 & 0.0 \\ 10.3 & 10.3\end{array}$

84

$\begin{array}{ll}0.0 & 0.0 \\ 0.0 & 0.0 \\ 0.0 & 0.0 \\ 0.0 & 0.0\end{array}$ $\begin{array}{ll}0.0 & 0.0 \\ 0.0 & 0.0 \\ 0.0 & 0.0 \\ 0.0 & 0.0\end{array}$

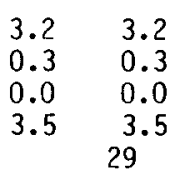

$0.0 \quad 0.0$

$0.0 \quad 0.0$

$0.0 \quad 0.0$

0.0
0

9.39 .3

$1.0 \quad 1.0$

$\begin{array}{rr}1.0 & 0.0\end{array}$

84

$\begin{array}{ll}0.0 & 0.0 \\ 0.0 & 0.0 \\ 0.0 & 0.0 \\ 0.0 & 0.0\end{array}$

$0.0 \quad 0.0$

$0.0 \quad 0.0$

$0.0 \quad 0.0$

0.0
0 $\begin{array}{llll}1.1 & 1.1 & 1.1 & 1.1\end{array}$

$\begin{array}{llll}0.1 & 0.1 & 0.1 & 0.1\end{array}$

$\begin{array}{llll}0.0 & 0.0 & 0.0 & 0.0\end{array}$

10

10

$$
\begin{array}{llll}
3.2 & 3.2 & 3.2 & 3.2 \\
0.3 & 0.3 & 0.3 & 0.3 \\
0.0 & 0.0 & 0.0 & 0.0 \\
3.5 & 3.5 & 3.5 & 3.5 \\
& 29 & & 29
\end{array}
$$

$\begin{array}{llll}0.0 & 0.0 & 0.0 & 0.0 \\ 0.0 & 0.0 & 0.0 & 0.0 \\ 0.0 & 0.0 & 0.0 & 0.0 \\ 0.0 & 0.0 & 0.0 & 0.0 \\ & 0 & & 0\end{array}$

$\begin{array}{rrrr}9.3 & 9.3 & 9.3 & 9.3 \\ 1.0 & 1.0 & 1.0 & 1.0 \\ 0.0 & 0.0 & 0.0 & 0.0 \\ 10.3 & 10.3 & 10.3 & 10.3 \\ & 84 & & 84\end{array}$

$\begin{array}{llll}0.0 & 0.0 & 0.0 & 0.0 \\ 0.0 & 0.0 & 0.0 & 0.0 \\ 0.0 & 0.0 & 0.0 & 0.0 \\ 0.0 & 0.0 & 0.0 & 0.0 \\ & 0 & & 0\end{array}$

$\begin{array}{llll}0.0 & 0.0 & 0.0 & 0.0 \\ 0.0 & 0.0 & 0.0 & 0.0 \\ 0.0 & 0.0 & 0.0 & 0.0 \\ 0.0 & 0.0 & 0.0 & 0.0 \\ & 0 & & 0\end{array}$
. 
D. RESOURCES BY SUB PROGRAM (cont.) ASSISTANT SECRETARY FOR ENERGY RESEARCH

( $\$$ IN MILLIONS - PERSONNEL IN FTE)

$\begin{array}{ll}F Y & 1982 \\ B A & \text { BO }\end{array}$

Energy Research Total

Total Operating

Capital Equipment

Total ER

Direct Personnel $\begin{array}{rr}70.9 & 72.6 \\ 5.2 & 6.6 \\ 1.4 & 2.6 \\ 77.5 & 81.8\end{array}$

784 \begin{tabular}{ll}
$F Y$ & 1983 \\
\hline$B$ & $B O$ \\
\hline
\end{tabular}

$\begin{array}{rr}72.4 & 72.6 \\ 5.7 & 5.0 \\ 2.9 & 2.8 \\ 80.4 & 80.4 \\ & 750\end{array}$

\begin{tabular}{ll}
$F Y \quad 1984$ \\
\hline$B A$ & $B 0$ \\
\hline
\end{tabular}

$\begin{array}{rr}88.6 & 83 . \\ 6.7 & 6 . \\ 0.0 & 0 . \\ 95.3 & 90 . \\ & 754\end{array}$

$\begin{array}{ll}F Y & 1985 \\ \underline{B A} \quad \underline{B O}\end{array}$

$84.5 \quad 84.3$

$6.7 \quad 6.7$

$\begin{array}{rr}0.0 & 0.0 \\ 91.0\end{array}$

758 \begin{tabular}{cc} 
FY & 1986 \\
$B A$ & BO \\
\hline
\end{tabular}

$84.7 \quad 84.6$

$6.8 \quad 6.8$

$\begin{array}{rr}0.0 & 0.0 \\ 91.5 & 91.4\end{array}$

761 \begin{tabular}{ll}
$F Y$ & 1987 \\
$B \bar{A}$ & $\underline{B} 0$ \\
\hline
\end{tabular}

$85.1 \quad 85.0$

$6.8 \quad 6.8$

$\begin{array}{rr}0.0 & 0.0 \\ 91.9 & 91.8\end{array}$

$\begin{array}{cc}91.9 & 91.8 \\ 765\end{array}$

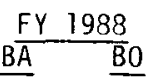

$85.4 \quad 85.3$

$6.8 \quad 6.8$

$0.0 \quad 0.0$

$92.2 \quad 92.1$
769 
D. RESOURCES BY SUB PROGRAM (cont.) ASSISTANT SECRETARY FOR NUCLEAR ENERGY

(\$ IN MILLIONS - PERSONNEL IN FTE)

AE20 Space \& Terr Appl Total Operating Capital Equipment Construction Subtotal

Direct Personnel

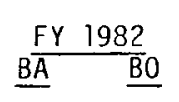

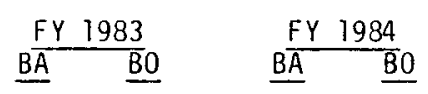

$\underline{F Y \quad 1985}$

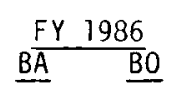

$F Y \quad 1987$
$\underline{B} \quad \underline{B} 0$

FY 1988

$\begin{array}{ll}3.6 & 4.4 \\ 0.3 & 0.5 \\ 0.0 & 0.0\end{array}$

$\begin{array}{ll}0.0 & 0.0 \\ 3.9 & 4.9\end{array}$

$\begin{array}{ll}4.4 & 4.3 \\ 0.2 & 0.2\end{array}$

$\begin{array}{ll}0.2 & 0.2 \\ 0.0 & 0.0\end{array}$

$\begin{array}{ll}4.6 & 4.5 \\ & 49\end{array}$

10.0
0.3

$\begin{array}{ll}0.3 & 0.3 \\ 0.0 & 0.0\end{array}$

$10.3 \quad 8.9$

$10.6 \quad 9.8$

$12.9 \quad 12.1$

$0.0 \quad 0.0$

$10.9 \quad 10.1$
89

$\begin{array}{ll}0.3 & 0.3 \\ 0.0 & 0.0\end{array}$

$\begin{array}{rr}0.0 & 0.0 \\ 13.2 & 12.4\end{array}$

$15.3 \quad 14.5$

$17.4 \quad 16.7$

110

$\begin{array}{llll}0.3 & 0.3 & 0.3 & 0.3\end{array}$

$\begin{array}{rrrr}0.0 & 0.0 & 0.0 & 0.0 \\ 15.6 & 14.8 & 17.7 & 17.0\end{array}$

132

151

AE-Space Nulcear Systems Total Operating Capital Equipment Construction Subtotal AE

Direct Personnel

$\begin{array}{rr}3.6 & 4.4 \\ 0.3 & 0.5 \\ 0.0 & 0.0 \\ 3.9 & 4.9\end{array}$

$\begin{array}{ll}4.4 & 4.3 \\ 0.2 & 0.2\end{array}$

$\begin{array}{ll}0.2 & 0.2 \\ 0.0 & 0.0\end{array}$

$\begin{array}{rr}10.0 & 8.6 \\ 0.3 & 0.3\end{array}$

$4.6 \quad 4.5$

$\begin{array}{rr}0.0 & 0.0 \\ 10.3 & 8.9\end{array}$

$10.6 \quad 9.8$

$12.9 \quad 12.1$

$15.3 \quad 14.5$

$\begin{array}{rr}0.3 & 0.3 \\ 0.0 & 0.0 \\ 13.2 & 12.4\end{array}$

$\begin{array}{rr}15.3 & 14.5 \\ 0.3 & 0.3\end{array}$

$\begin{array}{ll}0.3 & 0.3 \\ 0.0 & 0.0\end{array}$

$10.9 \quad 10.1$

$13.2 \quad 12.4$
110

$\begin{array}{rr}0.0 & 0.0 \\ 15.6 & 14.8\end{array}$ 132

$\begin{array}{ll}17.4 & 16.7\end{array}$ 78

$\begin{array}{ll}0.2 & 0.2 \\ 0.0 & 0.0 \\ 0.0 & 0.0 \\ 0.2 & 0.2 \\ & 2\end{array}$

$\begin{array}{ll}0.1 & 0.1 \\ 0.0 & 0.0 \\ 0.0 & 0.0 \\ 0.1 & 0.1 \\ & 1\end{array}$

$0.3 \quad 0.2$ Total Operating Capital Equipment Subtotal Construction

Direct Personnel

AF15 LMFBR Base Pgm Total Operating Capital Equipment Subtota? Construction

Direct Personnel

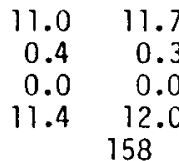

$\begin{array}{rr}9.3 & 9.7 \\ 0.0 & 0.0 \\ 0.0 & 0.0 \\ 9.3 & 9.7 \\ & 133\end{array}$

$\begin{array}{ll}0.0 & 0.0 \\ 0.0 & 0.0\end{array}$

$\begin{array}{ll}0.3 & 0.2 \\ & 2\end{array}$

$0.2 \quad 0.2$

$0.2 \quad 0.2$

0.20 .2

$0.0 \quad 0.0$

$0.0 \quad 0.0$

$\begin{array}{ll}0.2 & 0.2 \\ 2\end{array}$

$\begin{array}{ll}0.2 & 0.2 \\ & 2\end{array}$

$\begin{array}{ll}0.0 & 0.0 \\ 0.0 & 0.0\end{array}$

$\begin{array}{ll}0.0 & 0.0 \\ 0.2 & 0.2\end{array}$

der Reactors

Total Operating

Capital Equipment

Subtotal AF

Direct Personnel

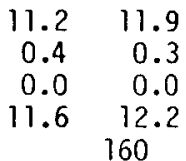

$\begin{array}{lr}9.4 & 9.8 \\ 0.0 & 0.0 \\ 0.0 & 0.0 \\ 9.4 & 9.8 \\ & 134\end{array}$

$\begin{array}{rr}11.0 & 7.6 \\ 0.1 & 0.1 \\ 0.0 & 0.0 \\ 11.1 & 7.7 \\ & 84\end{array}$

$\begin{array}{rr}10.3 & 9.6 \\ 0.1 & 0.1\end{array}$

$9.6 \quad 9.6$

$9.6 \quad 9.6$

$\begin{array}{ll}0.1 & 0.1 \\ 0.0 & 0.0\end{array}$

$9.7 \quad 9.7$
105

$\begin{array}{ll}0.1 & 0.1 \\ 0.0 & 0.0\end{array}$

$\begin{array}{ll}0.0 & 0.0 \\ 9.7 & 9.7\end{array}$

105

$10.4 \cdot 9.7$

105

$\begin{array}{llll}11.3 & 7.8 & 10.5 & 9.8\end{array}$

$9.8 \quad 9.8$

$9.8 \quad 9.8$

$\begin{array}{llll}11.3 & 7.8 & 10.5 & 9.8 \\ 0.1 & 0.1 & 0.1 & 0.1 \\ 0.0 & 0.0 & 0.0 & 0.0\end{array}$

$11.4 \quad 7.9$

$10.6 \quad 9.9$

$\begin{array}{ll}0.1 & 0.1 \\ 0.0 & 0.0\end{array}$

$9.9 \quad 9.9$

$\begin{array}{ll}0.7 & 0.1 \\ 0.0 & 0.0\end{array}$

9.9. 107.9 86

$\begin{array}{ll}0.5 & 0.5 \\ 0.0 & 0.0 \\ 0.0 & 0.0 \\ 0.5 & 0.5\end{array}$

$\begin{array}{ll}0.7 & 0.6 \\ 0.0 & 0.0 \\ 0.0 & 0.0 \\ 0.7 & 0.6 \\ & 8\end{array}$

$\begin{array}{ll}0.3 & 0.2 \\ 0.0 & 0.0 \\ 0.0 & 0.0 \\ 0.3 & 0.2 \\ & 2\end{array}$

$\begin{array}{ll}0.0 & 0.0 \\ 0.0 & 0.0 \\ 0.0 & 0.0 \\ 0.0 & 0.0 \\ & 0\end{array}$

$\begin{array}{ll}0.0 & 0.0 \\ 0.0 & 0.0 \\ 0.0 & 0.0 \\ 0.0 & 0.0 \\ & 0\end{array}$

$\begin{array}{ll}0.0 & 0.0 \\ 0.0 & 0.0 \\ 0.0 & 0.0 \\ 0.0 & 0.0\end{array}$

$0.0 \quad 0.0$ Subtotal

Total Operating Construction

Direct Personnel

4

0

0

0

$\begin{array}{ll}0.0 & 0.0 \\ 0.0 & 0.0\end{array}$

$\begin{array}{ll}0.0 & 0.0 \\ 0.0 & 0.0\end{array}$ 


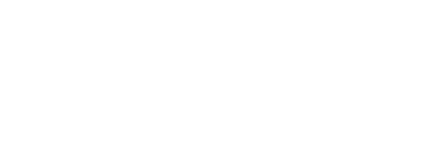

AG36 Lgt Water React

Total Operating

Capital Equipment

Subtotal

Direct Personnel

AG-Converter Reactors

Total Operating

Capital Equipment

Subtotal $A G$

Direct Personnel

AHIO Remedial Action

Total Operating

Capital Equipment

Subtotal

Direct Personnel

AH-Remedial Action Programs Total Operating

Capital Equipment

Construction

Direct Personnel

\section{AP05 Corm Waste Mgt}

Total Operating

Capital Equipment

Subtotal

Direct Personnel

AP-Comm Nuclear Waste Mgt

Total Operating

Capital Equipment

w
Construction

Direct Personnel
D. RESOURCES BY SUB PROGRAM (cont.) ASSISTANT SECRETARY FOR NUCLEAR ENERGY

( $\$$ IN MILLIONS - PERSONNEL IN FTE)

\begin{tabular}{|c|c|c|c|}
\hline \multicolumn{2}{|c|}{ FY 1982} & \multicolumn{2}{|c|}{ FY 1983} \\
\hline$B \overline{B A}$ & $\underline{B} 0$ & $B \bar{A}$ & $\underline{B} 0$ \\
\hline 0.2 & 0.2 & 0.2 & 0.2 \\
\hline 0.0 & 0.0 & 0.0 & 0.0 \\
\hline 0.0 & 0.0 & 0.0 & 0.0 \\
\hline 0.2 & $\begin{array}{l}0.2 \\
2\end{array}$ & 0.2 & $\begin{array}{l}0.2 \\
2\end{array}$ \\
\hline
\end{tabular}

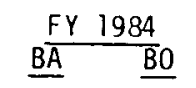

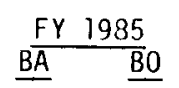

$\begin{array}{ll}0.9 & 0.7 \\ 0.0 & 0.0 \\ 0.0 & 0.0 \\ 0.9 & 0.7 \\ & 6\end{array}$

$\begin{array}{ll}1.0 & 0.9 \\ 0.0 & 0.0 \\ 0.0 & 0.0\end{array}$

$\begin{array}{ll}0.0 & 0.9\end{array}$

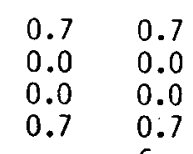

$\begin{array}{ll}0.9 & 0.8 \\ 0.0 & 0.0 \\ 0.0 & 0.0 \\ 0.9 & 0.8\end{array}$

$\begin{array}{ll}1.2 & 0.9 \\ 0.0 & 0.0 \\ 0.0 & 0.0 \\ 1.2 & 0.9\end{array}$

$1.0 \quad 0.9$

$0.0 \quad 0.0$

$0.0 \quad 0.0$

$\begin{array}{ll}1.0 & 0.9 \\ 9\end{array}$

$\begin{array}{llll}0.7 & 0.8 & 0.2 & 0.2 \\ 0.0 & 0.0 & 0.0 & 0.0 \\ 0.0 & 0.0 & 0.0 \hat{0} & 0.00 \\ 0.7 & 0.8 & 0.2 & 0.2 \\ & 9 & & 2\end{array}$

$\begin{array}{ll}0.3 & 0.3 \\ 0.0 & 0.0 \\ 0.0 & 0.0 \\ 0.3 & 0.3 \\ & 2\end{array}$

$\begin{array}{ll}0.0 & 0.0 \\ 0.0 & 0.0 \\ 0.0 & 0.0\end{array}$

$0.0 \quad 0.0$

$\begin{array}{ll}0.0 & 0.0 \\ & 0\end{array}$

$\begin{array}{ll}0.7 & 0.8 \\ 0.0 & 0.0 \\ 0.0 & 0.0 \\ 0.7 & 0.8\end{array}$

$\begin{array}{ll}0.2 & 0.2 \\ 0.0 & 0.0 \\ 0.0 & 0.0 \\ 0.2 & 0.2 \\ & 2\end{array}$

$\begin{array}{ll}0.3 & 0.3 \\ 0.0 & 0.0 \\ 0.0 & 0.0 \\ 0.3 & 0.3\end{array}$

$\begin{array}{ll}0.0 & 0.0 \\ 0.0 & 0.0 \\ 0.0 & 0.0\end{array}$

$\begin{array}{ll}0.0 & 0.0 \\ & 0\end{array}$

$\begin{array}{ll}0.5 & 1.0 \\ 0.0 & 0.0 \\ 0.0 & 0.0 \\ 0.5 & 1.0\end{array}$

$\begin{array}{ll}0.3 & 0.5 \\ 0.0 & 0.0 \\ 0.0 & 0.0 \\ 0.3 & 0.5\end{array}$

$\begin{array}{ll}0.0 & 0.0 \\ 0.0 & 0.0 \\ 0.0 & 0.0 \\ 0.0 & 0.0 \\ & 0\end{array}$

$0.0 \quad 0.0$

$0.0 \quad 0.0$

$0.0 \quad 0.0$

$\begin{array}{ll}0.0 & 0.0 \\ 0 & 0\end{array}$

$\begin{array}{ll}0.5 & 1.0 \\ 0.0 & 0.0 \\ 0.0 & 0.0 \\ 0.5 & 1.0 \\ & 9\end{array}$ $\begin{array}{ll}0.3 & 0.5 \\ 0.0 & 0.0 \\ 0.0 & 0.0 \\ 0.3 & 0.5 \\ & 5\end{array}$

\section{$\begin{array}{lll}0.5 & 0.0 & 0.0\end{array}$}

$\begin{array}{ll}0.0 & 0.0 \\ 0.0 & 0.0 \\ 0.0 & 0.0 \\ 0.0 & 0.0\end{array}$

$\begin{array}{ll}0.0 & 0.0 \\ 0.0 & 0.0 \\ 0.0 & 0.0 \\ 0.0 & 0.0 \\ & 0\end{array}$
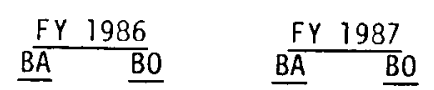

$\frac{F Y \quad 1988}{B A} \quad B 0$

$\begin{array}{ll}0.9 & 0.9 \\ 0.0 & 0.0 \\ 0.0 & 0.0 \\ 0.9 & 0.9\end{array}$

0.90 .9

$0.0 \quad 0.0$

$\begin{array}{ll}0.0 & 0.0 \\ 0.9 & 0.9\end{array}$

0.90 .9

$0.0 \quad 0.0$

$\begin{array}{ll}0.0 & 0.0 \\ 0.9 & 0.9\end{array}$

$\begin{array}{ll}0.9 & 0 . \\ 0.0 & 0.0 \\ 0.0 & 0.0 \\ 0.9 & 0.9 \\ & 9\end{array}$

0.9

$0.9 \quad 0.9$

$0.0 \quad 0.0$

$\begin{array}{ll}0.0 & 0.0 \\ 0.9 & 0.9\end{array}$

$0.9 \quad 0.9$

$0.0 \quad 0.0$

$0.0 \quad 0.0$

$0.9 \quad 0.9$

$\begin{array}{ll}0.0 & 0.0 \\ 0.0 & 0.0 \\ 0.0 & 0.0 \\ 0.0 & 0.0 \\ & 0\end{array}$

$0.0 \quad 0.0$

$0.0 \quad 0.0$

$\begin{array}{ll}0.0 & 0.0 \\ 0.0 & 0.0\end{array}$

$\begin{array}{ll}0.0 & 0.0\end{array}$

$0.0 \quad 0.0$

$0.0 \quad 0.0$

$0.0 \quad 0.0$

$0.0 \quad 0.0$

$\begin{array}{ll}0.0 & 0.0\end{array}$

$\begin{array}{ll}0.0 & 0.0 \\ 0.0 & 0.0\end{array}$

$\begin{array}{ll}0.0 & 0.0 \\ 0.0 & 0\end{array}$

$0.0 \quad 0.0$

$0.0 \quad 0.0$

$\begin{array}{ll}0.0 & 0.0 \\ 0.0 & 0.0\end{array}$

$0.0 \quad 0.0$

$0.0 \quad 0.0$

$0.0 \quad 0.0$

$0.0 \quad 0.0$

$0.0 \quad 0.0$

$\begin{array}{ll}0.0 & 0.0 \\ 0.0 & 0.0\end{array}$

$\begin{array}{ll}0.0 & 0.0\end{array}$

$0.0 \quad 0.0$

$0.0 \quad 0.0$

$\begin{array}{ll}0.0 & 0.0 \\ 0.0 & 0.0\end{array}$

$0.0 \quad 0.0$

$0.0 \quad 0.0$

$0.0 \quad 0.0$

$0.0 \quad 0.0$

$\begin{array}{ll}0.0 & 0.0 \\ 0.0 & 0.0 \\ 0.0 & 0.0 \\ 0.0 & 0.0 \\ & 0\end{array}$

0.
0.0
0.0

$\begin{array}{ll}0.0 & 0.0 \\ 0.0 & 0.0 \\ 0.0 & 0.0 \\ 0.0 & 0.0\end{array}$

$\begin{array}{ll}0.0 & 0.0 \\ 0.0 & 0.0 \\ 0.0 & 0.0 \\ 0.0 & 0.0\end{array}$

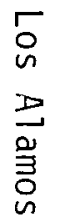



ASSISTANT SECRETARY FOR NUCLEAR ENERGY

( $\$$ IN MILLIONS - PERSONNEL IN FTE)

\begin{tabular}{|c|c|c|c|c|c|c|c|c|c|c|c|c|c|c|}
\hline & FY & 1982 & $F Y$ & 983 & $F Y$ & 984 & $F Y$ & 985 & FY & 986 & FY & 1987 & $F Y$ & 988 \\
\hline & $B \bar{A}$ & $B O$ & $B \bar{A}$ & $\underline{B} 0$ & $\underline{B \bar{A}}$ & $\bar{B} 0$ & $B \bar{A}$ & $\mathrm{~B} 0$ & $B \bar{A}$ & 80 & $B \bar{A}$ & $\mathrm{~B} 0$ & $B \bar{A}$ & $B 0$ \\
\hline $\begin{array}{l}\text { AW00 } \\
\text { Total operating } \\
\text { Capital Equipment } \\
\text { Construction } \\
\text { Subtotal } \\
\text { Direct Personel }\end{array}$ & $\begin{array}{l}0.0 \\
0.0 \\
0.0 \\
0.0\end{array}$ & $\begin{array}{l}0.0 \\
0.0 \\
0.8 \\
0.8 \\
0\end{array}$ & $\begin{array}{l}0.0 \\
0.0 \\
0.0 \\
0.0\end{array}$ & $\begin{array}{l}0.0 \\
0.0 \\
0.0 \\
0.0 \\
0\end{array}$ & $\begin{array}{l}0.0 \\
0.0 \\
0.0 \\
0.0\end{array}$ & $\begin{array}{l}0.0 \\
0.0 \\
0.0 \\
0.0 \\
0\end{array}$ & $\begin{array}{l}0.0 \\
0.0 \\
0.0 \\
0.0\end{array}$ & $\begin{array}{l}0.0 \\
0.0 \\
0.0 \\
0.0 \\
0\end{array}$ & $\begin{array}{l}0.0 \\
0.0 \\
0.0 \\
0.0\end{array}$ & $\begin{array}{l}0.0 \\
0.0 \\
0.0 \\
0.0 \\
0\end{array}$ & $\begin{array}{l}0.0 \\
0.0 \\
0.0 \\
0.0\end{array}$ & $\begin{array}{l}0.0 \\
0.0 \\
0.0 \\
0.0 \\
0\end{array}$ & $\begin{array}{l}0.0 \\
0.0 \\
0.0 \\
0.0\end{array}$ & $\begin{array}{l}0.0 \\
0.0 \\
0.0 \\
0.0 \\
0\end{array}$ \\
\hline $\begin{array}{l}\text { AW01 Adv Isotope } \\
\text { Total Operating } \\
\text { Capital Equipment } \\
\text { Construction } \\
\text { Subtotal } \\
\text { Direct Personel }\end{array}$ & $\begin{array}{r}18.4 \\
0.3 \\
0.0 \\
18.7\end{array}$ & $\begin{array}{r}20.8 \\
1.7 \\
0.0 \\
22.5 \\
174\end{array}$ & $\begin{array}{l}0.0 \\
0.0 \\
0.0 \\
0.0\end{array}$ & $\begin{array}{l}0.0 \\
0.0 \\
0.0 \\
0.0 \\
0\end{array}$ & $\begin{array}{l}0.0 \\
0.0 \\
0.0 \\
0.0\end{array}$ & $\begin{array}{l}0.0 \\
0.0 \\
0.0 \\
0.0 \\
0\end{array}$ & $\begin{array}{l}0.0 \\
0.0 \\
0.0 \\
0.0\end{array}$ & $\begin{array}{l}0.0 \\
0.0 \\
0.0 \\
0.0 \\
0\end{array}$ & $\begin{array}{l}0.0 \\
0.0 \\
0.0 \\
0.0\end{array}$ & $\begin{array}{l}0.0 \\
0.0 \\
0.0 \\
0.0 \\
0\end{array}$ & $\begin{array}{l}0.0 \\
0.0 \\
0.0 \\
0.0\end{array}$ & $\begin{array}{l}0.0 \\
0.0 \\
0.0 \\
0.0 \\
0\end{array}$ & $\begin{array}{l}0.0 \\
0.0 \\
0.0 \\
0.0\end{array}$ & $\begin{array}{l}0.0 \\
0.0 \\
0.0 \\
0.0 \\
0\end{array}$ \\
\hline $\begin{array}{c}\text { AW-ADV Isotope Separ Techn } \\
\text { Total Operating } \\
\text { Capital Equipment } \\
\text { Construction } \\
\text { Subtotal AW } \\
\text { Direct Personel }\end{array}$ & $\begin{array}{r}18.4 \\
0.3 \\
0.9 \\
19.6\end{array}$ & $\begin{array}{r}20.8 \\
1.7 \\
0.8 \\
23.3 \\
174\end{array}$ & $\begin{array}{l}0.0 \\
0.0 \\
0.0 \\
0.0\end{array}$ & $\begin{array}{l}0.0 \\
0.0 \\
0.0 \\
0.0 \\
0\end{array}$ & $\begin{array}{l}0.0 \\
0.0 \\
0.0 \\
0.0\end{array}$ & $\begin{array}{l}0.0 \\
0.0 \\
0.0 \\
0.0 \\
0\end{array}$ & $\begin{array}{l}0.0 \\
0.0 \\
0.0 \\
0.0\end{array}$ & $\begin{array}{l}0.0 \\
0.0 \\
0.0 \\
0.0 \\
0\end{array}$ & $\begin{array}{l}0.0 \\
0.0 \\
0.0 \\
0.0\end{array}$ & $\begin{array}{l}0.0 \\
0.0 \\
0.0 \\
0.0 \\
0\end{array}$ & $\begin{array}{l}0.0 \\
0.0 \\
0.0 \\
0.0\end{array}$ & $\begin{array}{l}0.0 \\
0.0 \\
0.0 \\
0.0 \\
0\end{array}$ & $\begin{array}{l}0.0 \\
0.0 \\
0.0 \\
0.0\end{array}$ & $\begin{array}{l}0.0 \\
0.0 \\
0.0 \\
0.0 \\
0\end{array}$ \\
\hline $\begin{array}{l}\text { CD20 Hydrogeo Survy } \\
\text { Total Operating } \\
\text { Capital Equipment } \\
\text { Construction } \\
\text { Subtotal } \\
\text { Direct Personnel }\end{array}$ & $\begin{array}{l}0.3 \\
0.0 \\
0.0 \\
0.3\end{array}$ & $\begin{array}{l}0.3 \\
0.0 \\
0.0 \\
0.3 \\
4\end{array}$ & $\begin{array}{l}0.0 \\
0.0 \\
0.0 \\
0.0\end{array}$ & $\begin{array}{l}0.0 \\
0.0 \\
0.0 \\
0.0 \\
0\end{array}$ & $\begin{array}{l}0.0 \\
0.0 \\
0.0 \\
0.0\end{array}$ & $\begin{array}{l}0.0 \\
0.0 \\
0.0 \\
0.0 \\
0\end{array}$ & $\begin{array}{l}0.0 \\
0.0 \\
0.0 \\
0.0\end{array}$ & $\begin{array}{l}0.0 \\
0.0 \\
0.0 \\
0.0 \\
0\end{array}$ & $\begin{array}{l}0.0 \\
0.0 \\
0.0 \\
0.0\end{array}$ & $\begin{array}{l}0.0 \\
0.0 \\
0.0 \\
0.0 \\
0\end{array}$ & $\begin{array}{l}0.0 \\
0.0 \\
0.0 \\
0.0\end{array}$ & $\begin{array}{l}0.0 \\
0.0 \\
0.0 \\
0.0 \\
0\end{array}$ & $\begin{array}{l}0.0 \\
0.0 \\
0.0 \\
0.0\end{array}$ & $\begin{array}{l}0.0 \\
0.0 \\
0.0 \\
0.0 \\
0\end{array}$ \\
\hline $\begin{array}{c}\text { CD-Uran Supply and Enrichment } \\
\text { Total Operating } \\
\text { Capital Equipment } \\
\text { Construction } \\
\text { Subtotal CD } \\
\text { Direct Personnel }\end{array}$ & $\begin{array}{l}0.3 \\
0.0 \\
0.0 \\
0.3\end{array}$ & $\begin{array}{l}0.3 \\
0.0 \\
0.0 \\
0.3 \\
4\end{array}$ & $\begin{array}{l}0.0 \\
0.0 \\
0.0 \\
0.0\end{array}$ & $\begin{array}{l}0.0 \\
0.0 \\
0.0 \\
0.0 \\
0\end{array}$ & $\begin{array}{l}0.0 \\
0.0 \\
0.0 \\
0.0\end{array}$ & $\begin{array}{l}0.0 \\
0.0 \\
0.0 \\
0.0 \\
0\end{array}$ & $\begin{array}{l}0.0 \\
0.0 \\
0.0 \\
0.0\end{array}$ & $\begin{array}{l}0.0 \\
0.0 \\
0.0 \\
0.0 \\
0\end{array}$ & $\begin{array}{l}0.0 \\
0.0 \\
0.0 \\
0.0\end{array}$ & $\begin{array}{l}0.0 \\
0.0 \\
0.0 \\
0.0 \\
0\end{array}$ & $\begin{array}{l}0.0 \\
0.0 \\
0.0 \\
0.0\end{array}$ & $\begin{array}{l}0.0 \\
0.0 \\
0.0 \\
0.0 \\
0\end{array}$ & $\begin{array}{l}0.0 \\
0.0 \\
0.0 \\
0.0\end{array}$ & $\begin{array}{l}0.0 \\
0.0 \\
0.0 \\
0.0 \\
0\end{array}$ \\
\hline $\begin{array}{c}\text { Nuclear Energy Total } \\
\text { Total Operating } \\
\text { Capital Equipment } \\
\text { Construction } \\
\text { Total NE } \\
\text { Direct Personnel }\end{array}$ & $\begin{array}{r}35.4 \\
1.0 \\
0.9 \\
37.3\end{array}$ & $\begin{array}{r}39.9 \\
2.5 \\
0.8 \\
43.2 \\
412\end{array}$ & $\begin{array}{r}15.2 \\
0.2 \\
0.0 \\
15.4\end{array}$ & $\begin{array}{r}15.6 \\
0.2 \\
0.0 \\
15.8 \\
200\end{array}$ & $\begin{array}{r}22.8 \\
0.4 \\
0.0 \\
23.2\end{array}$ & $\begin{array}{r}17.6 \\
0.4 \\
0.0 \\
18.0 \\
174\end{array}$ & $\begin{array}{r}22.1 \\
0.4 \\
0.0 \\
22.5\end{array}$ & $\begin{array}{r}20.5 \\
0.4 \\
0.0 \\
20.9 \\
204\end{array}$ & $\begin{array}{r}23.6 \\
0.4 \\
0.0 \\
24.0\end{array}$ & $\begin{array}{r}22.8 \\
0.4 \\
0.0 \\
23.2 \\
226\end{array}$ & $\begin{array}{r}26.0 \\
0.4 \\
0.0 \\
26.4\end{array}$ & $\begin{array}{r}25.2 \\
0.4 \\
0.0 \\
25.6 \\
248\end{array}$ & $\begin{array}{r}28.1 \\
0.4 \\
0.0 \\
28.5\end{array}$ & $\begin{array}{r}27.4 \\
0.4 \\
0.0 \\
27.8 \\
267\end{array}$ \\
\hline
\end{tabular}


D. RESOURCES BY SUB PROGRAM (cont.)

ASSISTANT SECRETARY FOR CONSERVATION/RENEW ENERGY (\$ IN MILLIONS - PERSONNEL IN FTE)

AK05 Power Delivery Total Operating Capital Equipment Subtotal Construction

Direct Personnel

\section{AK-Electric Energy Systems} Total Operating Capital Equipment Construction

Subtotal AK

Direct Personnel

AL05 Battery Storage Tota? Operating Capital Equipment

Subtotal Construction

Direct Personnel

AL10 Thermal Mech St

Total Operating Capital Equipment

Subtotal Construction

Direct Personnel

AL-Energy Storage Systems Total Operating Capital Equipment Subtotal AL

Direct Personnel

AM10 Geothermal Tech

$$
\text { Total Operating }
$$

Capital Equipment
Construction

Subtotal

$\ddot{\omega}$

Direct Personnel

\section{FY 1982}

$$
\begin{array}{ll}
F Y & 1983 \\
\hline B A & B \\
\hline
\end{array}
$$

$\begin{array}{ll}0.0 & 0.1 \\ 0.0 & 0.0\end{array}$

0.00 .0

$0.0 \quad 0.1$

$\begin{array}{ll}0.0 & 0.0 \\ 0.0 & 0.0 \\ 0.0 & 0.0 \\ 0.0 & 0.0 \\ & 0\end{array}$

$\begin{array}{ll}0.0 & 0.1 \\ 0.0 & 0.0\end{array}$

$0.0 \quad 0.0$

$\begin{array}{ll}0.0 & 0.1 \\ & 0\end{array}$

$\begin{array}{ll}1.6 & 0.3 \\ 0.0 & 0.0\end{array}$

$\begin{array}{ll}0.0 & 0.0 \\ 0.0 & 0.0\end{array}$

$\begin{array}{ll}1.6 & 0.3\end{array}$

$\begin{array}{ll}1.6 & 1.1 \\ 0.1 & 0.5 \\ 0.0 & 0.0 \\ 1.7 & 1.6\end{array}$

9

$\begin{array}{lr}3.2 & 1.4 \\ 0.1 & 0.5 \\ 0.0 & 0.0 \\ 3.3 & 1.9\end{array}$

12

$\begin{array}{rr}10.2 & 11.0 \\ 0.4 & 0.6 \\ 0.0 & 0.0 \\ 10.6 & 11.6 \\ & 80\end{array}$

$\begin{array}{ll}0.0 & 0.0 \\ 0.0 & 0.0 \\ 0.0 & 0.0 \\ 0.0 & 0.0\end{array}$

$\begin{array}{cc}1.0 & 2.3 \\ 0.0 & 0.0 \\ 0.0 & 0.0 \\ 1.0 & 2.3 \\ & 19\end{array}$

$0.5 \quad 1.3$

$0.0 \quad 0.0$

$0.0 \quad 0.0$

$\begin{array}{ll}0.0 & 0.0 \\ 0.0 & 0.0 \\ 0.0 & 0.0 \\ 0.0 & 0.0 \\ & 0\end{array}$

$\begin{array}{ll}0.0 & 0.0 \\ 0.0 & 0.0\end{array}$

$\begin{array}{ll}0.0 & 0.0\end{array}$

$\begin{array}{ll}0.0 & 0.0\end{array}$

$\begin{array}{ll}0.0 & 0.0 \\ & 0\end{array}$

$0.0 \quad 0.0$

$\begin{array}{ll}0.0 & 0.0 \\ 0.0 & 0.0\end{array}$

$0.0 \quad 0.0$

$\begin{array}{ll}0.0 & 0.0 \\ & 0\end{array}$

$0.0 \quad 0.0$

$0.0 \quad 0.0$

$0.0 \quad 0.0$

$\begin{array}{ll}0.0 & 0.0 \\ & 0\end{array}$

$0.0 \quad 0.0$

$0.0 \quad 0.0$

$0.0 \quad 0.0$

$0.0 \quad 0.0$

30

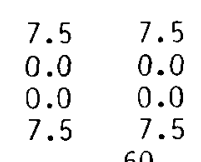

60

0

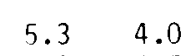

$0.5 \quad 0.5$

$0.0 \quad 0.0$

$\begin{array}{cc}5.8 & 4.5 \\ & 27\end{array}$$$
\begin{array}{ll}
F Y & 1984 \\
\hline B & B 0 \\
\hline
\end{array}
$$

$\begin{array}{ll}F Y & 1985 \\ B A & B 0\end{array}$

$\begin{array}{ll}0.0 & 0.0 \\ 0.0 & 0.0\end{array}$

$0.0 \quad 0.0$

$0.0 \quad 0.0$

0

$0.0 \quad 0.0$

$0.0 \quad 0.0$

$\begin{array}{ll}0.0 & 0.0 \\ 0.0 & 0.0\end{array}$

0.0
0

$0.0 \quad 0.0$

$0.0 \quad 0.0$

$\begin{array}{ll}0.0 & 0.0 \\ 0.0 & 0.0\end{array}$

0.000

$\begin{array}{ll}0.0 & 0.0 \\ 0.0 & 0.0\end{array}$

$0.0 \quad 0.0$

$0.0 \quad 0.0$

0.0

$0.0 \quad 0.0$

$0.0 \quad 0.0$

$0.0 \quad 0.0$

$0.0 \quad 0.0$ $\begin{array}{ll}4.0 & 4.0 \\ 0.5 & 0.5 \\ 0.0 & 0.0 \\ 4.5 & 4.5 \\ & 27\end{array}$ \begin{tabular}{cc}
$F Y$ & 1986 \\
$B \bar{A}$ & $\quad \bar{B} 0$ \\
\hline
\end{tabular}

$\begin{array}{ll}0.0 & 0.0 \\ 0.0 & 0.0\end{array}$

$0.0 \quad 0.0$

$0.0 \quad 0.0$

$\begin{array}{ll}0.0 & 0.0 \\ 0.0 & 0.0 \\ 0.0 & 0.0\end{array}$

$0.0 \quad 0.0$

$0.0 \quad 0.0$

$0.0 \quad 0.0$

$\begin{array}{ll}0.0 & 0.0\end{array}$

$0.0 \quad 0.0$

$0.0 \quad 0.0$

$\begin{array}{ll}0.0 & 0.0\end{array}$

0.0
0

$\begin{array}{ll}0.0 & 0.0\end{array}$

$0.0 \quad 0.0$

$0.0 \quad 0.0$

0

$0.0 \quad 0.0$

$0.0 \quad 0.0$

$0.0 \quad 0.0$

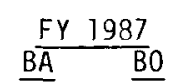

FY 1988

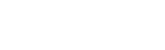

$\begin{array}{ll}0.0 & 0.0 \\ 0.0 & 0.0\end{array}$

$\begin{array}{ll}0.0 & 0.0 \\ 0.0 & 0.0\end{array}$

$\begin{array}{ll}0.0 & 0.0\end{array}$

$\begin{array}{ll}0.0 & 0.0\end{array}$

$\begin{array}{ll}0.0 & 0.0 \\ 0.0 & 0.0\end{array}$

$\begin{array}{ll}0.0 & 0.0 \\ 0.0 & 0.0\end{array}$

\section{$0.0 \quad 0.0$}

$0.0 \quad 0.0$

$0.0 \quad 0.0$

$0.0 \quad 0.0$

$\begin{array}{ll}0.0 & 0.0 \\ 0.0 & 0.0\end{array}$

$\begin{array}{ll}0.0 & 0.0 \\ 0.0 & 0.0\end{array}$

$0.0 \quad 0.0$

U. 0 Uิ.0

$0.0 \quad 0.0$

$0.0 \quad 0.0$

$\begin{array}{ll}0.0 & 0.0 \\ \text { uิ. } & \hat{0} . \hat{0}\end{array}$

$\begin{array}{ll}0.0 & 0.0 \\ 0.0 & 0.0\end{array}$

$0.0-0.0$

$\begin{array}{ll}0.0 & 0 . \\ 0.0 & 0 .\end{array}$

$0.0 \quad 0.0$

$\begin{array}{ll}0.0 & 0.0\end{array}$

$\begin{array}{ll}0.0 & 0.0 \\ 0.0 & 0.0\end{array}$

$\begin{array}{ll}0.0 & 0.0 \\ 0.0 & 0.0\end{array}$

$\begin{array}{ll}0.0 & 0.0\end{array}$

$0.0 \quad 0$.

$0.0 \quad 0$.

$0.0 \quad 0.0$

$0.0 \quad 0.0$

$0.0 \quad 0.0$

$\begin{array}{ll}0.0 & 0.0 \\ 0.0 & 0.0\end{array}$

$\begin{array}{ll}0.0 & 0.0 \\ 0.0 & 0.0 \\ 0.0 & 0.0 \\ 0.0 & 0.0 \\ & 0\end{array}$ 
ASSISTANT SECRETARY FOR CONSERVATION/RENEW ENERGY ( $\$$ IN MILLIONS - PERSONNEL IN FTE)

AM15 Hydrothermal Re

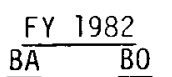

Total Operating

Capital Equipment

Subtotal

Direct Personnel

AM-Geothermal

otal Operating

Capital Equipment Construction

Subtotal AM

Direct Personnel

EBOI Solar App/Bldg

Total Operating

Capital Equipment

Subtotal Construction

Direct Personne 1

EB02 Solar App/Indy

Total Operating

Capital Equipment

Subtotal Construction

Direct Personnel

EB-Solar Energy

Total Operating Capital Equipment

Subtotal EB Construction

Direct Personnel

ECOI Building Systems

Total Operating Capital Equipment

Subtotal Construction

Direct Personne]

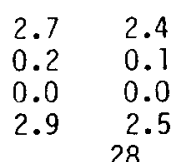

$\begin{array}{ll}0.2 & 0.2 \\ 0.0 & 0.0 \\ 0.0 & 0.0 \\ 0.2 & 0.2\end{array}$

$\begin{array}{ll}0.2 & 0.0 \\ 0.0 & 0.0 \\ 0.0 & 0.0 \\ 0.2 & 0.0 \\ & 0\end{array}$

$\begin{array}{ll}0.0 & 0.0 \\ 0.0 & 0.0 \\ 0.0 & 0.0 \\ 0.0 & 0.0\end{array}$
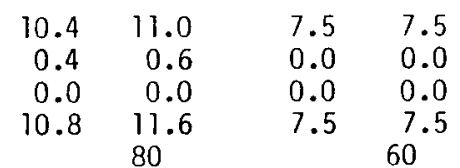

0.

$B$ BA $\quad$ B

$F Y \quad 1985$
$B A \quad B O$

$\frac{F Y \quad 1986}{B A}$

$\frac{F Y \quad 1987}{B A} \quad B 0$

$F Y \quad 1988$
$B A A$

$\begin{array}{llll}0.0 & 0.0 & 0.0 & 0.0 \\ 0.0 & 0.0 & 0.0 & 0.0 \\ 0.0 & 0.0 & 0.0 & 0.0 \\ 0.0 & 0.0 & 0.0 & 0.0 \\ & 0 & & 0\end{array}$

$0.0 \quad 0.0$

$0.0 \quad 0.0$

$\begin{array}{ll}0.0 & 0.0 \\ 0.0 & 0.0\end{array}$

0

$0.0 \quad 0.0$

$\begin{array}{ll}0.0 & 0.0 \\ 0.0 & 0.0\end{array}$

$0.0 \quad 0.0$

0

$0.0 \quad 0.0$

$0.0 \quad 0.0$

$0.0 \quad 0.0$

$\begin{array}{ll}0.0 & 0.0 \\ & 0\end{array}$

$0.0 \quad 0.0$

$0.0 \quad 0.0$

$0.0 \quad 0.0$

$\begin{array}{ll}0.0 & 0.0 \\ & 0\end{array}$

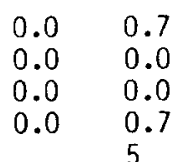

$\begin{array}{ll}0.0 & 0.0 \\ 0.0 & 0.0 \\ 0.0 & 0.0 \\ 0.0 & 0.0\end{array}$

$\begin{array}{ll}0.0 & 0.0 \\ 0.0 & 0.0\end{array}$

$\begin{array}{ll}0.0 & 0.0 \\ 0.0 & 0.0\end{array}$

$\begin{array}{ll}0.0 & 0.0 \\ & 0\end{array}$

$\begin{array}{ll}0.0 & 0.0 \\ 0.0 & 0.0\end{array}$

$\begin{array}{ll}0.0 & 0.0 \\ 0.0 & 0.0\end{array}$

$\begin{array}{ll}0.0 & 0.0 \\ & 0\end{array}$

$0.0 \quad 0.0$

$0.0 \quad 0.0$

$0.0 \quad 0.0$

$\begin{array}{ll}0.0 & 0.0 \\ & 0\end{array}$

$0.0 \quad 0.0$

$0.0 \quad 0.0$

$0.0 \quad 0.0$

$\begin{array}{ll}0.0 & 0.0 \\ & 0\end{array}$

$\begin{array}{ll}0.1 & 0.2 \\ 0.0 & 0.1 \\ 0.0 & 0.0 \\ 0.1 & 0.3\end{array}$

$\begin{array}{ll}0.0 & 0.0 \\ 0.0 & 0.0 \\ 0.0 & 0.0 \\ 0.0 & 0.0 \\ & 0\end{array}$

$\begin{array}{ll}0.0 & 0.0 \\ 0.0 & 0.0 \\ 0.0 & 0.0 \\ 0.0 & 0.0\end{array}$

$\begin{array}{ll}0.0 & 0 . \\ 0.0 & 0.0 \\ 0.0 & 0.0 \\ 0.0 & 0.0 \\ & 0\end{array}$

$\begin{array}{ll}0.0 & 0.0 \\ 0.0 & 0.0 \\ 0.0 & 0 \\ 0.0 & 0 \\ & 0\end{array}$

$\begin{array}{ll}0.0 & 0 \\ 0.0 & 0 \\ 0.0 & 0 \\ 0.0 & 0 \\ & 0\end{array}$

$0.0 \quad 0.0$

$0.0 \quad 0.0$

$0.0 \quad 0.0$

$0.0 \quad 0.0$

$\begin{array}{lrll}2.8 & 2.6 & 0.0 & 0.7 \\ 0.2 & 0.2 & 0.0 & 0.0 \\ 0.0 & 0.0 & 0.0 & 0.0 \\ 3.0 & 2.8 & 0.0 & 0.7 \\ & 29 & & 5\end{array}$

$\begin{array}{ll}0.0 & 0.0 \\ 0.0 & 0.0 \\ 0.0 & 0.0 \\ 0.0 & 0.0\end{array}$

$\begin{array}{ll}0.0 & 0.0 \\ 0.0 & 0.0 \\ 0.0 & 0.0 \\ 0.0 & 0.0 \\ & 0\end{array}$

$\begin{array}{ll}0.0 & 0.0 \\ 0.0 & 0.0 \\ 0.0 & 0 \\ 0.0 & 0 \\ & 0\end{array}$

$\begin{array}{ll}0.0 & 0.0 \\ 0.0 & 0.0 \\ 0.0 & 0.0 \\ 0.0 & 0.0 \\ & 0\end{array}$

$\begin{array}{ll}0.0 & 0.0 \\ 0.0 & 0.0 \\ 0.0 & 0.0 \\ 0.0 & 0.0 \\ & 0\end{array}$

$\begin{array}{ll}0.0 & 0.0 \\ 0.0 & 0.0 \\ 0.0 & 0.0 \\ 0.0 & 0.0 \\ & 0\end{array}$

$\begin{array}{ll}0.0 & 0 . \\ 0.0 & 0.0 \\ 0.0 & 0.0 \\ 0.0 & 0.0 \\ & 0\end{array}$

$0.0 \quad 0.0$

$\begin{array}{ll}0.0 & 0.0 \\ 0.0 & 0.0\end{array}$

$\begin{array}{ll}0.0 & 0.0 \\ & 0\end{array}$

$\begin{array}{llll}0.0 & 0.0 & 0.0 & 0.0 \\ 0.0 & 0.0 & 0.0 & 0.0 \\ 0.0 & 0.0 & 0.0 & 0.0 \\ 0.0 & 0.0 & 0.0 & 0.0 \\ & 0 & & 0\end{array}$




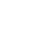

D. RESOURCES BY SUB PROGRAM (cont.)

ASSISTANT SECRETARY FOR CONSERVATION/RENEW ENERGY

$$
\text { ( } \$ \text { IN MILLIONS - PERSONNEL IN FTE) }
$$

ECO4 Urban Waste

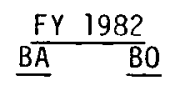

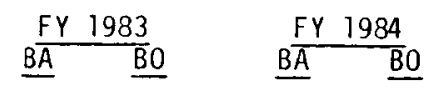

$\underline{B Y \quad 1985}$

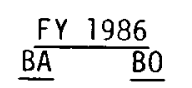

$\underline{B Y} \begin{array}{ll}\text { BY } & 1987 \\ & \underline{B} 0\end{array}$

$\frac{F Y 1988}{B A}$

Total Operating

Capital Equipment

Subtotal

Construction

$\begin{array}{llll}0.1- & 0.1 & 0.0 & 0.0 \\ 0.0 & 0.0 & 0.0 & 0.0 \\ 0.0 & 0.0 & 0.0 & 0.0 \\ 0.1- & 0.1 & 0.0 & 0.0\end{array}$

$\begin{array}{ll}0.0 & 0.0 \\ 0.0 & 0.0 \\ 0.0 & 0.0 \\ 0.0 & 0.0\end{array}$

$\begin{array}{ll}0.0 & 0.0 \\ 0.0 & 0.0 \\ 0.0 & 0.0 \\ 0.0 & 0.0 \\ & 0\end{array}$

$\begin{array}{ll}0.0 & 0.0 \\ 0.0 & 0.0 \\ 0.0 & 0.0 \\ 0.0 & 0.0\end{array}$

$0.0 \quad 0.0$

$\begin{array}{ll}0.0 & 0.0 \\ 0.0 & 0.0\end{array}$

$0.0 \quad 0.0$

Direct Personnel

$\begin{array}{ll}0.1 & 0.3 \\ 0.0 & 0.0 \\ 0.0 & 0.0 \\ 0.1 & 0.3\end{array}$

Subtotal EC

ing \& Community Systems Total Operating Capital Equipment

Direct Personnel

$\begin{array}{ll}0.0 & 0.0 \\ 0.0 & 0.0\end{array}$

$\begin{array}{ll}0.0 & 0.0 \\ 0.0 & 0.0 \\ 0.0 & 0.0\end{array}$

$\begin{array}{ll}0.0 & 0.0 \\ 0.0 & 0.0\end{array}$

$\begin{array}{ll}0.0 & 0.0 \\ 0.0 & 0.0 \\ 0.0 & 0.0 \\ 0.0 & 0.0\end{array}$

$\begin{array}{ll}0.0 & 0.0 \\ 0.0 & 0.0 \\ 0.0 & 0.0\end{array}$

$\begin{array}{ll}0.1 & 0.1 \\ 0.0 & 0.0 \\ 0.0 & 0.0 \\ 0.1 & 0.1\end{array}$

$\begin{array}{ll}0.0 & 0.0 \\ 0.0 & 0.0 \\ 0.0 & 0.0 \\ 0.0 & 0.0 \\ & 0\end{array}$

$\begin{array}{ll}0.0 & 0.0 \\ 0.0 & 0.0 \\ 0.0 & 0.0\end{array}$

Subtotal

Total Operating

Capital Equipment

Direct Personnel

EEO3 Elect Vehicle

Total Operating

Capital Equipment
Construction

Subtotal

Direct Personne?

EE-Transportation Energy Con

Total Operating

Capital Equipment

Subtotal EE

Direct Personnel

$\begin{array}{ll}0.6 & 0.6 \\ 0.0 & 0.0 \\ 0.0 & 0.0 \\ 0.6 & 0.6\end{array}$

$\begin{array}{ll}0.0 & 0.0 \\ 0.0 & 0.0 \\ 0.0 & 0.0 \\ 0.0 & 0.0 \\ & 0\end{array}$

$\begin{array}{ll}0.0 & 0.0 \\ 0.0 & 0.0\end{array}$

$\begin{array}{ll}0.0 & 0.0 \\ 0.0 & 0.0 \\ 0.0 & 0.0\end{array}$

$\begin{array}{ll}0.7 & 0.7 \\ 0.0 & 0.0 \\ 0.0 & 0.0 \\ 0.7 & 0.7 \\ & 7\end{array}$

$\begin{array}{ll}0.0 & 0.0 \\ 0.0 & 0.0 \\ 0.0 & 0.0 \\ 0.0 & 0.0 \\ & 0\end{array}$

$\begin{array}{ll}0.0 & 0.0 \\ 0.0 & 0.0 \\ 0.0 & 0.0 \\ 0.0 & 0.0 \\ & 0\end{array}$

$\begin{array}{ll}0.5 & 0.5 \\ 0.0 & 0.0 \\ 0.0 & 0.0 \\ 0.5 & 0.5\end{array}$

$\begin{array}{ll}0.6 & 0.6 \\ 0.0 & 0.0 \\ 0.0 & 0.0 \\ 0.6 & 0.6 \\ & 5\end{array}$

$\begin{array}{ll}0.0 & 0.0 \\ 0.0 & 0.0 \\ 0.0 & 0.0 \\ 0.0 & 0.0 \\ & 0\end{array}$

$\begin{array}{ll}0.0 & 0.0 \\ 0.0 & 0.0 \\ 0.0 & 0.0 \\ 0.0 & 0.0\end{array}$

$\begin{array}{ll}0.0 & 0.0 \\ 0.0 & 0.0 \\ 0.0 & 0.0 \\ 0.0 & 0.0\end{array}$

$\begin{array}{ll}0.0 & 0.0 \\ 0.0 & 0.0 \\ 0.0 & 0.0 \\ 0.0 & 0.0\end{array}$

$\begin{array}{ll}0.0 & 0.0 \\ 0.0 & 0.0 \\ 0.0 & 0.0 \\ 0.0 & 0.0\end{array}$

Direct Personnel

Total Operating
Total

Capital Equipment

$\omega_{0}^{\omega}$ 
D. RESOURCES BY SUB PROGRAM (cont.)

ASSISTANT SECRETARY FOR CONSERVATION/RENEW ENERGY

( $\$$ IN MILLIONS - PERSONNEL IN FTE)

$$
\begin{aligned}
& F Y 1982 \\
& B A \quad B 0 \\
& \hline B
\end{aligned}
$$

EG-Multi Sector

Total Operating

Capital Equipment Subtotal EG

Direct Personne

Conservation/Renew Total

Total Operating

Capital Equipment

Construction

Total CE

Direct Personnel

$\begin{array}{ll}0.5 & 0.5 \\ 0.0 & 0.0 \\ 0.0 & 0.0 \\ 0.5 & 0.5 \\ & 5\end{array}$

$\begin{array}{rr}17.7 & 16.6 \\ 0.7 & 1.3 \\ 0.0 & 0.0 \\ 18.4 & 17.9 \\ & 135\end{array}$

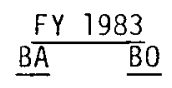

$\begin{array}{ll}0.6 & 0.6 \\ 0.0 & 0.0 \\ 0.0 & 0.0 \\ 0.6 & 0.6\end{array}$

$\begin{array}{cr}9.6 & 12.4 \\ 0.0 & 0.0 \\ 0.0 & 0.0 \\ 9.6 & 12.4 \\ & 100\end{array}$

\begin{tabular}{ll} 
FY & 1984 \\
\hline$B A$ & $B O$
\end{tabular}

\begin{tabular}{ll}
$F Y$ & 1985 \\
$B A$ & $B O$ \\
\hline
\end{tabular}

$\begin{array}{llll}0.0 & 0.0 & 0.0 & 0.0 \\ 0.0 & 0.0 & 0.0 & 0.0 \\ 0.0 & 0.0 & 0.0 & 0.0 \\ 0.0 & 0.0 & 0.0 & 0.0 \\ & 0 & & 0\end{array}$

$\begin{array}{ll}5.3 & 4.0 \\ 0.5 & 0.5 \\ 0.0 & 0.0 \\ 5.8 & 4.5 \\ & 27\end{array}$

$F Y \quad 1986$
$B A$

$\begin{array}{ll}0.0 & 0.0 \\ 0.0 & 0.0 \\ 0.0 & 0.0 \\ 0.0 & 0.0 \\ & 0\end{array}$

$\begin{array}{ll}4.0 & 4.0 \\ 0.5 & 0.5 \\ 0.0 & 0.0 \\ 4.5 & 4.5 \\ & 27\end{array}$

$\begin{array}{ll}0.0 & 0.0 \\ 0.0 & 0.0 \\ 0.0 & 0.0 \\ 0.0 & 0.0 \\ & 0\end{array}$

\begin{tabular}{ll} 
FY & 1987 \\
\hline A $\quad$ B0 \\
\hline
\end{tabular}

$F Y \quad 1988$
$B A$

$\begin{array}{llll}0.0 & 0.0 & 0.0 & 0.0\end{array}$

$\begin{array}{llll}0.0 & 0.0 & 0.0 & 0.0\end{array}$

$\begin{array}{llll}0.0 & 0.0 & 0.0 & 0.0\end{array}$

$\begin{array}{llll}0.0 & 0.0 & 0.0 & 0.0 \\ & 0 & & 0\end{array}$

$\begin{array}{llll}0.0 & 0.0 & 0.0 & 0.0 \\ 0.0 & 0.0 & 0.0 & 0.0 \\ 0.0 & 0.0 & 0.0 & 0.0 \\ 0.0 & 0.0 & 0.0 & 0.0 \\ & 0 & & 0\end{array}$


D. RESOURCES BY SUB PROGRAM (cont.) ASSISTANT SECRETARY FOR FOSSIL ENERGY

(\$ IN MILLIONS - PERSONNEL IN FTE)

AA05 Adv Envrnt? Ct]

Total Operating

Capital Equipment Subtotal Construction

Direct Personnel

AA15 Adv Research \& Text Total Operating Construction

Subtotal

Direct Personnel
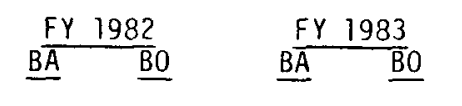

$$
\underline{B Y} \quad \underline{B Y} \quad \underline{B} \quad
$$
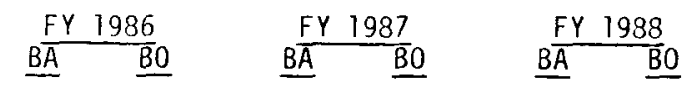

$\begin{array}{ll}0.4 & 0.5 \\ 0.1 & 0.2 \\ 0.0 & 0.0 \\ 0.5 & 0.7 \\ & 4\end{array}$

$\begin{array}{ll}0.0 & 0.0 \\ 0.0 & 0.0 \\ 0.0 & 0.0 \\ 0.0 & 0.0 \\ & 0\end{array}$

$\begin{array}{ll}0.0 & 0.0 \\ 0.0 & 0.0 \\ 0.0 & 0.0 \\ 0.0 & 0.0 \\ & 0\end{array}$

$\begin{array}{ll}0.0 & 0.0 \\ 0.0 & 0.0 \\ 0.0 & 0.0 \\ 0.0 & 0.0 \\ & 0\end{array}$

$\begin{array}{ll}0.0 & 0.0 \\ 0.0 & 0.0\end{array}$

$\begin{array}{ll}0.0 & 0.0 \\ 0.0 & 0.0\end{array}$

$\begin{array}{ll}0.0 & 0.0 \\ 0.0 & 0.0\end{array}$

$\begin{array}{ll}0.6 & 0.6 \\ 0.0 & 0.0 \\ 0.0 & 0.0 \\ 0.6 & 0.6\end{array}$

$\begin{array}{ll}0.6 & 0.6 \\ 0.0 & 0.0 \\ 0.0 & 0.0 \\ 0.6 & 0.6 \\ & 5\end{array}$

$\begin{array}{ll}0.5 & 0.4 \\ 0.1 & 0.1 \\ 0.0 & 0.0 \\ 0.6 & 0.5 \\ & 3\end{array}$

$\begin{array}{ll}0.4 & 0.4 \\ 0.1 & 0.1 \\ 0.0 & 0.0 \\ 0.5 & 0.5 \\ & 3\end{array}$

$\begin{array}{ll}0.7 & 0.3 \\ 0.0 & 0.0 \\ 0.0 & 0.0 \\ 0.7 & 0.3\end{array}$

$\begin{array}{ll}0.1 & 0.1 \\ 0.0 & 0.0 \\ 0.0 & 0.0 \\ 0.1 & 0.1\end{array}$

Subtotal

Total Operating Capital Equipment

Direct Personnel

AA65 Insitu Coal Gas

Total Operating Capital Equipment

Subtotal Construction

Direct Personnel

AA75 Mines R\&D

Total Operating Capital Equipment

Subtotal Construction

Direct Personne]

AA85 Surf Coal Gas

Total Operating Capital Equipment

Subtotal Construction

$\stackrel{\vec{E}}{ }$

Direct Personnel

$\begin{array}{ll}0.0 & 0.0 \\ 0.0 & 0.0 \\ 0.0 & 0.0 \\ 0.0 & 0.0 \\ & 0\end{array}$

$\begin{array}{ll}0.0 & 0.0 \\ 0.0 & 0.0 \\ 0.0 & 0.0 \\ 0.0 & 0.0\end{array}$

$\begin{array}{ll}0.7 & 0.5 \\ 0.0 & 0.0 \\ 0.0 & 0.0 \\ 0.7 & 0.5\end{array}$

$\begin{array}{ll}0.7 & 0.5 \\ 0.0 & 0.0 \\ 0.0 & 0.0\end{array}$

$\begin{array}{ll}0.0 & 0.0 \\ 0.7 & 0.5\end{array}$

$\begin{array}{ll}0.7 & 0.7 \\ 0.1 & 0.0\end{array}$

$\begin{array}{ll}0.0 & 0.0\end{array}$

$0.8 \quad 0.7$

$\begin{array}{ll}0.4 & 0.4 \\ 0.0 & 0.0 \\ 0.0 & 0.0 \\ 0.4 & 0.4\end{array}$

$\begin{array}{ll}0.0 & 0.0 \\ 0.0 & 0.0 \\ 0.0 & 0.0 \\ 0.0 & 0.0\end{array}$

$\begin{array}{ll}0.4 & 0.3 \\ 0.0 & 0.0 \\ 0.0 & 0.0 \\ 0.4 & 0.3\end{array}$

$\begin{array}{ll}0.3 & 0.3 \\ 0.0 & 0.0 \\ 0.0 & 0.0 \\ 0.3 & 0.3 \\ & 3\end{array}$

$\begin{array}{ll}0.5 & 0.4 \\ 0.1 & 0.1 \\ 0.0 & 0.0 \\ 0.6 & 0.5 \\ & 3\end{array}$

$\begin{array}{ll}0.4 & 0.4 \\ 0.1 & 0.1 \\ 0.0 & 0.0 \\ 0.5 & 0.5 \\ & 3\end{array}$

$\begin{array}{ll}0.4 & 0.4 \\ 0.1 & 0.1 \\ 0.0 & 0.0 \\ 0.5 & 0.5\end{array}$

$\begin{array}{ll}0.0 & 0.0 \\ 0.0 & 0.0\end{array}$

$0.0 \quad 0.0$

$0.0 \quad 0.0$

$0.0 \quad 0.0$

$\begin{array}{ll}0.0 & 0.0\end{array}$ 
D. RESOURCES BY SUB PROGRAM (cont.) ASSISTANT SECRETARY FOR FOSSIL ENERGY

( $\$$ IN MILLIONS - PERSONNEL IN FTE)

\begin{tabular}{|c|c|c|c|c|c|c|c|c|c|c|c|c|c|c|}
\hline & FY & 82 & FY & 983 & $\mathrm{FY}$ & 984 & FY & 85 & FY & 86 & FY & & $\mathrm{FY}$ & 88 \\
\hline & $\underline{B \bar{A}}$ & $\underline{\mathrm{B} 0}$ & $B A$ & $\underline{B} 0$ & $\underline{B A}$ & $\mathrm{~B} 0$ & $B \bar{A}$ & $\mathrm{BO}$ & $\underline{B A}$ & $\underline{\mathrm{B}} 0$ & $\underline{B \bar{A}}$ & $\underline{\mathrm{B}} 0$ & $B \bar{A}$ & $\underline{B} 0$ \\
\hline $\begin{array}{l}\text { AA-Coal Total Operating } \\
\text { Capital Equipment } \\
\text { Construction } \\
\text { Subtotal AA } \\
\text { Direct Personnel }\end{array}$ & $\begin{array}{l}2.8 \\
0.2 \\
0.0 \\
3.0\end{array}$ & $\begin{array}{l}2.4 \\
0.2 \\
0.0 \\
2.6 \\
20\end{array}$ & $\begin{array}{l}1.4 \\
0.0 \\
0.0 \\
1.4\end{array}$ & $\begin{array}{l}1.4 \\
0.0 \\
0.0 \\
1.4 \\
12\end{array}$ & $\begin{array}{l}1.7 \\
0.2 \\
0.0 \\
1.9\end{array}$ & $\begin{array}{l}1.3 \\
0.2 \\
0.0 \\
1.5 \\
10\end{array}$ & $\begin{array}{l}1.5 \\
0.2 \\
0.0 \\
1.7\end{array}$ & $\begin{array}{l}1.3 \\
0.2 \\
0.0 \\
1.5 \\
10\end{array}$ & $\begin{array}{l}1.3 \\
0.2 \\
0.0 \\
1.5\end{array}$ & $\begin{array}{l}1.3 \\
0.2 \\
0.0 \\
1.5 \\
10\end{array}$ & $\begin{array}{l}1.3 \\
0.2 \\
0.0 \\
1.5\end{array}$ & $\begin{array}{l}1.3 \\
0.2 \\
0.0 \\
1.5 \\
10\end{array}$ & $\begin{array}{l}1.3 \\
0.2 \\
0.0 \\
1.5\end{array}$ & $\begin{array}{l}1.3 \\
0.2 \\
0.0 \\
1.5 \\
10\end{array}$ \\
\hline $\begin{array}{c}\text { AB05 Enhanced Gas } \\
\text { Total Operating } \\
\text { Capital Equipment } \\
\text { Construction } \\
\text { Subtotal } \\
\text { Direct Personnel }\end{array}$ & $\begin{array}{l}0.8 \\
0.0 \\
0.0 \\
0.8\end{array}$ & $\begin{array}{l}0.8 \\
0.0 \\
0.0 \\
0.8 \\
9\end{array}$ & $\begin{array}{l}0.3 \\
0.0 \\
0.0 \\
0.3\end{array}$ & $\begin{array}{l}0.3 \\
0.0 \\
0.0 \\
0.3 \\
2\end{array}$ & $\begin{array}{l}0.0 \\
0.0 \\
0.0 \\
0.0\end{array}$ & $\begin{array}{l}0.0 \\
0.0 \\
0.0 \\
0.0 \\
0\end{array}$ & $\begin{array}{l}0.0 \\
0.0 \\
0.0 \\
0.0\end{array}$ & $\begin{array}{l}0.0 \\
0.0 \\
0.0 \\
0.0 \\
0\end{array}$ & $\begin{array}{l}0.0 \\
0.0 \\
0.0 \\
0.0\end{array}$ & $\begin{array}{l}0.0 \\
0.0 \\
0.0 \\
0.0 \\
0\end{array}$ & $\begin{array}{l}0.0 \\
0.0 \\
0.0 \\
0.0\end{array}$ & $\begin{array}{l}0.0 \\
0.0 \\
0.0 \\
0.0 \\
0\end{array}$ & $\begin{array}{l}0.0 \\
0.0 \\
0.0 \\
0.0\end{array}$ & $\begin{array}{l}0.0 \\
0.0 \\
0.0 \\
0.0 \\
0\end{array}$ \\
\hline $\begin{array}{l}\text { AB-Gas } \\
\text { Total Operating } \\
\text { Capital Equipment } \\
\text { Construction } \\
\text { Subtotal AB } \\
\text { Oirect Personnel }\end{array}$ & $\begin{array}{l}0.8 \\
0.0 \\
0.0 \\
0.8\end{array}$ & $\begin{array}{l}0.8 \\
0.0 \\
0.0 \\
0.8 \\
9\end{array}$ & $\begin{array}{l}0.3 \\
0.0 \\
0.0 \\
0.3\end{array}$ & $\begin{array}{l}0.3 \\
0.0 \\
0.0 \\
0.3 \\
2\end{array}$ & $\begin{array}{l}0.0 \\
0.0 \\
0.0 \\
0.0\end{array}$ & $\begin{array}{l}0.0 \\
0.0 \\
0.0 \\
0.0 \\
0\end{array}$ & $\begin{array}{l}0.0 \\
0.0 \\
0.0 \\
0.0\end{array}$ & $\begin{array}{l}0.0 \\
0.0 \\
0.0 \\
0.0 \\
0\end{array}$ & $\begin{array}{l}0.0 \\
0.0 \\
0.0 \\
0.0\end{array}$ & $\begin{array}{l}0.0 \\
0.0 \\
0.0 \\
0.0 \\
0\end{array}$ & $\begin{array}{l}0.0 \\
0.0 \\
0.0 \\
0.0\end{array}$ & $\begin{array}{l}0.0 \\
0.0 \\
0.0 \\
0.0 \\
0\end{array}$ & $\begin{array}{l}0.0 \\
0.0 \\
0.0 \\
0.0\end{array}$ & $\begin{array}{l}0.0 \\
0.0 \\
0.0 \\
0.0 \\
0\end{array}$ \\
\hline $\begin{array}{c}\text { AC15 Enhances 0il } \\
\text { Total Operating } \\
\text { Capital Equipment } \\
\text { Construction } \\
\text { Subtotal } \\
\text { Direct Personnel }\end{array}$ & $\begin{array}{l}0.0 \\
0.0 \\
0.0 \\
0.0\end{array}$ & $\begin{array}{l}0.0 \\
0.0 \\
0.0 \\
0.0 \\
0\end{array}$ & $\begin{array}{l}0.0 \\
0.0 \\
0.0 \\
0.0\end{array}$ & $\begin{array}{l}0.1 \\
0.0 \\
0.0 \\
0.0 \\
1\end{array}$ & $\begin{array}{l}0.0 \\
0.0 \\
0.0 \\
0.0\end{array}$ & $\begin{array}{l}0.0 \\
0.0 \\
0.0 \\
0.0 \\
0\end{array}$ & $\begin{array}{l}0.0 \\
0.0 \\
0.0 \\
0.0\end{array}$ & $\begin{array}{l}0.0 \\
0.0 \\
0.0 \\
0.0 \\
0\end{array}$ & $\begin{array}{l}0.0 \\
0.0 \\
0.0 \\
0.0\end{array}$ & $\begin{array}{l}0.0 \\
0.0 \\
0.0 \\
0.0 \\
0\end{array}$ & $\begin{array}{l}0.0 \\
0.0 \\
0.0 \\
0.0\end{array}$ & $\begin{array}{l}0.0 \\
0.0 \\
0.0 \\
0.0 \\
0\end{array}$ & $\begin{array}{l}0.0 \\
0.0 \\
0.0 \\
0.0\end{array}$ & $\begin{array}{l}0.0 \\
0.0 \\
0.0 \\
0.0 \\
0\end{array}$ \\
\hline $\begin{array}{l}\text { AC20 0il Shale } \\
\text { Total Operating } \\
\text { Capital Equipment } \\
\text { Construction } \\
\text { Subtotal } \\
\text { Direct Personnel }\end{array}$ & $\begin{array}{l}1.8 \\
0.2 \\
0.0 \\
2.0\end{array}$ & $\begin{array}{r}2.0 \\
0.2 \\
0.0 \\
2.2 \\
21\end{array}$ & $\begin{array}{l}1.2 \\
0.0 \\
0.0 \\
1.2\end{array}$ & $\begin{array}{l}1.4 \\
0.0 \\
0.0 \\
1.4 \\
15\end{array}$ & $\begin{array}{l}0.9 \\
0.0 \\
0.0 \\
0.9\end{array}$ & $\begin{array}{l}0.9 \\
0.0 \\
0.0 \\
0.9 \\
8\end{array}$ & $\begin{array}{l}0.9 \\
0.0 \\
0.0 \\
0.9\end{array}$ & $\begin{array}{l}0.9 \\
0.0 \\
0.0 \\
0.9 \\
8\end{array}$ & $\begin{array}{l}0.9 \\
0.0 \\
0.0 \\
0.9\end{array}$ & $\begin{array}{l}0.9 \\
0.0 \\
0.0 \\
0.9 \\
8\end{array}$ & $\begin{array}{l}0.9 \\
0.0 \\
0.0 \\
0.9\end{array}$ & $\begin{array}{l}0.9 \\
0.0 \\
0.0 \\
0.9 \\
8\end{array}$ & $\begin{array}{l}0.9 \\
0.0 \\
0.0 \\
0.9\end{array}$ & $\begin{array}{l}0.9 \\
0.0 \\
0.0 \\
0.9 \\
8\end{array}$ \\
\hline $\begin{array}{l}\text { AC-Petroleum } \\
\text { Total Operating } \\
\text { Capital Equipment } \\
\text { Construction } \\
\text { Subtotal AC } \\
\text { Direct Personnel }\end{array}$ & $\begin{array}{l}1.8 \\
0.2 \\
0.0 \\
2.0\end{array}$ & $\begin{array}{l}2.0 \\
0.2 \\
0.0 \\
2.2 \\
21\end{array}$ & $\begin{array}{l}1.2 \\
0.0 \\
0.0 \\
1.2\end{array}$ & $\begin{array}{l}1.5 \\
0.0 \\
0.0 \\
1.5 \\
16\end{array}$ & $\begin{array}{l}0.9 \\
0.0 \\
0.0 \\
0.9\end{array}$ & $\begin{array}{l}0.9 \\
0.0 \\
0.0 \\
0.9 \\
8\end{array}$ & $\begin{array}{l}0.9 \\
0.0 \\
0.0 \\
0.9\end{array}$ & $\begin{array}{l}0.9 \\
0.0 \\
0.0 \\
0.9 \\
8\end{array}$ & $\begin{array}{l}0.9 \\
0.0 \\
0.0 \\
0.9\end{array}$ & $\begin{array}{l}0.9 \\
0.0 \\
0.0 \\
0.9 \\
8\end{array}$ & $\begin{array}{l}0.9 \\
0.0 \\
0.0 \\
0.9\end{array}$ & $\begin{array}{l}0.9 \\
0.0 \\
0.0 \\
0.9 \\
8\end{array}$ & $\begin{array}{l}0.9 \\
0.0 \\
0.0 \\
0.9\end{array}$ & $\begin{array}{l}0.9 \\
0.0 \\
0.0 \\
0.9 \\
8\end{array}$ \\
\hline
\end{tabular}

\section{3} .2 5 


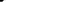

D. RESOURCES BY SUB PROGRAM (cont.) ASSISTANT SECRETARY FOR FOSSIL ENERGY

( $\$$ IN MILLIONS - PERSONNEL IN FTE)

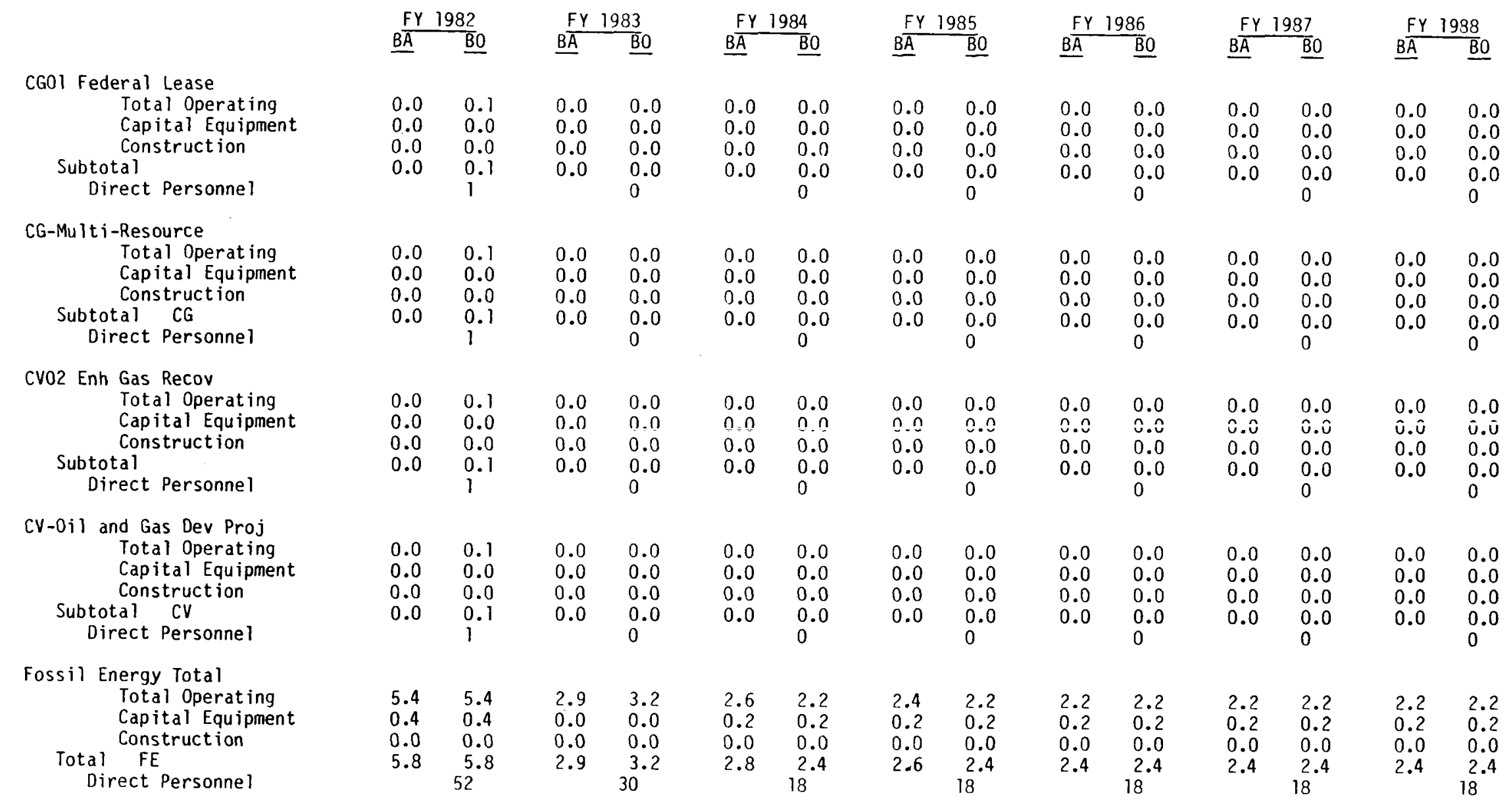


D. RESOURCES BY SUB PROGRAM (cont.) ASSISTANT SECRETARY FOR ENV. PRO./SAFETY/EP

(\$IN MILLIONS - PERSONNEL IN FTE)

HAOI Overview/Assint

Total Operating

Capital Equipment

Subtotal

Construction

Direct Personnel

HA-Biomed \& Environ Research

Total Operating

Capital Equipment

Constructio

Direct Personnel

Env Pro/Safety/EP Tota]

Total Operating

Capital Equipment

Total Const

Construction

Direct Personnel

$\begin{array}{ll}F Y & 1982 \\ B \bar{A} & \underline{B} 0\end{array}$

$$
\begin{array}{ll}
F Y & 1983 \\
B \bar{A} & \underline{B} 0
\end{array}
$$

\begin{tabular}{ll} 
FY & 1984 \\
\hline$B A$ & $B 0$ \\
\hline
\end{tabular}

\begin{tabular}{c|c}
$F Y$ & 1985 \\
\hline$B A$ & $B 0$
\end{tabular}
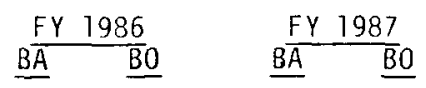

$\begin{array}{ll}F Y & 1988 \\ B A & B 0\end{array}$

$\begin{array}{ll}2.9 & 3.1 \\ 0.1 & 0.1 \\ 0.0 & 0.0 \\ 3.0 & 3.2\end{array}$

$\begin{array}{lr}1.6 & 1.6 \\ 0.1 & 0.1 \\ 0.0 & 0.0 \\ 1.7 & 1.7 \\ & 21\end{array}$

$\begin{array}{ll}2.1 & 2.0 \\ 0.6 & 0.6 \\ 0.0 & 0.0 \\ 2.7 & 2.6 \\ & 19\end{array}$

$2.0 \quad 2.0$

$\begin{array}{ll}2.0 & 2.0 \\ 0.6 & 0.6 \\ 0.0 & 0.0 \\ 2.6 & 2.6 \\ & 19\end{array}$

$2.0 \quad 2.0$

$0.6 \quad 0.6$

$\begin{array}{ll}0.0 & 0.0 \\ 2.6 & 2.6\end{array}$

19

2.02 .0

$0.6 \quad 0.6$

$\begin{array}{ll}0.0 & 0.0 \\ 2.6 & 2.6\end{array}$

$\begin{array}{ll}2.9 & 3.1 \\ 0.1 & 0.1 \\ 0.0 & 0.0 \\ 3.0 & 3.2 \\ & 28\end{array}$

$\begin{array}{rr}1.6 & 1.6 \\ 0.1 & 0.1 \\ 0.0 & 0.0 \\ 1.7 & 1.7 \\ & 21\end{array}$

$2.0 \quad 2.0$

$2.0 \quad 2.0$

$2.0 \quad 2.0$

$2.0 \quad 2.0$

$0.0 \quad 0.0$

$0.0 \quad 0.0$

$\begin{array}{ll}0.6 & 0.6 \\ 0.0 & 0.0\end{array}$

$\begin{array}{ll}2.0 & 0.0 \\ & 2.6\end{array}$

$\begin{array}{ll}0.6 & 0.6 \\ 0.0 & 0.0\end{array}$

$\begin{array}{ll}0.0 & 0.0 \\ 2.6 & 2.6\end{array}$

$\begin{array}{ll}0.6 & 0.6 \\ 0.0 & 0.0\end{array}$

19

19

$\begin{array}{ll}2.9 & 3.1 \\ 0.1 & 0.1 \\ 0.0 & 0.0 \\ 3.0 & 3.2 \\ & 28\end{array}$

$\begin{array}{lr}1.6 & 1.6 \\ 0.1 & 0.1 \\ 0.0 & 0.0 \\ 1.7 & 1.7 \\ & 21\end{array}$

$\begin{array}{cc}2.1 & 2.0 \\ 0.6 & 0.6 \\ 0.0 & 0.0 \\ 2.7 & 2.6 \\ & 19\end{array}$

$\begin{array}{cc}2.0 & 2.0 \\ 0.6 & 0.6 \\ 0.0 & 0.0 \\ 2.6 & 2.6 \\ & 19\end{array}$

$\begin{array}{cc}2.0 & 2.0 \\ 0.6 & 0.6 \\ 0.0 & 0.0 \\ 2.6 & 2.6 \\ & 19\end{array}$

$\begin{array}{ll}2.0 & 2.0 \\ 0.6 & 0.6 \\ 0.0 & 0.0 \\ 2.6 & 2.6 \\ & 19\end{array}$

$\begin{array}{ll}2.0 & 2.0 \\ 0.6 & 0.6 \\ 0.0 & 0.0 \\ 2.6 & 2.6 \\ & 19\end{array}$


D. RESOURCES BY SUB PROGRAM (cont.) EI AND PE COMBINED

(\$ IN MiLLIONS - PERSONNEL IN FTE)

PE01 Policy Analys

$\begin{array}{ll}\mathrm{FY} & 1982 \\ B \mathrm{~A} & \quad \underline{B} 0\end{array}$

$\frac{F Y 1983}{B A} \quad \underline{B} 0$

$\frac{F Y 1934}{B A} \quad B 0$

$F Y \quad 1985$
$B A$
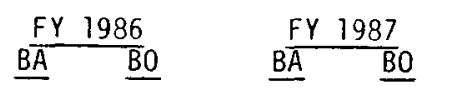

FY 1988

$\begin{array}{ll}0.9 & 0.9 \\ 0.0 & 0.0 \\ 0.0 & 0.0 \\ 0.9 & 0.9 \\ & 9\end{array}$

$\begin{array}{ll}0.0 & 0.0 \\ 0.0 & 0.0 \\ 0.0 & 0.0 \\ 0.0 & 0.0 \\ & 0\end{array}$

$\begin{array}{ll}0.0 & 0.0 \\ 0.0 & 0.0 \\ 0.0 & 0.0 \\ 0.0 & 0.0 \\ & 0\end{array}$

$\begin{array}{ll}0.0 & 0.0 \\ 0.0 & 0.0 \\ 0.0 & 0.0 \\ 0.0 & 0.0 \\ & 0\end{array}$

$\begin{array}{ll}0.0 & 0.0 \\ 0.0 & 0.0 \\ 0.0 & 0.0 \\ 0.0 & 0.0 \\ & 0\end{array}$

$0.0 \quad 0.0$

$0.0 \quad 0.0$

$0.0 \quad 0.0$

Subtotal

Direct Personnel

PE-Policy Anal \& Sys Studies Total Operating Capital Equipment Subtotal PE

Direct Personnel

TAO1 Energy Appl An Total Operating. Capita! Equipment Subtotal Construction

Direct Personne 1

$\begin{array}{ll}0.9 & 0.9 \\ 0.0 & 0.0 \\ 0.0 & 0.0 \\ 0.9 & 0.9 \\ & 9\end{array}$

$\begin{array}{ll}0.0 & 0.0 \\ 0.0 & 0.0 \\ 0.0 & 0.0 \\ 0.0 & 0.0 \\ & 0\end{array}$

$\begin{array}{ll}0.0 & 0.0 \\ 0.0 & 0.0 \\ 0.0 & 0.0 \\ 0.0 & 0.0 \\ & 0\end{array}$

$\begin{array}{ll}0.0 & 0.0 \\ 0.0 & 0.0 \\ 0.0 & 0.0\end{array}$

$\begin{array}{ll}0.0 & 0.0\end{array}$

$0.0 \quad 0.0$

$0.0 \quad 0.0$

$0.0 \quad 0.0$

$\begin{array}{ll}0.0 & 0.0 \\ & 0\end{array}$

$\begin{array}{ll}0.0 & 0.0 \\ 0.0 & 0.0 \\ 0.0 & 0.0 \\ 0.0 & 0.0 \\ & 0\end{array}$

$\begin{array}{ll}0.0 & 0.0 \\ 0.0 & 0.0 \\ 0.0 & 0.0 \\ 0.0 & 0.0 \\ & 0\end{array}$

$0.0 \quad 0.0$

ט.

$\begin{array}{ll}0.0 & 0.0 \\ 0.0 & 0.0\end{array}$

$\begin{array}{ll}0.0 & 0.0\end{array}$

$\begin{array}{ll}0.0 & 0.0 \\ 0.0 & 0.0 \\ 0.0 & 0.0 \\ 0.0 & 0.0 \\ & 0\end{array}$

$\begin{array}{ll}0.0 & 0.0 \\ 0.0 & 0.0 \\ 0.0 & 0.0 \\ 0.0 & 0.0 \\ & 0\end{array}$

$\begin{array}{ll}0.0 & 0.0 \\ 0.0 & 0.0 \\ 0.0 & 0.0 \\ 0.0 & 0.0 \\ & 0\end{array}$

$\begin{array}{ll}0.0 & 0.0 \\ 0.0 & 0.0 \\ 0.0 & 0.0\end{array}$

Subtotal TA

Direct Personnel

TD03 Data Info Serv Total Operating Capital Equipment

Subtotal Construction

Direct Personnel

$\begin{array}{ll}0.0 & 0.1 \\ 0.0 & 0.0 \\ 0.0 & 0.0 \\ 0.0 & 0.1\end{array}$

$\begin{array}{ll}0.0 & 0.0 \\ 0.0 & 0.0 \\ 0.0 & 0.0 \\ 0.0 & 0.0 \\ & 0\end{array}$

$\begin{array}{ll}0.0 & 0.0 \\ 0.0 & 0.0 \\ 0.0 & 0.0 \\ 0.0 & 0.0 \\ & 0\end{array}$

$\begin{array}{ll}0.0 & 0.0 \\ 0.0 & 0.0 \\ 0.0 & 0.0 \\ 0.0 & 0.0 \\ & 0\end{array}$

$\begin{array}{ll}0.0 & 0.0 \\ 0.0 & 0.0 \\ 0.0 & 0.0 \\ 0.0 & 0.0\end{array}$

$0.0 \quad 0.0$

$0.0 \quad 0.0$

$0.0 \quad 0.0$

$\begin{array}{ll}0.0 & 0.0\end{array}$

$\begin{array}{ll}0.0 & 0.0 \\ 0.0 & 0.0 \\ 0.0 & 0.0\end{array}$

$0.0 \quad 0.0$

$0.0 \quad 0.0$

$0.0 \quad 0.0$

$0.0 \quad 0.0$

$0.0 \quad 0.0$

$\begin{array}{ll}0.0 & 0.0 \\ 0.0 & 0.0\end{array}$

$0.0 \quad 0.0$

$\begin{array}{ll}0.0 & 0.0 \\ 0.0 & 0.0\end{array}$

$\begin{array}{ll}0 . \bar{U} & 0.0 \\ 0.0 & 0.0\end{array}$

$\begin{array}{ll}0.0 & 0.0 \\ 0.0 & 0.0\end{array}$

$0.0 \quad 0.0$

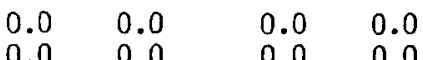

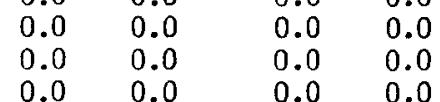

$\begin{array}{llll}0.0 & 0.0 & 0.0 & 0.0 \\ & 0 & & 0\end{array}$

$\begin{array}{ll}0.0 & 0.0 \\ 0.0 & 0.0 \\ 0.0 & 0.0 \\ 0.0 & 0.0 \\ & 0\end{array}$

$\begin{array}{llll}0.0 & 0.0 & 0.0 & 0.0 \\ 0.0 & 0.0 & 0.0 & 0.0\end{array}$

$\begin{array}{llll}0.0 & 0.0 & 0.0 & 0.0 \\ 0.0 & 0.0 & 0.0 & 0.0\end{array}$

$\begin{array}{llllllll}.0 & 0.0 & 0.0 & 0.0 & 0.0 & 0.0 & 0.0 & 0.0 \\ .0 & 0.0 & 0.0 & 0.0 & 0.0 & 0.0 & 0.0 & 0.0 \\ & 0 & & 0 & & 0 & & 0\end{array}$

TD-Data Information Services Total Operating Capital Equipment

Subtotal Construction

$\begin{array}{ll}\text { Direct Personnel } & \\ \text { Diret } & \end{array}$

$\begin{array}{llll}0.0 & 0.1 & 0.0 & 0.0 \\ 0.0 & 0.0 & 0.0 & 0.0 \\ 0.0 & 0.0 & 0.0 & 0.0 \\ 0.0 & 0.1 & 0.0 & 0.0\end{array}$

$\stackrel{\vec{B}}{\mathrm{G}}$

$\begin{array}{ll}0.0 & 0.0 \\ 0.0 & 0.0 \\ 0.0 & 0.0 \\ 0.0 & 0.0 \\ & 0 \\ & \\ 0.0 & 0.0 \\ 0.0 & 0.0 \\ 0.0 & 0.0 \\ 0.0 & 0.0 \\ & 0\end{array}$

$\begin{array}{llll}0.0 & 0.0 & 0.0 & 0.0 \\ 0.0 & 0.0 & 0.0 & 0.0 \\ 0.0 & 0.0 & 0.0 & 0.0 \\ 0.0 & 0.0 & 0.0 & 0.0 \\ & 0 & & 0 \\ & & & \\ 0.0 & 0.0 & 0.0 & 0.0 \\ 0.0 & 0.0 & 0.0 & 0.0 \\ 0.0 & 0.0 & 0.0 & 0.0 \\ 0.0 & 0.0 & 0.0 & 0.0 \\ & 0 & & 0\end{array}$


D. RESOURCES BY SUB PROGRAM (cont.)

EI AND PE COMBINED

( $\$$ IN MILLIONS - PERSONNEL IN FTE)

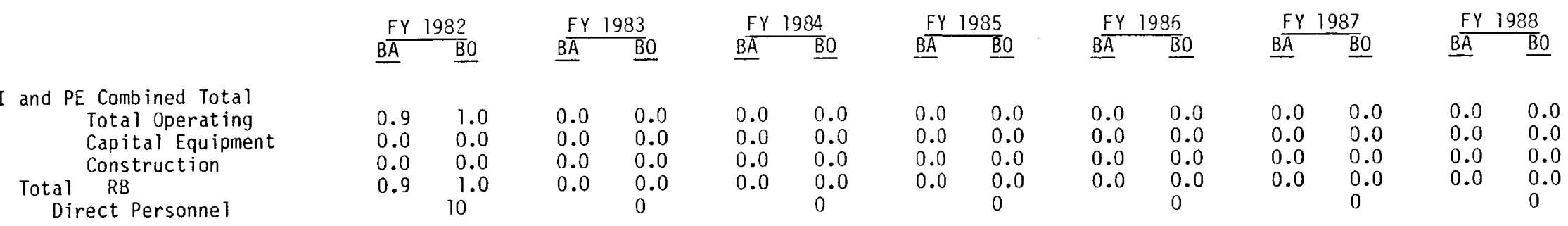


D. RESOURCES BY SUB PROGRAM (cont.)

ASSISTANT SECRETARY FOR MANAGEMENT \& ADMINISTRATION

(\$ IN MILLIONS - PERSONNEL IN FTE)

$$
\begin{array}{ll}
F Y & 1982 \\
B \quad & \underline{B} 0
\end{array}
$$

$$
\underline{F Y} \quad \underline{B} \quad \underline{B} \underline{B}
$$

$\begin{array}{ll}0.1 & 0.1 \\ 0.0 & 0.0 \\ 4.2 & 0.3 \\ 4.3 & 0.4 \\ & 1\end{array}$

$\begin{array}{ll}0.0 & 0.0 \\ 0.0 & 0.0 \\ 2.0 & 3.4 \\ 2.0 & 3.4 \\ & 0\end{array}$

$\begin{array}{llll}0.1 & 0.1 & 0.0 & 0.0 \\ 0.0 & 0.0 & 0.0 & 0.0 \\ 4.2 & 0.3 & 2.0 & 3.4 \\ 4.3 & 0.4 & 2.0 & 3.4 \\ & 1 & & 0\end{array}$

$\begin{array}{llll}0.1 & 0.1 & 0.0 & 0.0 \\ 0.0 & 0.0 . & 0.0 & 0.0 \\ 4.2 & 0.3 & 2.0 & 3.4 \\ 4.3 & 0.4 & 2.0 & 3.4 \\ & 1 & & 0\end{array}$

Direct Personnel
Diral

Management \& Admin Total

$$
\text { Total Operating }
$$$$
\text { Canital Equinment }
$$

Construction

$\begin{array}{ll}0.0 & 0.0 \\ 0.0 & 0.0 \\ 6.4 & 4.9 \\ 6.4 & 4.9 \\ & 0\end{array}$

$$
\begin{array}{ll}
\mathrm{FY} & 1984 \\
\mathrm{BA} & \underline{B} \mathrm{~B} \\
\hline
\end{array}
$$

$\begin{array}{ll}0.0 & 0.0 \\ 0.0 & 0.0 \\ 6.4 & 4.9 \\ 6.4 & 4.9 \\ & 0\end{array}$

\begin{tabular}{ll}
$F Y$ & 1985 \\
$B \bar{A} \quad \underline{B O}$ \\
\hline
\end{tabular}

$\begin{array}{ll}0.0 & 0.0 \\ 0.0 & 0.0 \\ 0.0 & 2.0 \\ 0.0 & 2.0 \\ & 0\end{array}$

$\begin{array}{ll}0.0 & 0.0 \\ 0.0 & 0.0 \\ 0.0 & 2.0 \\ 0.0 & 2.0 \\ & 0\end{array}$

$\begin{array}{ll}0.0 & 0.0 \\ 0.0 & 0.0 \\ 6.4 & 4.9 \\ 6.4 & 4.9\end{array}$

4.9
0

$\begin{array}{ll}0.0 & 0.0 \\ 0.0 & 0.0 \\ 0.0 & 2.0 \\ 0.0 & 2.0 \\ & 0\end{array}$

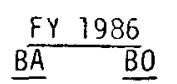

$\begin{array}{ll}0.0 & 0.0 \\ 0.0 & 0.0 \\ 0.0 & 0.0 \\ 0.0 & 0.0 \\ & 0\end{array}$

$\begin{array}{ll}F Y & 1987 \\ B \bar{A} \quad \underline{B O}\end{array}$

$\underline{F Y \quad 1988}$

$\begin{array}{llll}0.0 & 0.0 & 0.0 & 0.0\end{array}$

$0.0-0.0$

$\begin{array}{llll}0.0 & 0.0 & 0.0 & 0.0 \\ 0.0 & 0.0 & 0.0 & 0.0\end{array}$

$\begin{array}{llll}0.0 & 0.0 & 0.0 & 0.0\end{array}$

$0.0 \quad 0.0$

$\begin{array}{ll}0.0 & 0.0 \\ 0.0 & 0.0\end{array}$

$\begin{array}{ll}0.0 & 0.0 \\ 0.0 & 0.0\end{array}$

$\begin{array}{ll}0.0 & 0.0\end{array}$

$0.0 \quad 0.0$

$0.0 \quad 0.0$

$\begin{array}{llll}0.0 & 0.0 & 0.0 & 0.0\end{array}$

0

$\begin{array}{ll}0.0 & 0.0 \\ \hat{u} .0 & \hat{U} . \hat{U} \\ 0.0 & 0.0 \\ 0.0 & 0.0 \\ & 0\end{array}$

$\begin{array}{ll}0.0 & 0.0 \\ 0.0 & 0.0 \\ 0.0 & 0.0 \\ 0.0 & 0.0\end{array}$

$0.0 \quad 0.0$

$0 . \overline{0} \quad 0.0$

$\begin{array}{ll}0.0 & 0.0 \\ 0.0 & 0.0\end{array}$ 
O. RESOURCES BY SUB PROGRAM (cont.)

(\$ IN MILLIONS - PERSONNEL IN FTE)

Work For Other DOE Contr Total Operating Capital Equipment Subtotal

Construction

Direct Personnel

Total DOE Programs

$$
\text { Total Operating }
$$

Capital Equipment Construction

Total DOE

Direct Personne 1

WF0-Non DOE DOD Programs Total Operating

Capital Equipment

Subtotal

Direct Personnel

WF0-Non DOE NRC Programs Total Operating

Capital Equipment
Construction

Subtotal

Direct Personne 1

WF0-Non DOE Other

Total Operating

Capital Equipment

Subtotal

Direct Personnel

Total WFO - Non DOE

Total Operating

Capital Equipment

Total Lab Non DOE

Direct Personnel

\section{$F Y \quad 1982$
$B A$}

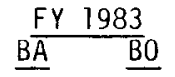

$27.1 \quad 27.1$

$\begin{array}{ll}0.0 & 0.0\end{array}$

$\begin{array}{rr}0.0 & 0.0 \\ 27.1 & 27.1\end{array}$

238

$\begin{array}{lll}437.7 & 443.2\end{array}$

$27.9 \quad 26.8$

$69.9 \quad 43.8$

$535.5 \quad 513.8$

4,099

$\begin{array}{rr}23.5 & 23.5 \\ 0.0 & 0.0 \\ 0.0 & 0.0^{\circ} \\ 23.5 & 23.5 \\ & 223\end{array}$

$\begin{array}{rr}32.0 & 32.0 \\ 0.0 & 0.0 \\ 0.0 & 0.0 \\ 32.0 & 32.0 \\ & 280\end{array}$

\begin{tabular}{ll}
$F Y$ & 1984 \\
$B A$ & $B O$ \\
\hline
\end{tabular}

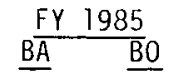

$\frac{F Y \quad 1986}{B A} \cdot \underline{B} 0$

$\begin{array}{rr}31.0 & 31.0 \\ 1.6 & 1.6 \\ 0.0 & 0.0 \\ 32.6 & 32.6 \\ & 266\end{array}$

$\begin{array}{rr}24.9 & 24.9 \\ 1.6 & 1.6 \\ 0.0 & 0.0 \\ 26.5 & 26.5 \\ & 220\end{array}$

$436.9 \quad 437.5$

$33.8 \quad 30.8$

$37.6 \quad 49.5$

$508.3 \quad 517.8$
3,880

$522.0 \quad 494.8$

$\begin{array}{ll}50.4 & 50.4\end{array}$

$25.1 \quad 37.3$

$597.5 \quad 576.5$

3,989

$\begin{array}{ll}527.7 & 522.2\end{array}$

$45.9 \quad 45.9$

$\begin{array}{ll}21.4 & 23.7\end{array}$

$595.0 \quad 591.8$

4,064

$\begin{array}{rr}28.7 & 28.7 \\ 0.0 & 0.0 \\ 0.0 & 0.0 \\ 28.7 & 28.7 \\ & 262\end{array}$

$28.7 \quad 28.7$

$\begin{array}{ll}0.0 & 0.0\end{array}$

$\begin{array}{ll}0.0 & 0.0\end{array}$

$28.7 \quad 28.7$
218

$29.8 \quad 29.8$
0.0

$0.0 \quad 0.0$

$\begin{array}{ll}0.0 & 0.0\end{array}$

$29.8 \quad 29.8$

226

$15.1 \quad 15.1$

$\begin{array}{ll}0.0 & 0.0 \\ 0.0 & 0.0\end{array}$

$\begin{array}{rr}0.0 & 0.0 \\ 15.1 & 15.1\end{array}$

140

$\begin{array}{rr}14.5 & 14.5 \\ 0.0 & 0.0 \\ 0.0 & 0.0 \\ 14.5 & 14.5 \\ & 133\end{array}$

$17.7 \quad 17.7$

$0.5 \quad 0.5$

$0.0 \quad 0.0$

$18.2 \quad i 8.2$

$\begin{array}{rr}17.7 & 17.7 \\ 0.5 & 0.5 \\ 0.0 & 0.0 \\ 18.2 & 18.2 \\ & 135\end{array}$

$15.5 \quad 15.5$

$\begin{array}{ll}0.0 & 0.0 \\ 0.0 & 0.0\end{array}$

$\begin{array}{rr}0.0 & 0.0 \\ 15.5 & 0.0 \\ & 15.5\end{array}$

106

$\begin{array}{rr}19.0 & 19.0 \\ 0.0 & 0.0 \\ 0.0 & 0.0 \\ 19.0 & 19.0 \\ & 125\end{array}$

$19.0 \quad 19.0$

$0.0 \quad 0.0$

$0.0 \quad 0.0$

$19.0 \quad 19.0$

$14.0 \quad 14.0$

$3.0 \quad 3.0$

$\begin{array}{rr}0.0 & 0.0\end{array}$

$\begin{array}{ll}17.0 \quad 17.0 & 80\end{array}$

$54.1 \quad 54.1$

$\begin{array}{rr}0.0 & 0.0 \\ 0.0 & 0.0\end{array}$

$\begin{array}{rr}0.0 & 0.0 \\ 54.1 & 54.1\end{array}$

469

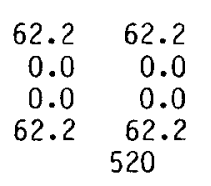

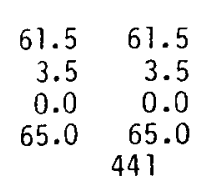

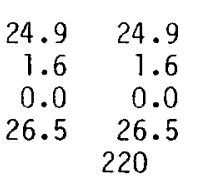

$520.6 \quad 520.0$

$42.4 \quad 42.4$

$31.9 \quad 31.9$

594.9
4,055

$\begin{array}{rr}30.8 & 30.8 \\ 0.0 & 0.0 \\ 0.0 & 0.0 \\ 30.8 & 30.8 \\ & 235\end{array}$

$\begin{array}{ll}17.7 & 17.7\end{array}$

$0.5 \quad 0.5$

$\begin{array}{ll}0.0 & 0.0\end{array}$

$18.2 \quad 18.2$
135

$\begin{array}{rr}14.0 & 14.0 \\ 3.1 & 3.1 \\ 0.0 & 0.0 \\ 17.1 & 17.1 \\ & 80\end{array}$

$\begin{array}{rr}62.5 & 62.5 \\ 3.6 & 3.6 \\ 0.0 & 0.0 \\ 66.1 & 66.1 \\ & 450\end{array}$

$\begin{array}{rr}63.8 & 63.8 \\ 4.0 & 4.0 \\ 0.0 & 0.0 \\ 67.8 & 67.8 \\ & 458\end{array}$
$64.9 \quad 64.9$

$4.1 \quad 4.1$

$0.0 \quad 0.0$

$69.0 \quad 69.0$
467

$\begin{array}{ll}\text { FY } & 1988 \\ B A & B 0\end{array}$

$24.9 \quad 24.9$

$1.6 \quad 1.6$

$26.5 \quad 26.5$

$516.9 \quad 517.2$

$41.3 \quad 41.3$

$558.2 \quad 558.5$

4,038

$\begin{array}{rrrr}32.1 & 32.1 & 33.2 & 33.2 \\ 0.0 & 0.0 & 0.0 & 0.0 \\ 0.0 & 0.0 & 0.0 & 0.0 \\ 32.1 & 32.1 & 33.2 & 33.2 \\ & 243 & & 252\end{array}$

$\begin{array}{rrrr}17.7 & 17.7 & 17.7 & 17.7\end{array}$

$\begin{array}{llll}0.5 & 0.5 & 0.5 & 0.5 \\ 0.0 & 0.0 & 0.0 & 0.0\end{array}$

$\begin{array}{rrrr}18.2 & 18.2 & 18.2 & 18.2\end{array}$

$\begin{array}{llll}14.0 & 14.0 & 14.0 & 14.0\end{array}$

$\begin{array}{llll}3.5 & 3.5 & 3.6 & 3.6\end{array}$

$\begin{array}{rrrr}0.0 & 0.0 & 0.0 & 0.0\end{array}$

$80-17.6$

80 
D. RESOURCES BY SUB PROGRAM (cont.) LABORATORY TOTALS

( $\$$ IN MILLIONS - PERSONNEL IN FTE)

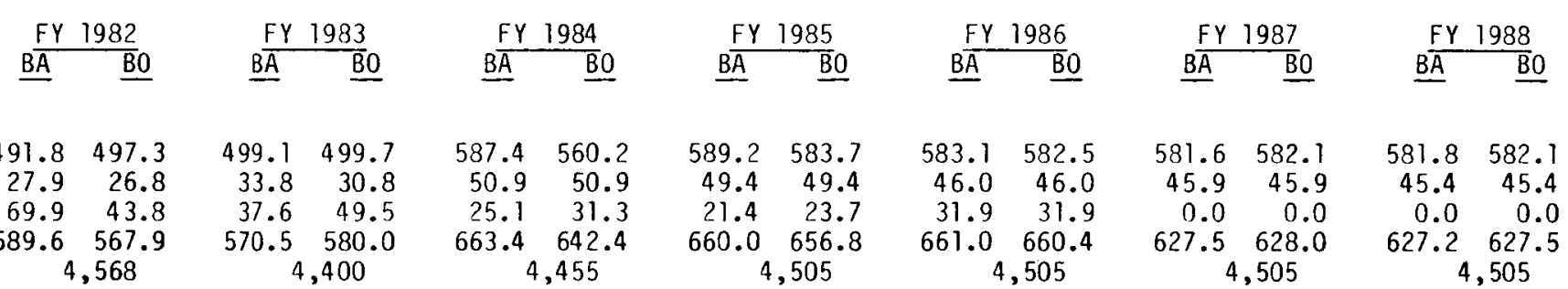

$\begin{array}{rr}69.9 & 43.8 \\ 589.6 & 567.9\end{array}$

4,568
4,455
Total Laboratory Programs Total Operating Capital Equipment Construction

Total Laboratory

Direct Personnel 
Los Al amos

E. PHASES OF R\&D ANALYSIS ${ }^{a}$

( $\$$ in Millions - Operating $B 0$ )

FY $1982 \quad$ FY $1983 \quad$ FY 1984

Office of Energy Research

Basic Research

19.7

23.3

26.1

Applied Research

19.6

19.6

23.9

Exploratory Development

3.5

3.6

4.1

Advanced Development

25.7

22.5

25.6

Engineering Development

$\frac{3.7}{72.2}$

$\frac{3.6}{72.6}$

$\underline{4.0}$

Total

83.7

Assistant Secretary for Nuclear Energy.

Basic Research

2.8

1.4

1.6

Applied Research

10.8

4.3

4.9

Exploratory Development

17.5

6.7

7.5

Advanced Development

3.9

1.6

1.8

Engineering Development

Total

$\frac{4.7}{39.7}$

1.6

1.8

17.6

Assistant Secretary for

Conservation and Renewable Energy

Basic Research

1.5

1.0

.3

Applied Research

4.4

3.0

1.0

Exploratory Development

7.2

4.3

1.4

Advanced Development

3.8

2.1

.7

Engineering Development

Total

$\frac{3.2}{20.1} \quad \frac{2.0}{12.4}$

$\frac{.6}{4.0}$

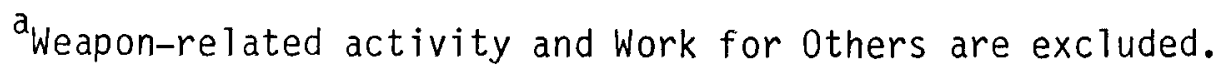


E. PHASES OF R\&D ANALYSIS a (continued)

( $\$$ in Millions -- Operating $B 0$ )

\section{FY $1982 \quad$ FY $1983 \quad$ FY 1984}

Assistant Secretary for Fossil Energy.

Basic Research

.8

.6

.4

Applied Research

3.9

1.7

1.1

Exploratory Development

.8

.4

.3

Advanced Development

.7

.4

.3

Engineering Development

.3

.1

6.5

3.2

$\frac{.1}{2.2}$

Miscellaneous DOE Programs

Basic Research

Applied Research

2.0

1.1

$-$

Exploratory Development

2.0

1.1

1.4

Advanced Development

Engineering Development

Total

$\frac{-}{4.0} \quad \frac{--}{2.2} \quad \frac{-}{2.8}$

Total Laboratory

Basic Research

\begin{tabular}{|c|c|c|}
\hline 24.8 & 26.3 & 28.4 \\
\hline 40.7 & 29.7 & 32.3 \\
\hline 31.0 & 16.1 & 14.7 \\
\hline 34.1 & 26.6 & 28.4 \\
\hline 11.9 & 7.3 & 6.5 \\
\hline 142.5 & 106.0 & 110.3 \\
\hline
\end{tabular}

Applied Research

Exploratory Development

Advanced Development

Engineering Development

Total 


\section{LOS ALAMOS NATIONAL LABORATORY}

F. Organization Chart

DIRECTOR
D.M. Kerr
DEPUTY DIRECTOR
R.N. Thorn

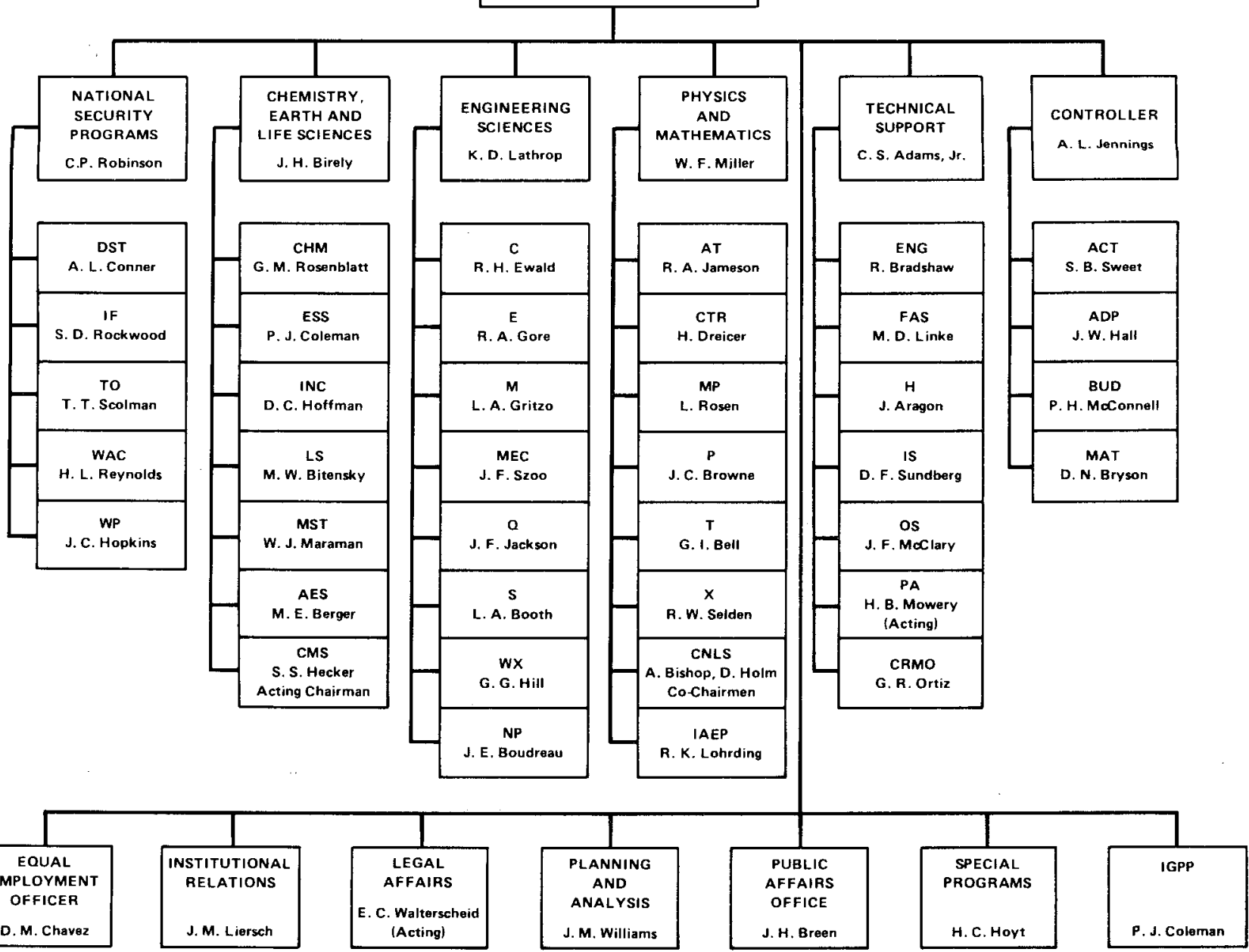

